\title{
CARACTERIZAÇÃO FLORÍSTICA, ESTRUTURAL E DA DINÂMICA DA REGENERAÇÃO DE ESPÉCIES NATIVAS EM UM POVOAMENTO COMERCIAL DE Eucalyptus grandis EM ITATINGA, SP
}

\section{PAULO HENRIQUE MAROSTEGAN E CARNEIRO}

Dissertação apresentada à Escola Superior de Agricultura "Luiz de Queiroz", Universidade de São Paulo, para a obtenção do título de Mestre em Ciências, Área de concentração: Ciências Florestais.

\section{PIRACICABA}

Estado de São Paulo - Brasil

Janeiro - 2002 


\title{
CARACTERIZAÇÃO FLORÍSTICA, ESTRUTURAL E DA DINÂMICA DA REGENERAÇÃO DE ESPÉCIES NATIVAS EM UM POVOAMENTO COMERCIAL DE Eucalyptus grandis EM ITATINGA, SP
}

\section{PAULO HENRIQUE MAROSTEGAN E CARNEIRO}

\author{
Engenheiro Florestal
}

Orientador: Prof. Dr. RICARDO RIBEIRO RODRIGUES

\begin{abstract}
Dissertação apresentada à Escola Superior de Agricultura "Luiz de Queiroz", Universidade de São Paulo, para a obtenção do título de Mestre em Ciências, Área de concentração: Ciências Florestais.
\end{abstract}

PIRACICABA

Estado de São Paulo - Brasil

Janeiro - 2002 


\section{Dados Internacionais de Catalogação na Publicação (CIP) DIVISÃO DE BIBLIOTECA E DOCUMENTAÇÃO - ESALQ/USP}

\section{Cameiro, Paulo Henrique Marostegan e}

Caracterização florística, estrutura e da dinâmica de regeneração de espécies nativa em um povoamento comercial de Eucalyptus gra nd is em Itatinga, SP / Paulo Henrique Marostegan e Cameiro. - - Piracicaba, 2002.

$131 \mathrm{p.}$.

Dissertação (mestrado) - - Escola Superior de Agricultura Luiz de Queiroz, 2002

Bibliografia.

1. Comunidades vegeta is 2. Euc a lipto 3. Flora 4. Florestas I. Título

CDD 634.9734

"Permitida a cópia total ou parcial deste documento, desde que citada a fonte - $\mathrm{O}$ autor" 
A Floriano Francisco Marostegan e Rosinha Proto Carneiro, acima de tudo, pelo exemplo de integridade, força e bondade 


\section{AGRADECIMENTOS}

A todas as pessoas, que de uma maneira ou outra, ajudaram na realização deste trabalho quero expressar o meu profundo agradecimento, especialmente para:

. ao Prof. Dr. Ricardo R. Rodrigues pela confiança e orientação,

. ao Eng. Flor. Marcelo Zotelli, companheiro e amigo das mais difíceis horas de campo,

. aos funcionários e estagiários do Laboratório de Botânica Sistemática da ESALQ, pelo apoio e companheirismo,

. A EUCATEX Florestal pelo auxílio nas atividades de campo e acesso a área do projeto.

. a minha família, amigos e, principalmente, a Juliana pelos constantes gestos de incentivo e pela compreensão da ausência. 


\section{SUMÁRIO}

LISTA DE FIGURAS....................................................................... vii

LISTA DE TABELAS .............................................................................. ix

LISTA DE QUADROS......................................................................

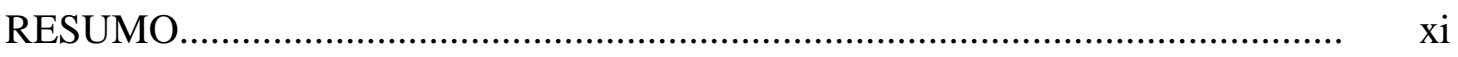

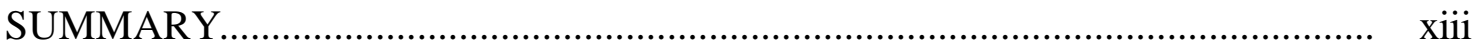

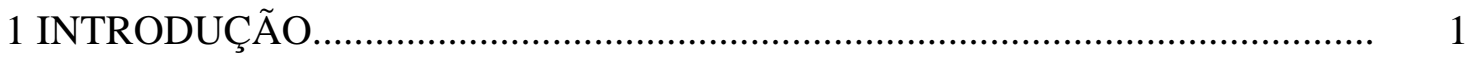

2 REVISÃO DE LITERATURA.................................................................. 4

3 MATERIAL E MÉTODOS...................................................................... 8

3.1 Caracterização da área de estudo. .......................................................... 8

3.2 Caracterização florística e estrutural da regeneração natural de espécies nativas no povoamento de E.grandis............................................................ 9

3.3 Estudo da evolução temporal da regeneração natural no sub-bosque de povoamentos de E. grandis...................................................................... 12

3.4 Avaliação das respostas da regeneração natural no sub-bosque de povoamentos de E. grandis quando submetidas a diferentes condições de manejo.

4 RESULTADOS E DISCUSSÃO

4.1 Análise da estrutura e da composição florística do sub-bosque de um povoamento de E. grandis.

4.2 Evolução Temporal da Regeneração Natural no sub-bosque de plantios de $E$. grandis. 
4.2.1Segundo levantamento (45 meses) realizado no povoamento comercial de

E. grandis, área amostral $-0,68$ ha................................................................ 32

4.2.2 Comparação entre os levantamentos (30 - 45 meses), área amostral - 0,68 ha.. 33

4.3 Regeneração Natural no Sub-bosque de povoamentos de E. grandis quando Submetidas a Diferentes Condições de Manejo.............................................. 46

4.3.1 Dinâmica da regeneração de espécies nativas no sub-bosque do povoamento de E. grandis (tratamento 1 - testemunha).................................................... 46

4.3.2 Dinâmica da regeneração de espécies nativas no sub-bosque de povoamentos de E. grandis, - Tratamento 2 (desbaste de $50 \%$ dos indivíduos do

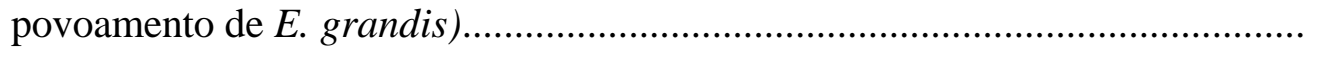

4.3.3 Dinâmica da regeneração de espécies nativas no sub-bosque de povoamentos de E. grandis, - Tratamento 3 (corte raso do povoamento de E. grandis).......... 59

4.3.4 Comparação entre os tratamentos........................................................... 75

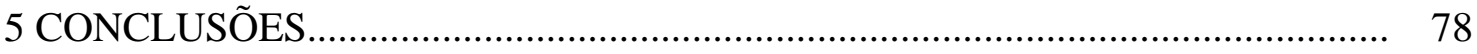

REFERÊNCIAS BIBLIOGRÁFICAS .......................................................... 80

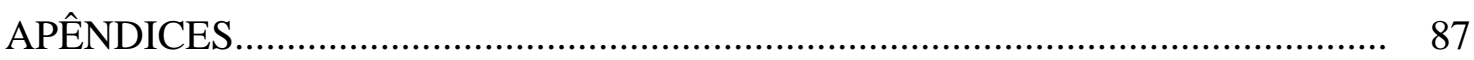




\section{LISTA DE FIGURAS}

1 Localização da área de estudo, Faz. São José do Bromado................................. 11

2 Curva do coletor para as espécies amostradas 30 meses após o corte da primeira rotação do E. grandis, Itatinga - SP.

3 Famílias que apresentaram maior riqueza florística na regeneração, 30 meses após o corte da primeira rotação , em Itatinga - SP

4 Famílias que apresentaram densidade de indivíduos na regeneração, 30 meses após o corte da primeira rotação, em Itatinga - SP

5 Espécies que apresentaram maior densidade na regeneração, 30 meses após o corte da primeira rotação, em Itatinga - SP

6 Classificação Sucessional das espécies amostradas na regeneração, 30 meses após o corte da primeira rotação , em Itatinga - SP

7 Classificação Sucessional dos indivíduos amostradas na regeneração, 30 meses após o corte da primeira rotação, em Itatinga - SP.

8 Distribuição das alturas das espécies amostradas na regeneração, 30 meses após o corte raso do povoamento, Itatinga - SP.

9 Distribuição das alturas das espécies amostradas na regeneração, 30 meses após o corte raso do povoamento,Itatinga - SP

10 Distribuição das alturas das espécies amostradas na regeneração, 30 meses após o corte raso do povoamento, Itatinga - SP

11 Distribuição das alturas das espécies amostradas na regeneração, 30 meses após o corte raso do povoamento, Itatinga - SP 
12 Comportamento da taxa de mortalidade total e por categoria sucessional na regeneração natural no sub-bosque de eucalipto (45, 54 e 61 meses após a exploração).- Tratamento 1 - Testemunha.

13 Comportamento da taxa de recrutamento total e por categoria sucessional da regeneração natural no sub-bosque do eucalipto $(45,54$ e 61 meses após a exploração) -Tratamento 1 - Testemunha.

14 Comportamento densidade de indivíduos por categoria sucessional da regeneração natural (45, 54 e 61 meses após a exploração) Tratamento 1 - testemunha.........

15 Comportamento da taxa de mortalidade total e por categoria sucessional da regeneração natural (45, 54 e 61 meses após a exploração) Tratamento 2: desbaste de $50 \%$ dos indivíduos do povoamento.

16 Comportamento da taxa de recrutamento total e por categoria sucessional da regeneração natural (45, 54 e 61 meses após a exploração) Tratamento 2: desbaste de $50 \%$ dos indivíduos do povoamento.

17 Comportamento da densidade de indivíduos por categoria da regeneração natural (45, 54 e 61 meses após a exploração) Tratamento 2: desbaste de 50\% dos indivíduos do Povoamento. 58

18 Comportamento da taxa de mortalidade total e por categoria sucessional da regeneração natural $(45,54$ e 61 meses após a exploração) Tratamento 3: corte raso do povoamento de eucalipto.

19 Comportamento da taxa de recrutamento total e por categoria sucessional, da regeneração natural (45, 54 e 61 meses após a exploração) Tratamento 3: corte raso do povoamento de eucalipto.

20 Comportamento da densidade de indivíduos por categoria sucessional da regeneração natural (45, 54 e 61 meses após a exploração) Tratamento 3: corte raso do povoamento de eucalipto 


\section{LISTA DE TABELAS}

1 Espécies que apresentaram um indivíduo amostrado no levantamento fitossociológico do sub-bosque de E.grandis, levantamento realizado 30 meses após o corte do povoamento

2 Parâmetros utilizados na análise das alterações temporais da regeneração de espécies nativas no sub-bosque de Eucalyptus grandis.................................

3 Taxas de recrutamento e mortalidade da regeneração de espécies nativas no subbosque de $E$. grandis, levantamentos realizados 30 e 45 meses após a exploração do eucalipto

4 Parâmetros utilizados na análise das alterações temporais da regeneração de espécies nativas 30, 45, 54 e 61 meses após a exploração da primeira rotação do povoamento, Tratamento 1 - Testemunha

5 Parâmetros utilizados na análise das alterações temporais da regeneração de espécies nativas 30, 45, 54 e 61 meses após a exploração do povoamento de eucalipto. Tratamento 2 - com desbaste de $50 \%$ do povoamento de $E$. grandis

6 Parâmetros utilizados na análise das alterações temporais da regeneração de espécies nativas 30, 45, 54 e 61 meses após a exploração do povoamento de eucalipto. Tratamento 3 - corte raso do E. grandis.

7 Evolução de alguns parâmetros da regeneração nos três tratamentos realizados no povoamento de E. grandis. Tratamento 1 : Testemunha, Tratamento 2 desbaste de $50 \%$ do povoamento de E. grandis, Tratamento 3 - corte raso do eucalipto 


\section{LISTA DE QUADROS}

1 Listagem das Espécies amostradas no Talhão 48 Faz. São José do Bromado, com seus respectivos nomes vulgares, categorias sucessionais e porte e padrão de distribuição espacial na área.................................................................. ...

2 Índices de diversidade e critérios de inclusão de levantamentos em sub-bosque de Eucalyptus grandis................................................................................... 31

5 Listagem das Espécies amostradas na regeneração de espécies nativas no sub-bosque de Eucalyptus gr andis, no Talhão 48, da Faz. São José do Bromado, Itatinga - SP. Com seus respectivos nomes vulgares, categorias

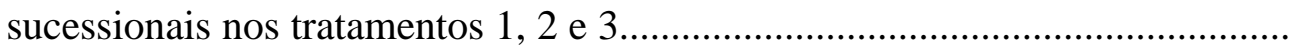




\title{
CARACTERIZAÇÃO FLORÍSTICA, ESTRUTURAL E DA DINÂMICA DA REGENERAÇÃO DE ESPÉCIES NATIVAS EM UM POVOAMENTO COMERCIAL DE Eucalyptus grandis EM ITATINGA, SP
}

\author{
Autor: PAULO HENRIQUE MAROSTEGAN E CARNEIRO \\ Orientador: Prof. Dr. RICARDO RIBEIRO RODRIGUES
}

\section{RESUMO}

Os objetivos deste trabalho foram analisar a composição florística, a estrutura, alguns aspectos da dinâmica da regeneração de espécies nativas no sub-bosque de povoamentos comerciais de Eucalyptus spp e estudar o impacto que algumas práticas silviculturais (desbaste e corte raso) sobre a regeneração. Para isso, foram locadas 17 parcelas (0,68 ha de área amostral) em um talhão de Eucalyptus grandis (Talhão 48), na Fazenda São José do Bromado, coordenadas geográficas 2313'30' 'S e 48³4'07' 'W, município de Itatinga - SP. Na avaliação da composição e estrutura da regeneração, realizada 30 meses após o corte da primeira rotação do povoamento de eucalipto, foram plaqueados e identificados todos os indivíduos arbóreos ou arbustivos com altura superior a 1,5m. O estudo da evolução temporal da regeneração foi realizado em 2 avaliações, 30 e 45 meses após a exploração do povoamento de eucalipto, utilizando o mesmo método de análise, sendo considerado morto o indivíduo amostrado nos levantamento anterior e não localizado na avaliação seguinte. 
Após a segunda avaliação as parcelas foram divididas em três tratamentos, sendo: Tratamento 1 - testemunha (área amostral de 0,2ha), no qual o povoamento de eucalipto foi mantido, Tratamento 2 (área amostral de 0,24ha) no qual foi realizado o desbaste de $50 \%$ do povoamento de eucalipto e Tratamento 3 (área amostral de 0,24ha) no qual foi realizado o corte raso do eucalipto. Após a implantação dos tratamentos (46 meses após a exploração do povoamento) foram realizadas duas avaliações, a primeira 54 meses e a segunda 61 meses após a exploração da primeira rotação do povoamento de E. grandis.

Foram amostrados 1900 indivíduos (104 espécies e 38 famílias) na primeira avaliação. A família de maior riqueza florística foi Myrtaceae seguida de Asteraceae, Fabaceae e Solanaceae, sendo esta última a que apresentou a maior densidade de indivíduos. As espécies de maior densidade relativa foram Solanum variabile e Matayba elaeagnoides. $76,66 \%$ dos indivíduos amostrados pertenciam a famílias que apresentaram padrão de distribuição espacial agregado.

$\mathrm{Na}$ avaliação da dinâmica da regeneração, constatou-se que o recrutamento de novos indivíduos no sub-bosque do eucalipto no período de 30-45 meses da exploração comercial se concentrou nos grupos de espécies secundárias iniciais, secundárias tardias e espécies típicas da condição de sub-bosque. Enquanto a mortalidade se concentrou nos indivíduos pertencentes ao grupo das espécies pioneiras e das espécies não classificadas sucessionalmente. No período o índice para diversidade de Shannon $\left(\mathrm{H}^{\prime}\right)$, apresentou crescimento de 3,48 para 3,573, e a equabilidade (J'), crescimento de 0,751 para 0,762, mostrando que houve ganho em relação a diversidade de espécies na área.

No estudo do impacto que diferentes práticas silviculturais impõem a regeneração, o tratamento 1 - testemunha foi o que apresentou as menores taxas de mortalidade e o maior ingresso de espécies no período analisado. As operações de corte e remoção causaram grande impacto nos tratamentos 2 - desbaste de $50 \%$ do povoamento de E. grandis e tratamento 3 - corte raso, aumentando a taxa de mortalidade e diminuindo a taxa de recrutamento de indivíduos na regeneração. $\mathrm{O}$ Tratamento 2 foi o único a apresentar ganhos em diversidade ( $\mathrm{H}^{\prime}$ ) em todos os levantamentos. 


\title{
FLORISTIC STRUCTURAL CHARACTERIZATION AND DYNAMIC REGENERATION OF NATIVE SPECIES ON A COMMERCIAL STAND OF Eucalyptus grandis IN ITATINGA, SÃO PAULO
}

\author{
Author: PAULO HENRIQUE MAROSTEGAN E CARNEIRO \\ Adviser: Prof. Dr. RICARDO RIBEIRO RODRIGUES
}

\section{SUMMARY}

The objectives of this study were to analyze a floristic composition, the structure, some aspects of the dynamics of regeneration of native species in understory of commercial stands of Eucalyptus spp and to study the impact that some silvicultural practices (thinning and clear cut) have on regeneration. For this purpose, 17 samples (0.68 ha total sample area) were located in a stand of Eucalyptus grandis (Stand 48), on the São José do Bromado Farm, geographical coordinates 23¹3'30's and 48 34'07' 'W, municipal of Itatinga, Sao Paulo. In the evaluation of the composition and structure of the regeneration, done 30 months after the clear cut of the first rotation of Eucalyptus grandis, all of the individual trees up to $1.5 \mathrm{~m}$ of height were tagged and identified. The study of the temporal evolution of regeneration was done in 2 evaluations, 30 and 45 months after the clear cut of the stand. The same method of analysis was used, being that the individual trees measured previously and not found in the second evaluation were considered dead. 
After the second evaluation the samples were divided into three treatments: Treatment 1- control (sample area of 0.2ha), of which the trees were maintained, Treatment 2 (sample area of $0.24 \mathrm{ha}$ ), of which $50 \%$ thinning was done, and Treatment 3 (sample area of $0.24 \mathrm{ha}$ ), of which clear cut was done. After the implementation of the treatments (46 months after the exploration), two evaluations were accomplished. The first at 54 months and the second at 61 months, after the exploration of the first rotation of the stand.

One thousand nine hundred trees (104 species and 38 families) were sampled in the first evaluation. The largest floristic family verified was Myrtaceae followed by Asteraceae, Fabaceae and Solanaceae, the family which presented the largest density of individuals. Whereas the species with the greatest relative density were Solanum variabile and Matayba elaeagnoides. Among the individual samples, $76.66 \%$ were of the families that present a pattern of aggregate spatial distribution.

In evaluating the dynamics of regeneration, it was found that the recruitment of new individuals in understory of eucalyptus during the period of 30-45 months after the commercial exploration was focused on the groups of initial secondary species, late secondary and typical species of understory. The mortality was concentrated in the group of pioneer species and non-classified species, respectively.

The index period to the Shannon diversity ( $\left.\mathrm{H}^{\prime}\right)$, presented growth of 3.48 to 3.573 , and eqüability (J'), growth of 0.751 to 0.762 , showing to have gained in relation to the diversity of species of the area.

The study of the impact that different silvicultural practices have on regeneration, treatment 1- presented the least incidence of mortality and the greatest incidence of species during the analysis period. The practices of thinning and clear cut caused a great impact on treatments 2 and 3, improving the incidence of mortality and decreasing the incidence of new individuals of regeneration. Treatment 2 was the only one to present gains in diversity ( $\left.\mathrm{H}^{\prime}\right)$ in all of the evaluations. 


\section{INTRODUÇÃO}

O modelo agrícola utilizado no Brasil causou a substituição gradativa e contínua de áreas ocupadas com formações florestais naturais por áreas destinadas a agricultura e pecuária. Isso foi demonstrado na ocupação de áreas para agropecuária no Estado de São Paulo, sendo que no inicio do século o Estado apresentava cerca de $80 \%$ do seu território ocupado por florestas e atualmente esta área foi reduzida para somente $13 \%$ da sua superfície total (Fundação SOS Mata Atlântica, 1993).

A situação no interior do Estado é ainda mais crítica uma vez que a maior parte da área ocupada por florestas nativas se concentra no litoral paulista (Complexo Atlântico) e os poucos remanescentes florestais localizados no interior se encontram fragmentados e perturbados pelas atividades de entorno, estimulando o isolamento reprodutivo e a conseqüente endogamia em várias espécies vegetais e principalmente animais, comprometendo assim a base genética da população e agravando os problemas de extinção das espécies (Kageyama et al., 1998).

O despertar da consciência ambiental na população, apoiada inclusive pela legislação pertinente, vem impondo restrições de mercado a produtos cujo processo de fabricação resulte na degradação dos recursos do ambiente. Essas restrições, traduzidas como preferências ou na lei de mercado, ainda pouco comuns no mercado interno brasileiro, tem se mostrado como fator determinante na aceitação de produtos nos principais mercados consumidores, como o europeu e o americano. 
As exigências legais e o novo comportamento do mercado exigiram de diversos setores da economia, inclusive o florestal, uma nova postura em relação ao meio ambiente. No setor florestal esta postura tem se definido na reestruturação do uso e ocupação das áreas ocupadas com florestas comerciais, promovendo a adequação ambiental de atividades produtivas. Nessa reorganização do espaço agrícola, áreas de preservação permanente (Código Florestal, lei ñ 4771/65) que foram impropriamente ocupadas por atividades agrícolas ou florestais, contrariando a legislação vigente, deverão ser restauradas de forma a promover a reocupação com florestas naturais.

Quando estas áreas de preservação permanente (APPs) estão ocupadas com povoamentos de eucalipto, que pelas suas características de ciclo longo e aplicação reduzida de pesticidas, principalmente herbicidas, ocorre um favorecimento da regeneração natural, sendo que a indução e a condução dessa regeneração natural podem ser utilizadas como as principais ferramentas no processo de restauração florestal. $\mathrm{O}$ potencial da regeneração natural como possível facilitadora da restauração de formações naturais biodiversas no interior de florestas econômicas monoespecíficas, em função da elevada biodiversidade existente nos estratos inferiores de várias culturas de eucalipto, tem sido comentado e demonstrado em diversos trabalhos (Schlittler, 1984; Talora, 1992; Lombardi, 1992; Borges, 1993; Poggiani \& Simões, 1993; Calegario et al., 1993b; Tabarelli et al., 1993; Rezende et al., 1994; Lima, 1996; Durigan et al., 1997, Nave et al., 1998).

Almeida (1982) vai além, sugerindo o manejo das espécies nativas ocorrentes no sub-bosque de povoamentos de eucalipto como uma das práticas culturais recomendadas, visando aumentar a complexidade do sistema e auxiliando também no controle de formigas cortadeiras.

Neste contexto, as principais indagações que motivaram a realização deste trabalho foram: é possível recuperar a floresta ribeirinha nativa com diversidade elevada apenas manejando a regeneração natural e eliminando o eucalipto; sendo viável esta recuperação, como eliminar o eucalipto de maneira a aumentar a chance de sucesso dessa recuperação? Para tentar responder, pelo menos em parte estas perguntas, foram definidos como objetivos específicos deste trabalho: contribuir para o acúmulo de dados 
sobre a composição e estrutura da regeneração de espécies nativas em povoamentos comerciais de Eucalyptus spp; avaliar alguns aspectos da dinâmica da regeneração natural no sub-bosque desses povoamentos; discutir a adoção de práticas silviculturais que favoreçam o sucesso da regeneração natural em substituição à cultura do eucalipto nas APPs, usando como parâmetros a diversidade das espécies e o desenvolvimento dos indivíduos regenerantes. 


\section{REVISÃO DE LITERATURA}

As florestas tropicais, maduras ou jovens, se apresentam como um mosaico de manchas em diferentes estágios de regeneração (Whitmore, 1982; Pickett, 1985; Oldeman, 1989). Como as espécies arbóreas apresentam performances diferentes na ocupação dessas manchas podem ser divididas em diferentes categorias sucessionais (Budowski, 1965; Deslow, 1980, 1987).

As substituições que se sucedem em um ecossistema após uma perturbação caracterizam um processo ecológico denominado sucessão secundária (Gomez-Pompa et al., 1991). Os mesmos autores descrevem vários métodos para o estudo dos processos de regeneração dos ecossistemas, entre eles: o estudo, em uma mesma zona ecológica, de diversos estágios sucessionais de idades conhecidas; a busca de informações ecológicas para poder interpretar os processos de regeneração ao longo do tempo e o acompanhamento de uma determinada área, submetida a perturbação, através do tempo.

O processo de sucessão se caracteriza, entre autros fatores, por ser aberto e estocástico, sendo influenciado por fatores ambientais e pelo histórico da área onde ocorre. Neste conceito, o processo de sucessão não apresenta um mas sim vários "caminhos" a serem seguidos rumo a estágios de vegetação mais complexos (Pickett et al., 1992)

O processo de sucessão secundária em florestas é um dos princípios nos quais se apoiam os métodos atuais de recomposição florestal (Kageyama \& Castro, 1989; Rodrigues \& Gandolfi, 1996; Kageyama \& Gandara, 2000). 
As três principais causas que levam a ocorrer o processo de sucessão em um área: a disponibilidade de um local com condições ambientais adequadas para suportar plantas, a chegada de sementes ao longo de tempo (dispersão) ou a presença prévia de sementes no solo (banco de sementes) e que as espécies que se instalarem no local pertençam a grupos sucessionais distintos, garantindo assim a substituição das espécies no decorrer do tempo (Rodrigues \& Gandolfi, 1996).

O potencial de regeneração das espécies em um determinado fragmento florestal, (resiliência) é variável no espaço e no tempo, podendo promover, quando eficientemente manejado, a restauração total ou parcial da vegetação na área remanescente (Rodrigues, 1999). Dentro deste contexto, a heterogeneidade da resiliência determina a composição do mosaico vegetacional de um remanescente florestal, no qual cada unidade vai ser ocupada por diferentes conjuntos de espécies, dependendo das características dessa unidade em termos de tamanho, época de abertura, contexto no qual esta inserida e outros (Pickett et al., 1995).

A condução da regeneração natural é um dos sistemas pelo quais se pode realizar a recomposição da vegetação florestal de uma área, podendo ser definida como um sistema a ser utilizado em áreas pouco perturbadas, áreas com remanescentes florestais no entorno e áreas cujo histórico de uso permitiu a manutenção de um certo potencial de auto recuperação, como áreas com solo pouco revolvido e/ou uso restrito ou inexistente de herbicidas e outros (Rodrigues \& Gandolfi, 1996).

Estudada inicialmente em conseqüência da sua influência no manejo de pragas florestais (Almeida, 1982), a regeneração de espécies nativas em povoamentos comerciais homogêneos tem sido alvo de diversos estudos (Schlittler, 1984; Talora, 1992; Lombardi, 1992; Borges, 1993; Poggiani et al., 1993; Calegario et al., 1993b; Tabarelli, 1993; Rezende et al., 1994; Lima, 1996; Durigan et al., 1997, Nave et al., 1998).

Estes estudos apresentam grande heterogeneidade em relação à composição florística ocorrente no sub-bosque de plantios comerciais. Esta heterogeneidade florística é resultado de uma série de fatores, com destaque para a própria heterogeneidade do ambiente, para as particularidades do histórico de ocupação da área, 
idade do plantio, espécie utilizada, práticas silviculturais adotadas ao longo do tempo no reflorestamento e características da paisagem regional, como tipos de unidades vegetacionais do entorno, fragmentação, proximidade de formações naturais, etc.

Enquanto no sub-bosque de Eucalyptus tereticornis em Rio Claro, SP, (Schlittler, 1984), no domínio de Florestas Estacionais Semideciduais (florestas interioranas), foram amostradas 100 espécies (63 espécies arbóreas, 22 arbustivas e 28 espécies herbáceas), sendo que entre as espécies arbóreas as famílias Leguminosae, Meliaceae, Asteraceae e Rubiaceae foram as de maior riqueza, em um povoamento de eucalipto em Santa Virgínia, SP, (Tabarelli, 1993), no domínio de Florestas Ombrófilas Densas (floresta atlântica senso stricto) foram amostradas 73 espécies arbóreas e as famílias de maior riqueza foram Lauraceae, Melastomataceae, Myrtaceae e Rubiaceae.

No levantamento do sub-bosque de povoamentos puros de E. tereticornis realizado no Horto Navarro de Andrade em Rio Claro, SP, (Talora, 1992), foram amostradas 41 espécies, as famílias que apresentaram a maior riqueza florística foram Myrtaceae, Meliaceae, Rubiaceae, Leguminosae, Lauraceae, Bombacaceae e Euphorbiaceae. No entanto, no sub-bosque de povoamentos de E. citriodora, também no Horto Navarro de Andrade (Talora, 1992), amostrou 40 espécies, sendo as famílias Rutaceae, Piperaceae e Solanaceae foram as de maior riqueza florística, seguidas de Myrtaceae, Ulmaceae e Bignoniaceae.

Em levantamento florístico similar aos anteriores, realizado em dois talhões de eucalipto em Minas Gerais (Calegario et al., 1993b), encontrou no sub-bosque sob Eucalyptus paniculata e E. grandis, as famílias Myrtaceae, Caesalpiniaceae, Moraceae, Lecythidaceae, Sapotaceae e Mimosaceae como as de maior riqueza florística. Porém foram amostradas mais espécies (56 espécies) no sub-bosque do talhão de E. grandis do que no de E. paniculata (49 espécies). Segundo o autor, essas diferenças florísticas se referem à existência de fragmentos florestais próximos a área do povoamento de $E$. grandis, fato que possibilitou a presença de um banco de sementes ativo na área. A maior riqueza de espécies amostrados no sub-bosque de $E$. grandis em relação ao $E$. paniculata, se devia também a maior abertura do dossel propiciada por essa espécie. 
A importância da proximidade de remanescentes florestais, como fonte de propágulos para áreas degradadas por ação antrópica, foi destacada por Rodrigues \& Gandolfi (1996). O aumento da riqueza de espécies na regeneração natural nos povoamentos comerciais com a proximidade de remanescentes florestais naturais foi constatado por Poggiani et al. (1993).

A existência e a composição do banco de sementes de espécies nativas em áreas de eucalipto e a influência que a proximidade de remanescentes florestais exercem sobre esse banco foi estudada por Borges (1993). Nesse trabalho o autor concluiu que a presença de um remanescente pode influenciar na composição do banco de sementes e que o potencial de regeneração do sub-bosque pode variar conforme a distância e as características da degradação. O trabalho constatou ainda que, apesar da existência de um banco de sementes viáveis nos povoamentos de eucalipto estudados, este era pobre em espécies arbóreas. Resultados similares foram encontrados em estudos sobre a composição do banco de sementes sob povoamentos de eucalipto na região de Caieras SP (Nave et al., 1998), mostrando um banco muito rico em espécies herbáceas e pobre em espécies arbustivas e arbóreas.

A predominância de espécies zoocóricas entre as encontradas no sub-bosque de povoamentos comercias foi constatada por Lombardi (1992) em povoamentos de Pinus elliottii e Taberelli (1993) em povoamentos de Eucalyptus spp.

Calegario et al. (1993a), trabalhando com a regeneração de espécies nativas em povoamentos de eucalipto em Belo Oriente, MG, testou vários índices de distribuição de espécies entre eles: não-aleatorizado, de Hanzen, de McGuinnes, de Fracker e Brischle e o índice de Morisita. O autor encontrou coerência entre os resultados obtidos para os diversos índices, ressaltando que os índices que empregam a razão entre variância e média (não-aleatorizado e de Hanzen) apresentaram maior consistência nos resultados. 


\section{MATERIAL E MÉTODOS}

\subsection{Caracterização da área de estudo}

A área de estudo está localizada ma Fazenda São José do Bromado (Figura 1), propriedade da Eucatex Florestal SA, no município de Itatinga (SP), nas coordenadas geográficas aproximadas de $23^{\circ} 13^{\prime} 30^{\prime}$ 'S e $48^{\circ} 34^{\prime} 07^{\prime}$ 'W. A fazenda se localiza na região do médio Paranapanema, na depressão periférica paulista, nos limites da Cuesta basáltica, abrangendo principalmente solos dos tipos Neossolos Quartzarênios e Latossolos, originados de arenitos do grupo pirambóia.

O clima da região é classificado, no sistema de Köppen, como Cwa indicando um clima úmido, quente com inverno seco. A média anual de temperatura é $18^{\circ} \mathrm{C}$, com mínima de $10^{\circ} \mathrm{C}$ no mês de julho e máxima de $28^{\circ} \mathrm{C}$ no mês de janeiro (Ivanauskas et al., 1997). A menor precipitação acontece no mês de julho (20-30mm), sendo o mês mais chuvoso janeiro (200-226mm).

Na Fazenda São José do Bromado predominam os plantios puros de Eucalyptus grandis e E. urophylla, ocupando uma área de 1040 ha ou 68,79\% da área total da propriedade. As áreas de vegetação nativa na fazenda representam 385,70 ha ou 25,51\% da sua área total, compreendendo áreas de floresta mesófila semi-decídua, floresta paludosa e cerrado. 
A área amostral foi locada no talhão 48 dessa fazenda. O talhão 48 esta localizado em área de relevo plano, em solo do tipo Neossolo Quartzarênico, classe que abrange os solos anteriormente classificados como áreia quartzoza (Embrapa, 1999), e apresenta uma área de 2,97 ha, totalmente ocupada com E. grandis em segunda rotação, com aproximadamente 3 anos na época da primeira amostragem (agosto de 1996). Esse talhão apresenta nas proximidades pequenos fragmentos de Floresta Paludosa (Mata de brejo) em estado avançado de degradação, com solo permanentemente encharcado. As parcelas amostrais foram locadas a aproximadamente $60 \mathrm{~m}$ lineares de um desses remanescentes florestais.

Dados da equipe de inventário da empresa caracterizam o talhão 48 como uma área de solo sem restrições químicas e físicas para o estabelecimento e desenvolvimento de povoamentos de Eucalyptus. O IMA (incremento médio anual) desse talhão, que representa um parâmetro de produtividade desse sítio, foi de 78 st/ha/ano, conforme medições da própria empresa em 1999. Esse valor é extremamente alto para os padrões de crescimento desta espécie no Estado de São Paulo, mesmo quando comparado com as médias encontradas para os demais talhões da propriedade, alguns inclusive próximos ao talhão 48, que foram de aproximadamente 37 st/ha/ano, o valor do IMA encontrado para o talhão 48 se mostra atípico (dados fornecidos pela empresa).

\subsection{Caracterização florística e estrutural da regeneração natural de espécies nativas no povoamento de E.grandis}

A caracterização fitossociológica do sub-bosque de $E$. grandis no Talhão 48 foi realizada usando o método de parcelas (Mueller-Dombois \& Ellenberg, 1974).

Foram locadas 17 parcelas de 20x20m no interior do talhão de E. grandis, totalizando 0,68ha de área amostral.

Nesse trabalho foram plaqueados, identificados, tiveram sua altura mensurada e localização determinada, todos os indivíduos arbóreos ou arbustivos com altura superior a $1,5 \mathrm{~m}$. 
A identificação das espécies foi realizada através de comparação do material coletado no campo com as excicatas depositadas no Herbário ESA da ESALQ/USP, com o uso de bibliografia pertinente e em alguns casos através de consultas a especialistas.

A caracterização sucessional das espécies amostradas foi baseada nos trabalhos de Gandolfi (1991), Gandolfi (1995), Nave et al. (1995), Rodrigues \& Gandolfi (1996), Rodrigues (1999) e Gandolfi (2000), considerando três categorias sucessionais: espécies pioneiras, secundárias iniciais e secundárias tardias. Além desses grupos foram categorizadas também as espécies típicas da condição de sub-bosque e as espécies que por falta de informações não puderam ser classificadas sucessionalmente.

A suficiência amostral da área foi definida através da construção e analise da curva do coletor, também conhecida como curva espécie $\mathrm{x}$ área.

Os parâmetros fitossociológicos calculados foram os normalmente utilizados em trabalhos dessa natureza (Mueller-Dombois \& Ellenberg 1974). O parâmetro cobertura ou dominância, normalmente expresso como função da área basal dos indivíduos amostrados, foi discutido nesse trabalho através da altura dos indivíduos na regeneração natural. Isso se justifica pelos valores reduzidos dos diâmetros apresentados pelas plantas amostradas nessa condição de sub-bosque de eucalipto. Em se tratando se tratando de uma regeneração natural e portando de indivíduos jovens e plântulas, a altura parece ser mais adequada que a área basal na discussão da dominância ou cobertura das espécies na comunidade. Dessa forma não se utilizou o IVI (Índice de Valor de Importância) e o IVC (Índice de Valor de Cobertura), na discussão da estrutura do subbosque, já que estes índices são compostos, incorporando o parâmetro dominância no seu cálculo (Martins, 1993).

Para o calculo dos parâmetros quantitativos utilizou-se o programa Fitopac, desenvolvido pelo Prof. Dr. George J. Shepherd do Departamento de Botânica da UNICAMP (Shepherd, 1995). 

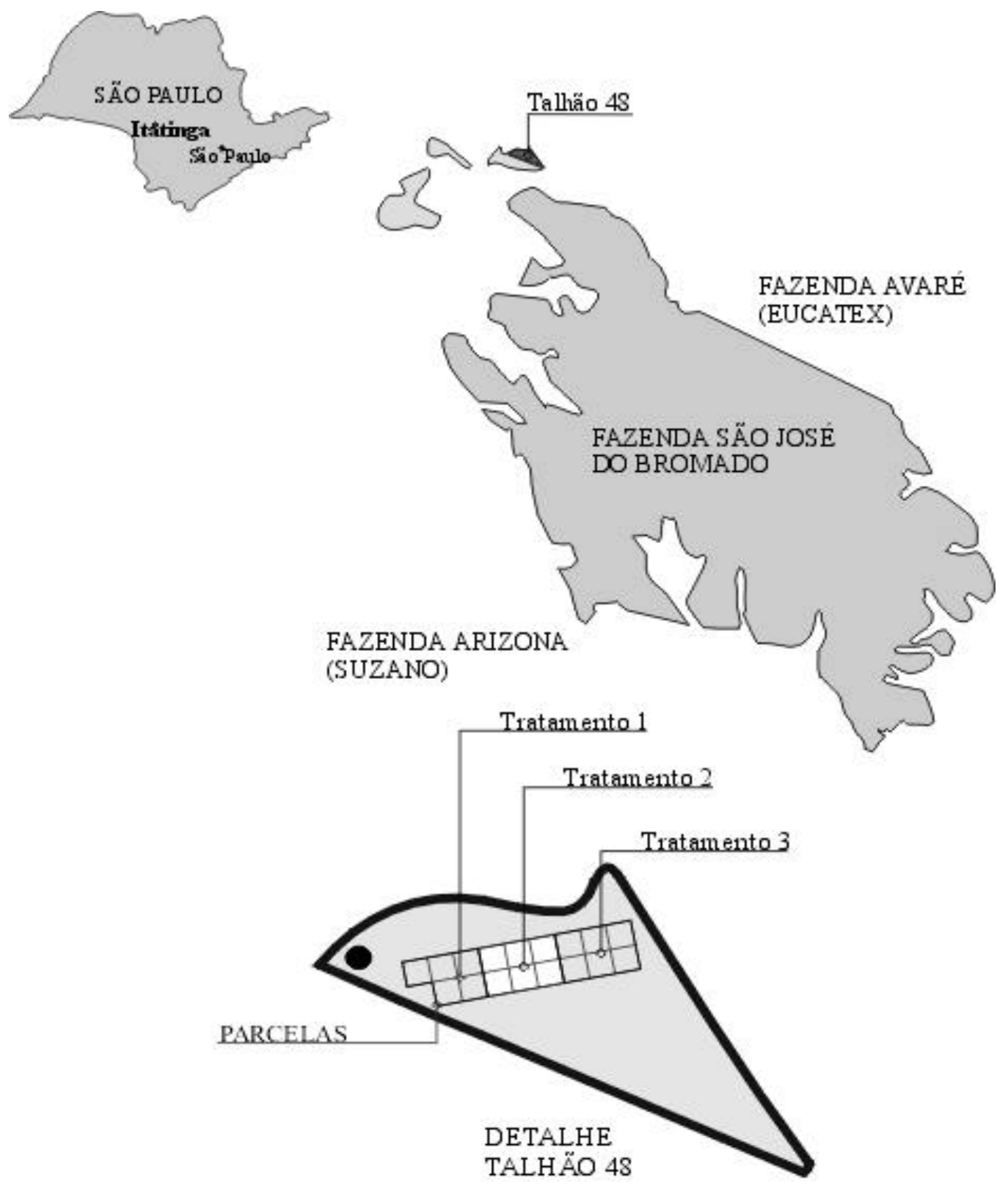

Figura 1- Localização da área de estudo, com a disposição das parcelas e dos blocos de tratamentos no talhão 48, da Faz. São José do Bromado, propriedade da Eucatex Florestal, no município de Itatinga, Estado de São Paulo. Tratamento 1: Testemunha, Tratamento 2: desbaste de $50 \%$ do povoamento de E. grandis, Tratamento 3: corte raso do eucalipto. 
Foi utilizado o índice não-aleatorizado $(\mathrm{R})$ para estimar os padrões de dispersão ou distribuição espacial das espécies (Calegario et al., 1993a; Barros, 1986), este índice é obtido através da razão entre a variância da distribuição dos indivíduos de cada espécie nas unidades amostrais $\left(\mathrm{s}^{2}\right)$, e a média dos indivíduos por unidade $(\mathrm{x})$, conforme indicado a seguir:

$$
R=\frac{s^{2}}{\bar{x}} \quad s^{2}=\frac{\sum f(x) \cdot x^{2}-\frac{\left(\sum f(x) \cdot x^{2}\right)^{2}}{\sum f(x)-1}}{\sum f(x)-1} \quad x=\frac{-\sum f(x) \cdot x}{\sum f(x)}
$$

Onde: R: Índice não-aleatorizado; $\mathrm{s}^{2}$ : variância da distribuição dos indivíduos de cada espécie nas unidades amostrais; $\mathrm{x}$ : média dos indivíduos por unidade amostral.

Este método se baseia na premissa que a distribuição dos indivíduos de qualquer espécie em uma floresta segue uma distribuição de Poisson, assim o valor R deve ser igual a 1, o que indica distribuição aleatória dos indivíduos da espécie. Valores de R menores que 1 indicam distribuição uniforme, enquanto valores maiores que 1 indicam distribuição agregada. Foi utilizado o teste qui-quadrado para verificar se o valor $\mathrm{R}$ obtido era estatisticamente diferente de 1, considerando o nível de probabilidade de 5\%, com (n-1) graus de liberdade, no qual n se refere ao número total de unidades amostrais.

\subsection{Estudo da evolução temporal da regeneração natural no sub-bosque de povoamentos de E. grandis}

Para analisar a evolução temporal foram utilizadas as mesmas parcelas já estabelecidas para a caracterização da composição florística e estrutura da regeneração natural no sub-bosque do povoamento de E. grandis.

Em cada parcela foram realizadas duas avaliações, a primeira com 30 meses e a segunda 45 meses após o corte da primeira rotação do povoamento de E. grandis. Em cada uma dessas avaliações foram contabilizados os indivíduos recrutados, considerando como indivíduos recrutados aqueles que entre uma avaliação e outra ingressaram no limite do critério amostral estabelecido de $1,5 \mathrm{~m}$ de altura. Os indivíduos mortos foram 
definidos como aqueles amostrados nos levantamentos anteriores e não localizados nas avaliações seguintes.

A mortalidade foi analisada através da taxa de mortalidade (me) proposta por Swaine \& Liberman (1987):

$$
m_{e}=\frac{[\ln (n o)-\ln (n i)]}{t}
$$

onde:

No - número de indivíduos da população amostrados no primeiro levantamento.

$\mathrm{Ni}$ - número de indivíduos da população amostrados no segundo levantamento.

$\mathrm{t}$ - tempo entre levantamentos.

Para a análise do recrutamento de indivíduos foi utilizada a taxa de ingresso anual (i), obtida através da relação:

$$
i=\frac{\frac{\ln (n o+I)}{n o}}{t}
$$

onde:

no - número de indivíduos amostrados na população inicial.

I - número de indivíduos amostrados no segundo levantamento (altura superior a 1,5m).

$\mathrm{t}$ - tempo entre levantamentos

Foi utilizado o teste qui-quadrado para se verificar se a taxas de mortalidade e recrutamento dos indivíduos nos grupos sucessionais e famílias apresentaram diferenças significativas entre si. 


\subsection{Avaliação das respostas da regeneração natural no sub-bosque de povoamentos de E. grandis quando submetidas a diferentes condições de manejo.}

As parcelas foram divididas em 3 tratamentos, sendo que estes foram dispostos em blocos de maneira a minimizar as interferências de um tratamento sobre o outro, uma vez que as parcelas estão distribuídas no campo de maneira contínua.

Os tratamentos a que foi submetido o povoamento de $E$. grandis foram:

- tratamento 1: constituído de cinco parcelas, totalizando 0,2 ha, nas quais o povoamento não recebeu nenhum tratamento, sendo denominada testemunha;

- tratamento 2: constituído de seis parcelas, totalizando 0,24 ha, onde ocorreu o desbaste sistemático de 50\% dos indivíduos de E. grandis, sendo os indivíduos retirados alternadamente. $\mathrm{O}$ desbaste não foi realizado em função da área basal ou dominância dos indivíduos do povoamento;

- tratamento 3: constituído de seis parcelas, totalizando 0,24ha, onde ocorreu o corte raso do povoamento de E. grandis.

Nos tratamentos 2 e 3, o corte e o transporte primário da madeira foram realizados de maneira a concentrar os danos sobre a regeneração em linhas alternadas do plantio, mantendo metade das linhas sem danos. Esta operação teve o objetivo de minimizar o impacto das atividades de colheita florestal sobre as espécies nativas presentes no subbosque.

O comportamento da regeneração de espécies nativas no sub-bosque foi avaliado em quatro momentos, 30 (agosto de 1996), 45 (novembro de 1997), 54 (agosto de 1998) e 61 (março de 1999) meses após o corte da primeira rotação do eucalipto. A implantação dos experimentos ocorreu em dezembro de 1997, ou seja, dois meses após a segunda avaliação da regeneração (45 meses após o corte da primeira rotação do povoamento de eucalipto).

Em cada avaliação foram contabilizados os indivíduos recrutados, considerando esses as plantas que entre uma avaliação e outra ultrapassaram a altura limite de $1,5 \mathrm{~m}$, e 
os mortos, sendo essas as plantas amostradas nos levantamentos anteriores e não localizadas nos posteriores.

A mortalidade foi analisada através da taxa de mortalidade (me) proposta por Swaine \& Liberman (1987), já apresentada anteriormente.

Para a análise do recrutamento de indivíduos também foi utilizada a taxa de ingresso anual (i), já apresentada anteriormente.

Foi utilizado o teste qui-quadrado para se verificar se a taxas de mortalidade e recrutamento dos indivíduos nos grupos sucessionais e famílias apresentaram diferenças significativas entre si. 


\section{RESULTADOS E DISCUSSÃO}

\subsection{Análise da estrutura e da composição florística do sub-bosque de um povoamento de E. grandis.}

A avaliação foi realizada em agosto de 1996. Nas 17 parcelas locadas foram amostrados 1900 indivíduos, distribuídos em 104 espécies de 38 famílias (Quadro 1), totalizando 0,68 ha de área amostral, o que projeta uma densidade de 2794 indivíduos

por hectare. Estes números representam 1 indivíduo arbóreo-arbustivo amostrado a cada 3,57 $\mathrm{m}^{2}$, e ainda, uma nova espécie a cada 18,26 plantas amostradas. A suficiência amostral foi determinada através da curva do coletor (Figura 2).

A família que apresentou maior riqueza florística foi Myrtaceae com 14 espécies, seguida por Asteraceae e Fabaceae (8), Solanaceae (7), Euphorbiaceae, Lauraceae e Rutaceae com 5 espécies cada, representando mais de 50\% das espécies amostradas (Figura 3). O fato das famílias Myrtaceae, Fabaceae e Lauraceae se apresentarem entre as de maior riqueza florística era esperado, uma vez que estas famílias normalmente apresentam grande riqueza florística em trabalhos realizados em Florestas Estacionais Semideciduais no Estado de São Paulo (Ivanauskas et al., 1999; Bernacci \& Leitão Filho, 1996; Gandolfi, 1991; Gabriel, 1991; Leitão Filho, 1987) 
Em relação a densidade relativa de indivíduos, as famílias que se destacaram foram Solanaceae com $17,21 \%$ do total de indivíduos amostrados, seguida por Sapindaceae (12,32\%), Mimosaceae (10,11\%), Myrtaceae (9,21\%) e Flacourtiaceae (7,95\%), representando 56,8\% do total de indivíduos amostrados, como apresentado na Figura 4.

As presenças das famílias Solanaceae e Asteraceae, que são caracterizadas por apresentarem um grande número de espécies iniciais da sucessão, entre as famílias de maior riqueza florística e as de maior densidade de indivíduos é um reflexo do critério de amostragem (incluir no estudo indivíduos com altura igual ou superior a 1,5m), e principalmente, do estágio de desenvolvimento do povoamento de E. grandis (a amostragem foi realizada 30 meses após o corte raso do eucalipto), desta maneira, pressupõe-se que grande parte dos indivíduos pertencentes a estas famílias tenham se estabelecido em condições de maior luminosidade, ou seja, antes do fechamento das copas do povoamento de eucalipto.

As espécies que apresentaram maior densidade relativa foram: Solanum variabile (16,16\%), Matayba elaeagnoides (9,68\%), Casearia sylvestris (7,47\%), Acacia velutina (7,21\%), Campomanesia guaviroba (4,37), Esenbeckia febrifuga (4,26\%) e Rapanea umbellata $(3,37 \%)$, totalizando mais de $50 \%$ da densidade relativa total (Figura 5).

As espécies $M$. elaeagnoides e $R$. umbellata apareceram entre as de maior densidade relativa em levantamento fitossociológico realizado por Ivanauskas et al. (1999) em fragmento de florestal estacional no município de Itatinga - SP.

Em relação a distribuição espacial dos indivíduos das espécies, 41 espécies representando 1456 indivíduos (76,66\% do total de plantas amostradas) apresentaram padrão de distribuição agregado, 36 espécies apresentaram padrão de distribuição aleatório, representando 21,92\% dos indivíduos amostrados. As 27 espécies restantes (1,42\% dos indivíduos) não puderam ser analisadas em relação a distribuição, pois apresentaram apenas 1 indivíduo amostrado (Quadro 1).

A tendência das espécies presentes no sub-bosque de povoamentos comerciais apresentarem padrão de distribuição espacial agregado foi constatada por Calegario et al. (1993 b), em Belo Oriente (MG). O mesmo autor correlacionou esta tendência com dois 
fatores: o primeiro referente às características reprodutivas das espécies, descrevendo que apresentariam padrão agregado espécies com sementes e frutos pesados e não ingeridos por animais (espécies barocóricas e autocóricas), o que dificultaria a sua dispersão, e o segundo, referente às condições do sítio, onde espécies que apresentassem exigências quanto a qualidade do sítio (fertilidade do solo, umidade, topografia), tenderiam a distribuição espacial agregada.

Outro fator que deve ser considerado na determinação do padrão de distribuição espacial agregado para as espécies é o regime da luz no piso florestal, desta maneira espécies heliófitas tenderiam a apresentar padrão de distribuição agregado nos locais onde a intensidade luminosa no piso florestal fosse mais elevada. Considerando que o objeto de estudo é um talhão homogêneo de E. grandis é esperado que fatores que influenciem a dinâmica de abertura de clareiras no dossel do povoamento, como taxas de mortalidade, tipo e intensidade de desbastes, manejo da brotação das cepas e outros, tenham grande influência sobre os padrões de distribuição espacial das espécies presentes no seu sub-bosque.

Em relação as síndromes de dispersão das espécies encontradas no sub-bosque de povoamentos homogêneos, Lombardi (1993), trabalhando com Pinus elliottii, e Tabarelli (1993), trabalhando com Eucalyptus spp, constataram a predominância no subbosque de espécies zoocóricas, seguidas de espécies anemocóricas, barocóricas e autocóricas, desta maneira, a contribuição de espécies com sementes e frutos pesados e não ingeridos por animais na composição do grupo das espécies com padrão de distribuição espacial agregado parece ser reduzida.

Foi observada na área intensa brotação de cepas que sofreram injúrias durante as diversas operações silviculturais promovidas pela empresa e no corte do eucalipto, este fato associado a presença de espécies que se utilizam da brotação de raízes gemíferas como estratégia de regeneração (Rodrigues, 1999), demonstram a importância da reprodução vegetativa na dinâmica de regeneração e sua influência na predominância do padrão de distribuição espacial agregado entre as espécies amostradas.

Deve-se levar em conta ainda, o sistema de manejo imposto às áreas comerciais de Eucalyptus spp, os quais submetem os talhões a desbastes ou ao corte raso 
periodicamente. A retirada total ou parcial da cobertura florestal induz um processo de regeneração natural semelhante ao observado em "grandes clareiras", onde diversos fatores como a composição do banco de sementes, a proximidade a fragmentos florestais, a época de corte, a capacidade das espécies de rebrotar através por raiz ou caule, e principalmente, o histórico e o nível de perturbação (tráfico de máquinas, áreas de arraste ou empilhamento da madeira, áreas de acúmulo de galhada) em cada trecho tendem a particularizar o processo de regeneração (Pickett et al, 1995). O resultado deste processo é uma ocupação semelhante a um mosaico de manchas, onde cada trecho ou mancha apresenta características florísticas e estruturais próprias e grande homogeneidade (predominância do padrão agregado de distribuição das espécies).

Em relação a distribuição das espécies por categoria sucessional, considerando as 104 espécies amostradas no estudo, 22 foram classificadas como pioneiras, 31 secundárias iniciais, 25 secundárias tardias, 14 como espécies típicas da condição de sub-bosque, as 12 espécies restantes não foram classificadas sucessionalmente (Figura 6).

Uma mostra de que o processo de ocupação da área por espécies nativas é recente, é a classificação sucessional das 10 espécies de maior densidade, na qual 4 são classificadas como pioneiras, 4 como secundárias iniciais, 1 como secundária tardia e 1 como típica de sub-bosque.

Para uma melhor compreensão da distribuição das espécies e indivíduos na estrutura do sub-bosque, considerou-se o número de indivíduos e a distribuição da altura por classe sucessional. Nesse sentido, no grupo das pioneiras foram amostrados 840 indivíduos, destes 498 (59\% do total) apresentaram altura inferior a 2,0 m, com maior concentração de indivíduos na classe de altura entre 1,75 a 2,0 m, com 250 indivíduos amostrados. Em relação as secundárias inicias foram amostrados 598 indivíduos, a classe de altura com maior número de plantas amostradas foi a de 1,5 a 1,75m, com 343 indivíduos. Para as espécies secundárias tardias, 288 indivíduos e maior concentração de indivíduos (197) com altura entre 1,5m e 1,75m. Para as espécies típicas da condição de sub-bosque, 123 indivíduos e maior concentração de indivíduos (35) com altura entre 
1,5m e 1,75m e para as espécies que não classificadas sucessionalmente, 51 indivíduos e classe modal de 1,75 e 2,0m, com 16 indivíduos (Figuras 7 e 8).

Vinte e sete das 104 espécies amostradas, ou seja, 25,9\% do total de espécies, apresentaram somente um indivíduo na amostra (Tabela 1). A baixa densidade de algumas espécies pode ser consequiência de:

- estas espécies serem características de estágios finais da sucessão, como a área estudada se encontra em estágio inicial de regeneração, dominada por espécies iniciais, estas espécies se encontrariam ainda em fase de ocupação da área e por isso com pequeno número de indivíduos;

- parte dessas espécies poderiam ser biologicamente raras, ou seja, espécies que mesmo em comunidades florestais primárias apresentam uma pequena densidade, o que pode ser o caso de Citronella paniculata.

- ser conseqüência de uma série de fatores inerentes a espécie como a síndrome de dispersão, a capacidade da espécie de se estabelecer ou não a partir de banco de sementes, a sua fenologia (época de produção de sementes, plurianuidade) e de fatores climáticos no período (favoráveis ou não ao estabelecimento e desenvolvimento da espécie) e ainda decorrentes da época em que foi realizada a exploração do povoamento de eucalipto, beneficiando espécies que frutificaram no período imediatamente anterior ou durante a exp loração do eucalipto.

A distribuição da altura dos indivíduos amostrados pode ser observado na Figura 8, o comportamento da curva se assemelha ao $\mathrm{J}$ invertido, com concentração de observações nas classes de alturas inferiores $(1,5$ - 1,75m e 1,75 a 2,00m).

Observando-se o comportamento das curvas de distribuição das alturas dos indivíduos por espécies notam-se três padrões de distribuição distintos. O primeiro, formado por espécies que apresentam padrão de distribuição de indivíduos por altura similar a curva $\mathbf{J}$ invertido, com maior densidade de indivíduos nas classes de altura inferiores. Este padrão indica altas taxas de recrutamento nas classes inferiores de altura, são exemplos deste comportamento as espécies: Acacia velutina, Tabernaemontana hystrix, Campomanesia guaviroba, C. guazumifolia, Cupania vernalis, Zanthoxylum rhoifolium (Figura 9), Matayba elaeagnoides, Solanum variabile (Figura 10). 
O segundo formado por espécies que apresentam distribuição de altura tendendo a distribuição normal. A distribuição de alturas ou diâmetros tendendo a curva normal é característica de populações coetâneas. Na área, este padrão representa espécies pioneiras ou secundárias iniciais que após a exploração do povoamento de eucalipto encontram condições microclimáticas para se estabelecer. Com o desenvolvimento do eucalipto estas condições se alteraram, notadamente a luminosidade, interferindo nos processos e diminuindo as taxas de recrutamento dessas espécies. São exemplos dessa condição: Gochnatia polymorpha, Schinus terebinthifolius, Baccharis dracunculifolia, Casearia sylvestris (Figura 10) e Cytharexyllum myriantum (Figura 11). As espécies Sebastiania brasiliensis, Paraptadenia rigida e Ocotea puberula (Figura 11), também apresentam padrão de distribuição de altura tendendo a curva normal com altas densidade de indivíduos em classes de maior altura, fato provavelmente causado por indivíduos remanescentes da primeira rotação do eucalipto e que foram poupados no corte do povoamento de eucalipto.

O terceiro grupo é formado por espécies que apresentam pulsos de recrutamento, representados pela concentração de indivíduos em determinadas classes de altura, neste grupo se encontram as espécies Ocotea pulchella e Esenbeckia febrifuga (Figura 11).

Considerando a divisão de espécies em grupos sucessionais, as espécies secundárias iniciais, tardias e típicas da condição de sub-bosque apresentam padrões de distribuição similares, com as maiores densidades de indivíduos nas classes de menor altura (Figura 8). As espécies pioneiras e as não classificadas sucessionalmente apresentam maior concentração de indivíduos na classe 1.75-2.00m (Figura 8), indicando queda no recrutamento de plantas para a classe inferior, provavelmente reflexo das mudanças nas condições microclimáticas impostas ao piso florestal pelo desenvolvimento do povoamento do eucalipto (maior sombreamento, menor umidade e outras). 
Tabela 1. Espécies que apresentaram um indivíduo amostrado no levantamento fitossociológico do sub-bosque de E.grandis, Itatinga, SP, levantamento realizado 30 meses após o corte do povoamento, e sua classificação sucessional. P - espécie pioneira; Si - espécie secundária inicial; St - espécie secundária tardia; Sb - espécie típica da condição de sub-bosque e Nc - espécie não classificada sucessionalmente.

\begin{tabular}{lccc}
\hline \multicolumn{1}{c}{ Espécie } & Densidade & Densidade relativa & Classificação Sucessional \\
\hline Achornea triplinervia & 1 & 0.05 & $\mathrm{P}$ \\
Annona cacans & 1 & 0.05 & $\mathrm{Si}$ \\
Campomanesia cf pubescens & 1 & 0.05 & $\mathrm{St}$ \\
Cecropia pachystachya. & 1 & 0.05 & $\mathrm{P}$ \\
Chomelia obtusa & 1 & 0,05 & $\mathrm{Sb}$ \\
Citronella paniculata & 1 & 0.05 & $\mathrm{St}$ \\
Copaifera langsdorffii & 1 & 0.05 & $\mathrm{St}$ \\
Coutarea hexandra & 1 & 0.05 & $\mathrm{Sb}$ \\
Didymopanax morototoni & 1 & 0.05 & $\mathrm{Nc}$ \\
Eugenia pyriformis & 1 & 0.05 & $\mathrm{Sb}$ \\
Eupathorium sp1 & 1 & 0.05 & $\mathrm{Nc}$ \\
Lacistema hasslerianum & 1 & 0.05 & $\mathrm{St}$ \\
Lithraea molleoides & 1 & 0.05 & $\mathrm{Si}$ \\
Machaerium nictitans & 1 & 0.05 & $\mathrm{Si}$ \\
Maytenus enonymoidis & 1 & 0.05 & $\mathrm{St}$ \\
Miconia langsdorffii & 1 & 0,05 & $\mathrm{Si}$ \\
Myrcia guianensis & 1 & 0.05 & $\mathrm{Sb}$ \\
Ocotea velloziana & 1 & 0,05 & $\mathrm{St}$ \\
Pera glabrata & 1 & 0.05 & $\mathrm{Si}$ \\
Piptadenia gonoacantha & 1 & 0.05 & $\mathrm{Si}$ \\
Pterocarpus rohrii & 1 & 0.05 & $\mathrm{Si}$ \\
Randia armata & 1 & 0,05 & $\mathrm{Sb}$ \\
Symplocus pubescens. & 1 & 0.05 & $\mathrm{St}$ \\
Vernonia cf eriolepis & 1 & 0.05 & $\mathrm{P}$ \\
Vernonia diffusa & 1 & 0,05 & $\mathrm{P}$ \\
Vernonia sp3 & 1 & 0.05 & $\mathrm{Nc}$ \\
Walteria sp & 1 & 0.05 & $\mathrm{Nc}$ \\
\hline
\end{tabular}




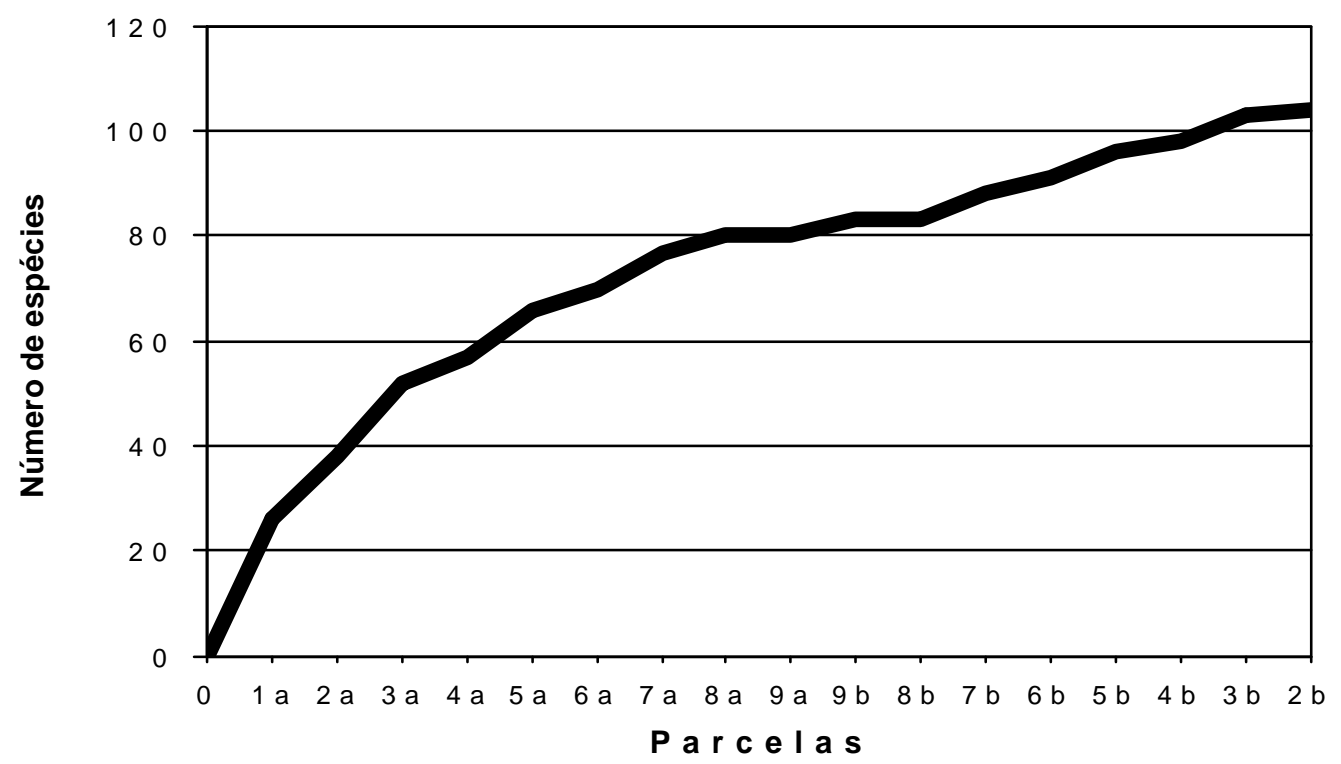

Figura 2 - Curva do coletor para as espécies amostradas na regeneração do sub-bosque E. grandis levantamento ealizado 30 meses após o corte da primeira rotação , em Itatinga $-\mathrm{SP}$.

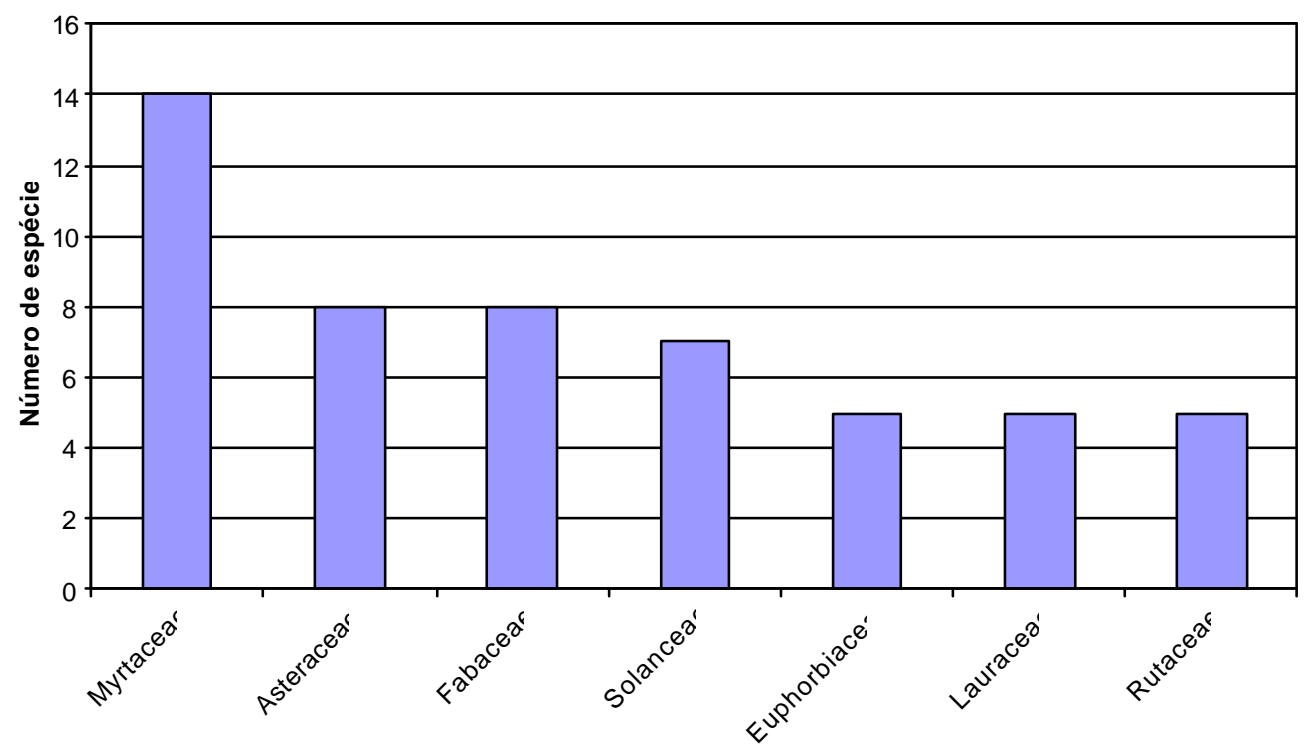

Figura 3 - Famílias que apresentaram maior riqueza florística na regeneração do subbosque $E$. grandis levantamento realizado 30 meses após o corte da primeira rotação , em Itatinga - SP. 


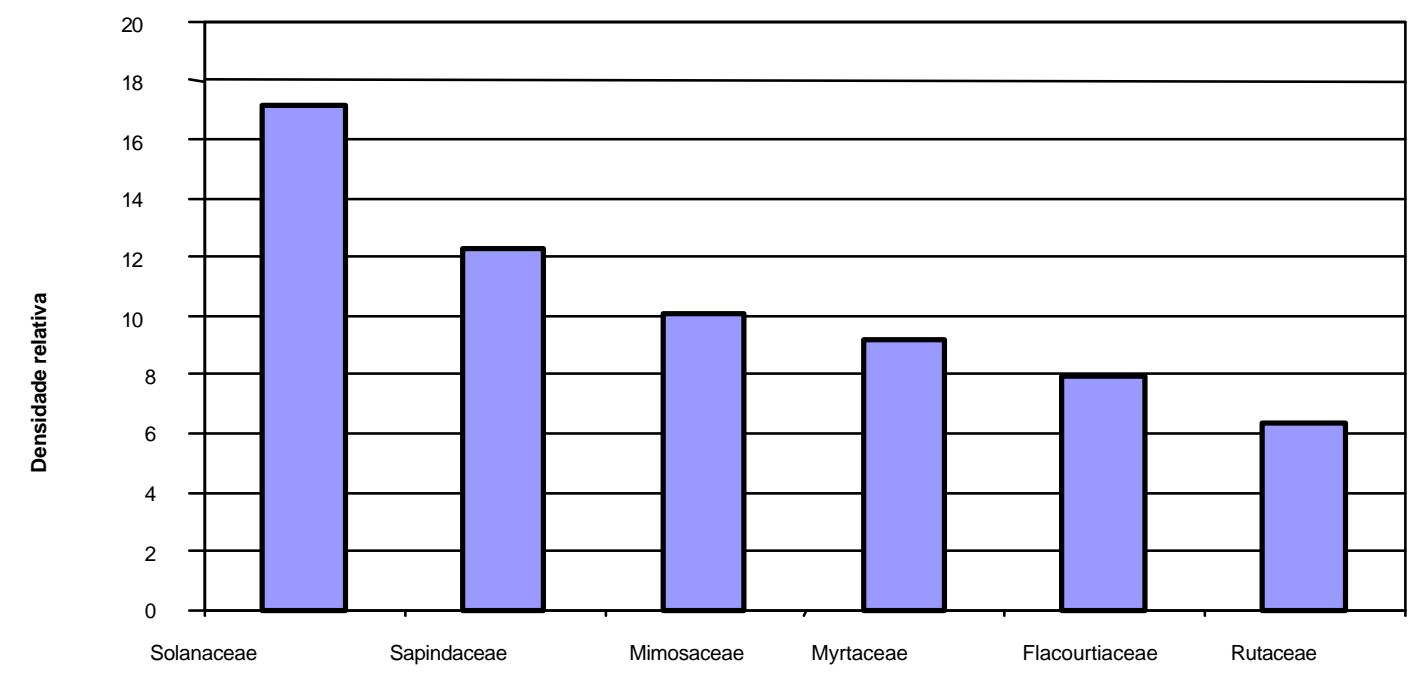

Figura 4 - Famílias que apresentaram densidade de indivíduos na regeneração do subbosque $E$. grandis levantamento realizado 30 meses após o corte da primeira rotação, em Itatinga $-\mathrm{SP}$.

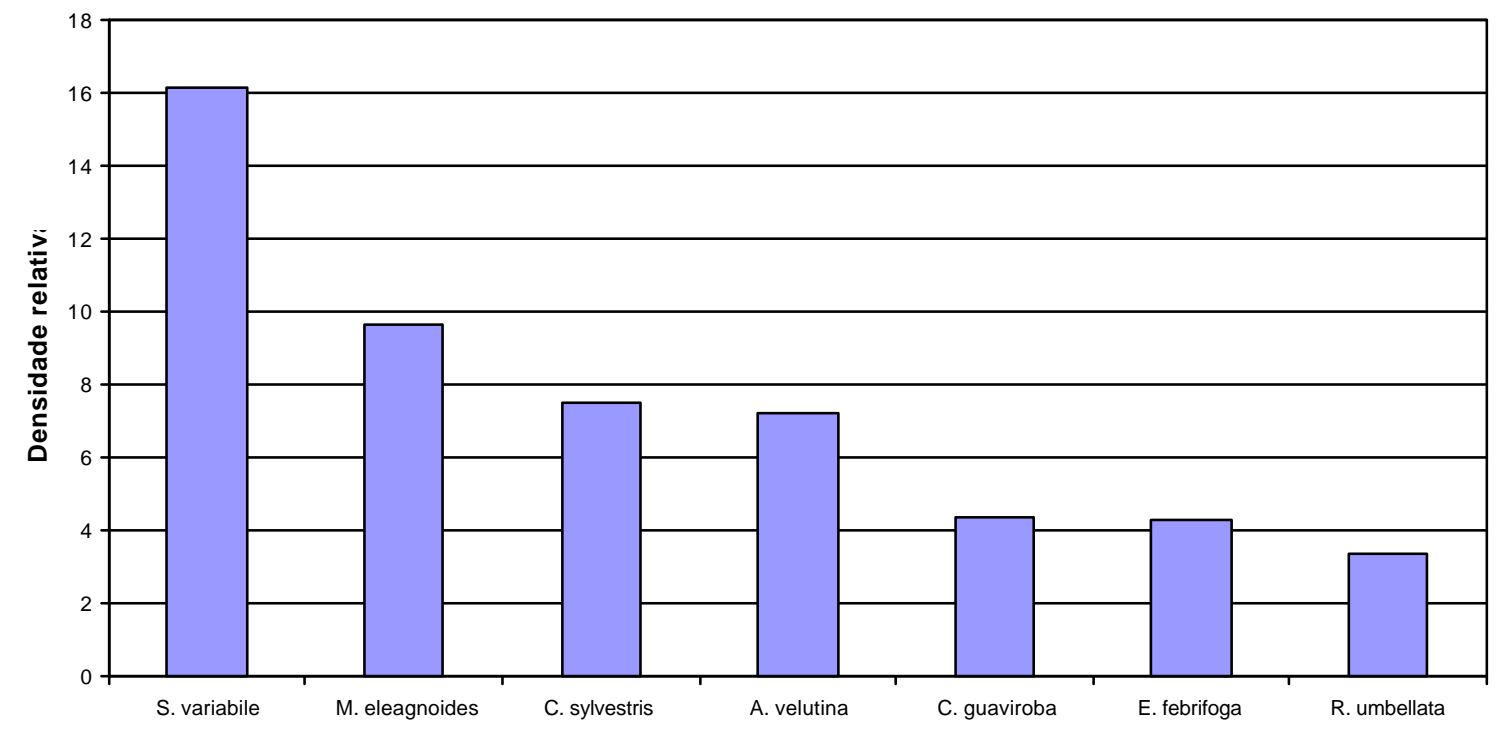

Figura 5 - Espécies que apresentaram maior densidade na rege neração do sub-bosque $E$. grandis levantamento realizado 30 meses após o corte da primeira rotação, em Itatinga $-\mathrm{SP}$. 


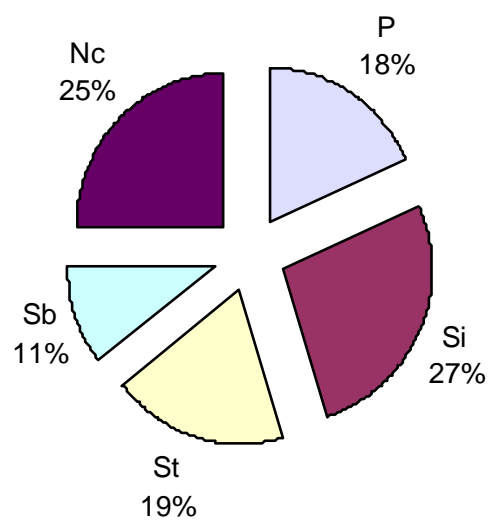

Figura 6 - Classificação Sucessional das espécies amostradas na regeneração do subbosque E. grandis levantamento realizado 30 meses após o corte da primeira rotação , em Itatinga - SP.onde: P- pioneira, Si - secundária inicial, St - secundária tardia, Sb típica da condição de sub-bosque e Nc - não classificada sucessional

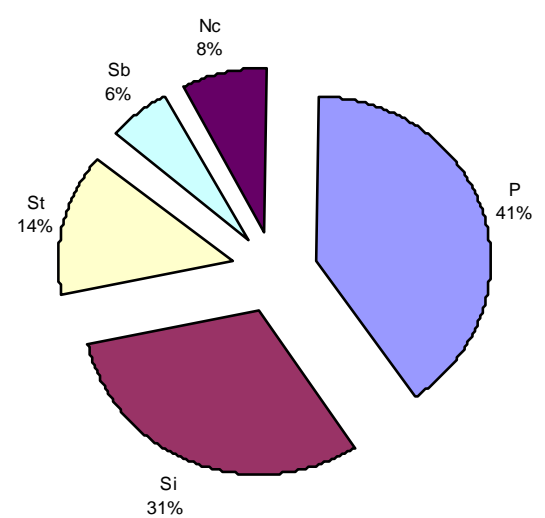

Figura 7 - Classificação Sucessional dos indivíduos amostradas na regeneração do subbosque E. grandis levantamento realizado 30 meses após o corte da primeira rotação , em Itatinga - SP.onde: P- pioneira, Si - secundária inicial, St - secundária tardia, Sb típica da condição de sub-bosque e Nc - não classificada sucessional 


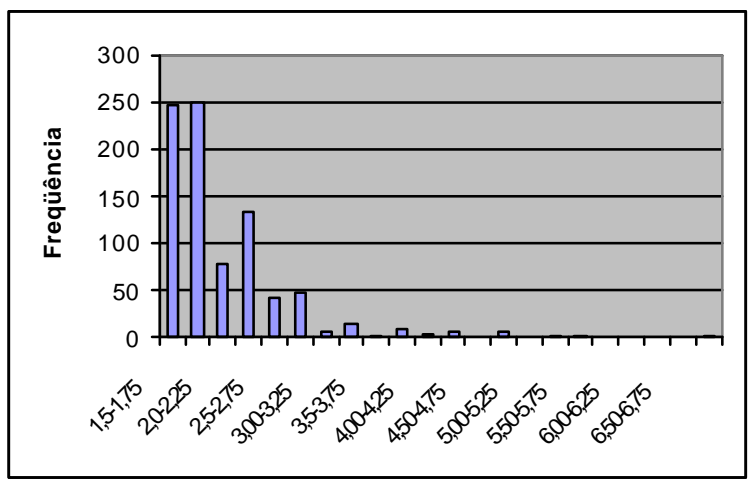

a) espécies pioneiras

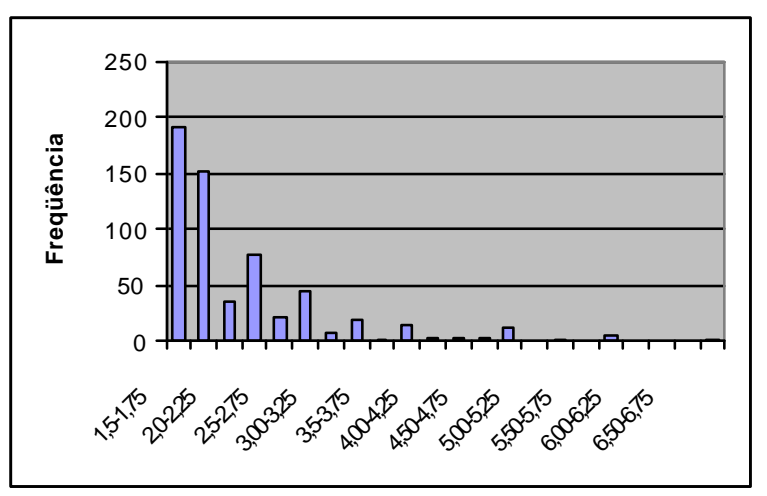

b) espécies secundárias iniciais

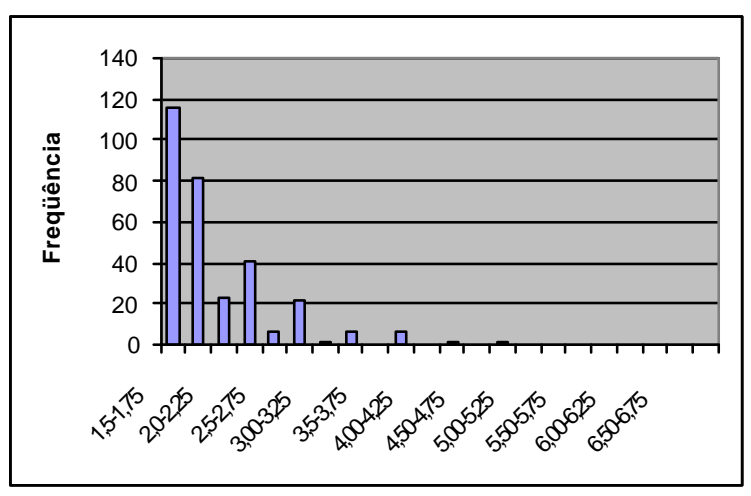

c) espécies secundárias tardias

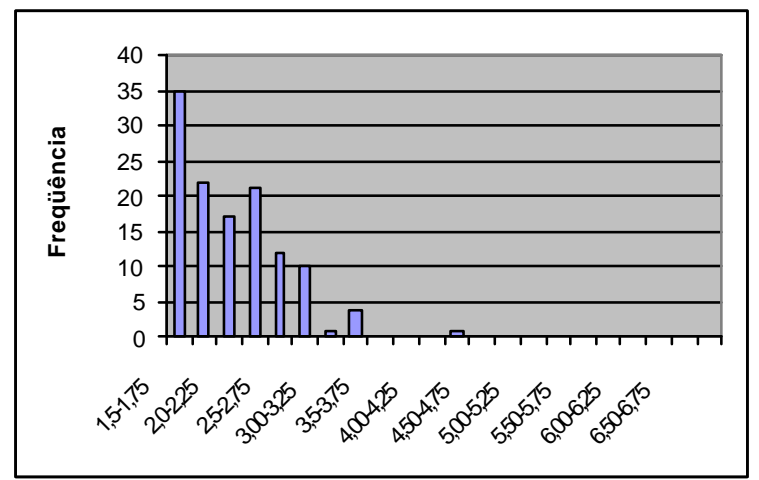

d) espécies típicas da condição de sub-bosque

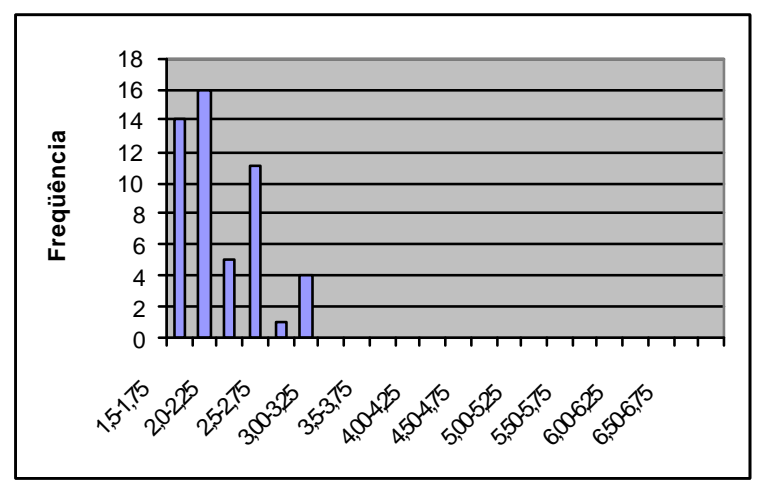

e) espécies não classificadas sucessionalmente

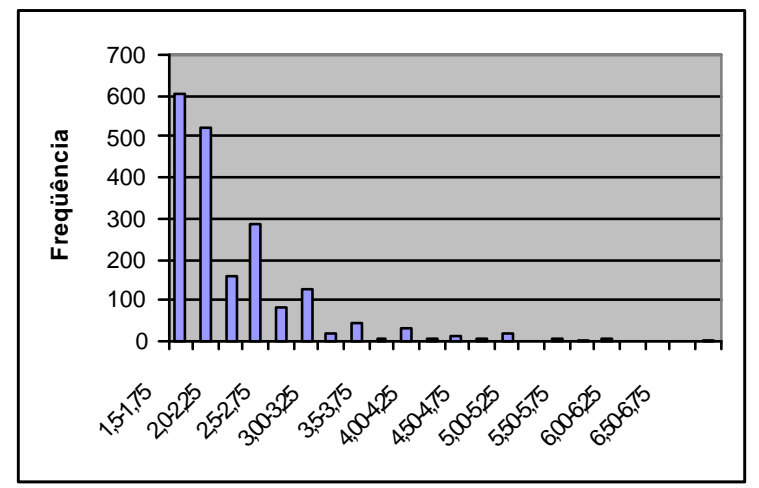

f) todos os indivíduos amostrados

Figura 8 - Distribuição das alturas das espécies amostradas na regeneração de espécies nativas no sub-bosque de $E$. grandis, levantamento realizado 30 meses após o corte raso do povoamento, agosto de 1996, Itatinga - SP. Onde: a) representa o conjunto de espécies classificadas com pioneiras; b) secundárias iniciais; c) secundárias tardias; d) espécies típicas da condição de sub-bosque; e) espécies não classificadas sucessionalmente e f) conjunto de todos os indivíduos amostrados. 


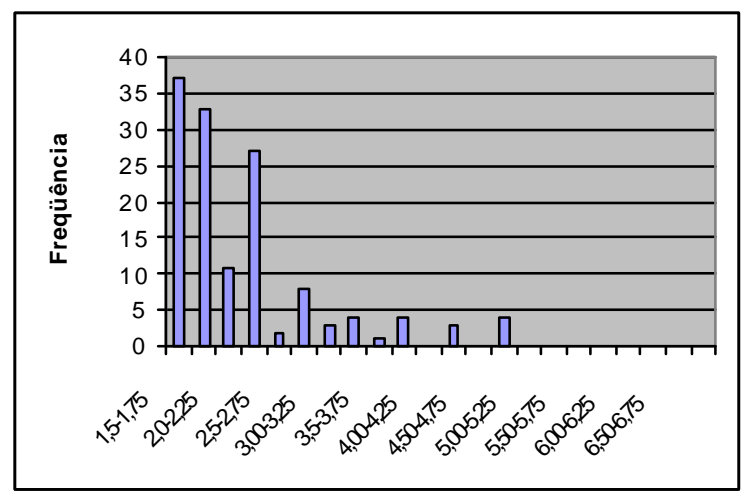

a) Acacia velutina

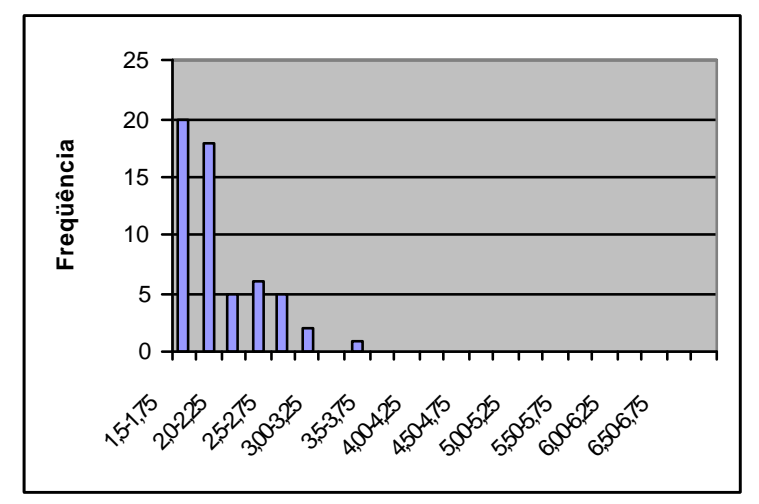

b) Tabernaemontana hystrix

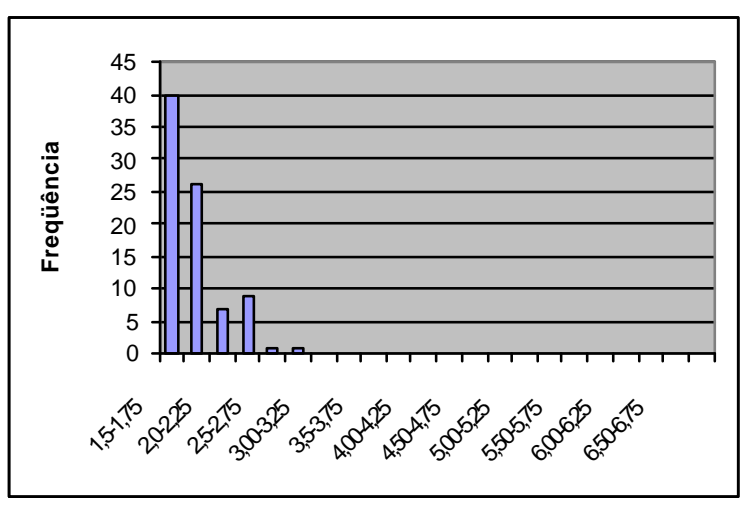

c) Campomanesia guaviroba

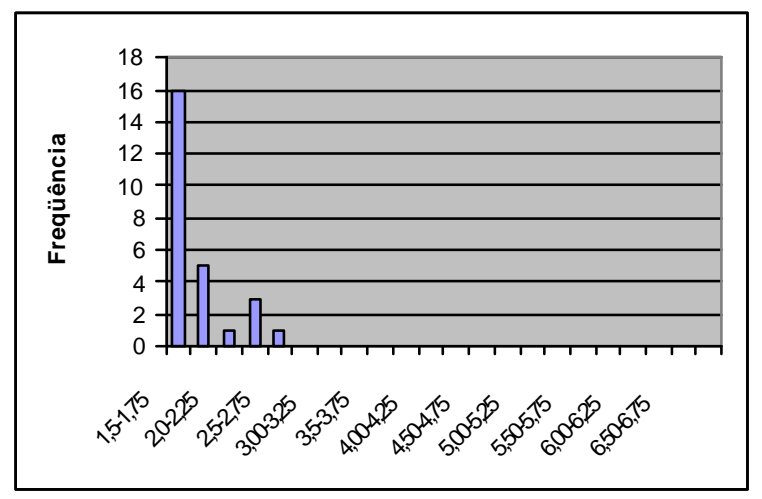

d) Campomanesiaguazumifolia

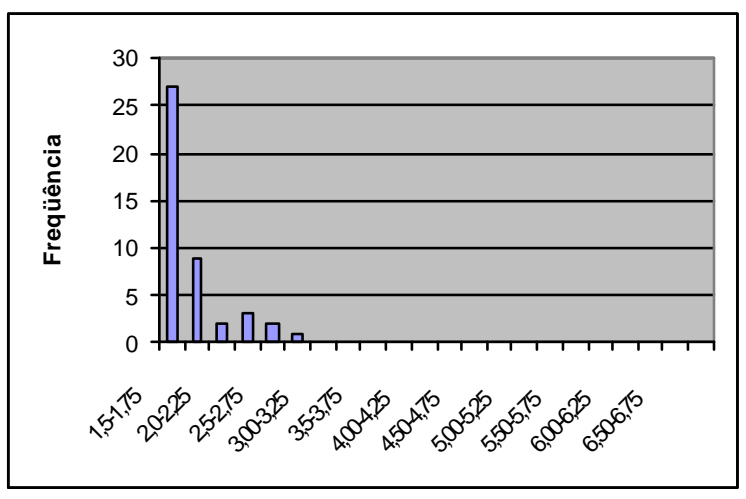

e) Cupania vernalis

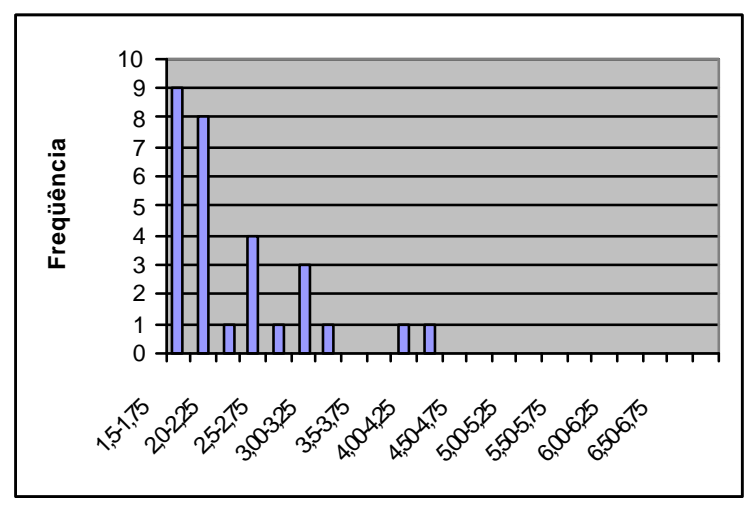

f) Zanthoxyllum rhoifolium

Figura 9 - Distribuição das alturas das espécies amostradas na regeneração de espécies nativas no sub-bosque de E. grandis, levantamento realizado 30 meses após o corte raso do povoamento, agosto de 1996, Itatinga - SP. 


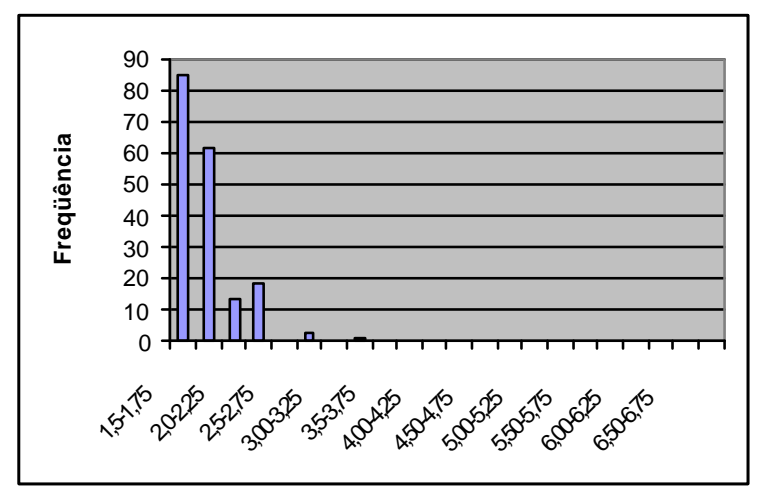

a) Matayba elaeagnoides

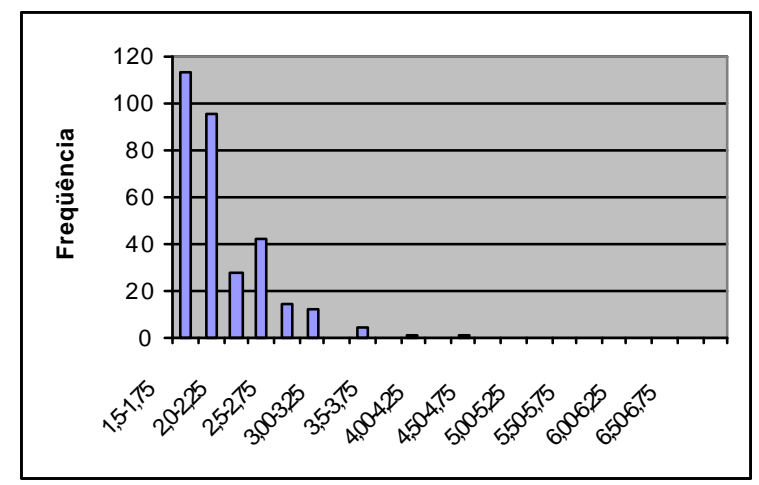

b) Solanum variabile

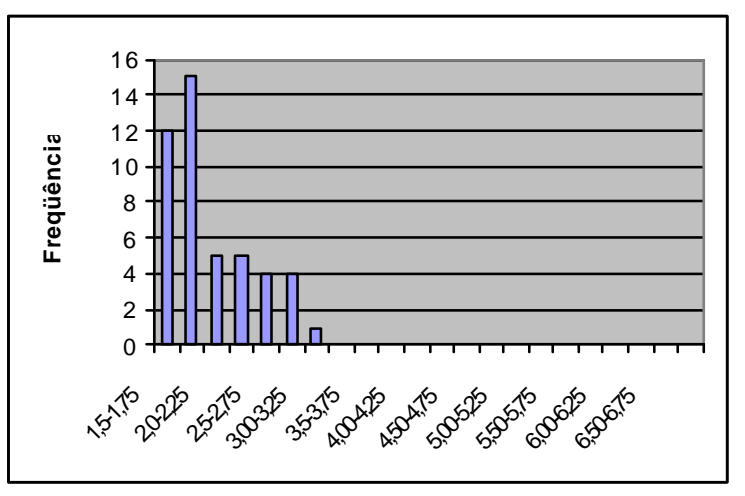

c) Gochnatia polymorpha

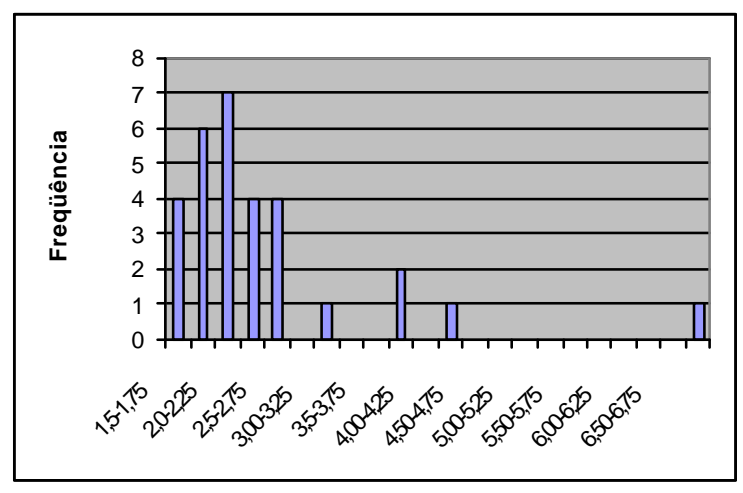

d) Schinus terebinthifolius

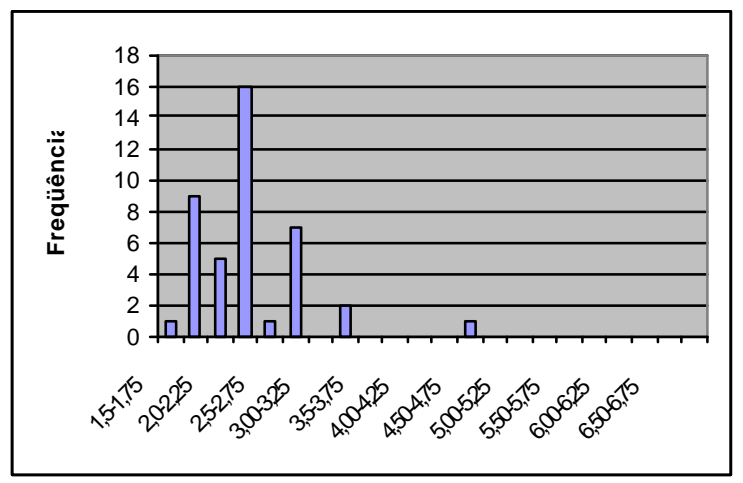

e) Baccharis dracunculifolia

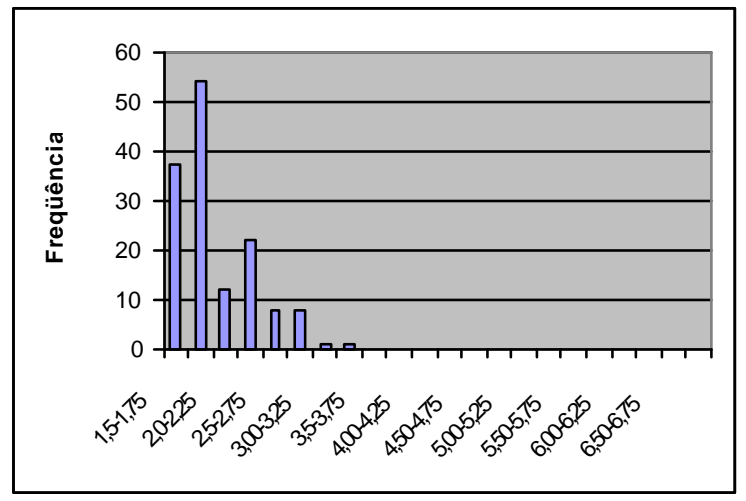

f) Casearia sylvestris

Figura 10 - Distribuição das alturas das espécies amostradas na regeneração de espécies nativas no sub-bosque de E. grandis, levantamento realizado 30 meses após o corte raso do povoamento, agosto de 1996, Itatinga - SP. 


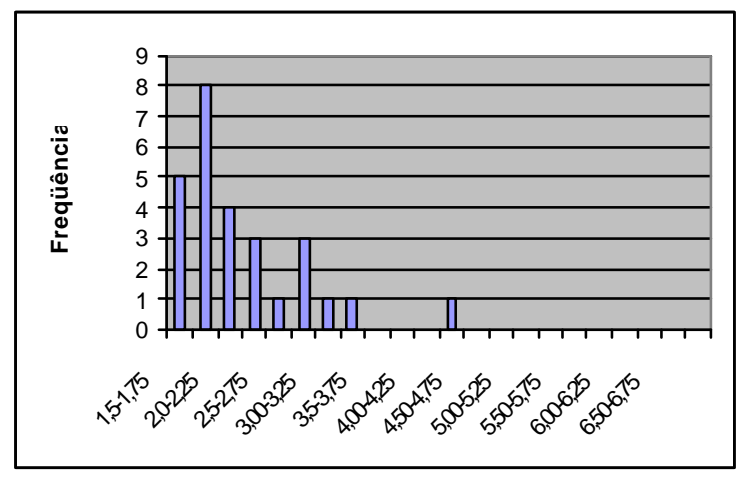

a) Cytharexyllum myriantum

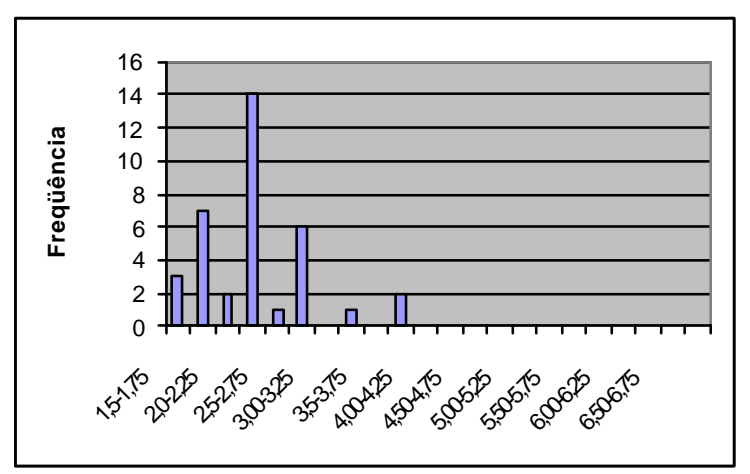

b) Sebastiania brasiliensis

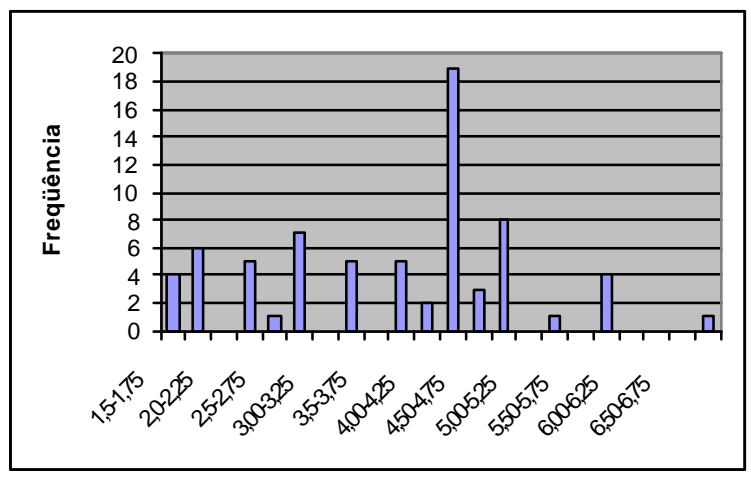

c) Paraptadenia rigida

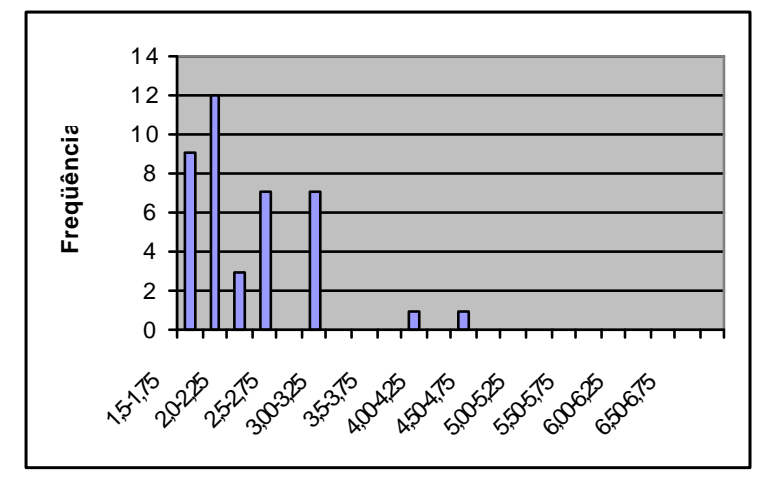

d) Ocotea puberula

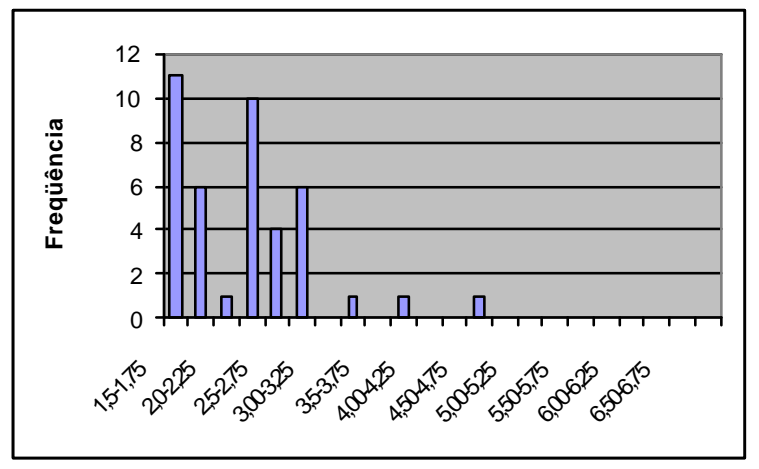

e) Ocotea pulchella

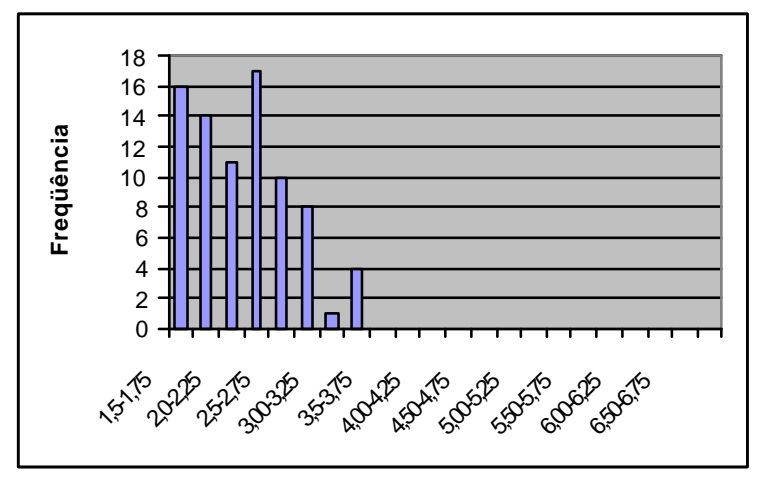

f) Esenbeckia febrifuga

Figura 11 - Distribuição das alturas das espécies amostradas na regeneração de espécies nativas no sub-bosque de E. grandis, levantamento realizado 30 meses após o corte raso do povoamento, agosto de 1996, Itatinga - SP. 
As espécies que apresentaram maior variação de altura foram: Paraptadenia rigida (1,5-7,0m), Schinus terebinthifolius (1,6-7,0m), Cedrela fissilis (1,5-6,0m), Prunus myrtifolia (1,8-6,0m), Rapanea ferruginea $(1,5-5,6 \mathrm{~m})$ e Solanum pseudoquina $(1,8-5,5 \mathrm{~m})$.

A amplitude da variação de altura dos indivíduos amostrados quando analisada conjuntamente com a distribuição de altura dos indivíduos da espécie, pode ser utilizada como um indicativo do histórico de ocupação das espécies na área. Assim, espécies com grande variância na altura dos indivíduos amostrados e altura máxima elevada apresentariam indivíduos remanescentes da primeira rotação que foram poupados no corte do povoamento de eucalipto, da mesma maneira, espécies com altura média e variância da altura reduzida representariam espécies com histórico recente de ocupação naquela área.

O Quadro 3 (Apêndice 1) apresenta as famílias e espécies que ocorreram no levantamento total da regeneração do sub-bosque no plantio de E.grandis (Talhão 48) e seus parâmetros fitossociológicos.

A diversidade de espécies foi calculada pelo índice de Shannon (H'). Considerando a área como um todo o $\mathrm{H}^{\prime}$ foi de 3,48 para espécies, enquanto a equabilidade (J') foi de 0,75. Na Quadro 2 são apresentados alguns índices de diversidade encontrados em outros levantamentos sobre a regeneração de espécies nativas em povoamentos comercias, assim como o critério de inclusão dos indivíduos nestes levantamentos.

$\mathrm{O}$ índice de diversidade ( $\mathrm{H}^{\prime}$ ) encontrado nesse trabalho foi elevado quando comparado com os demais levantamentos realizados em sub-bosque de plantios puros de Eucalyptus spp (Quadro 2). No entanto, alguns pontos devem ser levados em consideração quando se realiza a comparação entre os levantamentos, já que o critério de inclusão das espécies nesses trabalhos e o tamanho da área amostral (ROLIM, 1997) são definidores do índice. Outro fator a ser considerado é a qualidade do sítio no qual foram realizados os levantamentos, considerando-se que sítios mais preservados ou inseridos num contexto mais preservado tenderiam a apresentar valores mais elevados de diversidade. 


\begin{tabular}{|l|c|l|}
\hline Levantamento Fitossociológico & H' espécie & Critério de inclusão \\
\hline Sub-bosque de E. grandis (este trabalho) & 3,48 & altura $>1,5 \mathrm{~m}$ \\
\hline Sub-bosque de E. citriodora (Durigan et al., 1997) & 2.138 & DAP $>5 \mathrm{~cm}$ \\
\hline Sub-bosque de Eucalyptus spp (Nave et al., 1998) & 2.844 & altura $>1,5 \mathrm{~m}$ \\
\hline Sub-bosque Eucalipto (Rezende et al., 1994) & 3,14 & classes de altura \\
\hline Sub-bosque E. tereticornis (Talora, 1992) & 2,78 & $>1 \mathrm{~m}$ altura, <10cm PAP \\
\hline $\begin{array}{l}\text { Sub-bosque E. citriodora - Talora (1992) } \\
\text { Sub-bosque de E. tereticornis (Schlittler, 1984) - } \\
\text { latossolo vermelho amarelo }\end{array}$ & 3,02 & $>1 \mathrm{~m}$ altura, <10cm PAP \\
\hline $\begin{array}{l}\text { Sub-bosque de E. tereticornis (Schlittler, 1984) - } \\
\text { latossolo roxo }\end{array}$ & 2,95 & $\begin{array}{l}\text { altura }<1,0 \mathrm{~m} \text {, diâmetro } \\
\text { Qm }\end{array}$ \\
\hline
\end{tabular}

Quadro 2 - Diversidade e critérios de inclusão de levantamentos em sub-bosque de Eucalyptus spp.

Outros fatores podem influenciar as diferenças de diversidade de espécies no subbosque de povoamentos comerciais, entre eles a espécie comercial utilizada, o espaçamento usado no plantio e as práticas silviculturais empregadas na implantação e manejo do povoamento.

Rodrigues (1999) analisando a regeneração e a sucessão de espécies em um fragmento submetido a ação do fogo, constatou a complexidade do processo de sucessão florestal em fragmentos degradados antropicamente, correlacionado muito da heterogeneidade espacial e temporal da vegetação à heterogeneidade das características ambientais, mas principalmente às características da perturbação, quanto ao tipo, intensidade e recorrência em cada trecho do fragmento.

Esta heterogeneidade (ambiente e perturbação) também é constatada quando se considera a regeneração natural no sub-bosque de plantios puros de eucalipto, gerando uma grande variabilidade nos resultados dos levantamentos já realizados (Schlittler, 1984; Talora, 1992; Calegario et al., 1993; Tabarelli, 1993; Rezende et al., 1994; Durigan et al., 1997). 
Entre as principais causas da heterogeneidade ambiental estão as características locais do solo e o regime de oferta de luz imposto pelo povoamento de eucalipto. A oferta de luz no piso florestal é um fator importante, seja pela influência da quantidade e qualidade da luz no processo de regeneração das florestas tropicais, seja pelas possibilidades de conduzir o estabelecimento e desenvolvimento de espécies nativas no sub-bosque de povoamentos comerciais através da adoção de práticas de manejo que influenciem a oferta de luz no piso florestal. Algumas das práticas de manejo que podem ser consideradas são: espaçamento de plantio, espécie de eucalipto utilizada e utilização de regime de desbaste na condução dos plantios.

\subsection{Evolução Temporal da Regeneração Natural no sub-bosque de plantios de E. grandis.}

A caracterização florística e estrutural da regeneração de espécies nativas no subbosque de plantios de E. grandis, apresentada no item 4.1, foi utilizada como base (análise no tempo zero) para a análise da evolução temporal da regeneração.

\subsubsection{Segundo levantamento (45 meses) realizado no povoamento comercial de E. grandis, área amostral - 0,68 ha.}

O segundo levantamento foi realizado em novembro de 1997, portanto 45 meses após a exploração do eucalipto e 15 meses após o primeiro levantamento. Neste período não foram realizadas intervenções no povoamento, ou seja, não foram realizadas práticas como limpezas, desbastes, desrramas, etc. O quadro 1 e a Tabela 2 apresentam a espécies e os parâmetros encontrados neste levantamento.

Considerando as espécies, a de maior densidade no levantamento foi Matayba elaeagnoides representando 16,15 \% do total de indivíduos amostrados, seguida de Casearia sylvestris (9,93\% do total), Campomanesia guaviroba (6,47\%), Acacia 
velutina (5,85\%), Cupania vernalis $(5,77 \%)$, Esenbeckia febrifuga $(4,61 \%)$ e Solanum variabile $(4,14 \%)$, representando mais de $50 \%$ do total de indivíduos amostrados.

Vinte e sete espécies $(24,7 \%$ do total) apresentaram apenas um indivíduo amostrado, sendo que dessas 2 espécies foram classificadas sucessionalmente com pioneiras, 8 como secundárias iniciais, 5 com secundárias tardias, 3 com espécies típicas da condição de sub-bosque e 9 não foram classificadas sucessionalmente.

As famílias que apresentaram a maior riqueza florística foram Myrtaceae com 15 seguida por Rubiaceae e Fabaceae (8 espécies), Solanaceae e Asteraceae (7 espécies), Lauraceae (6 espécies) e Euphorbiaceae (5 espécies).

Em relação a densidade as famílias que apresentam os maiores índices foram: Sapindaceae, representando $23,08 \%$ do total de plantas amostradas, Myrtaceae (15,38\%), Mimosaceae (8,09\%), Flacourtiaceae (7,28\%), Rutaceae (6,55\%) e Solanaceae $(5,27 \%)$.

O Quadro 4 (Apêndice 1) apresenta as espécies que ocorreram no levantamento total da regeneração do sub-bosque no plantio de E. grandis (Talhão 48) e seus parâmetros fitossociológicos.

\subsubsection{Comparação entre os levantamentos (30 - 45 meses), área amostral $-0,68$ ha}

A Tabela 2 apresenta alguns parâmetros encontrados nos levantamentos realizados 30 e 45 meses após a exploração do povoamento de E. grandis em 17 parcelas $(0,68$ ha de área amostral).

Em relação a riqueza de espécies amostradas, na primeira amostragem (30 meses após a exploração do povoamento) foram amostradas 104 espécies pertencentes a 38 famílias, enquanto na segunda amostragem (45 meses após a exploração) foram amostradas 109 espécies (pertencentes a 37 famílias). 
Tabela 2. Parâmetros utilizados na análise das alterações temporais da regeneração de espécies nativas no sub-bosque de Eucalyptus grandis, considerando 17 parcelas ou 0,68 ha de área amostral, em Itatinga -SP. Levantamentos realizados 30 e 45 meses após exploração do povoamento.Onde: P- pioneira, Si - secundária inicial, $\mathrm{St}$ - secundária tardia, $\mathrm{Sb}$ - espécie típica da condição de sub-bosque, Nc - espécies não classificadas sucessionalmente, H' - índice de Shannon para diversidade, J' - equabilidade.

\begin{tabular}{|c|c|c|}
\hline & 30 meses & 45 meses \\
\hline Número de indivíduos & 1900 & 2582 \\
\hline Número de espécies & 104 & 109 \\
\hline Número de famílias & 38 & 37 \\
\hline Amostrado 1 indivíduo abustivo-arbóreo a cada: & $3,57 \mathrm{~m}^{2}$ & $2,63 \mathrm{~m}^{2}$ \\
\hline \multirow[t]{5}{*}{ Composição sucessional espécies } & P- 22 & $\mathrm{P}-22$ \\
\hline & $\mathrm{Si}-31$ & $\mathrm{Si}-33$ \\
\hline & St-25 & $\mathrm{St}-26$ \\
\hline & $\mathrm{Sb}-14$ & $\mathrm{Sb}-16$ \\
\hline & Nc-12 & Nc-12 \\
\hline \multirow[t]{5}{*}{ Composição sucessional indivíduos } & P-840 & P-783 \\
\hline & Si-598 & $\mathrm{Si}-1019$ \\
\hline & St-288 & St-494 \\
\hline & Sb- 123 & $\mathrm{Sb}-229$ \\
\hline & Nc-51 & $\mathrm{Nc}-57$ \\
\hline $\begin{array}{l}\text { Número de espécies com apenas um indivíduo } \\
\text { amostrado }\end{array}$ & 27 & 27 \\
\hline Altura média & 2,18 & 2,30 \\
\hline Classe Modal da altura & $1,5-1,75$ & $1,5-1,75$ \\
\hline $\mathrm{H}^{\prime}$ & 3,48 & 3,573 \\
\hline J' & 0,75 & 0,76 \\
\hline
\end{tabular}

Analisando a evolução dos parâmetros riqueza de espécies e densidade total de indivíduos por família, percebe-se que famílias que apresentaram, no primeiro 
levantamento, grande parte de suas espécies com características iniciais da sucessão apresentaram redução no número de espécies e indivíduos amostrados. Um exemplo típico dessa condição é a família Solanaceae, que se destacou como a família que apresentou a maior densidade de indivíduos no primeiro levantamento (327 indivíduos pertencentes a 8 espécies), sendo que no segundo levantamento ocupou a sexta posição em densidade, com 136 plantas amostradas mantendo o mesmo numero de espécies. $\mathrm{O}$ comportamento da população de Solanum variabile foi a responsável pela dinâmica do parâmetro densidade na família Solanaceae, enquanto esta espécie apresentou 307 indivíduos amostrados no primeiro levantamento, sendo a espécie de maior densidade na ocasião, no segundo levantamento esta espécie ocupou a sexta posição em relação a densidade com 107 indivíduos amostrados. Ainda em relação a $S$. variabile vale ressaltar que esta apresentou 211 indivíduos mortos no período, representando $72 \%$ do total de indivíduos de espécies pioneiras neste grupo e 45,8\% do total de indivíduos mortos no período.

Outro exemplo desta condição, a família Asteraceae apresentou 102 indivíduos, pertencentes a 8 espécies, mostrados no primeiro levantamento (sétima família com maior densidade de indivíduos), enquanto no segundo levantamento foram amostrados 54 indivíduos, pertencentes a 7 espécies (décima segunda família com maior densidade de indivíduos).

Comportamento oposto, caracterizado por ganhos em riqueza florística e densidade de indivíduos, foi encontrado para as famílias Myrtaceae e Rubiaceae, que apresentaram grande número de espécies classificadas como sendo finais da sucessão e típicas da condição de sub-bosque no primeiro levantamento. Neste levantamento foram amostrados 175 indivíduos, representando 14 espécies, pertencentes a família Myrtaceae e 10 indivíduos, 5 espécies, pertencentes a família Rubiaceae, no segundo levantamento foram amostrados 397 indivíduos, pertencentes a 15 espécies, para Myrtaceae e 37 indivíduos, 8 espécies, para Rubiaceae.

Considerando a separação das espécies em grupos ecológicos percebe-se um pequeno aumento no número de espécies secundárias iniciais no período (31 para 33 espécies). Porém, quando se analisa o equilíbrio entre as taxas de recrutamento e 
mortalidade dos indivíduos pertencentes a cada grupo ecológico, fica evidente o processo de sucessão ocorrendo na regeneração natural desse sub-bosque de eucalipto.

A taxa de recrutamento, enquanto as espécies pertencentes aos grupos das secundárias iniciais (taxa de recrutamento de 47,29\%), secundárias tardias $(48,18 \%$ ) e típicas da condição de sub-bosque $(53,80 \%)$ apresentaram taxas de recrutamento superiores a taxa de recrutamento total de indivíduos (37,65\%), as espécies pioneiras (recrutamento de $37,65 \%$ ) e do grupo das não classificadas sucessionalmente $(23,29 \%)$ apresentaram recrutamento inferior a taxa de recrutamento total no período.Vale ressaltar o comportamento das populações de Matayba elaeagnoides e Cupania vernalis, ambas da família Sapindaceae e pertencentes ao grupo das secundárias iniciais, que apresentaram as maiores taxas de recrutamento no período 126\% (184 para 417 indivíduos) e 272\% (40 para 149 indivíduos) respectivamente.

A taxa de mortalidade de indivíduos apresentou comportamento contrário, ou seja, maiores taxas de mortalidade para as espécies pioneiras e não classificadas sucessionalmente $(41,16 \%$ e $25,67 \%$ respectivamente) e menores taxas para espécies secundárias iniciais, tardias e típicas da condição de sub-bosque (8,60\%, 9,42\% e 8,21\% respectivamente), considerando uma taxa de mortalidade total no período de $22,17 \%$ (Tabela 3).

Os dados mostram que enquanto o número total de indivíduos cresceu 35,8\% (1900 indivíduos no primeiro levantamento para 2582 plantas no segundo), o número de indivíduos pertencentes a espécies secundárias iniciais cresceu 70,40\% (de 598 indivíduos para 1019 indivíduos amostrados), o de plantas pertencentes a espécies classificadas como secundárias tardias cresceu 71,53\%, o formado pelos indivíduos das espécies típicas da condição de sub-bosque cresceu 86,17\%, as espécies não classificadas sucessionalmente cresceu $11,76 \%$ e as espécies pioneiras apresentaram uma retração de 7,79\% na população amostrada. 
Tabela 3. Taxas de recrutamento e mortalidade da regeneração de espécies nativas no sub-bosque de E. grandis por categoria sucessional, levantamentos realizados 30 e 45 meses após a exploração do eucalipto, área amostral 0,68ha, em Itatinga - SP. M número de indivíduos mortos entre as medições; No - número inicial de indivíduos; Nf - número final de indivíduos; me - taxa de mortalidade; \%* - porcentagem de mortalidade; I - número de indivíduos recrutados entre levantamentos; i - taxa de recrutamento; \%** - porcentagem de recrutamento.

\begin{tabular}{lcccccccc}
\hline Categoria sucessional & $\mathrm{M}$ & $\mathrm{No}$ & $\mathrm{Nf}$ & $\mathrm{Me}$ & $\%^{*}$ & $\mathrm{I}$ & $\mathrm{i}$ & $\%^{* *}$ \\
\hline Pioneira & 341 & 840 & 783 & 0.416 & 41,66 & 284 & 0,232 & 23,29 \\
Secundária inicial & 61 & 598 & 1019 & 0.086 & 8,60 & 482 & 0,472 & 47,29 \\
Secundária tardia & 32 & 288 & 494 & 0,094 & 9,42 & 238 & 0,481 & 48,18 \\
Típica da condição de sub-bosque & 12 & 123 & 229 & 0,082 & 8,21 & 118 & 0,538 & 53,80 \\
Não classificada & 14 & 51 & 57 & 0.256 & 25,67 & 20 & 0,264 & 26,46 \\
Total & 460 & 1900 & 2582 & 0,221 & 22,17 & 1142 & 0,376 & 37,65 \\
\hline
\end{tabular}

Em relação aos 460 indivíduos mortos no período, 341 indivíduos (74,13\% do total) pertenciam a espécies classificadas como pioneiras. As espécies secundárias iniciais representaram 13,26\% dos indivíduos mortos (61 plantas), as secundárias tardias 0,06\% (32 indivíduos), as espécies típicas da condição de sub-bosque 0,02\% (12 indivíduos), e por fim 14 indivíduos considerados mortos ( $0,03 \%$ do total) pertenciam ao grupo das espécies não classificadas sucessionalmente.

Os resultados evidenciam que o recrutamento de novos indivíduos no sub-bosque do eucalipto no período de 30-45 meses da exploração comercial se concentrou nos grupos de espécies secundárias iniciais, secundárias tardias e espécies típicas da condição de sub-bosque. Enquanto a mortalidade se concentrou nos indivíduos pertencentes ao grupo das espécies pioneiras e das espécies não classificadas sucessionalmente.

Os valores de mortalidade e recrutamento de espécies no sub-bosque indicam que em algum momento entre o primeiro e o segundo levantamento, as condições ambientais no piso do talhão (notadamente o aumento do sombreamento) passaram a beneficiar o 
desenvolvimento de espécies secundárias iniciais, tardias e típicas da condição de subbosque em detrimento de espécies pioneiras.

Ainda sobre os grupos sucessionais outro aspecto importante foi a alteração temporal na altura dos grupos ecológicos, já que as espécies secundárias tardias e pioneiras apresentaram os maiores ganhos em altura média no período $(2,31 \mathrm{~m}$ para 2,41m, 2,11m para 2,28m e 2,13m para 2,39m respectivamente), as espécies típicas da condição de sub-bosque apresentaram uma redução da altura média no período $(2,20 \mathrm{~m}$ para 2,13m) e o grupo das não classificadas sucessionalmente apresentou aproximadamente a mesma altura média $(2,05 \mathrm{~m}$ para $2,09 \mathrm{~m})$. A redução na altura média apresentada pelas espécies típicas da condição de sub-bosque é função principalmente da alta taxa de recrutamento de indivíduos que ocorreu neste grupo no período.

A análise conjunta do índice para diversidade de Shannon $\left(\mathrm{H}^{\prime}\right)$, crescimento de 3,48 para 3,573 , e da equabilidade (J'), crescimento de 0,751 para 0,762 , mostra que houve ganho em relação a diversidade de espécies na área. 


\begin{tabular}{|c|c|c|c|c|c|c|c|c|}
\hline Família & Espécie & Autor & $\begin{array}{r}\text { Leva } \\
1\end{array}$ & 2 & Nome Vulgar & Porte & Distrib. & $\mathbf{C S}$ \\
\hline \multirow[t]{3}{*}{ Anacardiaceae } & Lithraea molleoides & (Vell) Engl. & $\mathrm{X}$ & $\mathrm{X}$ & Aroeira Brava & arbóreo & & $\mathrm{Si}$ \\
\hline & Schinus terebinthifolius & Roddi & $\mathrm{X}$ & $\mathrm{X}$ & Aroeira mansa & arbóreo & Aleatória & $\mathrm{P}$ \\
\hline & Tapirira guianensis & Aubl. & $\mathrm{X}$ & $\mathrm{X}$ & Pau-pombo & arbóreo & Agrupada & $\mathrm{Si}$ \\
\hline Annonaceae & Annona cacans & Warn. & $\mathrm{X}$ & & Araticum cagão & Arbóreo & & $\mathrm{Si}$ \\
\hline Apocynaceae & Tabernaemontana hystrix & Steud. & $\mathrm{X}$ & $\mathrm{X}$ & Leiteiro & arbóreo & Agrupada & $\mathrm{P}$ \\
\hline Aquipholiaceae & Ilex brasiliensis & (Sprend.) Loes. & $\mathrm{X}$ & $\mathrm{X}$ & & & Aleatória & $\mathrm{St}$ \\
\hline Araliaceae & Didymopanax morototoni & (Aubl) Decne. \& Planch. & $\mathrm{X}$ & & Mandiocão & arbóreo & & $\mathrm{Nc}$ \\
\hline Arecaceae & Syagrus romanzoffiana & (Cham.) Glassman & $\mathrm{X}$ & $\mathrm{X}$ & Jerivá & arbóreo & Agrupada & $\mathrm{Si}$ \\
\hline \multirow[t]{8}{*}{ Asteraceae } & Baccharis dracunculifolia & DC. & $\mathrm{X}$ & $\mathrm{X}$ & Vassoura & arbustivo & Agrupada & $\mathrm{P}$ \\
\hline & Eupatorium inulaefolium & H.B.K. & & $\mathrm{X}$ & & & & $\mathrm{Nc}$ \\
\hline & Gochnatia polymorpha & (Less.)Cabrera & $\mathrm{X}$ & $\mathrm{X}$ & Cambará & arbóreo & Agrupada & $\mathrm{Si}$ \\
\hline & Vernonia cf eriolepis & Gardner & $\mathrm{X}$ & & Assa peixe & arbustivo & & $\mathrm{Nc}$ \\
\hline & Vernonia diffusa & Less. & $\mathrm{X}$ & $X$ & Cambará-açu & arbustivo & & $\mathrm{P}$ \\
\hline & Vernonia polyanthes & (Spreng.) Less. & $\mathrm{X}$ & $\mathrm{X}$ & Assa-peixe & & Aleatória & $\mathrm{P}$ \\
\hline & Vernonia sp3 & & $\mathrm{X}$ & $\mathrm{X}$ & & & & $\mathrm{Nc}$ \\
\hline & Vernonia sp4 & & $\mathrm{X}$ & $\mathrm{X}$ & & & Agrupada & $\mathrm{Nc}$ \\
\hline Bignoniaceae & Tabebuia chrysotricha & (Mart. ex DC.) Standl. & $\bar{X}$ & $\mathrm{X}$ & Ipê-amarelo & arbóreo & Aleatória & $\mathrm{Si}$ \\
\hline Bombacaceae & Chorisia speciosa & A. St.-Hil. & & $\mathrm{X}$ & Paineira & arbóreo & & $\mathrm{Si}$ \\
\hline
\end{tabular}

Quadro 1 - Listagem das Espécies amostradas no Talhão 48, da Fazenda São José do Bromado, com seus respectivos nomes vulgares, categorias sucessionais e porte e padrão de distribuição espacial na área. P-Pioneira, Si Secundária Inicial, St- Secundária Tardia, Sbespécie característica da condição de Sub-bosque, Nc = espécie não classificada, CS- Categoria sucessional , 1- Levantamento 30 meses e 2- Levantamento 45 meses após a exploração da primeira rotação do povoamento de Eucalyptus grandis, Itatinga - SP. 


\begin{tabular}{|c|c|c|c|c|c|c|c|c|}
\hline Família & Espécie & Autor & \begin{tabular}{|r} 
Leva \\
1
\end{tabular} & 2 & Nome Vulgar & Porte & Distrib. & $\mathbf{C S}$ \\
\hline \multirow[t]{4}{*}{ Caesalpiniaceae } & Bauhinia germinata & Vogel. & $\mathrm{X}$ & $\mathrm{X}$ & Pata-de-vaca & arbóreo & Agrupada & $\mathrm{P}$ \\
\hline & Copaifera langsdorfii & Desf. & $\mathrm{X}$ & $\mathrm{X}$ & Copaíba & arbóreo & & $\mathrm{St}$ \\
\hline & Senna bicapsulares & (Benth.)H.S.Irwin \& Barneby. & $\mathrm{X}$ & $\mathrm{X}$ & Canudo de pito & arbustivo & Aleatória & $\mathrm{Si}$ \\
\hline & Senna splendida & (Vogel) H.S.Irwin \& Barbery & $\mathrm{X}$ & $\mathrm{X}$ & & & Aleatória & $\mathrm{Si}$ \\
\hline Cecropiaceae & Cecropia pachystachya & Trécul. & $\mathrm{X}$ & $\mathrm{X}$ & Embaúba & arbóreo & & $\mathrm{P}$ \\
\hline Celastraceae & Maytenus evonymoides & Reiss. & $\mathrm{X}$ & $\mathrm{X}$ & Cafezinho & & & $\mathrm{St}$ \\
\hline \multirow[t]{6}{*}{ Ebenaceae } & Diospyros inconstans & Jacq. & $\mathrm{X}$ & $\mathrm{X}$ & Fruta de jacu & arbóreo & Agrupada & $\mathrm{St}$ \\
\hline & Actinostemon klotzchii & (Didr.) Pax. & $\mathrm{X}$ & $\mathrm{X}$ & Branquilho & arbóreo & Agrupada & $\mathrm{St}$ \\
\hline & Alchornea triplinervia & (Spreng.) Müel. Arg. & $\mathrm{X}$ & $\mathrm{X}$ & Tapiá & arbóreo & & $\mathrm{P}$ \\
\hline & Pera glabrata & (Schott.) Bail. & $\mathrm{X}$ & $\mathrm{X}$ & Pau de sapateiro & arbóreo & & $\mathrm{Si}$ \\
\hline & Sebastiania brasiliensis & (L.) Spreng. & $\mathrm{X}$ & $\mathrm{X}$ & Leiteiro & arvoreta & Agrupada & $\mathrm{St}$ \\
\hline & Sebastiania klotzchiana & (Müel. Arg.) Müel. Arg. & $\mathrm{X}$ & $\mathrm{X}$ & Branquilho & arbóreo & Agrupada & $\mathrm{Sb}$ \\
\hline \multirow[t]{6}{*}{ Fabaceae } & Andira anthelmia & (Vell.) J.F. Macbr. & $\mathrm{X}$ & $\mathrm{X}$ & Manguinha & arbóreo & Aleatória & $\mathrm{Si}$ \\
\hline & Desmodium discolor & Vogel. & $\bar{X}$ & $\mathrm{X}$ & & arbustivo & Aleatória & $\mathrm{Nc}$ \\
\hline & Machaerium acutifolium & Vogel. & $\mathrm{X}$ & $\mathrm{X}$ & Jacarandá & arbóreo & Agrupada & $\mathrm{Si}$ \\
\hline & Machaerium brasiliense & Vogel. & $\bar{X}$ & $\mathrm{X}$ & Mosqueteiro & arbóreo & Aleatória & $\mathrm{Si}$ \\
\hline & Machaerium nictitans & (Vell.) Benth. & $\mathrm{X}$ & $\mathrm{X}$ & Bico de pato & arbóreo & & $\mathrm{Si}$ \\
\hline & Machaerium opacum & Vogel. & $\bar{X}$ & $\mathrm{X}$ & Jacarandá & arbóreo & Agrupada & $\mathrm{Nc}$ \\
\hline
\end{tabular}

Quadro 1 - Listagem das Espécies amostradas no Talhão 48, da Fazenda São José do Bromado, com seus respectivos nomes vulgares, categorias sucessionais e porte e padrão de distribuição espacial na área. P-Pioneira, Si Secundária Inicial, St- Secundária Tardia, Sbespécie característica da condição de Sub-bosque, Nc = espécie não classificada, CS- Categoria sucessional , 1- Levantamento 30 meses e 2 Levantamento 45 meses após a exploração da primeira rotação do povoamento de Eucalyptus grandis, Itatinga - SP. 


\begin{tabular}{|c|c|c|c|c|c|c|c|c|}
\hline Família & Espécie & Autor & \begin{tabular}{|r} 
Leva \\
1
\end{tabular} & 2 & Nome Vulgar & Porte & Distrib. & $\mathbf{C S}$ \\
\hline \multirow[t]{2}{*}{ Fabaceae } & Platypodium elegans & Vogel. & $\bar{X}$ & $\mathrm{X}$ & Amendoim & arbóreo & Agrupada & $\mathrm{Si}$ \\
\hline & Pterocarpus rohrii & Vahl. & $\mathrm{X}$ & $\mathrm{X}$ & Aldrago & Arbóreo & & $\mathrm{Si}$ \\
\hline \multirow[t]{2}{*}{ Flacourtiaceae } & Casearia decandra & Jacq. & $\bar{X}$ & $\mathrm{X}$ & Pau-de-espeto & arbóreo & Agrupada & $\mathrm{St}$ \\
\hline & Casearia sylvestris & Sw. & $\mathrm{X}$ & $\mathrm{X}$ & Guaçatonga & arvoreta & Aleatória & $\mathrm{P}$ \\
\hline Icacinaceae & Citronella paniculata & (Mart.) Howard. & $\mathrm{X}$ & $\mathrm{X}$ & & & & $\mathrm{St}$ \\
\hline Lacistemaceae & Lacistema hasslerianum & Choat. & $\mathrm{X}$ & $\mathrm{X}$ & & arvoreta & & $\mathrm{Si}$ \\
\hline \multirow[t]{6}{*}{ Lauraceae } & Endlicheria paniculata & (Spreng.) J.F. Macbr. & $\mathrm{X}$ & $\mathrm{X}$ & Canela peluda & arbóreo & Aleatória & $\mathrm{St}$ \\
\hline & Ocotea puberula & (Rich.) Nees. & $\mathrm{X}$ & $\mathrm{X}$ & Canela pimenta & arbóreo & Agrupada & $\mathrm{St}$ \\
\hline & Ocotea pulchella & (Nees.) Mez. & $\mathrm{X}$ & $\mathrm{X}$ & Canela lageana & arvoreta & Agrupada & $\mathrm{Si}$ \\
\hline & Ocotea velloziana & (Meisn.) Mez. & $\mathrm{X}$ & $\mathrm{X}$ & & arvoreta & & St \\
\hline & Ocotea velutina & (Nees.) Rohwer. & $\mathrm{X}$ & $\mathrm{X}$ & Canela peluda & arbóreo & Aleatória & $\mathrm{St}$ \\
\hline & Persea pyrifolia & Ness. \& Mart. ex Nees. & & $\mathrm{X}$ & Canela rosa & arbóreo & & $\mathrm{Nc}$ \\
\hline Loganaceae & Strychnos brasiliensis & (Spreng.) Mart. & $\mathrm{X}$ & $\mathrm{X}$ & Esporão de galo & arvoreta & Agrupada & $\mathrm{St}$ \\
\hline Malvaceae & Sida rhombifolia & $\mathrm{L}$ & $\mathrm{X}$ & $\mathrm{X}$ & guaxuma & herbáceo & Aleatória & $\mathrm{Nc}$ \\
\hline \multirow[t]{3}{*}{ Melastomataceae } & Leandra lacunosa & Cogn. & $\mathrm{X}$ & $\mathrm{X}$ & & & Agrupada & $\mathrm{Si}$ \\
\hline & Miconia langsdorfii & Cogn. & $\mathrm{X}$ & $\mathrm{X}$ & & & & $\mathrm{Si}$ \\
\hline & Miconia ligustroides & (DC.) Naud. & $\mathrm{X}$ & $\mathrm{X}$ & Vassoura brava & arvoreta & Aleatório & $\mathrm{P}$ \\
\hline Meliaceae & Cedrela fissilis & Vell. & $\mathrm{X}$ & $\mathrm{X}$ & Cedro & arbóreo & Agrupada & $\mathrm{Si}$ \\
\hline
\end{tabular}

Quadro 1 - Listagem das Espécies amostradas no Talhão 48, da Fazenda São José do Bromado, com seus respectivos nomes vulgares, categorias sucessionais e porte e padrão de distribuição espacial na área. P-Pioneira, Si Secundária Inicial, St- Secundária Tardia, Sbespécie característica da condição de Sub-bosque, $\mathrm{Nc}=$ espécie não classificada, CS- Categoria sucessional, 1 - Levantamento 30 meses e 2 - Levantamento 45 meses após a exploração da primeira rotação do povoamento de Eucalyptus grandis, Itatinga - SP. 


\begin{tabular}{|c|c|c|c|c|c|c|c|c|}
\hline Família & Espécie & Autor & $\begin{array}{r}\text { Leva } \\
1\end{array}$ & 2 & Nome Vulgar & Porte & Distrib. & $\overline{C S}$ \\
\hline \multirow[t]{3}{*}{ Mimosaceae } & Acacia velutina & DC. & $\mathrm{X}$ & $\mathrm{X}$ & Arranha- gato & arvoreta & Agrupada & $\mathrm{P}$ \\
\hline & Parapiptadenia rigida & (Benth.) Bernan. & $\mathrm{X}$ & $\mathrm{X}$ & Angico cedro & arbóreo & Agrupada & $\mathrm{Si}$ \\
\hline & Piptadenia gonoacantha & Mart. J.F.Macbr. & $\mathrm{X}$ & $\mathrm{X}$ & Pau-jacaré & arbóreo & & $\mathrm{Si}$ \\
\hline \multirow[t]{2}{*}{ Moraceae } & Chlorophora tinctoria & (L.) Glaud. & & $\mathrm{X}$ & Taiúva & arbóreo & & $\mathrm{Si}$ \\
\hline & Ficus glabra & Vell. & $\mathrm{X}$ & $\mathrm{X}$ & Figueira & arbóreo & Aleatória & $\mathrm{St}$ \\
\hline \multirow[t]{3}{*}{ Myrcinaceae } & Rapanea ferruginea & (Ruiz. \& Pav.) Mez. & $\mathrm{X}$ & $\mathrm{X}$ & Capororoca & arvoreta & Aleatória & $\mathrm{P}$ \\
\hline & Rapanea guyanensis & (Aubl.) & $\mathrm{X}$ & $\mathrm{X}$ & Capororoca & arvoreta & Aleatória & $\mathrm{Si}$ \\
\hline & Rapanea umbellata & (Mart.) Mez. & $\mathrm{X}$ & $\mathrm{X}$ & Capororoca & arbóreo & Agrupada & $\mathrm{Si}$ \\
\hline \multirow[t]{9}{*}{ Myrtaceae } & Blepharocalyx salicifolius & (Kunth.) O. Berg. & $\mathrm{X}$ & $\mathrm{X}$ & Cambuí & arbóreo & Aleatória & $\mathrm{Sb}$ \\
\hline & Calyptranthes concinna & DC. & $\mathrm{X}$ & $\mathrm{X}$ & Guamirim & arvoreta & Aleatória & $\mathrm{Sb}$ \\
\hline & Campomanesia cf pubescens & (DC.) O. Berg. & $\mathrm{X}$ & $\mathrm{X}$ & & & & $\mathrm{St}$ \\
\hline & Campomanesia guaviroba & (DC.) Kiaersk. & $\bar{X}$ & $\mathrm{X}$ & Guaviroba & arbóreo & Agrupada & $\mathrm{St}$ \\
\hline & Campomanesia guazumifolia & (Cambess.) O. Berg. & $\mathrm{X}$ & $\mathrm{X}$ & Sete Capote & arbóreo & Agrupada & $\mathrm{St}$ \\
\hline & Eugenia hiemalis & Cambess. & $\mathrm{X}$ & $\mathrm{X}$ & Cambuí & & Aleatória & $\mathrm{St}$ \\
\hline & Eugenia pyriformis & Cambess. & $\bar{X}$ & $\mathrm{X}$ & Uvaia & arvoreta & & $\mathrm{Sb}$ \\
\hline & Eugenia sp2 & & $\bar{X}$ & $\mathrm{X}$ & & & Agrupada & $\mathrm{Nc}$ \\
\hline & Myrcia bella & Cambess. & $\mathrm{X}$ & $X$ & Cambuí & & Aleatória & $\mathrm{St}$ \\
\hline
\end{tabular}

Quadro 1 - Listagem das Espécies amostradas no Talhão 48, da Fazenda São José do Bromado, com seus respectivos nomes vulgares, categorias sucessionais e porte e padrão de distribuição espacial na área. P-Pioneira, Si Secundária Inicial, St- Secundária Tardia, Sbespécie característica da condição de Sub-bosque, Nc = espécie não classificada, CS- Categoria sucessional , 1- Levantamento 30 meses e 2- Levantamento 45 meses após a exploração da primeira 1otação do povoamento de Eucalyptus grandis, Itatinga - SP. 


\begin{tabular}{|c|c|c|c|c|c|c|c|c|}
\hline Família & Espécie & Autor & \begin{tabular}{|r|} 
Leva \\
1
\end{tabular} & 2 & Nome Vulgar & Porte & Distrib. & $\mathbf{C S}$ \\
\hline \multirow[t]{6}{*}{ Myrtaceae } & Myrcia fallax & (Rich.) DC. & $\mathrm{X}$ & $\mathrm{X}$ & Cambuí & & Aleatória & $\mathrm{Si}$ \\
\hline & Myrcia guianensis & (Aubl.) DC. & $\mathrm{X}$ & $\mathrm{X}$ & & & & $\mathrm{Sb}$ \\
\hline & Myrcia laruotteana & Cambess. & $\mathrm{X}$ & $\mathrm{X}$ & Cambuí & & Agrupada & St \\
\hline & Myrcia multiflora & (Lam.) DC. & $\mathrm{X}$ & $\mathrm{X}$ & Cambuí & & Aleatória & $\mathrm{St}$ \\
\hline & Myrciaria floribunda & (Vest. ex Willd.) O. Berg. & & $\mathrm{X}$ & & arvoreta & & $\mathrm{Sb}$ \\
\hline & Myrtaceae sp2 & & $\mathrm{X}$ & $\mathrm{X}$ & & & Aleatória & $\mathrm{Nc}$ \\
\hline \multirow[t]{3}{*}{ Piperaceae } & Piper aduncum & $\mathrm{L}$. & $\mathrm{X}$ & $\mathrm{X}$ & Jaborandi & arbustivo & Aleatória & $\mathrm{Sb}$ \\
\hline & Piper amalago & L. & $\mathrm{X}$ & $\mathrm{X}$ & Jaborandi & arbustivo & Aleatória & $\mathrm{Sb}$ \\
\hline & Piper gaudichaudianum & Kunth. & $\mathrm{X}$ & $\mathrm{X}$ & Jaborandi & arbustivo & Agrupada & $\mathrm{Sb}$ \\
\hline Rhamnaceae & Rhamnus shaerosperma & Sw. & $\mathrm{X}$ & $\mathrm{X}$ & & arbóreo & Agrupada & $\mathrm{Si}$ \\
\hline Rosaceae & Prunus myrtifolia & (L.) Urb. & $\mathrm{X}$ & $\mathrm{X}$ & Pessegueiro bravo & arbóreo & Agrupada & $\mathrm{Si}$ \\
\hline \multirow[t]{8}{*}{ Rubiaceae } & Amaioua guianensis & Aubl. & & $\mathrm{X}$ & Marmelada brava & arvoreta & & $\mathrm{Si}$ \\
\hline & Chomelia obtusa & Cham. \& Schltdl. & $\bar{X}$ & $\mathrm{X}$ & & arvoreta & & $\mathrm{Sb}$ \\
\hline & Chomelia pohliana & Müel. & $\mathrm{X}$ & $\mathrm{X}$ & & & Aleatória & $\mathrm{Sb}$ \\
\hline & Coutarea hexandra & (Jacq.) K.Schum. & $\mathrm{X}$ & $\mathrm{X}$ & Quina & arvoreta & & $\mathrm{Sb}$ \\
\hline & Ixora venulosa & Benth. & & $\mathrm{X}$ & & arvoreta & & $\mathrm{Sb}$ \\
\hline & Psychotria carthaginensis & Jacq. & $\mathrm{X}$ & $X$ & Pau de Maria & arbustivo & Aleatória & $\mathrm{Sb}$ \\
\hline & Psychotria sessilis & (Vell.) Müel. Arg. & & $\mathrm{X}$ & & arvoreta & & St \\
\hline & Randia armata & (Sw.) DC. & $\mathrm{X}$ & $\mathrm{X}$ & Limão bravo & arbóreo & & $\mathrm{Sb}$ \\
\hline
\end{tabular}

Quadro 1 - Listagem das Espécies amostradas no Talhão 48, da Fazenda São José do Bromado, com seus respectivos nomes vulgares, categorias sucessionais e porte e padrão de distribuição espacial na área. P-Pioneira, Si Secundária Inicial, St- Secundária Tardia, Sbespécie característica da condição de Sub-bosque, Nc = espécie não classificada, CS- Categoria sucessional, 1- Levantamento 30 meses e 2 Levantamento 45 meses após a exploração da primeira rotação do povoamento de Eucalyptus grandis, Itatinga - SP. 


\begin{tabular}{|c|c|c|c|c|c|c|c|c|}
\hline Família & Espécie & Autor & \begin{tabular}{|r} 
Leva \\
1
\end{tabular} & 2 & Nome Vulgar & Porte & Distrib. & $\mathbf{C S}$ \\
\hline \multirow[t]{4}{*}{ Rutaceae } & Citrus limon & Burn. & $\bar{X}$ & $\mathrm{X}$ & Limão bravo & arvoreta & Aleatória & $\mathrm{Nc}$ \\
\hline & Esenbeckia febrifuga & (A. St. Hill) A.Juss. ex Mart. & $\mathrm{X}$ & $\mathrm{X}$ & Mamoninha & arvoreta & Agrupada & $\mathrm{Sb}$ \\
\hline & Helietta apiculata & Benth. & $\mathrm{X}$ & $X$ & Amarelinho & arvoreta & Agrupada & $\mathrm{Si}$ \\
\hline & Zanthoxylum rhoifolium & Lam. & $\mathrm{X}$ & $X$ & Mamica de porca & arbóreo & Aleatória & $\mathrm{Si}$ \\
\hline \multirow[t]{3}{*}{ Sapindaceae } & Allophyllus edulis & (St. Hill.) Radlk. & $\mathrm{X}$ & $X$ & Fruta de pombo & arvoreta & Aleatória & $\mathrm{P}$ \\
\hline & Cupania vernalis & Camb. & $\mathrm{X}$ & $\mathrm{X}$ & Pau de Cantil & arbóreo & Agrupada & $\mathrm{Si}$ \\
\hline & Matayba elaeagnoides & Radlk. & $\mathrm{X}$ & $X$ & Camboatã branco & arbóreo & Agrupada & $\mathrm{Si}$ \\
\hline Simaroubaceae & Picramnia sellowii & Planch. & $\mathrm{X}$ & $\mathrm{X}$ & & & Agrupada & $\mathrm{St}$ \\
\hline \multirow[t]{8}{*}{ Solanaceae } & Acnistus cauliflorus & Aff. & $\mathrm{X}$ & $\mathrm{X}$ & & & Aleatória & $\mathrm{P}$ \\
\hline & Cestrum sendtnerianum & Mart. ex Sendtn. & $\mathrm{X}$ & $\mathrm{X}$ & & arbustivo & Agrupada & $\mathrm{P}$ \\
\hline & Cestrum spl & & $\mathrm{X}$ & $X$ & & & Agrupada & $\mathrm{Nc}$ \\
\hline & Solanum bullatum & Vell. & $\mathrm{X}$ & $X$ & Capoeira branca & arbóreo & Agrupada & $\mathrm{P}$ \\
\hline & Solanum granuloso-leprosum & Dunal & & & Fumo Bravo & arvoreta & Aleatória & $\mathrm{P}$ \\
\hline & Solanum mauritianum & Scop. & & $X$ & & & & $\mathrm{Nc}$ \\
\hline & Solanum pseudoquina & A. St. Hill. & $\mathrm{X}$ & $X$ & Quina & arvoreta & Aleatória & $\mathrm{P}$ \\
\hline & Solanum variabile & Mart. & $\bar{X}$ & $\mathrm{X}$ & Juá-bravo & arbustivo & Agrupada & $\mathrm{P}$ \\
\hline Sterculiaceae & Waltheria indica & & & & & & & $\mathrm{Nc}$ \\
\hline
\end{tabular}

Quadro 1 - Listagem das Espécies amostradas no Talhão 48, da Fazenda São José do Bromado, com seus respectivos nomes vulgares, categorias sucessionais e porte e padrão de distribuição espacial na área. P-Pioneira, Si Secundária Inicial, St- Secundária Tardia, Sbespécie característica da condição de Sub-bosque, Nc = espécie não classificada, CS- Categoria sucessional, 1- Levantamento 30 meses e 2- Levantamento 45 meses após a exploração da primeira rotação do povoamento de Eucalyptus grandis, Itatinga - SP. 


\begin{tabular}{|c|c|c|c|c|c|c|c|c|}
\hline Família & Espécie & Autor & \begin{tabular}{|r|} 
Leva \\
1
\end{tabular} & 2 & Nome Vulgar & Porte & Distrib. & $\mathbf{C S}$ \\
\hline Styracaceae & Styrax acuminatus & Pohl. & $\mathrm{X}$ & $\mathrm{X}$ & & & Aleatória & St \\
\hline Symplocaceae & Symplocus pubescens & K1. & $\mathrm{X}$ & $\mathrm{X}$ & Sete sangrias & arbóreo & & St \\
\hline Ulmaceae & Trema micrantha & (L.) Blume. & & $\mathrm{X}$ & Crindiúva & arbóreo & & $\mathrm{P}$ \\
\hline \multirow[t]{4}{*}{ Verbenaceae } & Aegiphila sellowiana & Cham. & $\mathrm{X}$ & $\mathrm{X}$ & Tamanqueira & arvoreta & Aleatória & $\mathrm{P}$ \\
\hline & Aloysia virgata & (Ruiz. \& Pavon.) Juss. & & $\mathrm{X}$ & Lixeira & arbóreo & & $\mathrm{P}$ \\
\hline & Cytharexylum myrianthum & Cham. & $\mathrm{X}$ & $\mathrm{X}$ & Pau-viola & arbóreo & Agrupada & $\mathrm{P}$ \\
\hline & Vitex montevidensis & Cham. & $\mathrm{X}$ & $\mathrm{X}$ & Tarumã & arbóreo & Agrupada & $\mathrm{St}$ \\
\hline
\end{tabular}

Quadro 1 - Listagem das Espécies amostradas no Talhão 48, da Fazenda São José do Bromado, com seus respectivos nomes vulgares, categorias sucessionais e porte e padrão de distribuição espacial na área. P-Pioneira, Si Secundária Inicial, St- Secundária Tardia, Sbespécie característica da condição de Sub-bosque, Nc = espécie não classificada, CS- Categoria sucessional , 1- Levantamento 30 meses e 2- Levantamento 45 meses após a exploração da primeira rotação do povoamento de Eucalyptus grandis, Itatinga - SP. 


\subsection{Regeneração Natural no Sub-bosque de povoamentos de E. grandis quando Submetidas a Diferentes Condições de Manejo.}

A implantação de todos os tratamentos, inclusive o desbaste de $50 \%$ do povoamento (Tratamento 2) e o corte raso nas parcelas (Tratamento 3), ocorreu após o término do segundo levantamento, em dezembro de 1997. A exploração nos Tratamentos 2 e 3 foi realizada de maneira a concentrar o impacto das operações de derrubada e transporte primário em entrelinhas alternadas do povoamento, minimizando, ou mesmo evitando, os danos em pelo menos metade das entrelinhas do povoamento.

\subsubsection{Dinâmica da regeneração de espécies nativas no sub-bosque do povoamento de E. grandis (tratamento 1 - testemunha).}

Nesta avaliação foram realizados quatro levantamentos, respectivamente 30 meses (agosto de 1996), 45 meses (novembro de 1997), 54 meses (agosto de 1998) e 61 meses (março de 1999) após a exploração da primeira rotação do povoamento de E. grandis. Foram utilizadas 5 parcelas que totalizaram $2000 \mathrm{~m}^{2}$ de área amostral.

A Tabela 4 apresenta alguns dos parâmetros utilizados na análise da vegetação e a sua variação temporal. O Quadro 5 apresenta a listagem de espécies amostradas na área nos quatro levantamentos e o conjunto de Quadros 5 (apêndice 1) seus respectivos parâmetros fitossociológicos.

Em relação ao número de espécies percebe-se que, no período estudado de 31 meses (30 - 61 meses pós-exploração da primeira rotação de eucalipto) houve um incremento de espécies arbustivo-arbóreas na área passando de 68 aos 30 meses para 77 aos 61 meses. Considerando o número de espécies por família, a que apresentou o maior ganho em espécies no período foi Myrtaceae (10 espécies no primeiro levantamento para 15 espécies no quarto). Entre as famílias que apresentaram maior riqueza florística no decorrer dos levantamentos percebe-se dois padrões de comportamento, o primeiro referente às famílias que se caracterizaram, nesta amostragem, por apresentarem 
espécies típicas da condição de sub-bosque (como Myrtaceae e Rubiaceae) e espécies secundárias iniciais e/ou tardias (Lauraceae, Euphorbiacae, Fabaceae e outras) que mantiveram ou aumentaram o número de espécies amostradas m período. $\mathrm{O}$ segundo grupo se caracteriza por famílias que, no levantamento, apresentaram grande número de espécies arbustivas iniciais da sucessão (Solanaceae e Asteraceae) que no decorrer do estudo perderam riqueza florística.

Tabela 4. Parâmetros utilizados na análise das alterações temporais da regeneração de espécies nativas no sub-bosque de E. grandis, 30, 45, 54 e 61 meses após a exploração da primeira rotação do povoamento, área amostral 0,2 ha, Tratamento 1 - Testemunha, Itatinga - SP. Onde: P- pioneira, Si - secundária inicial, St - secundária tardia, Sb espécie típica da condição de sub-bosque, Nc - espécies não classificadas sucessionalmente, H' - índice de Shannon para diversidade; J'- equabilidade.

\begin{tabular}{|c|c|c|c|c|}
\hline Avaliação (meses) & 30 meses & 45 meses & 54 meses & 61 meses \\
\hline Área amostral (ha) & 0,2 & 0,2 & 0,2 & 0,2 \\
\hline Número de indivíduos & 711 & 939 & 1080 & 1329 \\
\hline Número de espécies & 68 & 66 & 71 & 77 \\
\hline Número de famílias & 28 & 27 & 29 & 29 \\
\hline 1 indivíduo abustivo-arbóreo a cada: & $2,81 \mathrm{~m}^{2}$ & $2,12 \mathrm{~m}^{2}$ & $1,85 \mathrm{~m}^{2}$ & $1,50 \mathrm{~m}^{2}$ \\
\hline \multirow[t]{5}{*}{ Composição sucessional espécies } & P- 18 & P-15 & P-15 & P-18 \\
\hline & $\mathrm{Si}-16$ & $\mathrm{Si}-17$ & $\mathrm{Si}-18$ & $\mathrm{Si}-19$ \\
\hline & St- 18 & St- 17 & St- 18 & St- 18 \\
\hline & $\mathrm{Sb}-6$ & $\mathrm{Sb}-9$ & $\mathrm{Sb}-11$ & $\mathrm{Sb}-11$ \\
\hline & Nc-9 & Nc-8 & Nc-9 & Nc-11 \\
\hline \multirow[t]{5}{*}{ Composição sucessional indivíduos } & P-367 & P-338 & P-332 & P-417 \\
\hline & Si-170 & Si-324 & Si-383 & Si-462 \\
\hline & St-141 & St-232 & St-286 & St-341 \\
\hline & $\mathrm{Sb}-12$ & $\mathrm{Sb}-29$ & $\mathrm{Sb}-55$ & $\mathrm{Sb}-82$ \\
\hline & Nc-21 & Nc-15 & Nc-27 & Nc-27 \\
\hline \multicolumn{5}{|l|}{ Número de espécies com apenas um } \\
\hline indivíduo amostrado & 25 & 19 & 18 & 20 \\
\hline Altura média & 2,21 & 2,34 & 2,37 & 2,44 \\
\hline Classe Modal de Altura & $1,5-1,75$ & $1,5-1,75$ & $1,5-1,75$ & $1,5-1,75$ \\
\hline $\mathrm{H}^{\prime}$ & 3,060 & 3,008 & 3,027 & 3,088 \\
\hline J' & 0,725 & 0,718 & 0,710 & 0,711 \\
\hline
\end{tabular}


Quando se considera a densidade de indivíduos amostrados em cada família estes padrões de comportamento se realçam, assim a densidade de indivíduos da família Myrtaceae, que se caracterizou nos levantamentos por apresentar espécies finais da sucessão ou típicas da condição de sub-bosque, aumentou 351\% (93 para 327 indivíduos no período). O número de indivíduos pertencentes à família Sapindaceae aumentou 415,29\% (85 para 357 indivíduos) influenciado, principalmente, pelo comportamento das espécies Matayba elaeagnoides e Cupania vernalis, a segunda espécie em particular apresentou 34 indivíduos amostrados no primeiro levantamento (30 meses) e 212 indivíduos no quarto levantamento (61 meses).

Em relação à família Solanaceae, é importante particularizar a dinâmica da população de Solanum variabile, espécie pioneira, cuja dinâmica populacional pode ser utilizada como modelo para as demais espécies amostradas das famílias Solanaceae e Asteraceae (espécies dos gêneros Solanum, Vernonia e Euphatorium). No primeiro levantamento (30 meses) Solanum variabile apresentou 103 indivíduos $(91,15 \%$ dos indivíduos amostrados para a família) e era a segunda espécie com maior densidade na área. Após este levantamento a população entrou em declínio, sendo que no quarto levantamento (61 meses) a espécie ocupou a décima sétima posição em densidade, com apenas 12 indivíduos amostrados, enquanto a família Solanaceae apresentava 36 indivíduos no levantamento.

Considerando a divisão de espécies em grupos ecológicos se percebe no período um aumento no número de espécies típicas da condição de sub-bosque (6 para 11 espécies), reflexo das mudanças ambientais impostas pelo desenvolvimento do povoamento de E. grandis e nos demais grupos ecológico o número de espécies se manteve constante.

O comportamento da taxa de mortalidade pode ser observado na Figura 12, que demonstra o comportamento desse parâmetro individualmente para cada categoria sucessional nos quatro levantamentos.

A taxa de mortalidade total apresentou um pico de $23,65 \%$ no segundo levantamento (45 meses). Analisando este parâmetro conjuntamente com os grupos sucessionais nota-se que este pico corresponde as maiores taxas de mortalidade para as 
espécies pioneiras e não classificadas sucessionalmente. Como já colocado, o grupo das espécies que não puderam ser classificadas sucessionalmente engloba espécies arbustivas ruderais (invasoras de culturas) que necessitam de alta incidência luminosa para o seu desenvolvimento.

As altas taxas de mortalidade nos grupos indicados são consequiência do desenvolvimento do povoamento de E. grandis. Em um primeiro momento, no qual as condições de luminosidade do piso florestal eram favoráveis, ocorreu o recrutamento de indivíduos de espécies pioneiras e ruderais. Com o desenvolvimento do povoamento as condições de sombreamento impostas pelo eucalipto comprometeram o recrutamento e o desenvolvimento de indivíduos destas espécies resultando, em condições mais drásticas, nas altas taxas de mortalidade encontradas para estes grupos no segundo levantamento (45 meses).

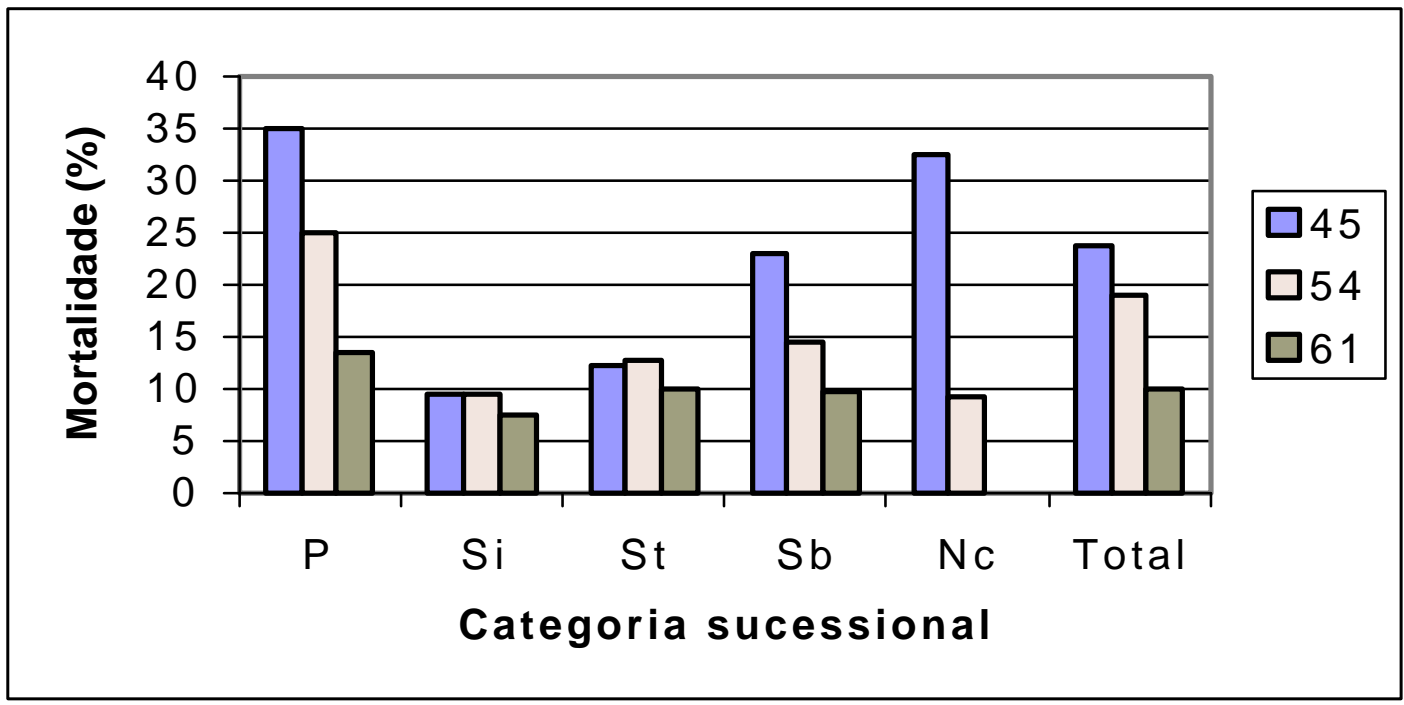

Figura 12 -Comportamento da taxa de mortalidade total e por categoria sucessional na regeneração natural no sub-bosque de eucalipto (45, 54 e 61 meses após a exploração) tendo como período inicial de análise 30 meses após a exploração da primeira rotação do povoamento de E. grandis. Tratamento 1 - testemunha, área amostral 0,2 ha, Itatinga SP. P- espécie pioneira, Si - secundária inicial, St - secundária tardia, Sb - típica da condição de sub-bosque e Nc - não classificada.

Em relação à taxa de recrutamento, Figura 13, esta apresentou um pico no segundo levantamento $36,13 \%$ ao ano. Quando se observam as taxas de recrutamento por 


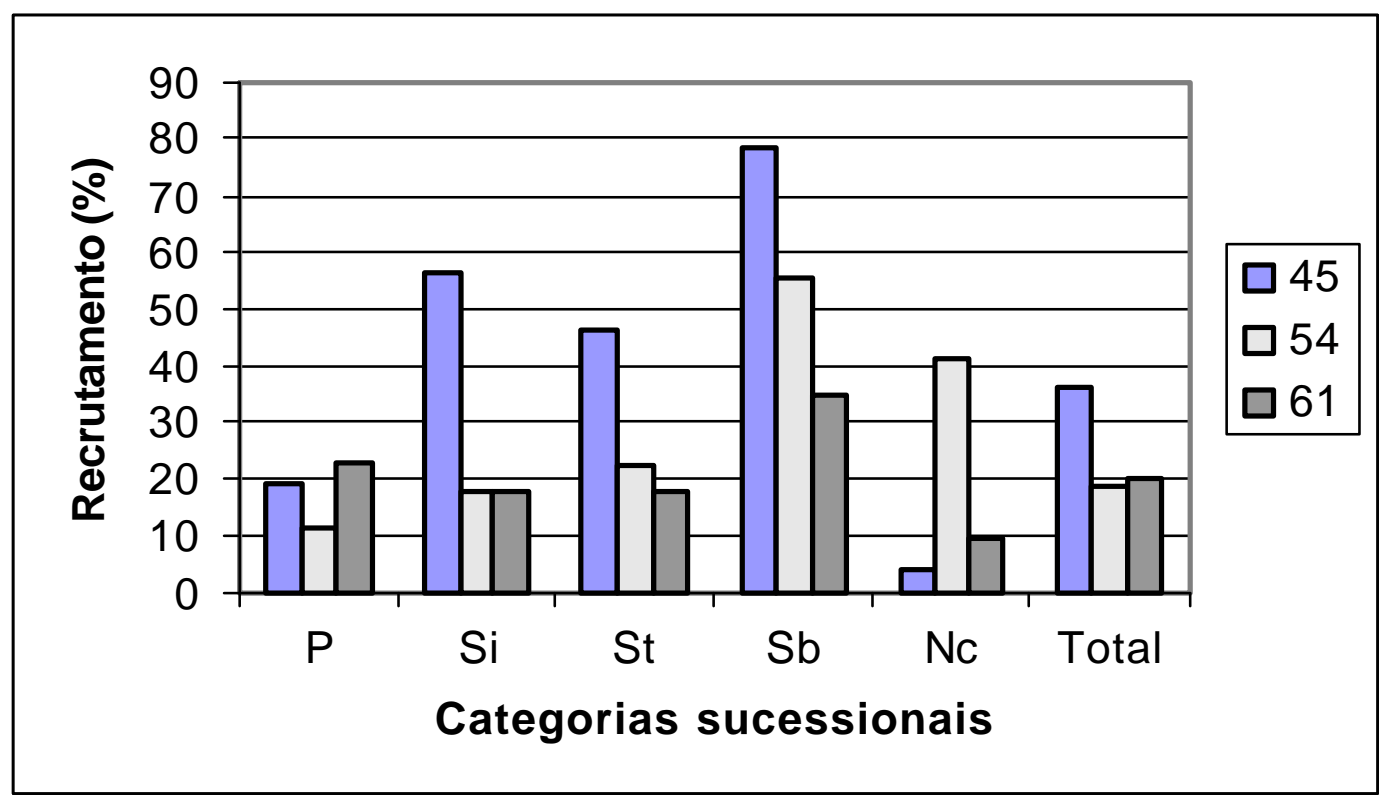

categoria sucessional, pode se observar que as maiores taxas de foram encontradas para as espécies típicas da condição de sub-bosque (oscilando entre 34,82\% no quarto levantamento a 78,46\% no segundo). Estes resultados são similares aos encontrados por Rodrigues (1999), que estudando a regeneração natural ocorrente em fragmentos florestais submetidos a ação do fogo em Campinas, SP, constatou grande crescimento populacional das espécies típicas da condição de sub-bosque 35 meses após a ocorrência do fogo.

Figura 13 -Comportamento da taxa de recrutamento total e por categoria sucessional da regeneração natural no sub-bosque do eucalipto (45, 54 e 61 meses após a exploração) tendo como período inicial de análise 30 meses após a exploração da primeira rotação do povoamento de E. grandis. Tratamento 1 - testemunha, área amostral 0,2 ha, Itatinga SP. P- espécie pioneira, $\mathrm{Si}$ - secundária inicial, $\mathrm{St}$ - secundária tardia, $\mathrm{Sb}$ - típica da condição de sub-bosque e Nc - não classificada.

Como resultado do equilíbrio entre as taxas de recrutamento e mortalidade percebe-se um incremento em densidade de indivíduos diferenciado para cada categoria sucessional. Assim, enquanto a população como um todo apresentou um crescimento de 86,91\% no período (711 para 1329 indivíduos), as espécies secundárias iniciais, tardias e 
típicas da condição de sub-bosque apresentaram taxas de crescimento de 171,76\%, $141,84 \%$ e 583,33\% respectivamente. As espécies pioneiras e aquelas que não puderam ser classificadas sucessionalmente apresentaram crescimento populacional de 13,62\% e $28,57 \%$ respectivamente no período (figura 14 ).

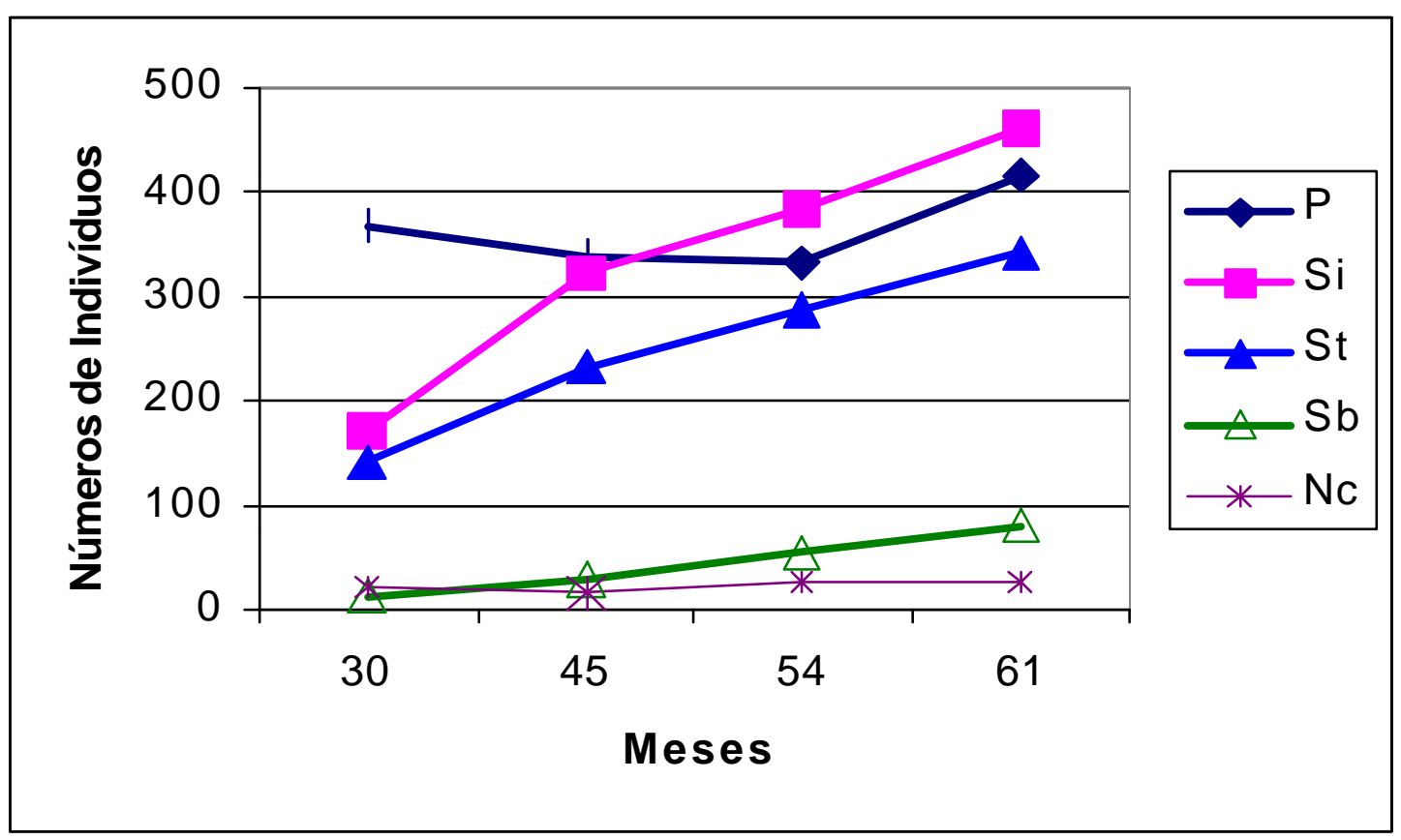

Figura 14 -Comportamento densidade de indivíduos por categoria sucessional da regeneração natural no sub-bosque do eucalipto (45, 54 e 61 meses após a exploração) tendo como período inicial de análise 30 meses após a exploração da primeira rotação do povoamento de E. grandis. Tratamento 1 - testemunha, área amostral 0,2 ha, Itatinga $\mathrm{SP}$. P- espécie pioneira, $\mathrm{Si}$ - secundária inicial, $\mathrm{St}$ - secundária tardia, $\mathrm{Sb}$ - típica da condição de sub-bosque e Nc - não classificada.

Os resultados são similares aos encontrados na amostragem anterior (0,68 ha), indicando que o recrutamento de novos indivíduos no período se concentrou nas espécies secundárias iniciais, tardias e típicas da condição de sub-bosque. O comportamento da mortalidade no período indicou concentração da mortalidade dos indivíduos de espécies pioneiras na fase inicial do desenvolvimento do povoamento de 
eucalipto, relacionada provavelmente com o fechamento das copas e conseqüente mudança no regime de luminosidade a qual o sub-bosque é submetido.

Apesar de influenciar significativamente as taxas de mortalidade e recrutamento, as mudanças ambientais ocorridas na condição de no sub-bosque parecem não influenciar o desenvolvimento dos indivíduos pioneiros já estabelecidos. Considerando o parâmetro altura média, o grupo de espécies que apresentou o maior incremento em altura no período foi o das pioneiras, com altura média de 2,17m aos 30 meses (classe modal de 1,5 - 1,75m) e 2,57m aos 61 meses (classe modal de 1,75 - 2.00). As secundárias iniciais e tardias apresentaram respectivamente ganhos de 2,45m para 2,56m e 2,09m para 2,22m no período. As espécies típicas da condição de sub-bosque e as não classificadas sucessionalmente mantiveram praticamente a mesma altura média $(1,83 \mathrm{~m}$ para $1,84 \mathrm{~m}$ e $2,13 \mathrm{~m}$ para $2,18 \mathrm{~m}$ respectivamente).

Em relação as espécies típicas da condição do sub-bosque, a ausência de incremento em altura no período foi conseqüência não da ausência de incremento nos indivíduos, mas sim das altas taxas recrutamento alcançadas por este grupo no período. A influência das taxas de recrutamento sobre a altura média dos grupos também deve ser considerada na comparação entre os incrementos alcançados pelas espécies pioneiras e secundárias iniciais e tardias.

O comportamento do índice de diversidade de Shannon ( $\left.\mathrm{H}^{\prime}\right)$, de 3,06 (30 meses) para 3,088 (61 meses), e da equabilidade ( $\left.\mathbf{J}^{\prime}\right)$, de 0,725 (30 meses) para 0,711 (61 meses), demonstraram estabilidade na diversidade da área no período.

Os resultados evidenciam que as mudanças ambientais impostas pelo desenvolvimento do povoamento do povoamento de E. grandis (principalmente o aumento do sombreamento) influenciaram a dinâmica de ocupação do sub-bosque por espécies nativas, induzindo através de taxas de mortalidade e recrutamento diferenciadas entre os grupos a substituição de espécies consideradas iniciais da sucessão por espécies finais. 


\subsubsection{Dinâmica da regeneração de espécies nativas no sub-bosque de povoamentos de E. grandis, - Tratamento 2 (desbaste de $50 \%$ dos indivíduos do povoamento de E. grandis)}

Nesta avaliação foi utilizado um conjunto de 6 parcelas, que totalizavam $2400 \mathrm{~m}^{2}$ de área amostral. Foram realizadas quatro avaliações, sendo as duas primeiras, 30 meses (agosto de 1996), 45 meses (novembro de 1997) após a exploração da primeira rotação do povoamento de E. grandis, realizadas antes da implantação dos tratamentos. Após o desbaste do povoamento de eucalipto em dezembro de 1997 foram realizadas a terceira avaliação, 54 meses (agosto de 1998), e a quarta, 61 meses (março de 1999) após a exploração da primeira rotação do povoame nto de E. grandis.

A Tabela 5 apresenta alguns dos parâmetros utilizados na análise da vegetação e a sua variação temporal. O Quadro 5 apresenta a listagem de espécies amostradas na área nos quatro levantamentos e o conjunto de Quadros 6 (apêndice 1) seus respectivos parâmetros fitossociológicos.

Nos levantamentos realizados 30 e 45 meses após a exploração da primeira rotação do povoamento de E. grandis, a regeneração de espécies nativas apresentou comportamento similar ao do tratamento testemunha, com aumento na densidade de indivíduos e na riqueza de espécies. As taxas de mortalidade e recrutamento também foram diferenciadas por categoria sucessional demonstrando uma tendência de ocupação da área por espécies pertencentes aos grupos das secundárias iniciais, tardias e típicas da condição de sub-bosque em substituição aos indivíduos das espécies pertencentes aos grupos das pioneiras e não classificadas sucessionalmente que ocuparam inicialmente a área. Este comportamento está relacionado com o aumento da condição de sombreamento imposto pelo desenvolvimento do povoamento de E. grandis.

O comportamento similar entre as espécies classificadas como pioneiras e as não classificadas sucessionalmente pode ser explicado pelo fato desta última categoria incorporar espécies arbustivas ruderais, que por falta de dados, não puderam ser classificadas sucessionalmente e também espécies identificadas ao nível de gênero, 
algumas destas pertencentes a gêneros com características tipicamente pioneiras (Vernonia, Eupatorium e outros).

O impacto das operações de corte e transporte primário da madeira pode ser observado no comportamento de alguns dos parâmetros listados na Tabela 5 .

Tabela 5. Parâmetros utilizados na análise das alterações temporais da regeneração de espécies nativas no sub-bosque de $E$. grandis, levantamentos realizados 30, 45, 54 e 61 meses após a exploração do povoamento de eucalipto, área amostral de 0,24ha, Itatinga - SP. Tratamento 2 - com desbaste de $50 \%$ do povoamento de E. grandis, implantado em dezembro de 1997 (46 meses após a exploração do povoamento). Onde: P- pioneira; $\mathrm{Si}$ - secundária inicial; $\mathrm{St}$ - secundária tardia, Sb - espécie típica da condição de subbosque, Nc - espécies não classificadas sucessionalmente, H' - índice de Shannon para diversidade, J' - equabilidade.

\begin{tabular}{lllll}
\hline Meses & 30 meses & 45 meses & 54 meses & 61 meses \\
\hline Número de indivíduos & 600 & 749 & 535 & 792 \\
Número de espécies & 70 & 78 & 79 & 86 \\
Número de famílias & 30 & 28 & 27 & 30 \\
Composição sucessional espécies & & & & \\
& $\mathrm{P}-15$ & $\mathrm{P}-17$ & $\mathrm{P}-17$ & $\mathrm{P}-19$ \\
& $\mathrm{Si}-23$ & $\mathrm{Si}-24$ & $\mathrm{Si}-24$ & $\mathrm{Si}-25$ \\
& $\mathrm{St}-17$ & $\mathrm{St}-18$ & $\mathrm{St}-18$ & $\mathrm{St}-18$ \\
& $\mathrm{Sb}-10$ & $\mathrm{Sb}-14$ & $\mathrm{Sb}-14$ & $\mathrm{Sb}-15$ \\
Composição sucessional considerando & $\mathrm{N}-5$ & $\mathrm{Nc}-5$ & $\mathrm{Nc}-6$ & $\mathrm{Nc}-3$ \\
indivíduos & $\mathrm{P}-290$ & $\mathrm{P}-237$ & $\mathrm{P}-153$ & $\mathrm{P}-285$ \\
& $\mathrm{Si}-220$ & $\mathrm{Si}-338$ & $\mathrm{Si}-252$ & $\mathrm{Si}-313$ \\
& $\mathrm{St}-63$ & $\mathrm{St}-120$ & $\mathrm{St}-89$ & $\mathrm{St}-116$ \\
& $\mathrm{Sb}-14$ & $\mathrm{Sb}-36$ & $\mathrm{Sb}-31$ & $\mathrm{Sb}-51$ \\
& $\mathrm{Nc}-13$ & $\mathrm{Nc}-18$ & $\mathrm{Nc}-9$ & $\mathrm{Nc}-27$ \\
Número de espécies & com apenas & $\mathrm{Nm}$ & & \\
indivíduo amostrado & & & & \\
Altura média & 23 & 26 & 27 & 26 \\
Classe modal da Altura & 2,17 & 2,28 & 2,34 & 2,36 \\
H' (espécies) & $1,75-2,0$ & $1,5-1,75$ & $1,5-1,75$ & $1,5-1,75$ \\
J' & 3,127 & 3,324 & 3,359 & 3,526 \\
\hline
\end{tabular}


Após o desbaste, em função do impacto sofrido pela regeneração natural durante as operações de colheita e remoção da madeira e a mudança dos fatores ambientais vigentes no piso florestal, notadamente o aumento da intensidade luminosa, ocorreu uma mudança na dinâmica da regeneração.

Esta mudança pode ser observada na análise de diferentes parâmetros, entre eles a taxa de mortalidade por grupo sucessional (Figura 15).

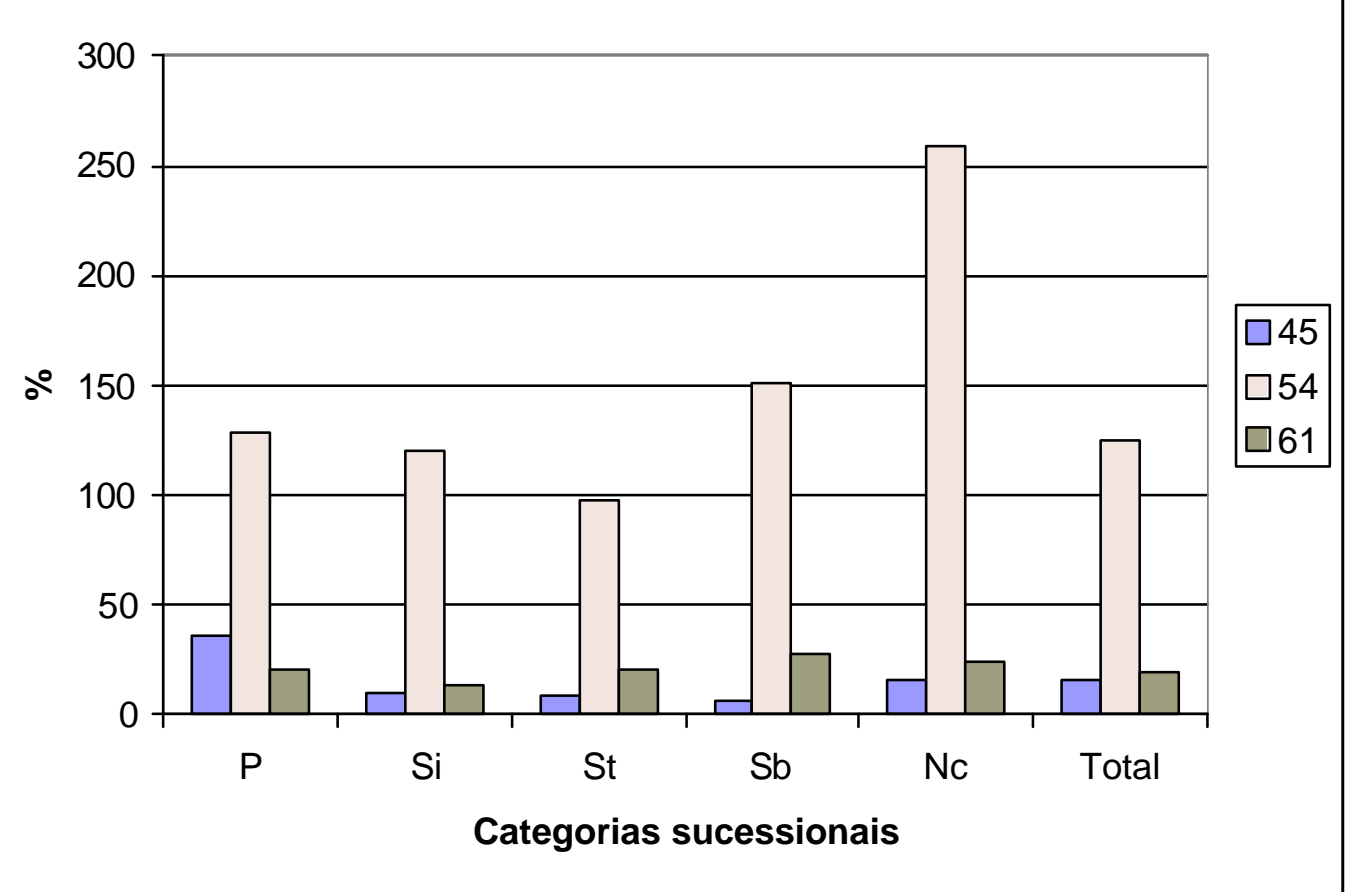

Figura 15 - Comportamento da taxa de mortalidade total e por categoria sucessional da regeneração natural no sub-bosque do eucalipto, (45, 54 e 61 meses após a exploração) tendo como período inicial de análise 30 meses após a exploração da primeira rotação do povoamento de E. grandis. Tratamento 2: desbaste de 50\% dos indivíduos do povoamento, área amostral de 0,24ha, Itatinga - SP, onde: $\mathrm{P}$ - espécie pioneira, Si secundária inicial, $\mathrm{St}$-secundária tardia, $\mathrm{Sb}$ - espécie típica da condição de sub-bosque e $\mathrm{Nc}$ - não classificadas. 
Observa-se que entre o primeiro (30 meses) e o segundo (45 meses) levantamento, as espécies secundárias iniciais, tardias e típicas da condição de sub-bosque apresentaram taxas de mortalidade significativamente menores que espécies pioneiras. $\mathrm{O}$ impacto do desbaste de $50 \%$ dos indivíduos de E. grandis na regeneração natural pode ser observado através das altas taxas de mortalidade alcançadas em todos os grupos sucessionais no terceiro levantamento (54 meses). O quarto levantamento (61 meses), influenciado pelas mudanças ambientais na regeneração, se destacou pela mudança no comportamento dos grupos sucessionais em relação a taxa de mortalidade, onde os grupos que obtiveram as menores taxas no segundo levantamento (secundárias iniciais, finais e típicas da condição de sub-bosque) apresentaram crescimento da mortalidade, enquanto o grupo das pioneiras que obteve a maior taxa no segundo levantamento (45 meses) apresentou tendência de queda na mortalidade.

A figura 16 demonstra o comportamento da taxa de recrutamento para as categorias sucessionais no período. A taxa de recrutamento também acusa o impacto do desbaste no povoamento de eucalipto sobre a regeneração natural, registrando as menores taxas no terceiro levantamento para todos os grupos sucessionais, notadamente para as espécies secundárias tardias. Ela também registra uma mudança no comportamento do recrutamento entre as categorias sucessionais, assim enquanto entre o primeiro e segundo levantamentos as espécies secundárias iniciais, tardias e típicas da condição de sub-bosque apresentavam as maiores taxas de recrutamento, entre o terceiro e quarto levantamento as espécies pioneiras e não classificadas sucessionalmente ocupavam esta posição em resposta ao aumento da intensidade luminosa no interior do talhão.

O comportamento da densidade de indivíduos por categoria sucessional, determinado pelo equilíbrio entre as taxas de recrutamento e mortalidade, pode ser avaliado na Figura 17. 


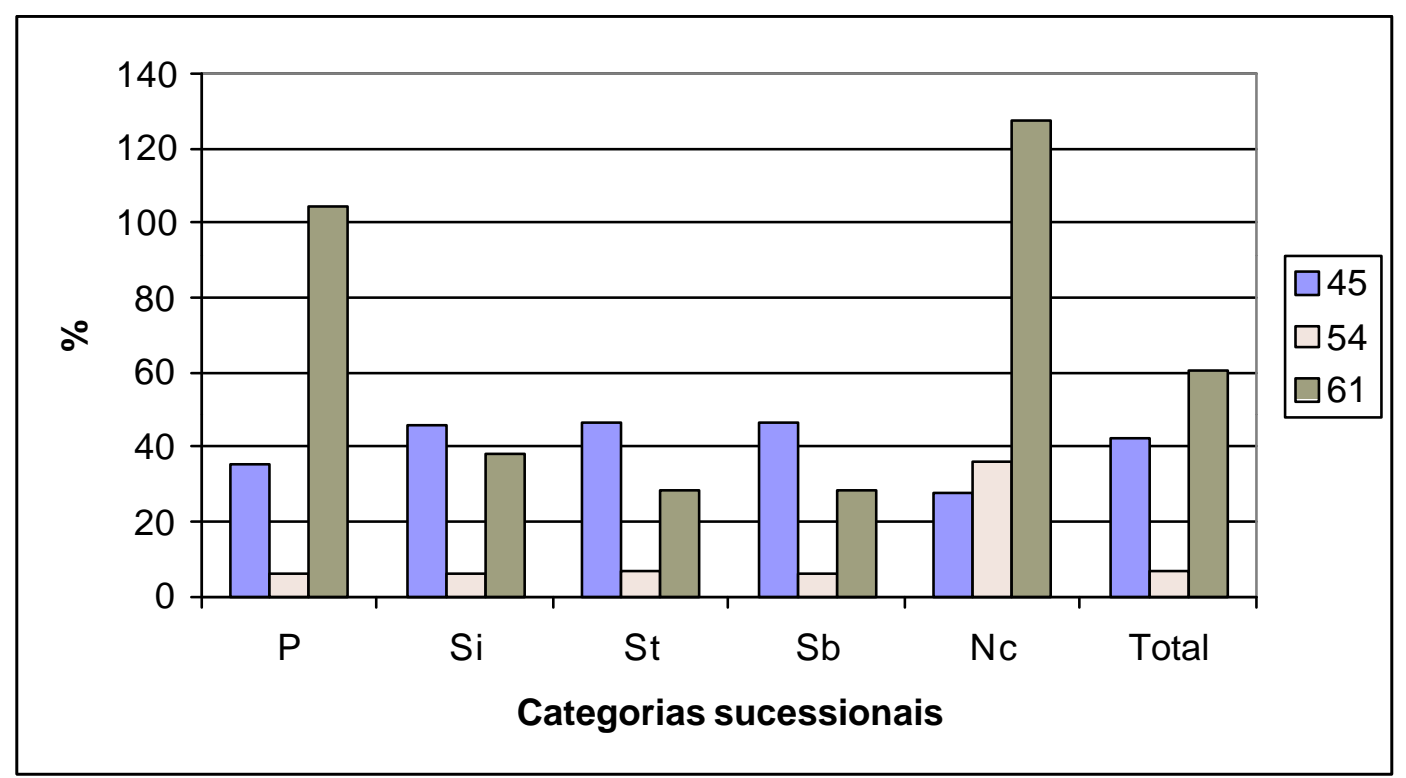

Figura 16 - Comportamento da taxa de recrutamento total e por categoria sucessional da regeneração natural no sub-bosque do eucalipto, (45, 54 e 61 meses após a exploração) tendo como período inicial de análise 30 meses após a exploração da primeira rotação do povoamento de E. grandis. Tratamento 2: desbaste de 50\% dos indivíduos do povoamento, área amostral de 0,24ha, Itatinga - SP, onde: $\mathrm{P}$ - espécie pioneira, $\mathrm{Si}$ secundária inicial, $\mathrm{St}$-secundária tardia, $\mathrm{Sb}$ - espécie típica da condição de sub-bosque e $\mathrm{Nc}-$ não classificadas.

O comportamento do índice Shannon (aumento de 3,127 aos 30 meses para 3,526 aos 61 meses), da equabilidade (aumento de 0,736 para 0,792 no período), somado ao ingresso de novas espécies na área, demonstra ganho em diversidade no período analisado. Este fato está correlacionado as mudanças climáticas impostas ao sub-bosque pelo desbaste do povoamento (aumento da luminosidade no piso florestal, redução da competição) e o conseqüente aumento do número de nichos para as espécies. 


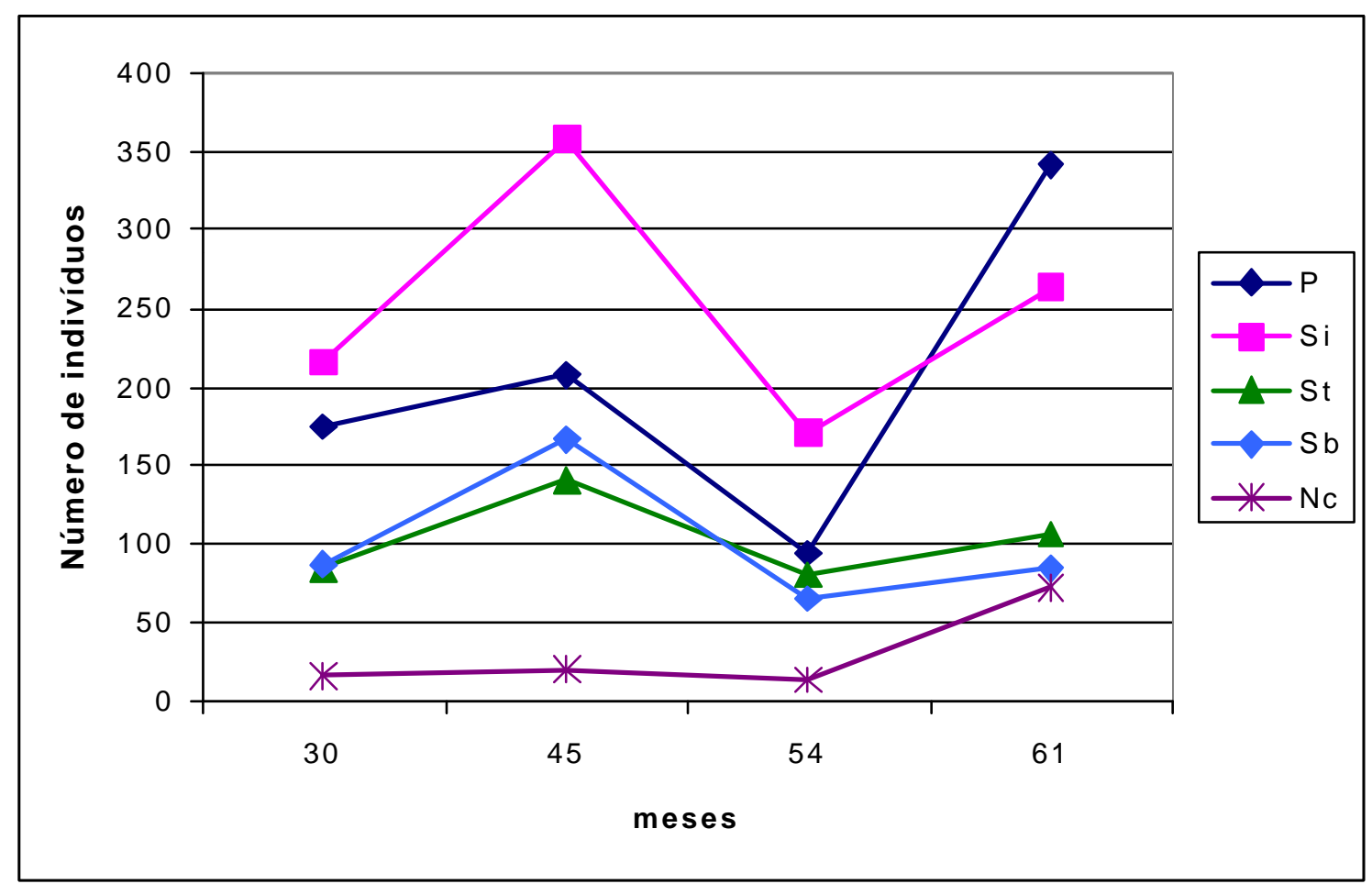

Figura 17 - Comportamento da densidade de indivíduos por categoria da regeneração natural no sub-bosque do eucalipto, (45, 54 e 61 meses após a exploração) tendo como período inicial de análise 30 meses após a exploração da primeira rotação do povoamento de E. grandis. Tratamento 2: desbaste de 50\% dos indivíduos do povoamento, área amostral de 0,24ha, Itatinga - SP, onde: $\mathrm{P}$ - espécie pioneira, Si secundária inicial, $\mathrm{St}$-secundária tardia, $\mathrm{Sb}$ - espécie típica da condição de sub-bosque e $\mathrm{Nc}$ - não classificadas.

Os principais impactos esperados ao sub-bosque após o desbaste do povoamento de E. grandis, eram: ambientais (representados pelo aumento da luminosidade, da disponibilidade de nutrientes, da temperatura e da amplitude de variação desta, diminuição da umidade e outros) e físicos (representado pelos danos físicos diretos aos indivíduos durante as operações de colheita e pelo acúmulo de resíduos do corte em algumas áreas).

O impacto das operações de colheita (corte e remoção) foi uniforme em toda a área, causando queda nas taxas de recrutamento e aumento da mortalidade em todas as 
categorias sucessionais, e conseqüentemente queda no número de indivíduos amostrados no levantamento realizado imediatamente após o corte (54 meses). No entanto, as respostas as mudanças ambientais no talhão foram diferenciadas por grupo sucessional, favorecendo os grupos de espécies pioneiras e as não classificadas sucessionalmento. Os demais grupos também apresentaram incremento em densidade, porém com crescimento menor do que apresentado antes da implantação do tratamento.

\subsubsection{Dinâmica da regeneração de espécies nativas no sub-bosque de povoamentos de E. grandis, - Tratamento 3 (corte raso do povoamento de E. grandis)}

Nesta avaliação foi utilizado um conjunto de 6 parcelas, que totalizavam $2400 \mathrm{~m}^{2}$ de área amostral. Foram realizadas quatro avaliações, sendo as duas primeiras, 30 meses (agosto de 1996), 45 meses (novembro de 1997) após a exploração da primeira rotação do povoamento de E. grandis, realizadas antes da implantação dos tratamentos. Após o corte raso do povoamento de eucalipto em dezembro de 1997 foram realizadas as avaliações restantes, a terceira, 54 meses (agosto de 1998), e a quarta, 61 meses (março de 1999) após a exploração da primeira rotação do povoamento de E. grandis.

A Tabela 6 apresenta alguns dos parâmetros utilizados na análise da vegetação e a sua variação temporal. O Quadro 5 apresenta a listagem de espécies amostradas na área nos quatro levantamentos e o conjunto de Quadros 7 (apêndice 1) seus respectivos parâmetros fitossociológicos.

Os comportamentos das taxas de mortalidade e recrutamento totais refletem o impacto das operações de corte e retirada da madeira do povoamento das parcelas do experimento (figuras 18 e 19) 
Tabela 6. Parâmetros utilizados na análise das alterações temporais da regeneração de espécies nativas no sub-bosque de $E$. grandis, levantamentos realizados 30, 45, 54 e 61 meses após a exploração do povoamento de eucalipto, área amostral de 0,24ha, Itatinga - SP. Tratamento 3 - corte raso do povoamento de E. grandis, implantado em dezembro de 1997 (46 meses após a exploração do povoamento). Onde: P- pioneira; Si secundária inicial; $\mathrm{St}$ - secundária tardia, $\mathrm{Sb}$ - espécie típica da condição de sub-bosque, Nc - espécies não classificadas sucessionalmente, H' - índice de Shannon para diversidade, J' - equabilidade.

\begin{tabular}{|c|c|c|c|c|}
\hline & 30 meses & 45 meses & 54 meses & 61 meses \\
\hline Número de indivíduos & 589 & 894 & 428 & 866 \\
\hline Número de espécies & 66 & 78 & 70 & 81 \\
\hline Número de famílias & 29 & 31 & 27 & 31 \\
\hline \multirow[t]{5}{*}{ Composição sucessional espécies } & P- 14 & P-17 & P-18 & P- 18 \\
\hline & $\mathrm{Si}-23$ & $\mathrm{Si}-27$ & $\mathrm{Si}-22$ & $\mathrm{Si}-26$ \\
\hline & St-16 & St-16 & St-14 & St-16 \\
\hline & $\mathrm{Sb}-9$ & Sb-11 & $\mathrm{Sb}-9$ & $\mathrm{Sb}-7$ \\
\hline & $\mathrm{Nc}-4$ & Nc-7 & $\mathrm{Nc}-7$ & $\mathrm{Nc}-14$ \\
\hline \multirow{5}{*}{$\begin{array}{l}\text { Composição sucessional considerando os } \\
\text { indivíduos }\end{array}$} & P-175 & P-208 & P-94 & $\mathrm{P}-341$ \\
\hline & $\mathrm{Si}-216$ & $\mathrm{Si}-357$ & Si-170 & $\mathrm{Si}-263$ \\
\hline & St- 84 & St-141 & St- 80 & St-106 \\
\hline & Sb-97 & Sb- 167 & $\mathrm{Sb}-65$ & $\mathrm{Sb}-84$ \\
\hline & Nc-17 & Nc-21 & Nc-14 & Nc-72 \\
\hline \multicolumn{5}{|l|}{ Número de espécies com apenas um } \\
\hline indivíduo amostrado & 12 & 17 & 28 & 24 \\
\hline Altura média & 2,17 & 2,28 & 2,23 & 2,26 \\
\hline Classe Modal de Altura & $1,5-1,75$ & $1,5-1,75$ & $1,5-1,75$ & $1,5-1,75$ \\
\hline H’ (espécies) & 3,396 & 3,442 & 3,397 & 3,549 \\
\hline J' & 0,811 & 0,79 & 0,80 & 0,808 \\
\hline
\end{tabular}

Quando se analisa a taxa de mortalidade por categoria sucessional, observa-se que antes da implantação do tratamento $\left(1^{\circ}\right.$ e $2^{\circ}$ levantamento) este parâmetro apresentava comportamento similar ao do tratamento testemunha (Figura 12). No terceiro levantamento ocorreu um aumento drástico nas taxas de mortalidade total, com uma mortalidade de $125 \%$ (o que significa a perda de mais da metade dos indivíduos 
amostrados no levantamento anterior), demonstrando claramente o impacto das operações de corte e remoção do eucalipto sobre a dinâmica de ocupação de espécies nativas na área. Como reflexo das mudanças ambientais (aumento da luminosidade, aumento de temperatura e de sua amplitude de variação durante o dia, diminuição da umidade, etc) impostas à área após a retirada da cobertura florestal percebe-se o aumento das taxas de mortalidade para as espécies típicas da condição do sub-bosque, reflexo.

A taxa de recrutamento, também espelha claramente o impacto da implantação do tratamento nos grupos sucessionais, através de baixas taxas de recrutamento para todos os grupos, consequiência dos danos sofridos pelas plântulas no processo e pelo impedimento físico que os restos vegetais da exploração representam para a germinação de sementes no solo. As mudanças ambientais causadas pela retirado do eucalipto beneficiaram os grupos de espécies pioneiras e das espécies não classificadas sucessionalmente que alcançaram taxas de recrutamento maiores do que as apresentadas antes da implantação do tratamento (segundo levantamento - 45 meses). Para os demais grupos sucessionais (secundárias iniciais, tardias e típicas da condição de sub-bosque) o ritmo do recrutamento de indivíduos diminuiu do segundo para o quarto levantamento(figura 19).

A figura 20 apresenta as densidades de indivíduos por categoria sucessional em cada levantamento, demonstrando o impacto da exploração do talhão (menor densidade de indivíduos no levantamento realizado após o corte raso, 54 meses) e a reocupação da área com espécies preferencialmente pioneiras. Representando uma mudança na dinâmica de ocupação da área, que apresentava antes da supressão do eucalipto a tendência de crescimento populacional para os grupos de secundárias iniciais, tardias e típicas da condição de sub-bosque e diminuição na densidade de espécies pioneiras.

Neste tratamento também foi observado o aumento do número de espécies amostrado e do índice de diversidade de Shannon (de 3,396 aos 30 meses para 3,549), a equabilidade se manteve praticamente constante no período $(0,811$ aos 30 meses e 0,808 aos 61 meses). Estes índices demonstram ganho em diversidade no período, causado pelas mudanças ambientais geradas pela retirada do plantio de E. grandis que 
favoreceram a entrada de espécies e o recrutamento de indivíduos de espécies iniciais da sucessão.

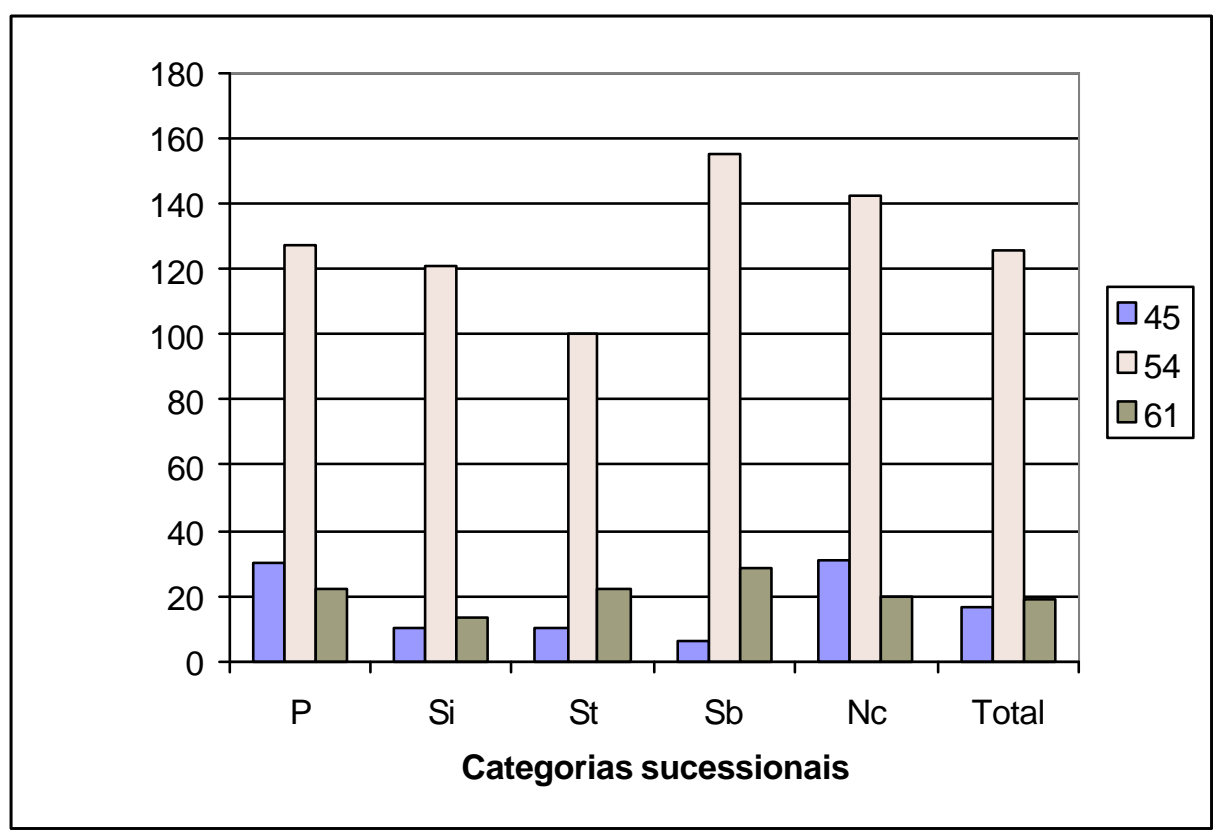

Figura 18 - Comportamento da taxa de mortalidade total e por categoria sucessional da regeneração natural no sub-bosque do eucalipto, (45, 54 e 61 meses após a exploração) tendo como período inicial de análise 30 meses após a exploração da primeira rotação do povoamento de E. grandis. Tratamento 3: corte raso do povoamento de eucalipto, área amostral de 0,24ha, Itatinga - SP, onde: $\mathrm{P}$ - espécie pioneira, Si - secundária inicial, St -secundária tardia, $\mathrm{Sb}$ - espécie típica da condição de sub-bosque e $\mathrm{Nc}$ - não classificadas, onde: $\mathrm{P}$ - espécie pioneira, $\mathrm{Si}$ - secundária inicial, St -secundária tardia, $\mathrm{Sb}$ - espécie típica da condição de sub-bosque e Nc - não classificadas. 


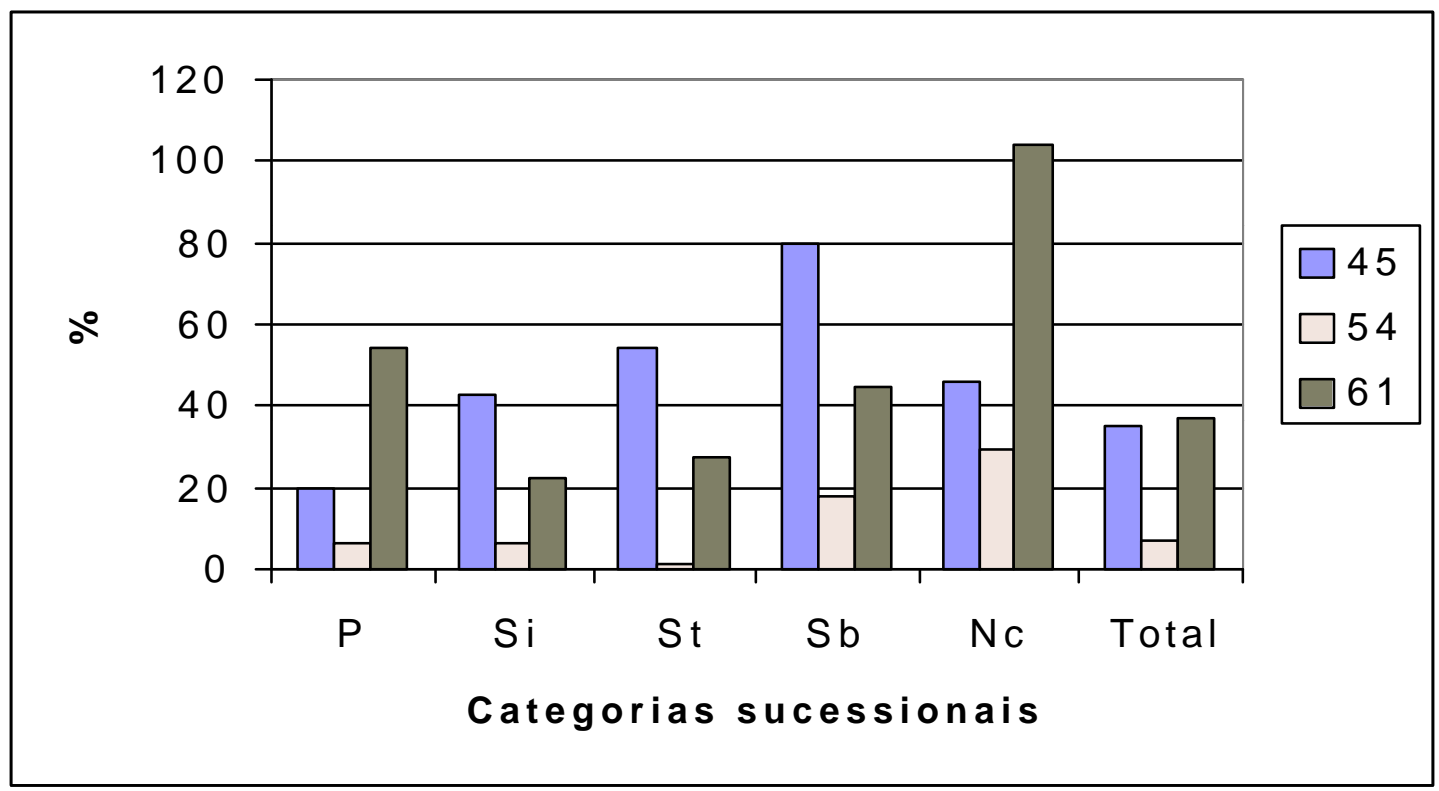

Figura 19 - Comportamento da taxa de recrutamento total e por categoria sucessional, da regeneração natural no sub-bosque do eucalipto, (45, 54 e 61 meses após a exploração) tendo como período inicial de análise 30 meses após a exploração da primeira rotação do povoamento de E. grandis. Tratamento 3: corte raso do povoamento de eucalipto, área amostral de 0,24ha, Itatinga - SP, onde: P - espécie pioneira, Si - secundária inicial, St -secundária tardia, $\mathrm{Sb}$ - espécie típica da condição de sub-bosque e $\mathrm{Nc}$ - não classificadas., no tratamento 3, corte raso do povoamento de E. grandis, onde: $\mathrm{P}$ espécie pioneira, $\mathrm{Si}$ - secundária inicial, $\mathrm{St}$-secundária tardia, $\mathrm{Sb}$ - espécie típica da condição de sub-bosque e $\mathrm{Nc}$ - não classificadas. 


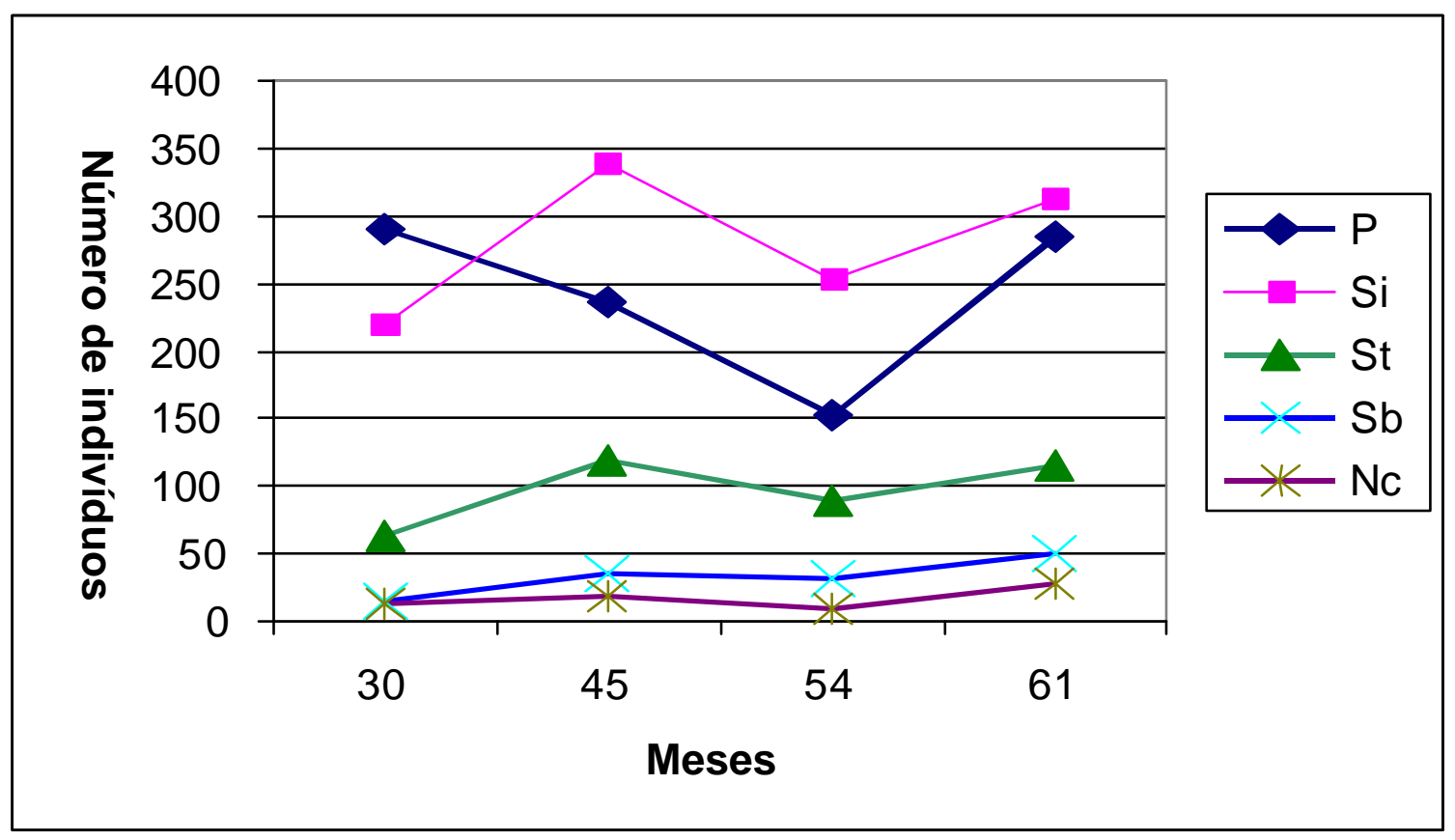

Figura 20 - Comportamento da densidade de indivíduos por categoria sucessional da regeneração natural no sub-bosque do eucalipto, $(45,54$ e 61 meses após a exploração) tendo como período inicial de análise 30 meses após a exploração da primeira rotação do povoamento de E. grandis. Tratamento 3: corte raso do povoamento de eucalipto, área amostral de 0,24ha, Itatinga - SP, onde: P - espécie pioneira, Si - secundária inicial, St -secundária tardia, $\mathrm{Sb}$ - espécie típica da condição de sub-bosque e $\mathrm{Nc}$ - não classificadas., no tratamento 3, corte raso do povoamento de E. grandis, onde: P espécie pioneira, $\mathrm{Si}$ - secundária inicial, $\mathrm{St}$-secundária tardia, $\mathrm{Sb}$ - espécie típica da condição de sub-bosque e $\mathrm{Nc}$ - não classificadas. 


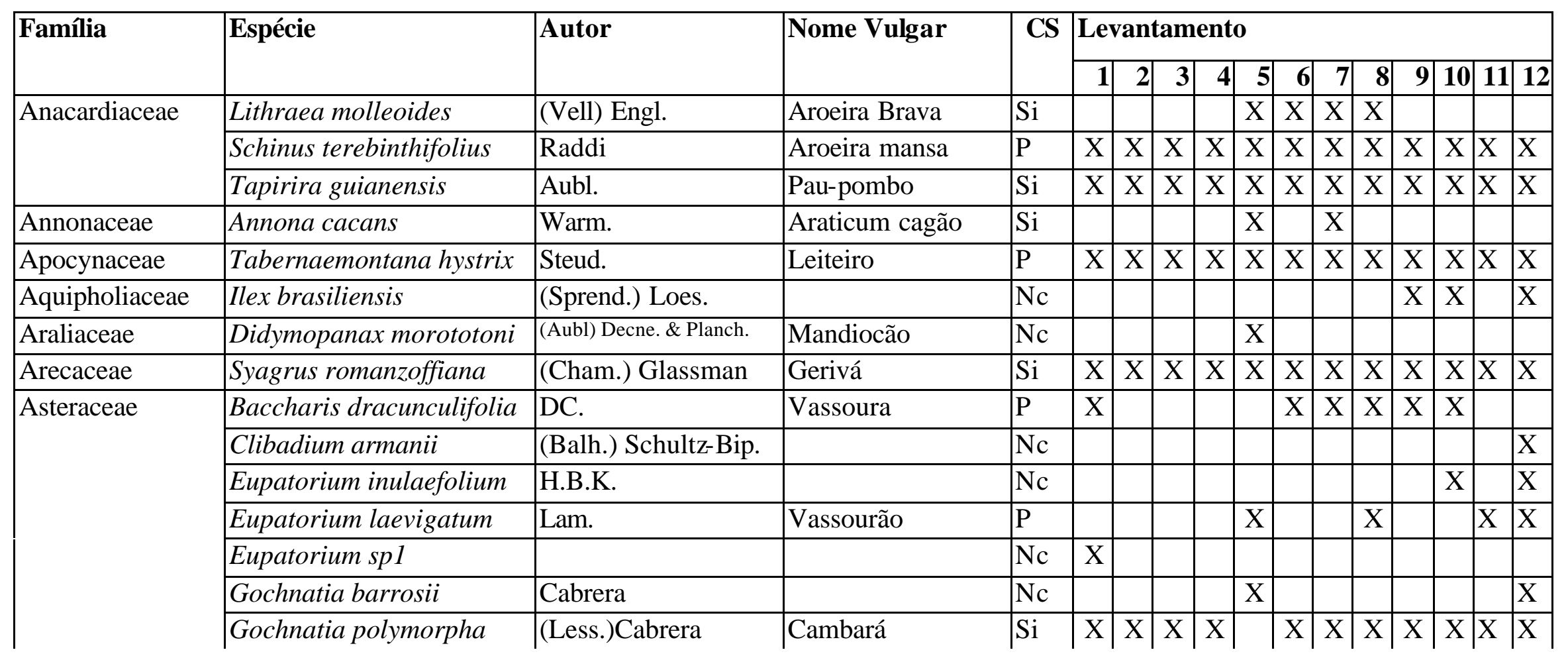

Quadro 5 - Listagem das Espécies amostradas na regeneração de espécies nativas no sub-bosque de Eucalyptus grandis, no Talhão 48, da Faz. São José do Bromado, Itatinga - SP. Com seus respectivos nomes vulgares, categorias sucessionais (CS). P-Pioneira, Si- Secundária Inicial, StSecundária Tardia, Sb- espécie característica da condição de Sub-bosque, Nc = espécie não classificada. Levantamentos: 1 (realizado 30 meses após a exploração do povoamento de eucalipto), 2 (45 meses), 3 (54 meses) e 4 (61 meses) realizados no Tratamento 1 - testemunha, no qual a cobertura florestal do eucalipto foi mantida. Levantamentos 5 (realizado 30 meses após a exploração do povoamento de eucalipto), 6 (45 meses), 7 (54 meses) e 8 (61 meses) realizados no tratamento 2 - rareamento de 50\% dos indivíduos do povoamento de E. grandis. Levantamentos 9 (realizado 30 meses após a exploração do povoamento de eucalipto), 10 (45 meses), 11 (54 meses) e 12 (61 meses) realizados no tratamento 3 corte raso do povoamento de E. grandis. Os tratamentos 2 e 3 foram implantados 46 meses após a exploração do eucalipto. 


\begin{tabular}{|c|c|c|c|c|c|c|c|c|c|c|c|c|c|c|c|}
\hline \multirow[t]{2}{*}{ Família } & \multirow[t]{2}{*}{ Espécie } & \multirow[t]{2}{*}{ Autor } & \multirow[t]{2}{*}{ Nome Vulgar } & \multicolumn{12}{|c|}{\begin{tabular}{|l|l|} 
CS & Levantamento \\
\end{tabular}} \\
\hline & & & & & & 2 & 3 & 4 & 5 & 6 & 7 & 8 & 9 & \begin{tabular}{l|l}
10 & 1
\end{tabular} & \begin{tabular}{l|l}
1 & 12 \\
1
\end{tabular} \\
\hline \multirow[t]{7}{*}{\begin{tabular}{|l} 
Asteraceae \\
\end{tabular}} & Vernonia diffusa & Less. & Cambará-açu & $\mathrm{P}$ & & & & & & & & & $\mathrm{X}$ & \begin{tabular}{l|l}
$X$ & $X$ \\
\end{tabular} & \\
\hline & \begin{tabular}{|l} 
Vernonia polyanthes \\
\end{tabular} & \begin{tabular}{|l|} 
(Spreng.) Less. \\
\end{tabular} & Assa-peixe & $\mathrm{P}$ & & & & & $\mathrm{X}$ & $\mathrm{X}$ & $\mathrm{X}$ & \begin{tabular}{l|l}
$\mathrm{X}$ & $\mathrm{y}$ \\
\end{tabular} & $\mathrm{X}$ & \begin{tabular}{l|l}
$\mathrm{X}$ & $\mathrm{X}$ \\
\end{tabular} & $\mathrm{X}$ \\
\hline & \begin{tabular}{|l} 
Vernonia scorpioides \\
\end{tabular} & (Lam.) Pres. & & $\mathrm{P}$ & & & & $\mathrm{X}$ & & & & & & & \\
\hline & Vernonia spl & & & $\mathrm{Nc}$ & & & & & & & $\mathrm{X}$ & & & & $\mathrm{X}$ \\
\hline & Vernonia sp2 & & & $\mathrm{Nc}$ & & & & & & & $\mathrm{X}$ & & & $\mathrm{X}$ & $\mathrm{X}$ \\
\hline & Vernonia sp3 & & & $\mathrm{Nc}$ & & & & & $\mathrm{X}$ & $\mathrm{X}$ & & & & & \\
\hline & Vernonia sp4 & & & $\mathrm{Nc}$ & $\mathrm{X}$ & $\mathrm{X}$ & $\mathrm{X}$ & $\mathrm{X}$ & & & & & & & \\
\hline Bignoniaceae & $\mid$ Tabebuia chrysotricha & (Mart. ex DC.) Standl. & Ipê-amarelo & $\mathrm{Si}$ & $\mathrm{X}$ & $\mathrm{X}$ & $\mathrm{X}$ & $\mathrm{X}$ & $\mathrm{X}$ & $\mathrm{X}$ & $\mathrm{X}$ & $\mathrm{X}$ & & $\mathrm{X}$ & $\mathrm{X}$ \\
\hline Bombacaceae & Chorisia speciosa & A. St.-Hil. & Paineira & $\mathrm{Si}$ & & $\mathrm{X}$ & & & & & & & & \begin{tabular}{l|l}
$X$ & $X$ \\
\end{tabular} & $\mathrm{X}$ \\
\hline \multirow[t]{4}{*}{ Caesalpiniaceae } & Bauhinia germinata & Vogel. & Pata-de-vaca & $\mathrm{Nc}$ & $\mathrm{X}$ & $\mathrm{X}$ & $\mathrm{X}$ & $\mathrm{X}$ & $\mathrm{X}$ & $\mathrm{X}$ & $\mathrm{X}$ & $\mathrm{X}$ & $\mathrm{X}$ & \begin{tabular}{l|l}
$X$ & $X$
\end{tabular} & $\mathrm{X}$ \\
\hline & Copaifera langsdorfii & Desf. & Copaíba & $\mathrm{St}$ & $\mathrm{X}$ & $\mathrm{X}$ & $\mathrm{X}$ & $\mathrm{X}$ & & & & & & & \\
\hline & Peltophorum dubium & (Spreng.)Taub. & Canafístula & $\mathrm{Si}$ & & & & & & & & & & & $\mathrm{X}$ \\
\hline & Senna bicapsulares & (Benth.)H.S.Irwin \& Barneby. & Canudo de pito & $\mathrm{Si}$ & $\mathrm{X}$ & $\mathrm{X}$ & $\mathrm{X}$ & $\mid \mathrm{X}$ & & & & & & \begin{tabular}{l|l}
$\mathrm{X}$ & $\mathrm{X}$
\end{tabular} & $\mathrm{X}$ \\
\hline
\end{tabular}

Quadro 5 - Listagem das Espécies amostradas na regeneração de espécies nativas no sub-bosque de Eucalyptus grandis, no Talhão 48, da Faz. São José do Bromado, Itatinga - SP. Com seus respectivos nomes vulgares, categorias sucessionais (CS). P-Pioneira, Si- Secundária Inicial, StSecundária Tardia, Sb- espécie característica da condição de Sub-bosque, Nc = espécie não classificada. Levantamentos: 1 (realizado 30 meses após a exploração do povoamento de eucalipto), 2 (45 meses), 3 (54 meses) e 4 (61 meses) realizados no Tratamento 1 - testemunha, no qual a cobertura florestal do eucalipto foi mantida. Levantamentos 5 (realizado 30 meses após a exploração do povoamento de eucalipto), 6 (45 meses), 7 (54 meses) e 8 (61 meses) realizados no tratamento 2 - rareamento de 50\% dos indivíduos do povoamento de E. grandis. Levantamentos 9 (realizado 30 meses após a exploração do povoamento de eucalipto), 10 (45 meses), 11 (54 meses) e 12 (61 meses) realizados no tratamento 3 corte raso do povoamento de E. grandis. Os tratamentos 2 e 3 foram implantados 46 meses após a exploração do eucalipto. 


\begin{tabular}{|c|c|c|c|c|c|c|c|c|c|c|c|c|c|c|c|c|}
\hline \multirow[t]{2}{*}{ Família } & \multirow[t]{2}{*}{ Espécie } & \multirow[t]{2}{*}{ Autor } & \multirow[t]{2}{*}{ Nome Vulgar } & \multirow[t]{2}{*}{$\mathbf{C S}$} & \multicolumn{12}{|c|}{ Levantamento } \\
\hline & & & & & 1 & 2 & 3 & 4 & 5 & 6 & 7 & 8 & 9 & 10 & 11 & 12 \\
\hline Caesalpiniaceae & Senna hirsute & (L.) H.S.Irwin \& Barbery & & $\mathrm{Nc}$ & & & & & & & & & & & & $\mathrm{X}$ \\
\hline Cecropiaceae & Cecropia pachystachya & Trécul. & Embaúba & $\mathrm{P}$ & & & & & & & & $\mathrm{X}$ & $\mathrm{X}$ & $\mathrm{X}$ & $\mathrm{X}$ & $\mathrm{X}$ \\
\hline Celastraceae & Maytenus evonymoides & Reiss. & Cafezinho & $\mathrm{St}$ & $\mathrm{X}$ & $\mathrm{X}$ & $\mathrm{X}$ & $\mathrm{X}$ & & & & & & & & \\
\hline Ebenaceae & Diospyros inconstans & Jacq. & Fruta de jacu & $\mathrm{St}$ & & & & & & & & & $\mathrm{X}$ & $\mathrm{X}$ & $\bar{X}$ & $\bar{X}$ \\
\hline \multirow[t]{5}{*}{ Euphorbiaceae } & Acalypha amblyodonta & (Mill.) Arg. & Branquilho & $\mathrm{Nc}$ & & & $\mathrm{X}$ & $\mathrm{X}$ & & & & & & & & \\
\hline & Actinostemon klotzchii & (Didr.) Pax. & Branquilho & $\mathrm{St}$ & & & & & & & $\mathrm{X}$ & & $\mathrm{X}$ & $\mathrm{X}$ & $\mathrm{X}$ & $\bar{X}$ \\
\hline & Alchornea triplinervia & (Spreng.) Müel. Arg. & Tapiá & $\mathrm{P}$ & $\mathrm{X}$ & $\mathrm{X}$ & $\mathrm{X}$ & $\mathrm{X}$ & & & & & & & & \\
\hline & Croton urucurana & Baill & Sangra d'água & $\mathrm{P}$ & & & & $\mathrm{X}$ & & & & & & & & \\
\hline & Pera glabrata & (Schott.) Bail. & Tamanqueira & $\mathrm{Si}$ & & & & & $\mathrm{X}$ & $\mathrm{X}$ & $\mathrm{X}$ & $\mathrm{X}$ & & $\mathrm{X}$ & $\mathrm{X}$ & $\bar{X}$ \\
\hline
\end{tabular}

Quadro 5 - Listagem das Espécies amostradas na regeneração de espécies nativas no sub-bosque de Eucalyptus grandis, no Talhão 48, da Faz. São José do Bromado, Itatinga - SP. Com seus respectivos nomes vulgares, categorias sucessionais (CS). P-Pioneira, Si- Secundária Inicial, StSecundária Tardia, Sb- espécie característica da condição de Sub-bosque, Nc = espécie não classificada. Levantamentos: 1 (realizado 30 meses após a exploração do povoamento de eucalipto), 2 (45 meses), 3 (54 meses) e 4 (61 meses) realizados no Tratamento 1 - testemunha, no qual a cobertura florestal do eucalipto foi mantida. Levantamentos 5 (realizado 30 meses após a exploração do povoamento de eucalipto), 6 (45 meses), 7 (54 meses) e 8 (61 meses) realizados no tratamento 2 - rareamento de 50\% dos indivíduos do povoamento de E. grandis. Levantamentos 9 (realizado 30 meses após a exploração do povoamento de eucalipto), 10 (45 meses), 11 (54 meses) e 12 (61 meses) realizados no tratamento 3 corte raso do povoamento de E. grandis. Os tratamentos 2 e 3 foram implantados 46 meses após a exploração do eucalipto. 


\begin{tabular}{|c|c|c|c|c|c|c|c|c|c|c|c|c|c|c|c|c|}
\hline \multirow[t]{2}{*}{ Família } & \multirow[t]{2}{*}{ Espécie } & \multirow[t]{2}{*}{ Autor } & \multirow[t]{2}{*}{ Nome Vulgar } & \multicolumn{13}{|c|}{\begin{tabular}{|l|l|} 
CS & Levantamento \\
\end{tabular}} \\
\hline & & & & & & 2 & 3 & 4 & 5 & & 7 & & & \begin{tabular}{l|l}
10 & 1
\end{tabular} & \begin{tabular}{l|l}
11 & 1
\end{tabular} & 12 \\
\hline \multirow[t]{10}{*}{ Fabaceae } & Acosmium subelegans & (Moblenbr.) Yakovlev. & Amendoim falso & $\mathrm{Nc}$ & & & & & & & & $\mathrm{X}$ & & & & \\
\hline & Andira anthelmia & (Vell.) J.F. Macbr. & Manguinha & $\mathrm{Si}$ & & & & $\mathrm{X}$ & $\mathrm{X}$ & $\mathrm{X}$ & $\mathrm{X}$ & $\mathrm{X}$ & $\mathrm{X}$ & $\bar{X} \mid \mathrm{X}$ & \begin{tabular}{l|l|l}
$X$ & $X$ \\
\end{tabular} & $\mathrm{X}$ \\
\hline & Desmodium discolor & Vogel. & & $\mathrm{Nc}$ & $\mathrm{X}$ & $\mathrm{X}$ & $\mathrm{X}$ & $\mathrm{X}$ & $\mathrm{X}$ & $\mathrm{X}$ & $\mathrm{X}$ & $\mathrm{X}$ & $\mathrm{X}$ & $\mathrm{X}$ & $\mathrm{X}$ & \\
\hline & Indigofera suffruticosa & Mill. & & $\mathrm{Nc}$ & & & & & & & & $\bar{X}$ & & & & \\
\hline & Machaerium acutifolium & Vogel. & Jacarandá do cerrado & $\mathrm{Si}$ & & & & & $\mathrm{X}$ & $\mathrm{X}$ & $\mathrm{X}$ & $\mathrm{X}$ & & & & \\
\hline & Macherium brasiliense & Vogel. & Mosqueteiro & $\mathrm{Si}$ & & & & & $\mathrm{X}$ & $\mathrm{X}$ & $\mathrm{X}$ & $\mathrm{X}$ & $\mathrm{X}$ & $\mathrm{X}$ & $\mathrm{X}$ & \\
\hline & Macherium nictitans & (Vell.) Benth. & Bico de pato & $\mathrm{Si}$ & & & & & & & & & $\bar{X}$ & $\mathrm{X}$ & & \\
\hline & Macherium opacum & Vogel. & Jacarandá & $\mathrm{Nc}$ & $\mathrm{X}$ & $\bar{X}$ & $\mathrm{X}$ & $\mathrm{X}$ & & & & & & \begin{tabular}{l|l}
$\mathrm{X}$ & $\mathrm{X}$ \\
\end{tabular} & \begin{tabular}{l|l}
$X$ & $X$ \\
\end{tabular} & \\
\hline & Platypodium elegans & Vogel. & Amendoim do campo & $\mathrm{Si}$ & $\mathrm{X}$ & $\mathrm{X}$ & $\mathrm{X}$ & $\mathrm{X}$ & $\mathrm{X}$ & $\bar{X}$ & $\mathrm{X}$ & $\mathrm{X}$ & & & & \\
\hline & Pterocarpus rohrii & Vahl. & & $\mathrm{Nc}$ & & & & & $\mathrm{X}$ & $\bar{X}$ & $\mathrm{X}$ & $\mathrm{X}$ & & & & \\
\hline \multirow[t]{2}{*}{ Flacourtiaceae } & Casearia decandra & Jacq. & Pau-de-espeto & $\mathrm{St}$ & $\mathrm{X}$ & & $\mathrm{X}$ & $\mathrm{X}$ & $\mathrm{X}$ & $\bar{X}$ & $\mathrm{X}$ & $\mathrm{X}$ & & & & \\
\hline & Casearia sylvestris & Sw. & Guaçatonga & $\mathrm{P}$ & $\mathrm{X}$ & $\mathrm{X}$ & $\mathrm{X}$ & $\mathrm{X}$ & $\mathrm{X}$ & $\mathrm{X}$ & $\mathrm{X}$ & $\mathrm{X}$ & $\bar{X}$ & \begin{tabular}{l|l}
$X$ & $X$ \\
$X$
\end{tabular} & \begin{tabular}{l|l}
$X$ & $X$ \\
\end{tabular} & \\
\hline Icacinaceae & Citronella paniculata & (Mart.) Howard. & & St & & & & & $\mathrm{X}$ & $\mathrm{X}$ & & & & & & \\
\hline Lacistemaceae & Lacistema hasslerianum & Choat. & & Si & & & & & & & & & & $\mathrm{X}$ & $\bar{x}$ & \\
\hline
\end{tabular}

Quadro 5 - Listagem das Espécies amostradas na regeneração de espécies nativas no sub-bosque de Eucalyptus grandis, no Talhão 48, da Faz. São José do Bromado, Itatinga - SP. Com seus respectivos nomes vulgares, categorias sucessionais (CS). P-Pioneira, Si- Secundária Inicial, StSecundária Tardia, Sb- espécie característica da condição de Sub-bosque, Nc = espécie não classificada. Levantamentos: 1 (realizado 30 meses após a exploração do povoamento de eucalipto), 2 (45 meses), 3 (54 meses) e 4 (61 meses) realizados no Tratamento 1 - testemunha, no qual a cobertura florestal do eucalipto foi mantida. Levantamentos 5 (realizado 30 meses após a exploração do povoamento de eucalipto), 6 (45 meses), 7 (54 meses) e 8 (61 meses) realizados no tratamento 2 - rareamento de 50\% dos indivíduos do povoamento de E. grandis. Levantamentos 9 (realizado 30 meses após a exploração do povoamento de eucalipto), 10 (45 meses), 11 (54 meses) e 12 (61 meses) realizados no tratamento 3 corte raso do povoamento de E. grandis. Os tratamentos 2 e 3 foram implantados 46 meses após a exploração do eucalipto. 


\begin{tabular}{|c|c|c|c|c|c|c|c|c|c|c|c|c|c|c|c|c|}
\hline \multirow[t]{2}{*}{ Família } & \multirow[t]{2}{*}{ Espécie } & \multirow[t]{2}{*}{ Autor } & \multirow[t]{2}{*}{ Nome Vulgar } & \multirow[t]{2}{*}{$\mathbf{C S}$} & \multicolumn{12}{|c|}{ Levantamento } \\
\hline & & & & & 1 & 2 & $\overline{3}$ & $\overline{4}$ & 5 & 6 & 7 & 8 & \begin{tabular}{c|}
9 \\
\end{tabular} & 10 & 11 & \begin{tabular}{|l|}
12 \\
\end{tabular} \\
\hline \multirow[t]{3}{*}{ Lauraceae } & Endlicheria paniculata & (Spreng.) J.F. Macbr. & Canelinha & St & $\mathrm{X}$ & $\mathrm{X}$ & $\mathrm{X}$ & $\mathrm{X}$ & $\mathrm{X}$ & $\mathrm{X}$ & $\mathrm{X}$ & $\mathrm{X}$ & $\mathrm{X}$ & $\mathrm{X}$ & $\mathrm{X}$ & $\mathrm{X}$ \\
\hline & Ocotea pulchella & (Nees.) Mez. & Canela lageana & $\mathrm{Si}$ & $\mathrm{X}$ & $\mathrm{X}$ & $\bar{X}$ & $\mathrm{X}$ & $\mathrm{X}$ & $\mathrm{X}$ & $\mathrm{X}$ & $\mathrm{X}$ & $\mathrm{X}$ & $\mathrm{X}$ & $\mathrm{X}$ & $\mathrm{X}$ \\
\hline & Ocotea velutina & (Nees.) Rohwer. & Canela peluda & St & $\mathrm{X}$ & $\mathrm{X}$ & $\mathrm{X}$ & $\mathrm{X}$ & $\mathrm{X}$ & $\mathrm{X}$ & $\mathrm{X}$ & $\mathrm{X}$ & $\mathrm{X}$ & $\mathrm{X}$ & $\mathrm{X}$ & $\mathrm{X}$ \\
\hline Magnoliaceae & Talauma ovata & A.St.-Hil. & Pinha do brejo & $\mathrm{Si}$ & & & & & & & & $\mathrm{X}$ & & & & \\
\hline Malpighiaceae & Byrsonima intermédia & A. Juss. & Murisi & $\mathrm{Nc}$ & & & & & & & & & & & & $\mathrm{X}$ \\
\hline Malvaceae & Sida rhombifolia & $\mathrm{L}$ & guaxuma & $\mathrm{Nc}$ & $\mathrm{X}$ & & & & $\mathrm{X}$ & $\mathrm{X}$ & & & & & & \\
\hline \multirow[t]{2}{*}{ Melastomataceae } & Leandra lacunosa & Cogn. & & $\mathrm{Nc}$ & & & & & $\mathrm{X}$ & $\mathrm{X}$ & $\mathrm{X}$ & $\mathrm{X}$ & & & & \\
\hline & Miconia langsdorfii & Cogn. & & $\mathrm{Nc}$ & $\mathrm{X}$ & $\mathrm{X}$ & $\mathrm{X}$ & $\mathrm{X}$ & & & & $\mathrm{X}$ & & $\mathrm{X}$ & $\mathrm{X}$ & $\mathrm{X}$ \\
\hline
\end{tabular}

Quadro 5 - Listagem das Espécies amostradas na regeneração de espécies nativas no sub-bosque de Eucalyptus grandis, no Talhão 48, da Faz. São José do Bromado, Itatinga - SP. Com seus respectivos nomes vulgares, categorias sucessionais (CS). P-Pioneira, Si- Secundária Inicial, StSecundária Tardia, Sb- espécie característica da condição de Sub-bosque, Nc = espécie não classificada. Levantamentos: 1 (realizado 30 meses após a exploração do povoamento de eucalipto), 2 (45 meses), 3 (54 meses) e 4 (61 meses) realizados no Tratamento 1 - testemunha, no qual a cobertura florestal do eucalipto foi mantida. Levantamentos 5 (realizado 30 meses após a exploração do povoamento de eucalipto), 6 (45 meses), 7 (54 meses) e 8 (61 meses) realizados no tratamento 2 - rareamento de 50\% dos indivíduos do povoamento de E. grandis. Levantamentos 9 (realizado 30 meses após a exploração do povoamento de eucalipto), 10 (45 meses), 11 (54 meses) e 12 (61 meses) realizados no tratamento 3 corte raso do povoamento de E. grandis. Os tratamentos 2 e 3 foram implantados 46 meses após a exploração do eucalipto. 


\begin{tabular}{|c|c|c|c|c|c|c|c|c|c|c|c|c|c|c|c|}
\hline \multirow[t]{2}{*}{ Família } & \multirow[t]{2}{*}{ Espécie } & \multirow[t]{2}{*}{ Autor } & \multirow[t]{2}{*}{ Nome Vulgar } & \multicolumn{12}{|c|}{\begin{tabular}{|l|l|} 
CS & Levantamento \\
\end{tabular}} \\
\hline & & & & & & & 3 & & & & 7 & & 9 & & $11 \mid 12$ \\
\hline \multirow{2}{*}{ Meliaceae } & Cedrela fissilis & Vell. & Cedro & $\mathrm{Si}$ & $\mathrm{X}$ & $\mathrm{X}$ & $\bar{X}$ & $\bar{X}$ & $\mathrm{X}$ & $\mathrm{X}$ & $\bar{X}$ & $\mathrm{X}$ & $\bar{X}$ & & \begin{tabular}{l|l}
$X$ \\
$X$
\end{tabular} \\
\hline & Guarea guidonia & (L.) Sleumer. & Marinheiro & $\mathrm{Si}$ & & & & & & & $\mathrm{X}$ & $\mathrm{X}$ & & & \\
\hline \multirow[t]{3}{*}{ Mimosaceae } & Acácia velutina & DC. & Arranha-gato & $\mathrm{P}$ & $\mathrm{X}$ & $\mathrm{X}$ & $\mathrm{X}$ & $\mathrm{X}$ & $\bar{X}$ & $\mathrm{X}$ & $\mathrm{X}$ & 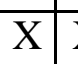 & $\mathrm{X}$ & \begin{tabular}{l|l}
$X$ & $x$ \\
\end{tabular} & \begin{tabular}{|l|l}
$\mathrm{X}$ & $\mathrm{X}$
\end{tabular} \\
\hline & Parapiptadenia rigida & (Benth.) Bernan. & Angico cedro & $\mathrm{Si}$ & $\mathrm{X}$ & $\mathrm{X}$ & $\mathrm{X}$ & $\mathrm{X}$ & $\mathrm{X}$ & $\mathrm{X}$ & $\mathrm{X}$ & $\begin{array}{ll}\mathrm{X} & 2 \\
\mathrm{n}\end{array}$ & $\mathrm{X}$ & $\mathrm{X} X$ & \begin{tabular}{l|l}
$\mathrm{X}$ & $\mathrm{X}$ \\
\end{tabular} \\
\hline & Piptadenia gonoacantha & Mart. J.F.Macbr. & Pau-jacaré & Si & & & & & & & & & $\mathrm{X}$ & \begin{tabular}{l|l}
$X$ & $x$ \\
\end{tabular} & \begin{tabular}{|l|l}
$\mathrm{X}$ & $\mathrm{X}$
\end{tabular} \\
\hline \multirow[t]{2}{*}{ Moraceae } & Chlorophora tinctoria & (L.) Glaud. & Taiúva & $\mathrm{Si}$ & & & $\mathrm{X}$ & $\mathrm{X}$ & & $\mathrm{X}$ & & & & & \\
\hline & Ficus glabra & Vell. & Figueira & St & & & & & $\mathrm{X}$ & $\mathrm{X}$ & $\mathrm{X}$ & $\mathrm{X}$ & $\bar{X}$ & $\bar{X} \mid \bar{X}$ & \begin{tabular}{l|l}
$X$ \\
$X$
\end{tabular} \\
\hline \multirow[t]{3}{*}{ Myrcinaceae } & Rapanea ferruginea & (Ruiz. \& Pav.) Mez. & Capororoca branca & $\mathrm{P}$ & $\mathrm{X}$ & $\mathrm{X}$ & $\mathrm{X}$ & $\mathrm{X}$ & $\mathrm{X}$ & $\mathrm{X}$ & $\bar{X}$ & $\mathrm{X}$ & $\bar{X}$ & $\bar{X} \mid \bar{X}$ & \begin{tabular}{l|l}
$X$ \\
$X$
\end{tabular} \\
\hline & \begin{tabular}{|l} 
Rapanea guyanensis \\
\end{tabular} & (Aubl.) & Capororoca & $\mathrm{Si}$ & & & & & $\mathrm{X}$ & $\mathrm{X}$ & $\mathrm{X}$ & $\mathrm{X}$ & $\bar{X}$ & \begin{tabular}{l|l}
$X$ & $X$ \\
\end{tabular} & \begin{tabular}{|l|l}
$X$ & $X$ \\
\end{tabular} \\
\hline & Rapanea umbellata & (Mart.) Mez. & Capororoca & $\mathrm{Si}$ & & & & & $\bar{X}$ & $\mathrm{X}$ & $\bar{X}$ & $\mathrm{X}$ & $\bar{X}$ & \begin{tabular}{l|l}
$\mathrm{X}$ & $\mathrm{X}$ \\
$\mathrm{n}$
\end{tabular} & \begin{tabular}{l|l}
$\mathrm{X}$ & $\mathrm{X}$
\end{tabular} \\
\hline \multirow[t]{5}{*}{ Myrtaceae } & Blepharocalyx salicifolius & (Kunth.) O. Berg. & Cambuí & $\mathrm{Nc}$ & $\mathrm{X}$ & $\mathrm{X}$ & $\bar{X}$ & $\mathrm{X}$ & $\mathrm{X}$ & $\mathrm{X}$ & $\mathrm{X}$ & $\mathrm{X}$ & $\bar{X}$ & $\bar{X} \mid \bar{X}$ & \\
\hline & Calyptranthes concinna & DC. & Guamirim & $\mathrm{Sb}$ & $\mathrm{X}$ & $\mathrm{X}$ & $\mathrm{X}$ & $\mathrm{X}$ & $\mathrm{X}$ & $\mathrm{X}$ & $\mathrm{X}$ & $\mathrm{X}$ & $\bar{X}$ & \begin{tabular}{l|l}
$X$ & $X$ \\
$X$
\end{tabular} & \begin{tabular}{l|l}
$X$ \\
\end{tabular} \\
\hline & Campomanesia cfpubescens & (DC.) O. Berg. & & $\mathrm{Nc}$ & & & & & $\mathrm{X}$ & $\mathrm{X}$ & $\mathrm{X}$ & $\mathrm{X}$ & & & \\
\hline & Campomanesia guaviroba & (DC.) Kiaersk. & Guaviroba & St & $\mathrm{X}$ & $\mathrm{X}$ & $\mathrm{X}$ & $\mathrm{X}$ & $\mathrm{X}$ & $\mathrm{X}$ & $\mathrm{X}$ & $\mathrm{X}$ & $\mathrm{X}$ & \begin{tabular}{l|l}
$X$ \\
$X$
\end{tabular} & \begin{tabular}{l|l}
$X$ & $X$ \\
\end{tabular} \\
\hline & Campomanesia guazumifolia & \begin{tabular}{|l} 
(Cambess.) O. Berg. \\
\end{tabular} & Capote & St & $\mathrm{X}$ & & & & $\mathrm{X}$ & $\mathrm{X}$ & & $\mathrm{X}$ & & & \\
\hline
\end{tabular}

Quadro 5 - Listagem das Espécies amostradas na regeneração de espécies nativas no sub-bosque de Eucalyptus grandis, no Talhão 48, da Faz. São José do Bromado, Itatinga - SP. Com seus respectivos nomes vulgares, categorias sucessionais (CS). P-Pioneira, Si- Secundária Inicial, StSecundária Tardia, Sb- espécie característica da condição de Sub-bosque, Nc = espécie não classificada. Levantamentos: 1 (realizado 30 meses após a exploração do povoamento de eucalipto), 2 (45 meses), 3 (54 meses) e 4 (61 meses) realizados no Tratamento 1 - testemunha, no qual a cobertura florestal do eucalipto foi mantida. Levantamentos 5 (realizado 30 meses após a exploração do povoamento de eucalipto), 6 (45 meses), 7 (54 meses) e 8 (61 meses) realizados no tratamento 2 - rareamento de 50\% dos indivíduos do povoamento de E. grandis. Levantamentos 9 (realizado 30 meses após a exploração do povoamento de eucalipto), 10 (45 meses), 11 (54 meses) e 12 (61 meses) realizados no tratamento 3 corte raso do povoamento de E. grandis. Os tratamentos 2 e 3 foram implantados 46 meses após a exploração do eucalipto 


\begin{tabular}{|c|c|c|c|c|c|c|c|c|c|c|c|c|c|c|c|c|}
\hline \multirow[t]{2}{*}{ Família } & \multirow[t]{2}{*}{ Espécie } & \multirow[t]{2}{*}{ Autor } & \multirow[t]{2}{*}{ Nome Vulgar } & \multirow[t]{2}{*}{$\mathbf{C S}$} & \multicolumn{12}{|c|}{ Levantamento } \\
\hline & & & & & 1 & 2 & 3 & 4 & 5 & 6 & 7 & 8 & 9 & 10 & 11 & 12 \\
\hline \multirow[t]{9}{*}{ Myrtaceae } & Eugenia blastantha & (O.Berg.) D. Legrand. & Cambuí d'água & $\mathrm{St}$ & & & & & & & $\mathrm{X}$ & $\mathrm{X}$ & & & & \\
\hline & Eugenia pyriformis & Cambess. & Uvaia & $\mathrm{Sb}$ & & $\mathrm{X}$ & $\mathrm{X}$ & $\mathrm{X}$ & $\mathrm{X}$ & $\mathrm{X}$ & $\mathrm{X}$ & $\mathrm{X}$ & & & & \\
\hline & Eugenia sp2 & & & $\mathrm{Nc}$ & $\mathrm{X}$ & $\mathrm{X}$ & $\mathrm{X}$ & $\mathrm{X}$ & $\mathrm{X}$ & $\mathrm{X}$ & $\mathrm{X}$ & $\mathrm{X}$ & $\mathrm{X}$ & $\mathrm{X}$ & $\mathrm{X}$ & $\mathrm{X}$ \\
\hline & Myrcia bella & Cambess. & Cambuí & $\mathrm{St}$ & $\mathrm{X}$ & $\mathrm{X}$ & $\mathrm{X}$ & $\mathrm{X}$ & $\mathrm{X}$ & $\mathrm{X}$ & $\mathrm{X}$ & $\mathrm{X}$ & & & $\mathrm{X}$ & $\mathrm{X}$ \\
\hline & Myrcia guianensis & (Aubl.) DC. & & $\mathrm{Nc}$ & & & & & $\mathrm{X}$ & $\mathrm{X}$ & $X$ & $\mathrm{X}$ & & & & \\
\hline & Myrcia laruotteana & Cambess. & Cambuí & $\mathrm{St}$ & $\mathrm{X}$ & $\mathrm{X}$ & $\mathrm{X}$ & $\mathrm{X}$ & & $\mathrm{X}$ & $\mathrm{X}$ & $\mathrm{X}$ & & $\mathrm{X}$ & $\mathrm{X}$ & $\mathrm{X}$ \\
\hline & Myrcia multiflora & (Lam.) DC. & Cambuí & $\mathrm{St}$ & $\mathrm{X}$ & $\mathrm{X}$ & $\mathrm{X}$ & $\mathrm{X}$ & $\mathrm{X}$ & $\mathrm{X}$ & $X$ & $\mathrm{X}$ & $\mathrm{X}$ & $\mathrm{X}$ & $\mathrm{X}$ & $\mathrm{X}$ \\
\hline & Myrciaria floribunda & (Vest. ex Willd.) O. Berg. & & $\mathrm{Sb}$ & & $\mathrm{X}$ & $\mathrm{X}$ & $\mathrm{X}$ & & $\mathrm{X}$ & $\mathrm{X}$ & $\mathrm{X}$ & & $\mathrm{X}$ & $\mathrm{X}$ & $\mathrm{X}$ \\
\hline & Myrtaceae spl & & & $\mathrm{Nc}$ & & & & & & & $\bar{X}$ & $\mathrm{X}$ & & & & $\mathrm{X}$ \\
\hline
\end{tabular}

Quadro 5 - Listagem das Espécies amostradas na regeneração de espécies nativas no sub-bosque de Eucalyptus grandis, no Talhão 48, da Faz. São José do Bromado, Itatinga - SP. Com seus respectivos nomes vulgares, categorias sucessionais (CS). P-Pioneira, Si- Secundária Inicial, StSecundária Tardia, Sb- espécie característica da condição de Sub-bosque, Nc = espécie não classificada. Levantamentos: 1 (realizado 30 meses após a exploração do povoamento de eucalipto), 2 (45 meses), 3 (54 meses) e 4 (61 meses) realizados no Tratamento 1 - testemunha, no qual a cobertura florestal do eucalipto foi mantida. Levantamentos 5 (realizado 30 meses após a exploração do povoamento de eucalipto), 6 (45 meses), 7 (54 meses) e 8 (61 meses) realizados no tratamento 2 - rareamento de 50\% dos indivíduos do povoamento de E. grandis. Levantamentos 9 (realizado 30 meses após a exploração do povoamento de eucalipto), 10 (45 meses), 11 (54 meses) e 12 (61 meses) realizados no tratamento 3 corte raso do povoamento de E. grandis. Os tratamentos 2 e 3 foram implantados 46 meses após a exploração do eucalipto 


\begin{tabular}{|c|c|c|c|c|c|c|c|c|c|c|c|c|c|c|c|c|}
\hline \multirow[t]{2}{*}{ Família } & \multirow[t]{2}{*}{ Espécie } & \multirow[t]{2}{*}{ Autor } & \multirow[t]{2}{*}{ Nome Vulgar } & \multicolumn{13}{|c|}{\begin{tabular}{|l|l|} 
CS & Levantamento
\end{tabular}} \\
\hline & & & & & 1 & 2 & 3 & 4 & 5 & & 7 & & 9 & \begin{tabular}{l|l}
10 & 1 \\
10
\end{tabular} & & 12 \\
\hline Myrtaceae & Psydium cinereum & Mart. ex DC & & $\mathrm{Nc}$ & & & & $\mathrm{X}$ & & & & & & & & \\
\hline \multirow[t]{3}{*}{ Piperaceae } & Piper aduncum & L. & Jaborandi & $\mathrm{Sb}$ & & & & & $\mathrm{X}$ & $\mathrm{X}$ & $\mathrm{X}$ & $\mathrm{X}$ & $\mathrm{X}$ & $\mathrm{X} \mid \mathrm{X}$ & \begin{tabular}{l|l}
$X$ & $X$ \\
\end{tabular} & $\bar{X}$ \\
\hline & Piper amalago & L. & Jaborandi & $\mathrm{Sb}$ & & & & & $\mathrm{X}$ & $\mathrm{X}$ & $\mathrm{X}$ & $\mathrm{X}$ & $\mathrm{X}$ & $\mathrm{X}$ & & \\
\hline & Piper gaudichaudianum & Kunth. & Jaborandi & $\mathrm{Sb}$ & $\mathrm{X}$ & $\mathrm{X}$ & $\mathrm{X}$ & $\mathrm{X}$ & & $\mathrm{X}$ & $\mathrm{X}$ & $\mathrm{X}$ & $\mathrm{X}$ & $\mathrm{X} \mid \mathrm{X}$ & \begin{tabular}{l|l}
$X$ & $X$ \\
\end{tabular} & $\bar{X}$ \\
\hline Rhamnaceae & Rhamnus shaerosperma & Sw. & & $\mathrm{Si}$ & $\mathrm{X}$ & $\mathrm{X}$ & $\mathrm{X}$ & $\mathrm{X}$ & $\mathrm{X}$ & $\mathrm{X}$ & $\mathrm{X}$ & $\mathrm{X}$ & $\mathrm{X}$ & \begin{tabular}{l|l}
$X$ \\
$X$
\end{tabular} & \begin{tabular}{l|l}
$X$ & $X$ \\
\end{tabular} & $\bar{X}$ \\
\hline Rosaceae & Prunus myrtifolia & (L.) Urb. & Pessegueiro bravo & $\mathrm{Si}$ & & & & & & $\mathrm{X}$ & $\mathrm{X}$ & $\mathrm{X}$ & $\mathrm{X}$ & $\mathrm{X} \mid \mathrm{X}$ & \begin{tabular}{l|l}
$X$ & $X$ \\
\end{tabular} & $\bar{X}$ \\
\hline \multirow[t]{8}{*}{ Rubiaceae } & Amaioua guianensis & Aubl. & Marmelada brava & $\mathrm{Si}$ & & & & & & & & & & $\mathrm{X} \mid \mathrm{X}$ & \begin{tabular}{l|l}
$X$ & $X$ \\
\end{tabular} & $\bar{X}$ \\
\hline & Chomelia obtusa & Cham. \& Schltdl. & & $\mathrm{Sb}$ & & & & & $\mathrm{X}$ & $\mathrm{X}$ & $\mathrm{X}$ & $\mathrm{X}$ & & $\mathrm{X}$ & & $\mathrm{X}$ \\
\hline & Chomelia pohliana & Müel. & & $\mathrm{Nc}$ & $\mathrm{X}$ & $\mathrm{X}$ & $\mathrm{X}$ & $\mathrm{X}$ & & & & & $\mathrm{X}$ & \begin{tabular}{l|l}
$X$ & $X$ \\
\end{tabular} & $\bar{X}$ & \\
\hline & Coutarea hexandra & (Jacq.) K. Schum. & Quina & $\mathrm{Sb}$ & $\mathrm{X}$ & $\mathrm{X}$ & $\mathrm{X}$ & $\mathrm{X}$ & & & & & & & & \\
\hline & Ixora venulosa & Benth. & & $\mathrm{Sb}$ & & & $\mathrm{X}$ & $\mathrm{X}$ & & $\bar{X}$ & $\mathrm{X}$ & $\mathrm{X}$ & & & & \\
\hline & Psychotria carthaginensis & Jacq. & Pau de Maria & $\mathrm{Sb}$ & & $\mathrm{X}$ & $\mathrm{X}$ & $\mathrm{X}$ & $\mathrm{X}$ & $\mathrm{X}$ & $\mathrm{X}$ & $\mathrm{X}$ & $\mathrm{X}$ & $\mathrm{X} \mid \mathrm{X}$ & \begin{tabular}{l|l}
$\mathrm{X}$ & $\mathrm{x}$ \\
\end{tabular} & $\bar{X}$ \\
\hline & Psychotria sessilis & (Vell.) Müel. Arg. & & St & & & & & & $\mathrm{X}$ & & & & & & \\
\hline & Randia armata & (Sw.) DC. & Limão bravo & $\mathrm{Sb}$ & & & & & $\mathrm{X}$ & $\mathrm{X}$ & $\mathrm{X}$ & $\mathrm{X}$ & & & & \\
\hline
\end{tabular}

Quadro 5 - Listagem das Espécies amostradas na regeneração de espécies nativas no sub-bosque de Eucalyptus grandis, no Talhão 48, da Faz. São José do Bromado, Itatinga - SP. Com seus respectivos nomes vulgares, categorias sucessionais (CS). P-Pioneira, Si- Secundária Inicial, StSecundária Tardia, Sb- espécie característica da condição de Sub-bosque, Nc = espécie não classificada. Levantamentos: 1 (realizado 30 meses após a exploração do povoamento de eucalipto), 2 (45 meses), 3 (54 meses) e 4 (61 meses) realizados no Tratamento 1 - testemunha, no qual a cobertura florestal do eucalipto foi mantida. Levantamentos 5 (realizado 30 meses após a exploração do povoamento de eucalipto), 6 (45 meses), 7 (54 meses) e 8 (61 meses) realizados no tratamento 2 - rareamento de 50\% dos indivíduos do povoamento de E. grandis. Levantamentos 9 (realizado 30 meses após a exploração do povoamento de eucalipto), 10 (45 meses), 11 (54 meses) e 12 (61 meses) realizados no tratamento 3 corte raso do povoamento de $E$. grandis. Os tratamentos 2 e 3 foram implantados 46 meses após a exploração do eucalipto 


\begin{tabular}{|c|c|c|c|c|c|c|c|c|c|c|c|c|c|c|c|c|}
\hline \multirow[t]{2}{*}{ Família } & \multirow[t]{2}{*}{ Espécie } & \multirow[t]{2}{*}{ Autor } & \multirow[t]{2}{*}{ Nome Vulgar } & \multicolumn{13}{|c|}{\begin{tabular}{|l|l|} 
CS & Levantamento
\end{tabular}} \\
\hline & & & & & & 2 & 3 & 4 & & & 7 & & 9 & & & 12 \\
\hline \multirow[t]{4}{*}{ Rutaceae } & Citrus limon & Burn. & Limão bravo & $\mathrm{Si}$ & $\mathrm{X}$ & $\mathrm{X}$ & $\mathrm{X}$ & $\mathrm{X}$ & & & & & $\mathrm{X}$ & $\mathrm{X}$ & \begin{tabular}{l|l}
$X$ & $X$ \\
\end{tabular} & $\bar{X}$ \\
\hline & Esenbeckia febrifuga & (A St Hill) A.Juss ex Mart. & Mamoninha & $\mathrm{Sb}$ & & & & & $\mathrm{X}$ & $\mathrm{X}$ & $\mathrm{X}$ & $\mathrm{X}$ & $\mathrm{X}$ & $\mathrm{X}$ & \begin{tabular}{l|l}
$X$ & $X$ \\
\end{tabular} & $\bar{X}$ \\
\hline & Helietta apiculata & Benth. & Amarelinho & $\mathrm{Nc}$ & $\mathrm{X}$ & $\mathrm{X}$ & $\mathrm{X}$ & $\mathrm{X}$ & $\mathrm{X}$ & & & & $\mathrm{X}$ & $\mathrm{X}$ & \begin{tabular}{l|l}
$X$ & $X$ \\
\end{tabular} & $\bar{X}$ \\
\hline & Zanthoxylum rhoifolium & Lam. & Mamica de porca & $\mathrm{Si}$ & $\mathrm{X}$ & $\mathrm{X}$ & $\mathrm{X}$ & $\mathrm{X}$ & $\mathrm{X}$ & $\mathrm{X}$ & $\mathrm{X}$ & $\mathrm{X}$ & $\mathrm{X}$ & $\mathrm{X}$ & \begin{tabular}{l|l}
$X$ & $X$ \\
\end{tabular} & $\bar{X}$ \\
\hline \multirow[t]{3}{*}{ Sapindaceae } & Allophyllus edulis & (St. Hill.) Radlk. & Fruta de pombo & $\mathrm{P}$ & $\mathrm{X}$ & $\mathrm{X}$ & $\mathrm{X}$ & $\mathrm{X}$ & $\mathrm{X}$ & $\mathrm{X}$ & $\mathrm{X}$ & $\mathrm{X}$ & $\mathrm{X}$ & $\mathrm{X}$ & \begin{tabular}{l|l}
$X$ & $X$ \\
\end{tabular} & $\bar{X}$ \\
\hline & Cupania vernalis & Camb. & Pau de Cantil & $\mathrm{Si}$ & $\mathrm{X}$ & $\mathrm{X}$ & $\mathrm{X}$ & $\mathrm{X}$ & & $\mathrm{X}$ & & & $\mathrm{X}$ & $\left.\mathrm{X}\right|_{2} \quad a^{2}$ & \begin{tabular}{l|l}
$X$ & $X$ \\
\end{tabular} & $\bar{X}$ \\
\hline & Matayba eleagnoides & Radlk. & Camboatã branco & $\mathrm{Si}$ & $\mathrm{X}$ & $\mathrm{X}$ & $\mathrm{X}$ & $\mathrm{X}$ & $\mathrm{X}$ & $\mathrm{X}$ & $\mathrm{X}$ & $\mathrm{X}$ & $\bar{X}$ & $\left.\bar{X}\right|_{2}$ & \begin{tabular}{l|l}
$X$ & $X$ \\
\end{tabular} & $\bar{X}$ \\
\hline Simaroubaceae & Picramnia sellowii & Planch. & & $\mathrm{Nc}$ & & & & & $\mathrm{X}$ & $\mathrm{X}$ & $\mathrm{X}$ & $\mathrm{X}$ & & & & \\
\hline \multirow[t]{6}{*}{ Solanaceae } & Acnistus cauliflorus & Aff. & & $\mathrm{P}$ & & & & & $\mathrm{X}$ & $\mathrm{X}$ & $\mathrm{X}$ & $\mathrm{X}$ & & & & \\
\hline & Cestrum sendtnerianum & Mart. ex Sendtn. & & $\mathrm{Nc}$ & $\mathrm{X}$ & & & & & $\mathrm{X}$ & $\mathrm{X}$ & $\mathrm{X}$ & $\mathrm{X}$ & $\mathrm{X}$ & & $\bar{X}$ \\
\hline & Cestrum spl & & & $\mathrm{Nc}$ & $\mathrm{X}$ & $\mathrm{X}$ & $\mathrm{X}$ & $\mathrm{X}$ & & & & & & & & \\
\hline & Solanum bullatum & Vell. & Capoeira branca & $\mathrm{P}$ & $\mathrm{X}$ & $\mathrm{X}$ & $\mathrm{X}$ & $\mathrm{X}$ & & & & & & & \begin{tabular}{l|l}
$X$ & $X$ \\
\end{tabular} & $\bar{X}$ \\
\hline & \begin{tabular}{|l} 
Solanum granuloso-leprosum \\
\end{tabular} & Dunal. & Fumo Bravo & $\mathrm{P}$ & $\mathrm{X}$ & & & & & & $\mathrm{X}$ & $\mathrm{X}$ & & & & $\mathrm{X}$ \\
\hline & Solanum mauritianum & Scop. & & $\mathrm{Nc}$ & & & & & & & & & & $\mathrm{X}$ & & $\bar{X}$ \\
\hline
\end{tabular}

Quadro 5 - Listagem das Espécies amostradas na regeneração de espécies nativas no sub-bosque de Eucalyptus grandis, no Talhão 48, da Faz. São José do Bromado, Itatinga - SP. Com seus respectivos nomes vulgares, categorias sucessionais (CS). P-Pioneira, Si- Secundária Inicial, StSecundária Tardia, Sb- espécie característica da condição de Sub-bosque, Nc = espécie não classificada. Levantamentos: 1 (realizado 30 meses após a exploração do povoamento de eucalipto), 2 (45 meses), 3 (54 meses) e 4 (61 meses) realizados no Tratamento 1 - testemunha, no qual a cobertura florestal do eucalipto foi mantida. Levantamentos 5 (realizado 30 meses após a exploração do povoamento de eucalipto), 6 (45 meses), 7 (54 meses) e 8 (61 meses) realizados no tratamento 2 - rareamento de 50\% dos indivíduos do povoamento de E. grandis. Levantamentos 9 (realizado 30 meses após a exploração do povoamento de eucalipto), 10 (45 meses), 11 (54 meses) e 12 (61 meses) realizados no tratamento 3 corte raso do povoamento de E. grandis. Os tratamentos 2 e 3 foram implantados 46 meses após a exploração do eucalipto 


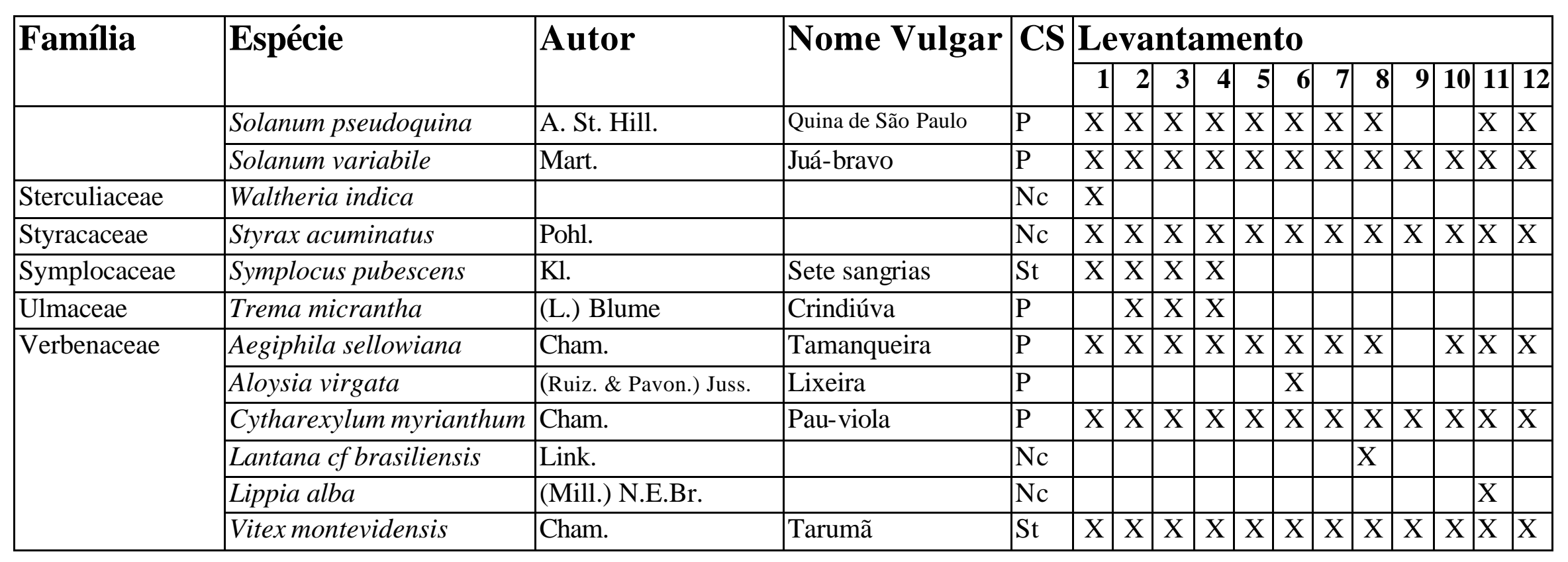

Quadro 5 - Listagem das Espécies amostradas na regeneração de espécies nativas no sub-bosque de Eucalyptus grandis, no Talhão 48, da Faz. São José do Bromado, Itatinga - SP. Com seus respectivos nomes vulgares, categorias sucessionais (CS). P-Pioneira, SiSecundária Inicial, St- Secundária Tardia, Sb- espécie característica da condição de Sub-bosque, Nc = espécie não classificada. Levantamentos: 1 (realizado 30 meses após a exploração do povoamento de eucalipto), 2 (45 meses), 3 (54 meses) e 4 (61 meses) realizados no Tratamento 1 - testemunha, no qual a cobertura florestal do eucalipto foi mantida. Levantamentos 5 (realizado 30 meses após a exploração do povoamento de eucalipto), 6 (45 meses), 7 (54 meses) e 8 (61 meses) realizados no tratamento 2 - rareamento de $50 \%$ dos indivíduos do povoamento de E. grandis. Levantamentos 9 (realizado 30 meses após a exploração do povoamento de eucalipto), 10 (45 meses), 11 (54 meses) e 12 (61 meses) realizados no tratamento 3 - corte raso do povoamento de E. grandis. Os tratamentos 2 e 3 foram implantados 46 meses após a exploração do eucalipto 


\subsubsection{Comparação entre os tratamentos}

A Tabela 7 apresenta a variação temporal dos parâmetros utilizados na comparação entre os tratamentos nos diversos levantamentos.

O impacto do manejo do povoamento de E. grandis na regeneração pode ser notada através da sua influência na taxa de mortalidade nos tratamentos 2 (desbaste de $50 \%$ do povoamento de eucalipto) e 3 (corte raso do povoamento) que atingiu picos de $62 \%$ e $125 \%$ respectivamente no levantamento realizado após a implantação dos tratamentos.

Tabela 7. Evolução de alguns parâmetros da regeneração nos três tratamentos realizados no povoamento de $E$. grandis. Tratamento 1 : Testemunha, Tratamento 2 - desbaste de $50 \%$ do povoamento de E. grandis, Tratamento 3 - corte raso do eucalipto., Município de Itatinga - SP. O primeiro levantamento ocorreu 30 meses após a exploração da primeira rotação do eucalipto; $2^{\circ}$ - segundo levantamento (45 meses); $3^{\circ}$ - terceiro levantamento (54 meses) e $4^{\circ}$ - quarto levantamento (61 meses). Os tratamentos foram implantados após o segundo levantamento.

\begin{tabular}{llllllllll}
\hline & \multicolumn{3}{l}{ Testemunha } & \multicolumn{4}{c}{ Tratamento 2 } & \multicolumn{3}{c}{ Tratamento 3 } \\
\hline & $2^{\circ}$ & $3^{\circ}$ & $4^{\circ}$ & $2^{\circ}$ & $3^{\circ}$ & $4^{\circ}$ & $2^{\circ}$ & $3^{\circ}$ & $4^{\circ}$ \\
Taxas de mortalidade \% & 23,65 & 15,81 & 11,04 & 28,72 & 62,41 & 19,06 & 16,20 & 125,4 & 19,15 \\
Taxas de recrutamento \% & 36,42 & 31,02 & 44,24 & 35,06 & 6,75 & 36,84 & 42,50 & 6,77 & 60,43 \\
Crescimento \% & 32,2 & 15,01 & 23,05 & 24,08 & $-0,28$ & 48,03 & 51,78 & $-0,52$ & 102,3 \\
Riqueza de espécies & 66 & 71 & 77 & 78 & 79 & 86 & 78 & 70 & 81 \\
Altura média & 2.34 & 2.37 & 2.44 & 2.28 & 2.34 & 2.36 & 2.28 & 2.23 & 2.26 \\
H' espécies & 3.008 & 3.027 & 3.088 & 3.324 & 3.359 & 3.526 & 3.442 & 3.397 & 3.549 \\
\hline
\end{tabular}


$\mathrm{O}$ tratamento que apresentou as taxas de mortalidade mais baixas, como era esperado, foi o testemunha, é importante ressaltar o fato deste índice se manter em queda neste tratamento, isto indica que as condições de sombreamento impostas pelo plantio de E. grandis foram severas demais para as espécies pioneiras que ocupavam a área inicialmente, causando uma acentuada mortalidade desses indivíduos no início do experimento (entre o primeiro e segundo levantamentos).

A taxa de recrutamento também sofreu influência das operações da colheita, apresentando baixas taxas logo após o desbaste de $50 \%$ ou corte raso do eucalipto. Como já foi colocado, isto ocorreu em função de dois fatores, o primeiro foi o dano físico direto às plântulas e indivíduos jovens pelas operações de corte e remoção da madeira do talhão. O segundo, o grande acúmulo de restos vegetais no solo, que se tornou uma barreira física para a germinação de sementes e rebrota dos indivíduos amostrados.

No entanto, como resposta às mudanças ambientais no sub-bosque percebe-se um aumento nas taxas de recrutamento, concentrada nas classes de espécies pioneiras e não classificadas sucessionalmente. Outro fator que parece influenciar o comportamento do recrutamento foi a acentuada brotação de indivíduos que haviam sido danificados na exploração do talhão. Esta estratégia de regeneração já foi constatada em áreas de fragmentos florestais submetidos à ação do fogo por Rodrigues (1999), e apresentou grande importância na reocupação das áreas exploradas neste experimento.

A taxa de crescimento apresenta comportamento similar a taxa de recrutamento, apresentando índice de crescimento negativo no levantamento posterior a exploração florestal e picos de crescimento no quarto levantamento, as causas desse comportamento foram discutidas anteriormente.

As mudanças ambientais e o impacto da implantação dos tratamentos causaram respostas diferenciadas nos grupos formados pelas classes sucessionais. Para o grupo formado pelas espécies secundárias iniciais, tardias e típicas da condição de sub-bosque a supressão da cobertura florestal (Tratamentos 2 e 3) causou diminuição nas taxas de recrutamento e aumento das taxas de mortalidade quando comparadas a situação anterior a implantação dos tratamentos (segundo levantamento - 45 meses). No tratamento 
testemunha estes grupos apresentaram queda na mortalidade no período e, a partir do segundo levantamento, queda na taxa de recrutamento.

O grupo formado por espécies pioneiras e não classificadas sucessionalmente foi beneficiado pelas mudanças ambientais, apresentando aumento das taxas de recrutamento nos levantamentos realizados após a implantação dos tratamentos. O tratamento testemunha apresentava a tendência de diminuição do recrutamentos de espécies destes grupos no período.

Em relação à riqueza de espécies, o tratamento que apresentou o maior ingresso de espécies no período foi o testemunha, este resultado não era esperado uma vez que a abertura do dossel propiciou um maior número de nichos para as espécies nos demais tratamentos podendo se esperar, portanto, que os maiores ingressos de espécies na área ocorressem nestes tratamentos. O fator que parece ter modificado esta lógica foi a colonização por espécies herbáceas agressivas, principalmente gramíneas, nos tratamentos 2 e 3 , a presença desse extrato pode estar se constituindo em uma barreira física para o recrutamento de novas espécies na área

Em relação à diversidade, é interessante o comportamento do tratamento 2 (desbaste de $50 \%$ dos indivíduos do povoamento de eucalipto), neste caso o índice H' apresentou crescimento em todos os levantamentos.

$\mathrm{Na}$ comparação entre os tratamentos fica evidente a influência do manejo adotado na área sobre a dinâmica de ocupação de espécies nativas no sub-bosque do povoamento de eucalipto. Estas diferenças são determinadas pela substituição de espécies, por taxas de recrutamento e mortalidade diferenciadas para cada classe sucessional em cada tratamento, resultando, provavelmente, em comunidades finais com características florísticas e estruturais distintas. 


\section{CONCLUSÕES}

A análise conjunta dos resultados demonstra que vem ocorrendo um intenso processo de sucessão secundária no sub-bosque talhão de E.grandis no dossel. São evidências desse fato:

- a densidade e diversidade de indivíduos de espécies nativas amostrados na regeneração;

. a presença de espécies com baixa densidade de indivíduos e o recrutamento constante de novas espécies no período;

- a presença de taxas de recrutamento e mortalidade diferenciadas para cada classe sucessional, indicando o substituição de espécies iniciais por finais do processo de sucessão.

Os parâmetros analisados demonstram o recrutamento de espécies pioneiras e invasoras na fase inicial de desenvolvimento do eucalipto, esta fase se prolonga até o fechamento das copas do povoamento. A partir desse momento, as condições ambientais no piso do talhão (notadamente o aumento do sombreamento) passam a beneficiar o desenvolvimento de espécies secundárias iniciais, tardias e típicas da condição de subbosque em detrimento de espécies pioneiras.

Desta maneira e pode-se concluir que, estando o povoamento de Eucalyptus spp próximo de alguma fonte de propágulos, é viável a condução da regeneração natural no sub-bosque de povoamentos comercias com o objetivo de restaurar a vegetação natural. Os três tratamentos analisados mostraram do ponto de vista da regeneração condições para realizar a revegetação da área através da condução da regeneração natural. 
Um fator importante na escolha da ação a ser realizado no povoamento de eucalipto é um planejamento adequado nas operações de colheita florestal. Realizandoas de maneira a minimizar os danos aos indivíduos da regeneração, e portanto, contribuindo para que o processo de recuperação da área ocorra de maneira mais intensa, mais rápida e portanto com maior sucesso. 


\section{REFERÊNCIAS BIBLIOGRAFICAS}

ALMEIDA, A.F.; ALVES, J.E.M.; MENDES FILHO, J.M. Manutenção do sub-bosque em floresta de Eucalyptus urophylla e a distribuição regular de porta-iscas, visando o controle preventivo de saúvas (Atta spp). In: CONGRESSO FLORESTAL BRASILEIRO, 4., Belo Horizonte, 1982. Anais. Belo Horizonte: s.ed., 1982. p.139-141.

BARROS, P.L.C. Estudo fitossociológico de uma floresta tropical úmida no planalto de Curuá-Una, Amazônia brasileira. Curitiba: UFPR, 1986, 148p. Tese (Doutorado) Universidade Federal do Paraná.

BERNACCI, L.C.; LEITÃO FILHO, H.F. Flora fanerógama da floresta da fazenda São Vicente, Campinas, SP. Revista Brasileira de Botânica, v.19, p. 153-168, 1996.

BORGES, H.B.; ENGEL, V.L. Influência de fragmentos de vegetação nativa na composição do banco de sementes de povoamentos implantados de eucalipto. In: CONGRESSO FLORESTAL PANEMERICANO, 1.; CONGRESSO FLORESTAL BRASILEIRO, 7.,Curitiba, 1993. Anais. Curitiba: SBS,SBEF, 1993. p.434-437.

BUDOWISK, G. Distribution of tropical American rain forest species in the light sucessional processes. Turrialba, v. 15, n. 1, p. 40-42, 1965 
CALEGARIO, N.; SOUZA, A.L. de; MARANGON, L.C.; SILVA, A.F. da. Estimativa dos parâmetros de distribuição e de associação de espécies vegetais nativas regeneradas no sub-bosque de Eucalyptus, no município de Belo Oriente, MG. Revista Árvore, v. 17, n. 2, p. 146-161, $1993 \mathrm{a}$.

CALEGARIO, N.; SOUZA, A.L. de; MARANGON, L.C.; SILVA, A.F. da. Parâmetros florísticos e fitossociológicos da regeneração natural de espécies arbóreas nativas no sub-bosque de povoamentos de Eucalyptus. Revista Árvore, v. 17, n. 1, p. 16-29, $1993 b$.

DESLOW, J. S. Gap partioning among tropical rainforest trees. Biotropica. v.12, p.47$55,1980$.

DESLOW, J. S. Tropical rainforest gaps and tree species diversity. Annual Review of Ecology and Systematics, v. 18, p.431-451, 1987.

DURIGAN, G.; FRANCO, G.A.D.C.; PASTORE, J.A.; AGUIAR, O.T.de. Regeneração natural da vegetação de cerrado sob floresta de Eucalyptus citriodora. Revista do Instituto Florestal, v. 9, n.1, p.71-85, 1997.

EMPRESA BRASILEIRA DE PESQUISA AGROPECUÁRIA. Sistema brasileiro de classificação de solos. Brasília: Embrapa Produção de Informação, 1999. 412p.

FUNDAÇÃO SOS MATA ATLÂNTICA, INSTITUTO NACIONAL DE PESQUISAS ESPACIAIS. Evolução dos remanescentes florestais e ecossistemas associados no domínio da mata atlântica no período 1985-1900. Relatório. São Paulo, 1993. 
GABRIEL, E.M.N. Florística e fitossociologia do estrato arbóreo em áreas de ocorrência de floresta mesófila semidecídua em diferentes estágios sucessionais no Município de Bofete, SP. Rio Claro, 1996. 210p. Tese (Doutorado) - Instituto de Ciências Biológicas, Universidade Estadual Paulista "Julio de Mesquita Filho".

GANDOLFI, S. Estudo florístico e fitossociológico de uma floresta residual na área do aeroporto internacional de São Paulo, município de Guarulhos, SP. Campinas, 1991. 230p. Dissertação (Mestrado) - Instituto de Biologia, Universidade de Campinas

GANDOLFI, S. História de uma floresta estacional semidecidual no município de Campinas (São Paulo, Brasil). Campinas, 2000. 520p. Tese (Doutorado) - Instituto de Biologia - Universidade de Campinas.

GANDOLFI, S.; LEITÃO FILHO, H.F.; BEZERRA, C.L.F. Levantamento florístico e caráter sucessional das espécies arbóreas de uma floresta semidecídua no município de Guarullhos. Revista Brasileira de Biologia, v.5, n. 4, p. 753-767, 1995.

GÓMEZ-POMPA, A; WHITMORE, T.C.; HADLEY, M. Rain forest regeneration and management. Paris:Unesco, 1991. 457p.

IVANAUSKAS, N.M.; RODRIGUES, R.R.; NAVE, A.G. Fitossociologia de um trecho de floresta estacional semidecidual em Itatinga, São Paulo. Scientia Florestalis, n.56, p 83-99, dez. 1999.

LEITÃO FILHO, H.F. Considerações sobre florística de floresta tropicais e subtropicais do Brasil, IPEF, n. 45, p. 41-56, 1987.

LIMA, W. P. O impacto ambiental do eucalipto. 2 ed. São Paulo: EDUSP, 1996. $301 \mathrm{p}$. 
KAGEYAMA, P.Y.; CASTRO, C.F. A. Sucessão secundária, estrutura genética e plantações de espécies arbóreas nativas. IPEF, n. 41/42, p.83-93, 1989.

KAGEYAMA, P. Y.; GANDARA, F.B. Recuperação de áreas ciliares. In: RODRIGUES, R.R.; LEITÃO FILHO, H.F. Matas ciliares: conservação e recuperação. São Paulo. EDUSP, 2000. p. 249-269.

KAGEYAMA, P.Y.; GANDARA, F.B.; SOUZA, L.M.I. Consequiências genéticas da fragmentação sobre populações de espécies arbóreas. Série Técnica IPEF,. v.12, n.32, p. 65-70, dez. 1998.

LOMBARDI, J.A.; MOTTA JÚNIOR, J.C. Levantamento do sub-bosque de um reflorestamento monoespecífico de Pinus elliottii em relação as síndromes de dispersão. Turrialba, v.42, n.4, p. 438-442, 1992.

MARTINS, F.R. Estrutura de uma floresta mesófila. 2.ed. Campinas: Ed. Unicamp, 1993. 246p.

MÜELLER-DAMBOIS, D.; ELLEBERG, H. Aims and methods in vegetation ecology. New York: Jonh Willey, 1974. 547p.

NAVE, A G.; RODRIGUES, R.R.; GALDONFI, S. Planejamento e recuperação ambiental da faz. São Pedro da Mata, Riolândia, SP. Piracicaba, 1995. 50p. (Relatório Técnico)

NAVE.A.G.; CARNEIRO, P.H.M.e; RODRIGUES, R.R; GAMDOLFI, S.. Estudo de impacto ambiental para o centro tecnológico de resíduos município de Caieras, SP - análise da vegetação. Piracicaba, 1998. 104p. (Relatório Técnico). 
OLDEMAN, R.A.A. Dynamics in tropical rain forest. In: HOLM.-NILESEN, L.B; J.C. NIELSEN; BALSLEN, H. (Ed). Tropical forest, botanics dynamics, speciation and diversity. London: Academic Press, 1989. p 3-21.

PICKETT, S.T.A.; OSTFELD, R.S. The shifting paradigm in ecology. In: KNIGHT; R.L.; BATES, S.F.(Ed). A new century for natural resources management. Washington: Island Press, 1995. p 261-278.

PICKETT, S.T.A.; WITHER, P.S. (Ed) The ecology of natural disturbance and paths dynamics. Orlando: Academic Press, 1985. p 3-13: Natural disturbance and paths dynamics: a introduction..

PICKETT, S.T.A.; PARKER, V.T.; FIEDLER, P. The new paradigm in ecology: implications for conservation biology above the species level. In: FIEDLER, P; JAIN, S. Conservation biology: the theory and practice of nature conservation, preservation and management. New York: Springer-Verlag,1992. p.65-88.

POGGIANI, F.; SIMÕES, J.L. Influência das espécies usadas no reflorestamento e a proximidade de um fragmento florestal na regeneração do Sub-bosque em áreas degradadas pela mineração. In: CONGRESSO FLORESTAL PANEMERICANO, 1.; CONGRESSO FLORESTAL BRASILEIRO, 7, Curitiba, 1993. Anais. Curitiba: SBS,SBEF, 1993. p.50-54.

REZENDE, L.M.; VALE, A B.; SOUZA, A L.; REIS, M.G.F.; SILVA, A F.; NEVES,

J.C.L. Regeneração natural de espécies florestais nativas em sub-bosque de Eucalyptus grandis e em mata secundária no município de Viçosa, Zona da Mata, MG. In: SIMPÓSIO SUL-AMERICANO, 1., SIMPÓSIO NACIONAL DE RECUPERAÇÃO DE ÁREAS DEGRADADAS, 2, Curitiba, 1994. Anais . Curitiba: FUPEF, 1994. p. 409-418 
RODRIGUES, R.R. Colonização e enriquecimento de um fragmento florestal urbano após a ocorrência de fogo. Fazenda Santa Elisa, Campinas, SP: Avaliação temporal da regeneração natural (66 meses) e do crescimento (51 meses) de 30 espécies florestais plantadas em consórcios sucessionais. Piracicaba, 1999. Tese (Livre Docência) - Escola Superior de Agricultura Luiz de Queiroz, Universidade de são Paulo.

RODRIGUES, R.R.; GANDOLFI, S. Recomposição de florestas nativas: princípios gerais e subsídios para uma definição metodológica. Revista Brasileira de Horticultura Ornamental, v.2, n.1, p. 4-15, 1996.

ROLIM, S.G.; NASCIMENTO, H. E. M. Análise da riqueza, diversidade e relação espécie-abundância de uma comunidade arbórea tropical em diferentes intensidades amostrais. Scientia Florestales, n.52. p. 7-16, dez. 1997.

SCHLITTLER, F.H.M. Composição florística e estrutura fitossociológica do subbosque de uma plantação de Eucalyptus tereticornis Sm., no município de Rio Claro, SP. Rio Claro, 1984. Dissertação (Mestrado) - Instituto de Biociências, Universidade Estadual Paulista "Julio de Mesquita Filho".

SHEPHERD, G.J. FITOPAC: manual do usuário. Campinas: Universidade de Campinas, Departamento de Botânica, 1995. 72p.

SWAINE, M.D.; LIEBERMAN, D. Note on the calculation of mortality rates. Journal of Tropical Ecology, v.3, p. ii-iii, 1987.

TABARELLI, M.; VILLANI, J.P.; MANTOVANI, W. A recuperação da floresta atlântica sob plantios de Eucalyptus no núcleo Santa Virgínia, SP. Revista do Instituto Florestal, v. 5, n.2, p. 182-201,. 1993. 
TALORA, D.C. Levantamento fitossociológico de duas comunidades de sub-bosque em diferentes estágios de regeneração no Horto florestal "Navarro de Andrade", Município de Rio Claro - SP. Rio Claro, 1992. 143p. Monografia (Graduação) Instituto de Biociências , Universidade Estadual Paulista "Julio de Mesquita Filho".

WHITMORE, T.C. On pattern and process in forests. In: NEWMAN, E.I. The plant community as a working mechanim. Oxford: Blackwell, 1982. p.45-59. 


\section{APÊNDICES}




\begin{tabular}{|c|c|c|c|c|c|c|c|c|c|}
\hline especie & $\begin{array}{l}\text { No } \\
\text { Ind }\end{array}$ & $\begin{array}{l}\text { No } \\
\text { Amo }\end{array}$ & $\begin{array}{c}\text { Dens. } \\
\text { Re }\end{array}$ & $\begin{array}{c}\text { Freq. } \\
\text { Re }\end{array}$ & $\begin{array}{c}\text { Freq. } \\
\text { Ab }\end{array}$ & $\begin{array}{c}\text { Dens } \\
\text { Ab }\end{array}$ & $\begin{array}{l}\text { Alt } \\
\text { Min }\end{array}$ & $\begin{array}{l}\text { Alt } \\
\operatorname{Max}\end{array}$ & $\begin{array}{l}\text { Alt } \\
\text { Med }\end{array}$ \\
\hline$\ldots \ldots$ & 307 & 17 & 16.16 & 3.5 & 10 & 4 & 1.5 & 4.5 & 2.0 \\
\hline Matayba elaeagnoides.......... & 184 & 17 & 9.68 & 3.50 & 100.0 & 270.6 & 1.5 & 3.5 & 1.9 \\
\hline Casearia sylvestris........... & 142 & 17 & 7.47 & 3.50 & 100.0 & 208.8 & 1.5 & 3.3 & 2.0 \\
\hline Acacia velutina.............. & 137 & 8 & 7.21 & 1.65 & 47.06 & 201.5 & 1.5 & 5.0 & 2.3 \\
\hline Campomanesia guaviroba........ & 83 & 10 & 4.37 & 2.06 & 58.82 & 122.1 & 1.5 & 3.0 & 1.9 \\
\hline Esenbeckia febrifuga.......... & 81 & 4 & 4.26 & 0.82 & 23.53 & 119.1 & 1.5 & 3.5 & 2.3 \\
\hline Rapanea umbellata........... & 64 & 9 & 3.37 & 1.85 & 52.94 & 94.1 & 1.5 & 5.0 & 2.3 \\
\hline Tabernaemontana hystrix....... & 56 & 9 & 2.95 & 1.85 & 52.94 & 82.4 & 1.5 & 3.5 & 2.0 \\
\hline Parapiptadenia rigida......... & 54 & 10 & 2.84 & 2.06 & 58.82 & 79.4 & 1.5 & 7.0 & 3.7 \\
\hline Gochnatia polymorpha.......... & 46 & 14 & 2.42 & 2.88 & 82.35 & 67.6 & 1.5 & 3.1 & 2.1 \\
\hline Baccharis dracunculifolia..... & 46 & 13 & 2.42 & 2.67 & 76.47 & 01.0 & 1.5 & 5.0 & 2.4 \\
\hline Ocotea pulchella............. & 41 & 14 & 2.16 & 2.88 & 82.35 & 60.3 & 1.5 & 5.0 & 2.4 \\
\hline Ocotea puberula............. & 40 & 13 & 2.11 & 2.67 & 76.47 & 58.8 & 1.5 & 4.5 & 2.3 \\
\hline Schinus terebinthifolius...... & 35 & 14 & 1.84 & 2.88 & 82.35 & 51.5 & 1.6 & 7.0 & 2.6 \\
\hline Zanthoxylum rhoifolium....... & 29 & 14 & 1.53 & 2.88 & 82.35 & 42.6 & 1.5 & 4.1 & 2.2 \\
\hline Cupania vernalis............. & 40 & 7 & 2.11 & 1.44 & 41.18 & 58.8 & 1.5 & 3.0 & 1.8 \\
\hline Sebastiania brasiliensis...... & 36 & 8 & 1.89 & 1.65 & 47.06 & 52.9 & 1.5 & 4.0 & 2.5 \\
\hline Cytharexylum myrianthum....... & 27 & 10 & 1.42 & 2.06 & 58.82 & 39.7 & 1.5 & 4.5 & 2.3 \\
\hline Myrcia multiflora............ & 22 & 11 & 1.16 & 2.26 & 64.71 & 32.4 & 1.5 & 3.0 & 1.8 \\
\hline Rapanea ferruginea............ & 21 & 10 & 1.11 & 2.06 & 58.82 & 30.9 & 1.5 & 5.6 & 2.5 \\
\hline Desmodium discolor........... & 18 & 11 & 0.95 & 2.26 & 64.71 & 26.5 & 1.6 & 3.0 & 2.2 \\
\hline Miconia ligustroides.......... & 17 & 11 & 0.89 & 2.26 & 64.71 & 25.0 & 1.5 & 3.2 & 1.8 \\
\hline Cedrela fissilis............ & 21 & 8 & 1.11 & 1.65 & 47.06 & 30.9 & 1.5 & 6.0 & 2.6 \\
\hline Syagrus romanzoffiana......... & 18 & 9 & 0.95 & 1.85 & 52.94 & 26.5 & 1.5 & 4.0 & 2.6 \\
\hline Rhamnus shaerosperma......... & 18 & 7 & 0.95 & 1.44 & 41.18 & 26.5 & 1.5 & 3.5 & 2.6 \\
\hline Tapirira guianensis.......... & 14 & 9 & 0.74 & 1.85 & 52.94 & 20.6 & 1.5 & 3.0 & 2.1 \\
\hline styrax acuminatus........... & 14 & 8 & 0.74 & 1.65 & 47.06 & 20.6 & 1.6 & 4.0 & 2.6 \\
\hline Allophyllus edulis............ & 10 & 9 & 0.53 & 1.85 & 52.94 & 14.7 & 1.5 & 2.5 & 1.8 \\
\hline Campomanesia guazumifolia..... & 16 & 5 & 0.84 & 1.03 & 29.41 & 23.5 & 1.5 & 2.6 & 2.0 \\
\hline Platypodium elegans. & 13 & 6 & 0.68 & 1.23 & 35.29 & 19.1 & 1.9 & 5.0 & 3.5 \\
\hline
\end{tabular}

Quadro 3 - Parâmetros fitossociológicos encontrados para as espécies amostradas no sub-bosque de E. grandis (talhão 48), 30 meses após a exploração da primeira rotação do eucalipto, área amostral de 0,68 ha, onde: $\mathrm{N}^{\circ}$. Ind. - Número de Indivíduos; $\mathrm{N}^{\circ}$ Amo - Número de unidades amostrais em que a espécie foi amostrada; Dens.re - Densidade relativa da espécie; Freq. Rel Frequência relativa da espécie; Freq $\mathrm{Ab}$ - Frequência absoluta da espécie; Dens $\mathrm{Ab}$ - Densidade abusoluta da espécie; Alt Min- altura mínima amostrada na espécie; Alt Max - Altura máxima amostrada na espécie e Alt Med - Altura média apresentada pela espécie. 


\begin{tabular}{|c|c|c|c|c|c|c|c|c|c|}
\hline especie & $\begin{array}{l}\text { No } \\
\text { Ind }\end{array}$ & $\begin{array}{l}\text { No } \\
\text { Amo }\end{array}$ & $\begin{array}{c}\text { Dens. } \\
\text { Re }\end{array}$ & $\begin{array}{c}\text { Freq. } \\
\operatorname{Re}\end{array}$ & $\begin{array}{c}\text { Freq. } \\
\text { Ab }\end{array}$ & $\begin{array}{c}\text { Dens. } \\
\text { Ab }\end{array}$ & $\begin{array}{l}\text { Alt } \\
\text { Min }\end{array}$ & $\begin{array}{l}\text { Alt } \\
\operatorname{Max}\end{array}$ & $\begin{array}{l}\text { Alt } \\
\text { Med }\end{array}$ \\
\hline Bauhinia germinata........... & 11 & 6 & 0.58 & 1.23 & 35.29 & 16.2 & 1.6 & 3.0 & 2.1 \\
\hline 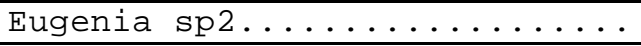 & 11 & 6 & 0.58 & 1.23 & 35.29 & 16.2 & 1.5 & 3.0 & 2.0 \\
\hline Myrcia laruotteana........... & 11 & 5 & 0.58 & 1.03 & 29.41 & 16.2 & 1.5 & 2.8 & 1.8 \\
\hline $\begin{array}{l}\text { Eugenia hiemalis............ } \\
\text { Strychnos brasiliensis....... }\end{array}$ & $\begin{array}{l}8 \\
9\end{array}$ & $\begin{array}{l}6 \\
5\end{array}$ & $\begin{array}{l}0.42 \\
0.47\end{array}$ & $\begin{array}{l}1.23 \\
1.03\end{array}$ & $\begin{array}{l}35.29 \\
29.41\end{array}$ & $\begin{array}{l}11.8 \\
13.2\end{array}$ & $\begin{array}{l}1.6 \\
1.5\end{array}$ & $\begin{array}{l}2.0 \\
2.5\end{array}$ & $\begin{array}{l}1.7 \\
1.7\end{array}$ \\
\hline Calyptranthes concinna........ & 6 & 6 & 0.32 & 1.23 & 35.29 & 8.8 & 1.5 & 2.2 & 1.8 \\
\hline Piper gaudichaudianum......... & 8 & 4 & 0.42 & 0.82 & 23.53 & 11.8 & 1.5 & 2.7 & 2.0 \\
\hline Prunus myrtifolia............ & 8 & 4 & 0.42 & 0.82 & 23.53 & 11.8 & 1.8 & 6.0 & 3.3 \\
\hline Endlicheria paniculata........ & 6 & 5 & 0.32 & 1.03 & 29.41 & 8.8 & 1.6 & 5.0 & 2.6 \\
\hline Rapanea guyanensis............ & 6 & 5 & 0.32 & 1.03 & 29.41 & 8.8 & 1.5 & 2.0 & 1.7 \\
\hline Aegiphila sellowiana......... & 6 & 5 & 0.32 & 1.03 & 29.41 & 8.8 & 1.5 & 4.2 & 2.8 \\
\hline Casearia decandra............. & 9 & 3 & 0.47 & 0.62 & 17.65 & 13.2 & 1.6 & 4.0 & 2.4 \\
\hline Vitex montevidensis........... & 7 & 4 & 0.37 & 0.82 & 23.53 & 10.3 & 1.7 & 2.5 & 1.9 \\
\hline Cestrum sendtnerianum...... & 6 & 4 & 0.32 & 0.82 & 23.53 & 8.8 & 2.0 & 4.0 & 2.5 \\
\hline Helietta apiculata........... & 6 & 4 & 0.32 & 0.82 & 23.53 & 8.8 & 1.6 & 2.8 & 2.2 \\
\hline 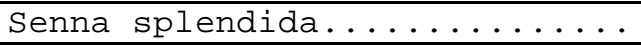 & 5 & 4 & 0.26 & 0.82 & 23.53 & 7.4 & 1.5 & 2.5 & 1.8 \\
\hline Vernonia polyanthes........... & 4 & 4 & 0.21 & 0.82 & 23.53 & 5.9 & 1.7 & 2.3 & 2.0 \\
\hline Solanum pseudoquina........... & 4 & 4 & 0.21 & 0.82 & 23.53 & 5.9 & 1.8 & 5.5 & 2.9 \\
\hline Citrus limon................ & 4 & 4 & 0.21 & 0.82 & 23.53 & 5.9 & 1.6 & 2.5 & 2.0 \\
\hline Senna bicapsulares............ & 4 & 4 & 0.21 & 0.82 & 23.53 & 5.9 & 1.5 & 4.0 & 3.0 \\
\hline Tabebuia chrysotricha......... & 5 & 3 & 0.26 & 0.62 & 17.65 & 7.4 & 1.5 & 2.0 & 1.7 \\
\hline Sebastiania klotzchiana....... & 6 & 2 & 0.32 & 0.41 & 11.76 & 8.8 & 1.6 & 4.5 & 2.3 \\
\hline Andira anthelmia............ & 4 & 3 & 0.21 & 0.62 & 17.65 & 5.9 & 1.6 & 2.5 & 2.1 \\
\hline Blepharocalyx salicifolius.... & 4 & 3 & 0.21 & 0.62 & 17.65 & 5.9 & 1.5 & 2.5 & 1.9 \\
\hline Ocotea velutina............... & 4 & 3 & 0.21 & 0.62 & 17.65 & 5.9 & 2.2 & 3.5 & 2.8 \\
\hline Chomelia pohliana............ & 4 & 3 & 0.21 & 0.62 & 17.65 & 5.9 & 1.7 & 2.4 & 2.0 \\
\hline 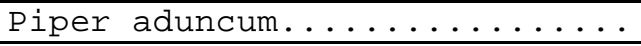 & 4 & 3 & 0.21 & 0.62 & 17.65 & 5.9 & 1.7 & 2.9 & 2.2 \\
\hline Myrtaceae sp2......... & 4 & 3 & 0.21 & 0.62 & 17.65 & 5.9 & 1.5 & 2.0 & 1.7 \\
\hline 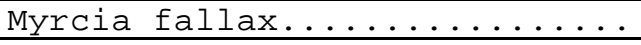 & 4 & 3 & 0.21 & 0.62 & 17.65 & 5.9 & 1.8 & 2.5 & 2.2 \\
\hline 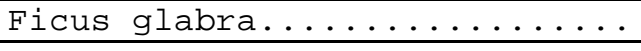 & 3 & 3 & 0.16 & 0.62 & 17.65 & 4.4 & 2.1 & 3.0 & 2.5 \\
\hline 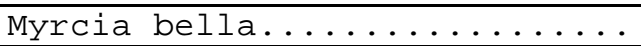 & 3 & 3 & 0.16 & 0.62 & 17.65 & 4.4 & 1.6 & 3.4 & 2.2 \\
\hline Sida rhombifolia............ & 3 & 2 & 0.16 & 0.41 & 11.76 & 4.4 & 1.6 & 2.5 & 2.0 \\
\hline Acnistus cauliflorus......... & 3 & 2 & 0.16 & 0.41 & 11.76 & 4.4 & 2.0 & 4.0 & 2.8 \\
\hline
\end{tabular}

Quadro 3 - Parâmetros fitossociológicos encontrados para as espécies amostradas no sub-bosque de E. grandis (talhão 48), 30 meses após a exploração da primeira rotação do eucalipto, área amostral de 0,68 ha, onde: №. Ind. - Número de Indivíduos; № Amo - Número de unidades amostrais em que a espécie foi amostrada; Dens.re - Densidade relativa da espécie; Freq. Rel Frequência relativa da espécie; Freq Ab - Frequência absoluta da espécie; Dens Ab - Densidade abusoluta da espécie; Alt Min- altura mínima amostrada na espécie; Alt Max - Altura máxima amostrada na espécie e Alt Med - Altura média apresentada pela espécie. 


\begin{abstract}
Estrutura da Regeneração de Espécies Nativas no Sub-bosque de Plantios de E. grandis

No No Dens. Freq. Freq. Dens. Alt Alt Alt

especie

Ind Amo Re

$\mathrm{Re}$

$\mathrm{Ab}$

Ab Min Max Med
\end{abstract}

\begin{tabular}{|c|c|c|c|c|c|c|c|c|c|}
\hline Ilex brasiliensis........... & 3 & 2 & 0.16 & 0.41 & 11.76 & 4.4 & 1.8 & 2.5 & 2.0 \\
\hline Psychotria carthaginensis..... & 3 & 2 & 0.16 & 0.41 & 11.76 & 4.4 & 1.5 & 1.8 & 1.6 \\
\hline Actinostemon klotzchii....... & 4 & 1 & 0.21 & 0.21 & 5.88 & 5.9 & 1.9 & 3.0 & 2.4 \\
\hline Solanum granuloso-leprosum.... & 2 & 2 & 0.11 & 0.41 & 11.76 & 2.9 & 1.7 & 2.0 & 1.9 \\
\hline 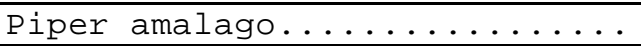 & 2 & 2 & 0.11 & 0.41 & 11.76 & 2.9 & 1.5 & 3.0 & 2.3 \\
\hline Machaerium brasiliense...... & 2 & 2 & 0.11 & 0.41 & 11.76 & 2.9 & 2.5 & 6.0 & 4.3 \\
\hline 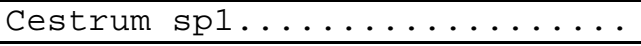 & 3 & 1 & 0.16 & 0.21 & 5.88 & 4.4 & 1.6 & 2.4 & 2.0 \\
\hline Diospyros inconstans......... & 2 & 1 & 0.11 & 0.21 & 5.88 & 2.9 & 1.5 & 1.7 & 1.6 \\
\hline Leandra lacunosa............. & 2 & 1 & 0.11 & 0.21 & 5.88 & 2.9 & 1.7 & 1.8 & 1.8 \\
\hline Solanum bullatum............ & 2 & 1 & 0.11 & 0.21 & 5.88 & 2.9 & 2.8 & 4.0 & 3.4 \\
\hline Picramnia sellowii........... & 2 & 1 & 0.11 & 0.21 & 5.88 & 2.9 & 2.0 & 2.0 & 2.0 \\
\hline Machaerium opacum............ & 2 & 1 & 0.11 & 0.21 & 5.88 & 2.9 & 2.3 & 3.0 & 2.7 \\
\hline Machaerium acutifolium........ & 2 & 1 & 0.11 & 0.21 & 5.88 & 2.9 & 1.7 & 2.4 & 2.1 \\
\hline 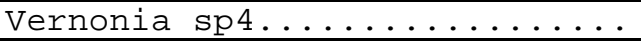 & 2 & 1 & 0.11 & 0.21 & 5.88 & 2.9 & 2.0 & 2.2 & 2.1 \\
\hline Campomanesia cf pubescens..... & 1 & 1 & 0.05 & 0.21 & 5.88 & 1.5 & 1.5 & 1.5 & 1.5 \\
\hline 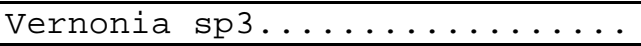 & 1 & 1 & 0.05 & 0.21 & 5.88 & 1.5 & 2.0 & 2.0 & 2.0 \\
\hline 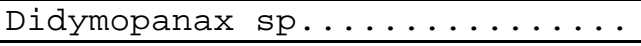 & 1 & 1 & 0.05 & 0.21 & 5.88 & 1.5 & 1.5 & 1.5 & 1.5 \\
\hline Piptadenia gonoacantha........ & 1 & 1 & 0.05 & 0.21 & 5.88 & 1.5 & 4.0 & 4.0 & 4.0 \\
\hline 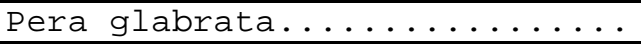 & 1 & 1 & 0.05 & 0.21 & 5.88 & 1.5 & 2.0 & 2.0 & 2.0 \\
\hline Lacistema hasslerianum........ & 1 & 1 & 0.05 & 0.21 & 5.88 & 1.5 & 3.0 & 3.0 & 3.0 \\
\hline Alchornea triplinervia........ & 1 & 1 & 0.05 & 0.21 & 5.88 & 1.5 & 2.0 & 2.0 & 2.0 \\
\hline Vernonia diffusa............. & 1 & 1 & 0.05 & 0.21 & 5.88 & 1.5 & 1.9 & 1.9 & 1.9 \\
\hline Symplocus pubescens........... & 1 & 1 & 0.05 & 0.21 & 5.88 & 1.5 & 3.5 & 3.5 & 3.5 \\
\hline 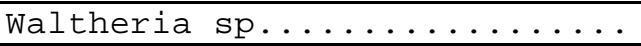 & 1 & 1 & 0.05 & 0.21 & 5.88 & 1.5 & 1.8 & 1.8 & 1.8 \\
\hline Miconia langsdorffii......... & 1 & 1 & 0.05 & 0.21 & 5.88 & 1.5 & 1.6 & 1.6 & 1.6 \\
\hline Vernonia cf eriolepis......... & 1 & 1 & 0.05 & 0.21 & 5.88 & 1.5 & 1.7 & 1.7 & 1.7 \\
\hline Maytenus evonymoidis......... & 1 & 1 & 0.05 & 0.21 & 5.88 & 1.5 & 2.3 & 2.3 & 2.3 \\
\hline Ocotea velloziana............. & 1 & 1 & 0.05 & 0.21 & 5.88 & 1.5 & 2.7 & 2.7 & 2.7 \\
\hline Cecropia pachystachya......... & 1 & 1 & 0.05 & 0.21 & 5.88 & 1.5 & 2.7 & 2.7 & 2.7 \\
\hline 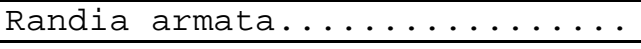 & 1 & 1 & 0.05 & 0.21 & 5.88 & 1.5 & 2.7 & 2.7 & 2.7 \\
\hline Coutarea hexandra............ & 1 & 1 & 0.05 & 0.21 & 5.88 & 1.5 & 1.9 & 1.9 & 1.9 \\
\hline
\end{tabular}

Quadro 3 - Parâmetros fitossociológicos encontrados para as espécies amostradas no sub-bosque de E. grandis (talhão 48), 30 meses após a exploração da primeira rotação do eucalipto, área amostral de 0,68 ha, onde: $\mathrm{N}^{\circ}$. Ind. - Número de Indivíduos; № Amo - Número de unidades amostrais em que a espécie foi amostrada; Dens.re - Densidade relativa da espécie; Freq. Rel Frequência relativa da espécie; Freq Ab - Frequência absoluta da espécie; Dens Ab - Densidade abusoluta da espécie; Alt Min- altura mínima amostrada na espécie; Alt Max - Altura máxima amostrada na espécie e Alt Med - Altura média apresentada pela espécie. 


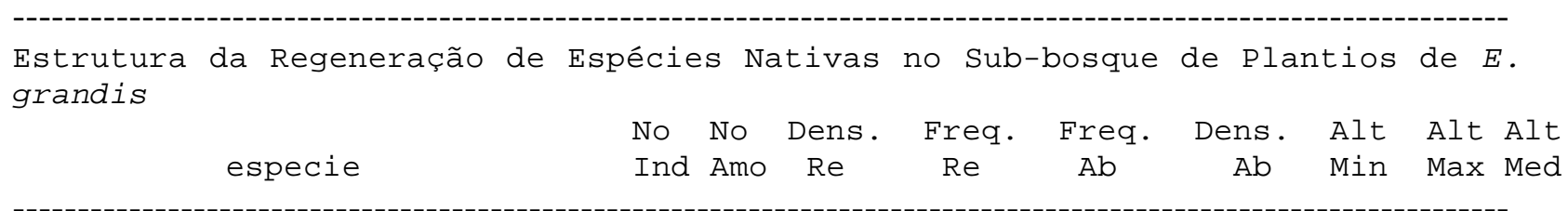

\begin{tabular}{|c|c|c|c|c|c|c|c|c|c|}
\hline Citronella paniculata......... & 1 & 1 & 0.05 & 0.21 & 5.88 & 1.5 & 1.6 & 1.6 & 1.6 \\
\hline Euphatorium sp1.............. & 1 & 1 & 0.05 & 0.21 & 5.88 & 1.5 & 1.6 & 1.6 & 1.6 \\
\hline Chomelia obtusa............ & 1 & 1 & 0.05 & 0.21 & 5.88 & 1.5 & 2.0 & 2.0 & 2.0 \\
\hline Copaifera langsdorffii........ & 1 & 1 & 0.05 & 0.21 & 5.88 & 1.5 & 2.2 & 2.2 & 2.2 \\
\hline Pterocarpus rohrii........... & 1 & 1 & 0.05 & 0.21 & 5.88 & 1.5 & 2.5 & 2.5 & 2.5 \\
\hline Myrcia guianensis............ & 1 & 1 & 0.05 & 0.21 & 5.88 & 1.5 & 2.1 & 2.1 & 2.1 \\
\hline Machaerium nictitans......... & 1 & 1 & 0.05 & 0.21 & 5.88 & 1.5 & 1.7 & 1.7 & 1.7 \\
\hline Eugenia pyriformis........... & 1 & 1 & 0.05 & 0.21 & 5.88 & 1.5 & 1.6 & 1.6 & 1.6 \\
\hline Annona cacans............... & 1 & 1 & 0.05 & 0.21 & 5.88 & 1.5 & 2.2 & 2.2 & 2.2 \\
\hline Lithraea molleoides........... & 1 & 1 & 0.05 & 0.21 & 5.88 & 1.5 & 2.1 & 2.1 & 2.1 \\
\hline
\end{tabular}

Quadro 3 - Parâmetros fitossociológicos encontrados para as espécies amostradas no sub-bosque de E. grandis (talhão 48), 30 meses após a exploração da primeira rotação do eucalipto, área amostral de 0,68 ha, onde: $\mathrm{N}^{\circ}$. Ind. - Número de Indivíduos; $\mathrm{N}^{\circ}$ Amo - Número de unidades amostrais em que a espécie foi amostrada; Dens.re - Densidade relativa da espécie; Freq. Rel Frequência relativa da espécie; Freq Ab - Frequência absoluta da espécie; Dens Ab - Densidade abusoluta da espécie; Alt Min- altura mínima amostrada na espécie; Alt Max - Altura máxima amostrada na espécie e Alt Med - Altura média apresentada pela espécie. 


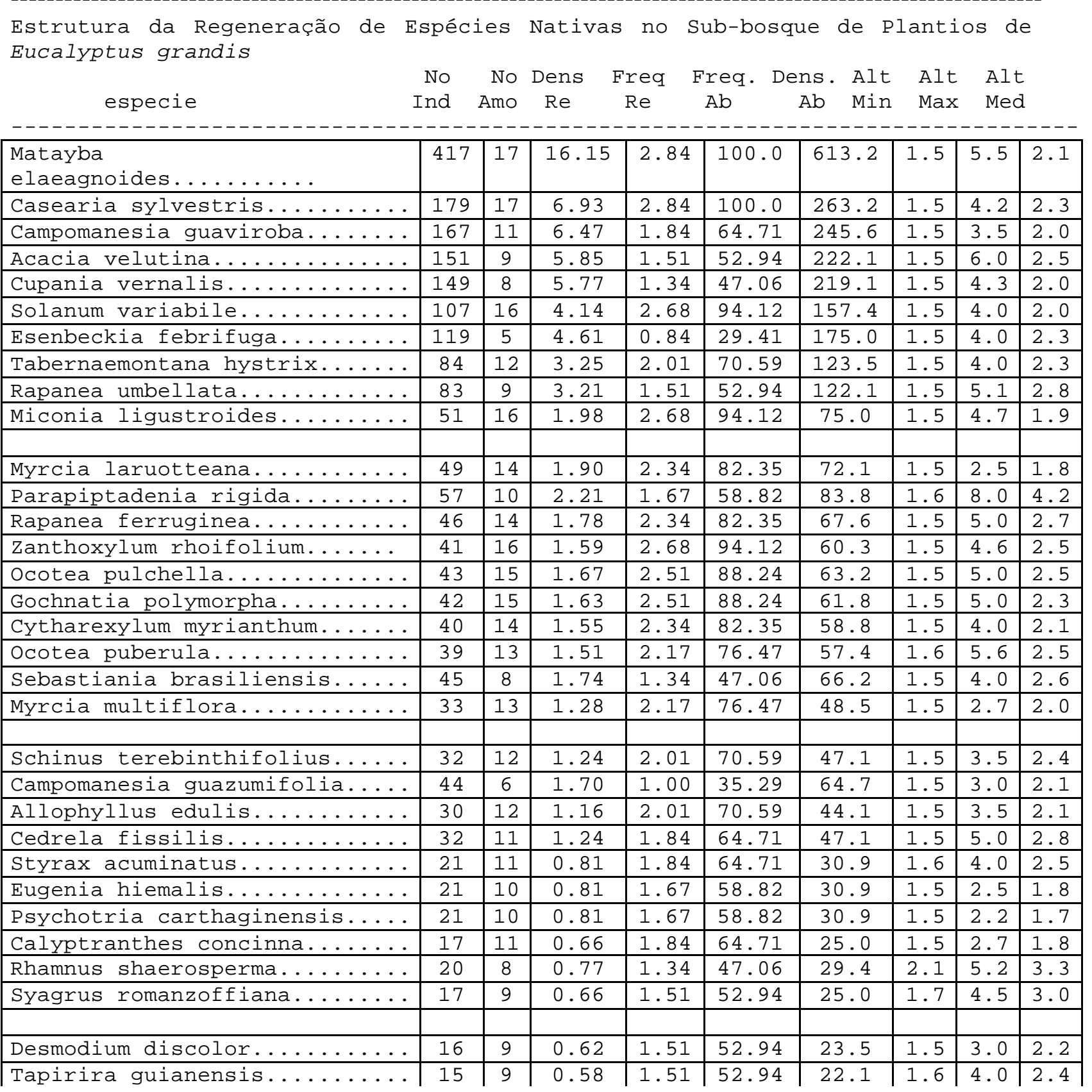

Quadro 4 - Parâmetros fitossociológicos encontrados para as espécies amostradas no sub-bosque de E. grandis (talhão 48), 45 meses após o corte da primeira rotação do povoamento de eucalipto, área amostral 0,72ha, onde: № Ind. - Número de Indivíduos; No Amo - Número de unidades amostrais em que a espécie foi amostrada; Dens.re - Densidade relativa da espécie; Freq. Rel - Frequência relativa da espécie; Freq Ab - Frequência absoluta da espécie; Dens Ab Densidade abusoluta da espécie; Alt Min- altura mínima amostrada na espécie; Alt Max Altura máxima amostrada na espécie e Alt Med - Altura média apresentada pela espécie. 
Estrutura da Regeneração de Espécies Nativas no Sub-bosque de Plantios de Eucalyptus grandis

$\begin{array}{rrrrrrr} & \text { No } & \text { No Dens } & \text { Freq } & \text { Freq. Dens. Alt Alt Alt } \\ \text { especie } & \text { Ind } & \text { Amo } & \text { Re } & \text { Re } & \text { Ab } & \text { Ab Min Max Med }\end{array}$

\begin{tabular}{|c|c|c|c|c|c|c|c|c|c|}
\hline Bauhinia germinata........... & 15 & 9 & 0.58 & 1.51 & 52.94 & 22.1 & 1.7 & 3.0 & 2.3 \\
\hline Myrtaceae sp2......... & 14 & 9 & 0.54 & 1.51 & 52.94 & 20.6 & 1.5 & 2.5 & 1.7 \\
\hline Myrciaria floribunda.......... & 14 & 9 & 0.54 & 1.51 & 52.94 & 20.6 & 1.5 & 2.0 & 1.7 \\
\hline Piper gaudichaudianum......... & 18 & 7 & 0.70 & 1.17 & 41.18 & 26.5 & 1.5 & 2.6 & 2.0 \\
\hline Rapanea guyanensis........... & 13 & 8 & 0.50 & 1.34 & 47.06 & 19.1 & 1.5 & 2.9 & 1.9 \\
\hline Tabebuia chrysotricha.......... & 11 & 8 & 0.43 & 1.34 & 47.06 & 16.2 & 1.5 & 2.5 & 1.7 \\
\hline Prunus myrtifolia............ & 13 & 7 & 0.50 & 1.17 & 41.18 & 19.1 & 2.0 & 6.2 & 3.6 \\
\hline Solanum pseudoquina.......... & 10 & 8 & 0.39 & 1.34 & 47.06 & 14.7 & 1.5 & 2.5 & 1.9 \\
\hline Vitex montevidensis........... & 14 & 6 & 0.54 & 1.00 & 35.29 & 20.6 & 1.5 & 3.0 & 2.1 \\
\hline 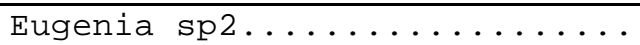 & 11 & 7 & 0.43 & 1.17 & 41.18 & 16.2 & 1.5 & 3.5 & 2.3 \\
\hline Strychnos brasiliensis........ & 13 & 5 & 0.50 & 0.84 & 29.41 & 19.1 & 1.5 & 2.7 & 1.9 \\
\hline Platypodium elegans........... & 13 & 5 & 0.50 & 0.84 & 29.41 & 19.1 & 2.0 & 5.0 & 3.6 \\
\hline Aegiphila sellowiana.......... & 8 & 7 & 0.31 & 1.17 & 41.18 & 11.8 & 2.1 & 4.5 & 2.9 \\
\hline Blepharocalyx salicifolius.... & 9 & 6 & 0.35 & 1.00 & 35.29 & 13.2 & 1.5 & 2.9 & 1.9 \\
\hline Senna splendida............. & 6 & 6 & 0.23 & 1.00 & 35.29 & 8.8 & 1.5 & 2.6 & 2.0 \\
\hline 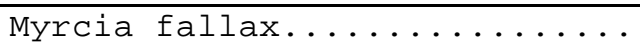 & 8 & 5 & 0.31 & 0.84 & 29.41 & 11.8 & 1.6 & 3.5 & 2.5 \\
\hline Cestrum sendtnerianum...... & 7 & 5 & 0.27 & 0.84 & 29.41 & 10.3 & 1.5 & 3.6 & 2.2 \\
\hline Chomelia pohliana............ & 9 & 4 & 0.35 & 0.67 & 23.53 & 13.2 & 1.5 & 2.5 & 2.1 \\
\hline Andira anthelmia............. & 5 & 5 & 0.19 & 0.84 & 29.41 & 7.4 & 1.5 & 3.0 & 2.1 \\
\hline 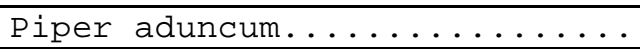 & 5 & 4 & 0.19 & 0.67 & 23.53 & 7.4 & 1.9 & 3.5 & 2.6 \\
\hline Senna bicapsulares............. & 5 & 4 & 0.19 & 0.67 & 23.53 & 7.4 & 2.0 & 4.5 & 3.3 \\
\hline Casearia decandra............ & 9 & 2 & 0.35 & 0.33 & 11.76 & 13.2 & 1.5 & 4.5 & 2.8 \\
\hline Baccharis dracunculifolia..... & 4 & 4 & 0.15 & 0.67 & 23.53 & 5.9 & 2.0 & 2.5 & 2.4 \\
\hline Citrus limon............... & 4 & 4 & 0.15 & 0.67 & 23.53 & 5.9 & 1.8 & 3.0 & 2.3 \\
\hline Endlicheria paniculata........ & 4 & 4 & 0.15 & 0.67 & 23.53 & 5.9 & 2.8 & 5.0 & 3.7 \\
\hline 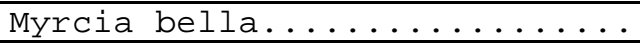 & 4 & 4 & 0.15 & 0.67 & 23.53 & 5.9 & 1.6 & 2.5 & 2.1 \\
\hline Sebastiania klotzchiana....... & 6 & 3 & 0.23 & 0.50 & 17.65 & 8.8 & 1.5 & 5.6 & 2.7 \\
\hline Miconia langsdorfii.......... & 8 & 2 & 0.31 & 0.33 & 11.76 & 11.8 & 1.5 & 2.5 & 1.8 \\
\hline Helietta apiculata.......... & 5 & 3 & 0.19 & 0.50 & 17.65 & 7.4 & 1.8 & 3.5 & 2.5 \\
\hline Ocotea velutina............. & 5 & 3 & 0.19 & 0.50 & 17.65 & 7.4 & 2.0 & 4.5 & 3.7 \\
\hline 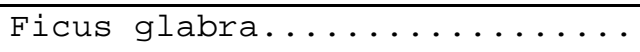 & 3 & 3 & 0.12 & 0.50 & 17.65 & 4.4 & 2.6 & 4.3 & 3.3 \\
\hline
\end{tabular}

Quadro 4 - Parâmetros fitossociológicos encontrados para as espécies amostradas no sub-bosque de E. grandis (talhão 48), 45 meses após o corte da primeira rotação do povoamento de eucalipto, área amostral 0,72ha, onde: $\mathrm{N}^{\circ}$. Ind. - Número de Indivíduos; $\mathrm{N}^{\circ}$ Amo - Número de unidades amostrais em que a espécie foi amostrada; Dens.re - Densidade relativa da espécie; Freq. Rel - Frequência relativa da espécie; Freq Ab - Frequência absoluta da espécie; Dens Ab Densidade abusoluta da espécie; Alt Min- altura mínima amostrada na espécie; Alt Max Altura máxima amostrada na espécie e Alt Med - Altura média apresentada pela espécie. 
Estrutura da Regeneração de Espécies Nativas no Sub-bosque de Plantios de Eucalyptus grandis

\begin{tabular}{|c|c|c|c|c|c|c|c|c|}
\hline especie & $\begin{array}{l}\text { No } \\
\text { Ind }\end{array}$ & $\begin{array}{l}\text { No } \\
\text { Amo }\end{array}$ & $\begin{array}{c}\text { Dens } \\
\operatorname{Re}\end{array}$ & $\begin{array}{c}\text { Freq } \\
\text { Re }\end{array}$ & $\begin{array}{c}\text { Freq } \\
\text { Ab }\end{array}$ & $\begin{array}{c}\text { Dens } \\
\text { Ab }\end{array}$ & $\begin{array}{l}\text { Alt } \\
\text { Min }\end{array}$ & $\begin{array}{l}\text { Alt } \\
\text { Max }\end{array}$ \\
\hline
\end{tabular}

\begin{tabular}{|c|c|c|c|c|c|c|c|c|c|}
\hline Pera glabrata............... & 3 & 3 & 0.12 & 0.50 & 17.65 & 4.4 & 1.6 & 2.6 & 2.1 \\
\hline Vernonia polyanthes............ & 3 & 3 & 0.12 & 0.50 & 17.65 & 4.4 & 1.7 & 3.0 & 2.4 \\
\hline 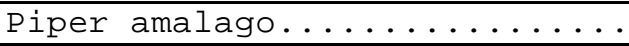 & 3 & 3 & 0.12 & 0.50 & 17.65 & 4.4 & 1.8 & 3.0 & 2.3 \\
\hline Solanum bullatum............ & 5 & 2 & 0.19 & 0.33 & 11.76 & 7.4 & 1.6 & 6.0 & 3.3 \\
\hline Diospyros inconstans......... & 4 & 2 & 0.15 & 0.33 & 11.76 & 5.9 & 1.6 & 2.3 & 1.9 \\
\hline Acnistus cauliflorus.......... & 3 & 2 & 0.12 & 0.33 & 11.76 & 4.4 & 2.0 & 4.5 & 3.0 \\
\hline Ilex brasiliensis............ & 3 & 2 & 0.12 & 0.33 & 11.76 & 4.4 & 2.3 & 4.1 & 3.3 \\
\hline Machaerium opacum............ & 3 & 2 & 0.12 & 0.33 & 11.76 & 4.4 & 1.7 & 2.8 & 2.2 \\
\hline Machaerium brasiliense........ & 2 & 2 & 0.08 & 0.33 & 11.76 & 2.9 & 2.9 & 6.0 & 4.4 \\
\hline Cecropia pachystachya......... & 2 & 2 & 0.08 & 0.33 & 11.76 & 2.9 & 2.2 & 3.1 & 2.7 \\
\hline Chomelia obtusa............. & 2 & 2 & 0.08 & 0.33 & 11.76 & 2.9 & 2.0 & 2.6 & 2.3 \\
\hline Aloysia virgata............. & 2 & 2 & 0.08 & 0.33 & 11.76 & 2.9 & 2.5 & 3.0 & 2.8 \\
\hline Eugenia pyriformis........... & 2 & 2 & 0.08 & 0.33 & 11.76 & 2.9 & 1.7 & 1.9 & 1.8 \\
\hline Actinostemon klotzchii........ & 4 & 1 & 0.15 & 0.17 & 5.88 & 5.9 & 2.1 & 4.0 & 2.9 \\
\hline Campomanesia cf pubescens..... & 3 & 1 & 0.12 & 0.17 & 5.88 & 4.4 & 1.6 & 2.2 & 1.9 \\
\hline Cestrum $\operatorname{sp1} \ldots \ldots \ldots \ldots \ldots \ldots$ & 3 & 1 & 0.12 & 0.17 & 5.88 & 4.4 & 2.0 & 2.7 & 2.3 \\
\hline Picramnia sellowii........... & 3 & 1 & 0.12 & 0.17 & 5.88 & 4.4 & 2.8 & 3.0 & 2.9 \\
\hline Leandra lacunosa............ & 2 & 1 & 0.08 & 0.17 & 5.88 & 2.9 & 2.0 & 2.0 & 2.0 \\
\hline Vernonia diffusa............ & 2 & 1 & 0.08 & 0.17 & 5.88 & 2.9 & 5.5 & 7.0 & 6.3 \\
\hline Machaerium acutifolium........ & 1 & 1 & 0.04 & 0.17 & 5.88 & 1.5 & 2.1 & 2.1 & 2.1 \\
\hline Chorisia speciosa............. & 1 & 1 & 0.04 & 0.17 & 5.88 & 1.5 & 1.5 & 1.5 & 1.5 \\
\hline Lacistema hasslerianum........ & 1 & 1 & 0.04 & 0.17 & 5.88 & 1.5 & 4.7 & 4.7 & 4.7 \\
\hline Chlorophora tinctoria......... & 1 & 1 & 0.04 & 0.17 & 5.88 & 1.5 & 2.0 & 2.0 & 2.0 \\
\hline Piptadenia gonoacantha........ & 1 & 1 & 0.04 & 0.17 & 5.88 & 1.5 & 5.1 & 5.1 & 5.1 \\
\hline Trema micrantha.............. & 1 & 1 & 0.04 & 0.17 & 5.88 & 1.5 & 1.5 & 1.5 & 1.5 \\
\hline 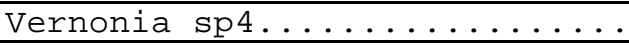 & 1 & 1 & 0.04 & 0.17 & 5.88 & 1.5 & 2.0 & 2.0 & 2.0 \\
\hline Symplocus pubescens.......... & 1 & 1 & 0.04 & 0.17 & 5.88 & 1.5 & 5.5 & 5.5 & 5.5 \\
\hline Solanum mauritianum........... & 1 & 1 & 0.04 & 0.17 & 5.88 & 1.5 & 1.8 & 1.8 & 1.8 \\
\hline Alchornea triplinervia......... & 1 & 1 & 0.04 & 0.17 & 5.88 & 1.5 & 4.0 & 4.0 & 4.0 \\
\hline 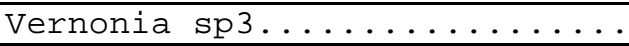 & 1 & 1 & 0.04 & 0.17 & 5.88 & 1.5 & 3.5 & 3.5 & 3.5 \\
\hline Sida rhombifolia............. & 1 & 1 & 0.04 & 0.17 & 5.88 & 1.5 & 1.6 & 1.6 & 1.6 \\
\hline Persea pyrifolia............. & 1 & 1 & 0.04 & 0.17 & 5.88 & 1.5 & 1.8 & 1.8 & 1.8 \\
\hline
\end{tabular}

Quadro 4 - Parâmetros fitossociológicos encontrados para as espécies amostradas no sub-bosque de E. grandis (talhão 48), 45 meses após o corte da primeira rotação do povoamento de eucalipto, área amostral 0,72ha, onde: $\mathrm{N}^{\circ}$. Ind. - Número de Indivíduos; No Amo - Número de unidades amostrais em que a espécie foi amostrada; Dens.re - Densidade relativa da espécie; Freq. Rel - Frequência relativa da espécie; Freq Ab - Frequência absoluta da espécie; Dens Ab Densidade abusoluta da espécie; Alt Min- altura mínima amostrada na espécie; Alt Max Altura máxima amostrada na espécie e Alt Med - Altura média apresentada pela espécie. 


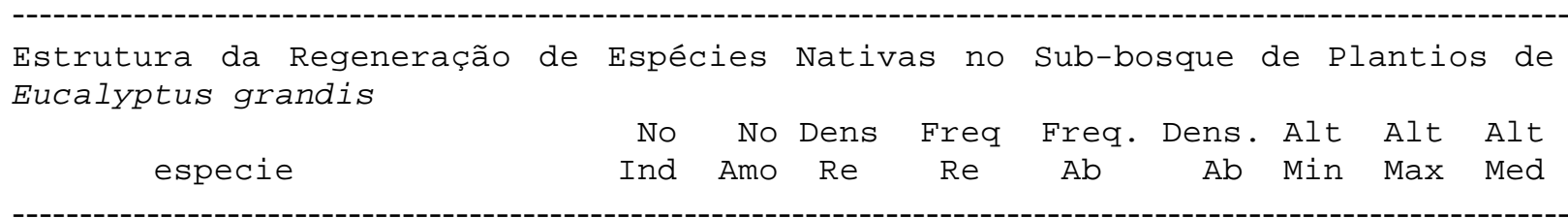

\begin{tabular}{|c|c|c|c|c|c|c|c|c|c|}
\hline 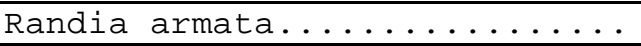 & 1 & 1 & 0.04 & 0.17 & 5.88 & 1.5 & 3.0 & 3.0 & 3.0 \\
\hline Psychotria sessilis........... & 1 & 1 & 0.04 & 0.17 & 5.88 & 1.5 & 1.6 & 1.6 & 1.6 \\
\hline Ocotea velloziana............ & 1 & 1 & 0.04 & 0.17 & 5.88 & 1.5 & 4.0 & 4.0 & 4.0 \\
\hline Maytenus evonymoidis........... & 1 & 1 & 0.04 & 0.17 & 5.88 & 1.5 & 3.4 & 3.4 & 3.4 \\
\hline Ixora venulosa............... & 1 & 1 & 0.04 & 0.17 & 5.88 & 1.5 & 2.0 & 2.0 & 2.0 \\
\hline Coutarea hexandra............ & 1 & 1 & 0.04 & 0.17 & 5.88 & 1.5 & 2.0 & 2.0 & 2.0 \\
\hline Amaioua guianensis........... & 1 & 1 & 0.04 & 0.17 & 5.88 & 1.5 & 1.7 & 1.7 & 1.7 \\
\hline Citronella paniculata........ & 1 & 1 & 0.04 & 0.17 & 5.88 & 1.5 & 1.7 & 1.7 & 1.7 \\
\hline Pterocarpus rohrii........... & 1 & 1 & 0.04 & 0.17 & 5.88 & 1.5 & 2.6 & 2.6 & 2.6 \\
\hline Myrcia guianensis............ & 1 & 1 & 0.04 & 0.17 & 5.88 & 1.5 & 2.7 & 2.7 & 2.7 \\
\hline Copaifera langsdorfii........ & 1 & 1 & 0.04 & 0.17 & 5.88 & 1.5 & 2.6 & 2.6 & 2.6 \\
\hline Machaerium nictitans.......... & 1 & 1 & 0.04 & 0.17 & 5.88 & 1.5 & 2.8 & 2.8 & 2.8 \\
\hline Eupatorium inulaefolium....... & 1 & 1 & 0.04 & 0.17 & 5.88 & 1.5 & 1.6 & 1.6 & 1.6 \\
\hline Lithraea molleoides........... & 1 & 1 & 0.04 & 0.17 & 5.88 & 1.5 & 1.8 & 1.8 & 1.8 \\
\hline
\end{tabular}

Quadro 4 - Parâmetros fitossociológicos encontrados para as espécies amostradas no sub-bosque de E. grandis (talhão 48), 45 meses após o corte da primeira rotação do povoamento de eucalipto, área amostral 0,72ha, onde: $\mathrm{N}^{\circ}$. Ind. - Número de Indivíduos; No Amo - Número de unidades amostrais em que a espécie foi amostrada; Dens.re - Densidade relativa da espécie; Freq. Rel - Frequência relativa da espécie; Freq Ab - Frequência absoluta da espécie; Dens Ab Densidade abusoluta da espécie; Alt Min- altura mínima amostrada na espécie; Alt Max Altura máxima amostrada na espécie e Alt Med - Altura média apresentada pela espécie. 


\section{Conjunto de Quadros 6: Parâmetros Fitossociológicos das espécies e famílias amostradas no tratamento 1 - testemunha do povoamento de $E$. grandis nos diversos levantamentos do Sub-bosque do Talhão 48.}

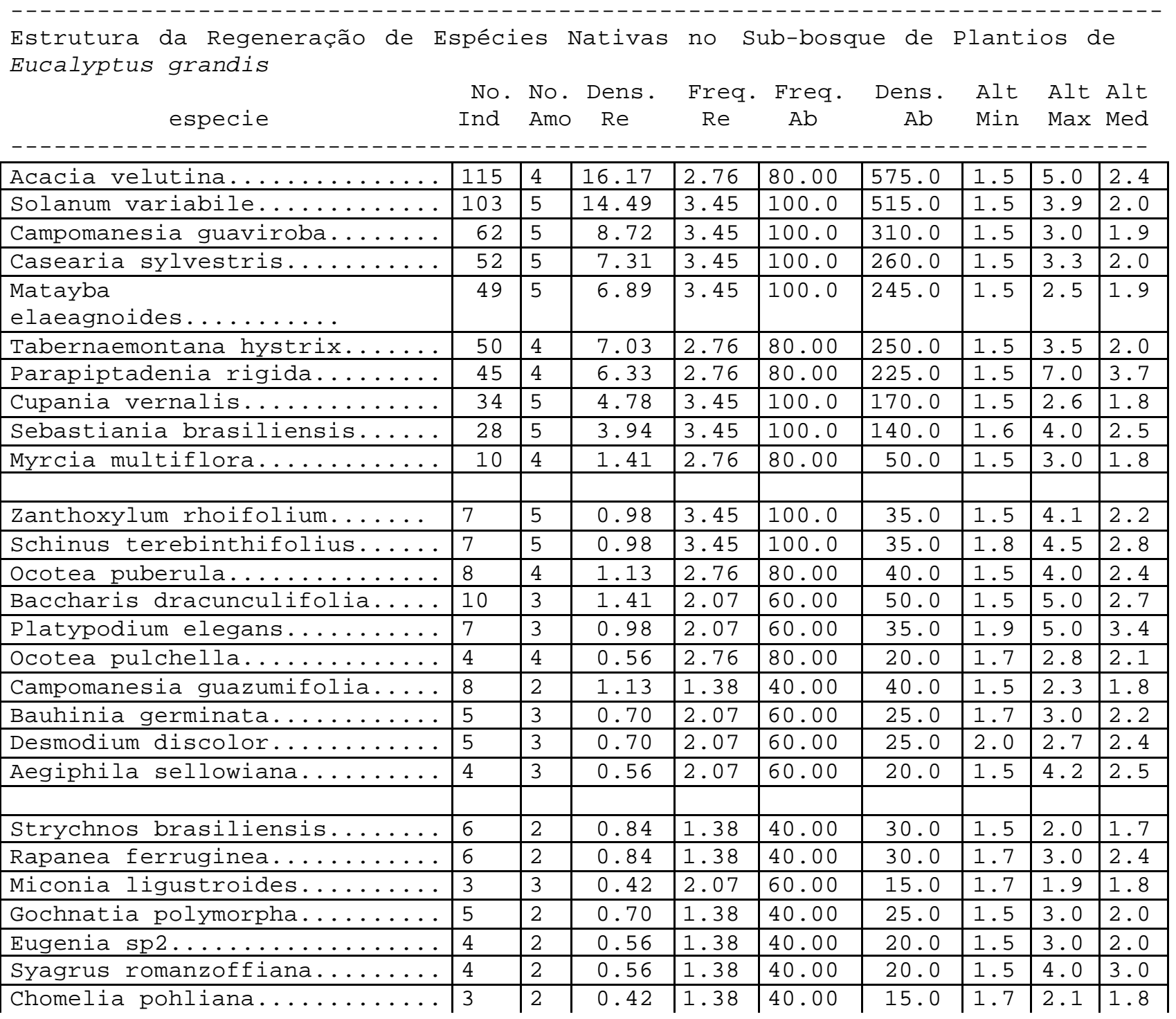

Quadro 6.1 - Parâmetros fitossociológicos encontrados para as espécies amostradas no subbosque de E. grandis (talhão 48), 30 meses após a exploração da primeira rotação do povoamento de eucalipto, área amostral 0,2 ha, Tratamento 1- Testemunha, onde: $\mathrm{N}^{\circ}$. Ind. Número de Indivíduos; $\mathrm{N}^{\circ}$ Amo - Número de unidades amostrais em que a espécie foi amostrada; Dens.re - Densidade relativa da espécie; Freq. Rel - Frequência relativa da espécie; Freq Ab - Frequência absoluta da espécie; Dens Ab - Densidade abusoluta da espécie; Alt Minaltura mínima amostrada na espécie; Alt Max - Altura máxima amostrada na espécie e Alt Med - Altura média apresentada pela espécie. 


\begin{tabular}{|c|c|c|c|c|c|c|c|c|c|}
\hline especie & $\begin{array}{l}\text { No. } \\
\text { Ind }\end{array}$ & $\begin{array}{l}\text { No } \\
\text { Amo }\end{array}$ & $\begin{array}{l}\text { Dens. } \\
\text { Re }\end{array}$ & $\begin{array}{l}\text { Freq. } \\
\text { Re }\end{array}$ & $\begin{array}{l}\text { Freq. } \\
\text { Ab }\end{array}$ & $\begin{array}{l}\text { Dens. } \\
\text { Ab }\end{array}$ & $\begin{array}{l}\text { Alt } \\
\text { Min }\end{array}$ & $\begin{array}{l}\text { Alt } \\
\text { Max }\end{array}$ & $\begin{array}{l}\text { Alt } \\
\text { Med }\end{array}$ \\
\hline \multicolumn{10}{|c|}{------------------------------------------------------------------------------------------} \\
\hline Endlicheria paniculata........ & 3 & 2 & 0.42 & 1.38 & 40.00 & 15.0 & 1.6 & 5.0 & 3.4 \\
\hline Tabebuia chrysotricha......... & 3 & 2 & 0.42 & 1.38 & 40.00 & 15.0 & 1.6 & 2.0 & 1.7 \\
\hline Eugenia hiemalis............. & 3 & 2 & 0.42 & 1.38 & 40.00 & 15.0 & 1.6 & 1.6 & 1.6 \\
\hline Sebastiania klotzchiana........ & 5 & 1 & 0.70 & 0.69 & 20.00 & 25.0 & 1.6 & 2.3 & 1.9 \\
\hline Tapirira guianensis.......... & 5 & 1 & 0.70 & 0.69 & 20.00 & 25.0 & 1.5 & 2.7 & 2.0 \\
\hline Myrcia laruotteana........... & 2 & 2 & 0.28 & 1.38 & 40.00 & 10.0 & 1.5 & 1.8 & 1.6 \\
\hline Allophyllus edulis........... & 2 & 2 & 0.28 & 1.38 & 40.00 & 10.0 & 1.8 & 2.0 & 1.9 \\
\hline Citrus limon............... & 2 & 2 & 0.28 & 1.38 & 40.00 & 10.0 & 1.9 & 2.2 & 2.0 \\
\hline Solanum pseudoquina........... & 2 & 2 & 0.28 & 1.38 & 40.00 & 10.0 & 1.8 & 1.8 & 1.8 \\
\hline Solanum granuloso-leprosum.... & 2 & 2 & 0.28 & 1.38 & 40.00 & 10.0 & 1.7 & 2.0 & 1.9 \\
\hline 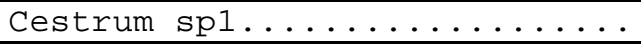 & 3 & 1 & 0.42 & 0.69 & 20.00 & 15.0 & 1.6 & 2.4 & 2.0 \\
\hline Solanum bullatum............. & 2 & 1 & 0.28 & 0.69 & 20.00 & 10.0 & 2.8 & 4.0 & 3.4 \\
\hline Casearia decandra............ & 2 & 1 & 0.28 & 0.69 & 20.00 & 10.0 & 1.7 & 3.1 & 2.4 \\
\hline Machaerium opacum............ & 2 & 1 & 0.28 & 0.69 & 20.00 & 10.0 & 2.3 & 3.0 & 2.7 \\
\hline 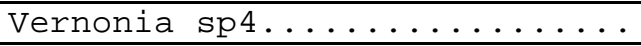 & 2 & 1 & 0.28 & 0.69 & 20.00 & 10.0 & 2.0 & 2.2 & 2.1 \\
\hline Vitex montevidensis........... & 2 & 1 & 0.28 & 0.69 & 20.00 & 10.0 & 1.7 & 1.8 & 1.8 \\
\hline Miconia langsdorfii.......... & 1 & 1 & 0.14 & 0.69 & 20.00 & 5.0 & 1.6 & 1.6 & 1.6 \\
\hline 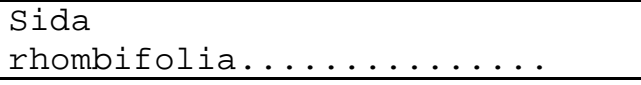 & 1 & 1 & 0.14 & 0.69 & 20.00 & 5.0 & 1.8 & 1.8 & 1.8 \\
\hline Maytenus evonymoidis.......... & 1 & 1 & 0.14 & 0.69 & 20.00 & 5.0 & 2.3 & 2.3 & 2.3 \\
\hline Cestrum sendtnerianum....... & 1 & 1 & 0.14 & 0.69 & 20.00 & 5.0 & 2.0 & 2.0 & 2.0 \\
\hline Ocotea velutina.............. & 1 & 1 & 0.14 & 0.69 & 20.00 & 5.0 & 3.0 & 3.0 & 3.0 \\
\hline Senna splendida.............. & 1 & 1 & 0.14 & 0.69 & 20.00 & 5.0 & 2.5 & 2.5 & 2.5 \\
\hline Ocotea velloziana............ & 1 & 1 & 0.14 & 0.69 & 20.00 & 5.0 & 2.7 & 2.7 & 2.7 \\
\hline Helietta apiculata........... & 1 & 1 & 0.14 & 0.69 & 20.00 & 5.0 & 2.4 & 2.4 & 2.4 \\
\hline Senna bicapsulares............ & 1 & 1 & 0.14 & 0.69 & 20.00 & 5.0 & 1.5 & 1.5 & 1.5 \\
\hline Coutarea hexandra............. & 1 & 1 & 0.14 & 0.69 & 20.00 & 5.0 & 1.9 & 1.9 & 1.9 \\
\hline Rhamnus shaerosperma.......... & 1 & 1 & 0.14 & 0.69 & 20.00 & 5.0 & 2.0 & 2.0 & 2.0 \\
\hline Copaifera langsdorfii........ & 1 & 1 & 0.14 & 0.69 & 20.00 & 5.0 & 2.2 & 2.2 & 2.2 \\
\hline 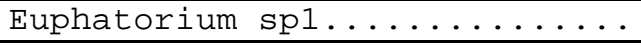 & 1 & 1 & 0.14 & 0.69 & 20.00 & 5.0 & 1.6 & 1.6 & 1.6 \\
\hline Piper gaudichaudianum......... & 1 & 1 & 0.14 & 0.69 & 20.00 & 5.0 & 1.5 & 1.5 & 1.5 \\
\hline 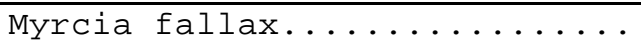 & 1 & 1 & 0.14 & 0.69 & 20.00 & 5.0 & 1.8 & 1.8 & 1.8 \\
\hline
\end{tabular}

Quadro 6.1 - Parâmetros fitossociológicos encontrados para as espécies amostradas no subbosque de E. grandis (talhão 48), 30 meses após a exploração da primeira rotação do povoamento de eucalipto, área amostral 0,2 ha, Tratamento 1- Testemunha, onde: $\mathrm{N}^{\circ}$. Ind. Número de Indivíduos; $\mathrm{N}^{\circ}$ Amo - Número de unidades amostrais em que a espécie foi amostrada; Dens.re - Densidade relativa da espécie; Freq. Rel - Frequência relativa da espécie; Freq Ab - Frequência absoluta da espécie; Dens Ab - Densidade abusoluta da espécie; Alt Minaltura mínima amostrada na espécie; Alt Max - Altura máxima amostrada na espécie e Alt Med - Altura média apresentada pela espécie. 


\begin{tabular}{|c|c|c|c|c|c|c|c|c|c|}
\hline \multirow{2}{*}{$\begin{array}{l}\text { Estrutura da Regeneração de } \\
\text { Eucalyptus grandis } \\
\text { especie }\end{array}$} & \multicolumn{2}{|c|}{ spécies } & \multirow{2}{*}{$\begin{array}{l}\text { Nativas } \\
\text { Dens. } \\
\quad \operatorname{Re}\end{array}$} & \multicolumn{3}{|c|}{ no sub-bosque de } & \multicolumn{3}{|c|}{ lantios de } \\
\hline & $\begin{array}{l}\text { No. } \\
\text { Ind }\end{array}$ & $\begin{array}{l}\text { No. } \\
\text { Amo }\end{array}$ & & $\begin{array}{c}\text { Freq. } \\
\text { Re }\end{array}$ & $\begin{array}{c}\text { Freq. } \\
\text { Ab }\end{array}$ & $\begin{array}{c}\text { Dens. } \\
\text { Ab }\end{array}$ & $\begin{array}{l}\text { Alt } \\
\text { Min }\end{array}$ & $\begin{array}{l}\text { Alt } \\
\operatorname{Max}\end{array}$ & $\begin{array}{l}\text { Alt } \\
\text { Med }\end{array}$ \\
\hline Myrcia bella. & 1 & 1 & 0.14 & 0.69 & 20.00 & 5.0 & 3.4 & 3.4 & 3.4 \\
\hline Calyptranthes concinna........ & 1 & 1 & 0.14 & 0.69 & 20.00 & 5.0 & 1.8 & 1.8 & 1.8 \\
\hline Blepharocalyx salicifolius. & 1 & 1 & .14 & 0.69 & 24 & 5.0 & 1.9 & 1.9 & 1.9 \\
\hline 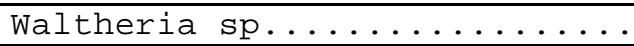 & 1 & 1 & 0.14 & 0.69 & 00 & 5.0 & 1.8 & 1.8 & 1.8 \\
\hline Cytharexylum myrianthum....... & 1 & 1 & 0.14 & 0.69 & 20.00 & 5.0 & 1.5 & 1.5 & 1.5 \\
\hline Cedrela fissilis.............. & 1 & 1 & 0.14 & 0.69 & 20.00 & 5.0 & 2.1 & 2.1 & 2.1 \\
\hline Symplocus pubescens.......... & 1 & 1 & 0.14 & 0.69 & 20.00 & 5.0 & 3.5 & 3.5 & 3.5 \\
\hline Styrax acuminatus........... & 1 & 1 & 0.14 & 0.69 & 20.00 & 5.0 & 2.6 & 2.6 & 2.6 \\
\hline Alchornea triplinervia........ & 1 & 1 & 0.14 & 0.69 & 20.00 & 5.0 & 2.0 & 2.0 & 2.0 \\
\hline Vernonia cf eriolepis.......... & 1 & 1 & 0.14 & 0.69 & 20.00 & 5.0 & 1.7 & 1.7 & 1.7 \\
\hline
\end{tabular}

Quadro 6.1 - Parâmetros fitossociológicos encontrados para as espécies amostradas no subbosque de E. grandis (talhão 48), 30 meses após a exploração da primeira rotação do povoamento de eucalipto, área amostral 0,2 ha, Tratamento $1-$ Testemunha, onde: $\mathrm{N}^{\circ}$. Ind. Número de Indivíduos; $\mathrm{N}^{\circ}$ Amo - Número de unidades amostrais em que a espécie foi amostrada; Dens.re - Densidade relativa da espécie; Freq. Rel - Frequência relativa da espécie; Freq Ab - Frequência absoluta da espécie; Dens Ab - Densidade abusoluta da espécie; Alt Minaltura mínima amostrada na espécie; Alt Max - Altura máxima amostrada na espécie e Alt Med - Altura média apresentada pela espécie. 


\begin{tabular}{|c|c|c|c|c|c|c|c|c|c|}
\hline especie & $\begin{array}{l}\text { No. } \\
\text { Ind }\end{array}$ & $\begin{array}{l}\text { No. } \\
\text { Amo }\end{array}$ & $\begin{array}{c}\text { Dens. } \\
\text { Re }\end{array}$ & $\begin{array}{c}\text { Freq. } \\
\text { Re }\end{array}$ & $\begin{array}{c}\text { Freq. } \\
\text { Ab }\end{array}$ & $\begin{array}{c}\text { Dens. } \\
\text { Ab }\end{array}$ & $\begin{array}{l}\text { Alt. } \\
\text { Min }\end{array}$ & $\begin{array}{l}\text { Alt } \\
\operatorname{Max}\end{array}$ & $\begin{array}{l}\text { Alt } \\
\text { Med }\end{array}$ \\
\hline \multicolumn{10}{|c|}{-------------------------------------------------------------------------------} \\
\hline upania vernalis............. & 131 & 5 & 13.95 & 3.07 & 100.0 & 655.0 & 1.5 & 3.4 & 1.9 \\
\hline Acacia velutina............. & 130 & 4 & 13.84 & 2.45 & 80.00 & 650.0 & 1.5 & 6.0 & 2.5 \\
\hline Campomanesia guaviroba........ & 115 & 5 & 12.25 & 3.07 & 100.0 & 575.0 & 1.5 & 3.5 & 2.0 \\
\hline Matayba elaeagnoides.......... & 96 & 5 & 10.22 & 3.07 & 0.0 & 480.0 & 1.5 & 3.3 & 2.1 \\
\hline Casearia sylvestris.......... & 69 & 5 & 7.35 & 3.07 & 100.0 & 345.0 & 1.5 & 4.0 & 2.2 \\
\hline Tabernaemontana hystrix....... & 71 & 4 & 7.56 & 2.45 & 80.00 & 355.0 & 1.5 & 4.0 & 2.3 \\
\hline Parapiptadenia rigida........ & 48 & 4 & 5.11 & 2.45 & 00 & 240.0 & 1.6 & 8.0 & 4.3 \\
\hline Sebastiania brasiliensis...... & 35 & 5 & 3.73 & 3.07 & .0 & 175.0 & 1.5 & 4.0 & 2.6 \\
\hline Solanum variabile........... & 21 & 5 & 2.24 & 3.07 & .0 & 105.0 & 1.5 & 4.0 & 2.1 \\
\hline Campomanesia guazumifolia..... & 21 & 2 & 2.24 & 1.23 & 00 & 105.0 & 1.5 & 3.0 & 2.1 \\
\hline Rapanea ferruginea........... & 10 & 4 & 1.06 & 2.45 & & 50.0 & 1.6 & 5.0 & 2.8 \\
\hline Myrcia multiflora............ & 10 & 4 & 1.06 & 2.45 & 00 & 50.0 & 1.5 & 2.2 & 1.9 \\
\hline Eugenia hiemalis............ & 12 & 3 & 1.28 & 1.84 & 00 & 60.0 & 1.5 & 2.4 & 1.8 \\
\hline Strychnos brasiliensis........ & 11 & 3 & 1.17 & 1.84 & 00 & 55.0 & 1.5 & 2.4 & 1.8 \\
\hline Myrciaria floribunda......... & 8 & 4 & 0.85 & 2.45 & 80.00 & 40.0 & 1.5 & 2.0 & 1.7 \\
\hline Zanthoxylum rhoifolium....... & 6 & 4 & 0.64 & 2.45 & 00 & 30.0 & 1.7 & 4.5 & 2.7 \\
\hline Ocotea puberula.............. & 6 & 4 & 0.64 & 2.45 & 00 & 30.0 & 1.9 & 5.5 & 3.2 \\
\hline Solanum pseudoquina........... & 5 & 4 & 0.53 & 2.45 & 80.00 & 25.0 & 1.5 & 2.5 & 2.0 \\
\hline Schinus terebinthifolius...... & 5 & 4 & 0.53 & 2.45 & 00 & 25.0 & 1.9 & 3.5 & 2.7 \\
\hline Miconia ligustroides.......... & 4 & 4 & 0.43 & 2.45 & 80.00 & 20.0 & 2.2 & 2.5 & 2.4 \\
\hline Ocotea pulchella... & 4 & 4 & 3 & 2.45 & 0 & 20.0 & 1.7 & 3.5 & 2.6 \\
\hline Cytharexylum myrianthum....... & 4 & 4 & 0.43 & 2.45 & 00 & 20.0 & 1.6 & 2.5 & 2.2 \\
\hline Vitex montevidensis.......... & 8 & 2 & 0.85 & 1.23 & .00 & 40.0 & 1.7 & 2.5 & 2.1 \\
\hline Myrcia laruotteana............ & 5 & 3 & 0.53 & 1.84 & 60.00 & 25.0 & 1.5 & 2.0 & 1.7 \\
\hline Gochnatia polymorpha.......... & 5 & 3 & 0.53 & 1.84 & 60.00 & 25.0 & 1.8 & 2.4 & 2.0 \\
\hline Bauhinia germinata........... & 5 & 3 & 0.53 & 1.84 & 60.00 & 25.0 & 1.9 & 3.0 & 2.2 \\
\hline Platypodium elegans.......... & 7 & 2 & 0.75 & 1.23 & 40.00 & 35.0 & 2.0 & 5.0 & 3.5 \\
\hline Tabebuia chrysotricha......... & 4 & 3 & 0.43 & 1.84 & 60.00 & 20.0 & 1.5 & 2.0 & 1.7 \\
\hline Allophyllus edulis............ & 4 & 3 & 0.43 & 1.84 & 60.00 & 20.0 & 1.7 & 3.5 & 2.5 \\
\hline Chomelia pohlian & 4 & 3 & 0.43 & 1.84 & 60.00 & 20.0 & 1.5 & 2.5 & 1.9 \\
\hline
\end{tabular}

Quadro 6.2 - Parâmetros fitossociológicos encontrados para as espécies amostradas no subbosque de E. grandis (talhão 48), 45 meses após a exploração da primeira rotação do povoamento de eucalipto, área amostral 0,2 ha, Tratamento 1 - Testemunha, onde: $\mathrm{N}^{\circ}$. Ind. Número de Indivíduos; $\mathrm{N}^{\circ}$ Amo - Número de unidades amostrais em que a espécie foi amostrada; Dens.re - Densidade relativa da espécie; Freq. Rel - Frequência relativa da espécie; Freq Ab - Frequência absoluta da espécie; Dens Ab - Densidade abusoluta da espécie; Alt Minaltura mínima amostrada na espécie; Alt Max - Altura máxima amostrada na espécie e Alt Med - Altura média apresentada pela espécie. 
Estrutura da Regeneração de Espécies Nativas no Sub-bosque de Plantios de Eucalyptus grandis

$\begin{array}{llccccc} & \text { No. } & \text { No. } & \text { Dens. } & \text { Freq. Freq. Dens. Alt. Alt Alt } \\ \text { especie } & \text { Ind Amo } & \text { Re } & \text { Re } & \text { Ab } & \text { Ab } & \text { Min Max Med }\end{array}$

\begin{tabular}{|c|c|c|c|c|c|c|c|c|c|}
\hline 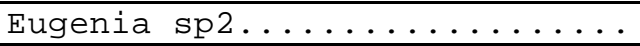 & 4 & 3 & 0.43 & 1.84 & 60.00 & 20.0 & 1.5 & 3.5 & 2.3 \\
\hline Syagrus romanzoffiana.......... & 6 & 2 & 0.64 & 1.23 & 40.00 & 30.0 & 2.0 & 4.5 & 3.4 \\
\hline 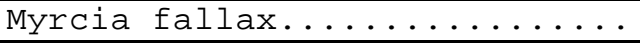 & 3 & 3 & 0.32 & 1.84 & 60.00 & 15.0 & 1.6 & 2.7 & 2.1 \\
\hline Calyptranthes concinna........ & 3 & 3 & 0.32 & 1.84 & 60.00 & 15.0 & 1.5 & 1.9 & 1.7 \\
\hline Solanum bullatum............. & 5 & 2 & 0.53 & 1.23 & 40.00 & 25.0 & 1.6 & 6.0 & 3.3 \\
\hline Tapirira guianensis........... & 6 & 1 & 0.64 & 0.61 & 20.00 & 30.0 & 1.6 & 3.5 & 2.3 \\
\hline Blepharocalyx salicifolius.... & 3 & 2 & 0.32 & 1.23 & 40.00 & 15.0 & 1.5 & 2.0 & 1.7 \\
\hline Aegiphila sellowiana.......... & 3 & 2 & 0.32 & 1.23 & 40.00 & 15.0 & 3.0 & 4.5 & 3.7 \\
\hline Desmodium discolor............ & 3 & 2 & 0.32 & 1.23 & 40.00 & 15.0 & 2.0 & 2.6 & 2.4 \\
\hline Styrax acuminatus............ & 2 & 2 & 0.21 & 1.23 & 40.00 & 10.0 & 1.8 & 3.0 & 2.4 \\
\hline Citrus limon.............. & 2 & 2 & 0.21 & 1.23 & 40.00 & 10.0 & 1.8 & 2.5 & 2.2 \\
\hline Senna splendida.............. & 2 & 2 & 0.21 & 1.23 & 40.00 & 10.0 & 2.0 & 2.6 & 2.3 \\
\hline Endlicheria paniculata........ & 2 & 2 & 0.21 & 1.23 & 40.00 & 10.0 & 4.0 & 5.0 & 4.5 \\
\hline Sebastiania klotzchiana....... & 4 & 1 & 0.43 & 0.61 & 20.00 & 20.0 & 1.6 & 2.9 & 2.3 \\
\hline Cestrum $\operatorname{sp1} 1 \ldots \ldots \ldots \ldots$ & 3 & 1 & 0.32 & 0.61 & 20.00 & 15.0 & 2.0 & 2.7 & 2.3 \\
\hline Myrtaceae sp2......... & 2 & 1 & 0.21 & 0.61 & 20.00 & 10.0 & 1.6 & 1.9 & 1.8 \\
\hline Senna bicapsulares............ & 2 & 1 & 0.21 & 0.61 & 20.00 & 10.0 & 2.0 & 3.0 & 2.5 \\
\hline Machaerium opacum............ & 2 & 1 & 0.21 & 0.61 & 20.00 & 10.0 & 1.7 & 2.8 & 2.3 \\
\hline Trema micrantha.............. & 1 & 1 & 0.11 & 0.61 & 20.00 & 5.0 & 1.5 & 1.5 & 1.5 \\
\hline Symplocus pubescens.......... & 1 & 1 & 0.11 & 0.61 & 20.00 & 5.0 & 5.5 & 5.5 & 5.5 \\
\hline Cedrela fissilis............. & 1 & 1 & 0.11 & 0.61 & 20.00 & 5.0 & 3.5 & 3.5 & 3.5 \\
\hline Miconia langsdorfii......... & 1 & 1 & 0.11 & 0.61 & 20.00 & 5.0 & 2.0 & 2.0 & 2.0 \\
\hline Helietta apiculata........... & 1 & 1 & 0.11 & 0.61 & 20.00 & 5.0 & 3.5 & 3.5 & 3.5 \\
\hline Alchornea triplinervia....... & 1 & 1 & 0.11 & 0.61 & 20.00 & 5.0 & 4.0 & 4.0 & 4.0 \\
\hline Psychotria carthaginensis..... & 1 & 1 & 0.11 & 0.61 & 20.00 & 5.0 & 1.5 & 1.5 & 1.5 \\
\hline Persea pyrifolia............. & 1 & 1 & 0.11 & 0.61 & 20.00 & 5.0 & 1.8 & 1.8 & 1.8 \\
\hline Coutarea hexandra........... & 1 & 1 & 0.11 & 0.61 & 20.00 & 5.0 & 2.0 & 2.0 & 2.0 \\
\hline
\end{tabular}

Quadro 6.2 - Parâmetros fitossociológicos encontrados para as espécies amostradas no subbosque de E. grandis (talhão 48), 45 meses após a exploração da primeira rotação do povoamento de eucalipto, área amostral 0,2 ha, Tratamento 1 - Testemunha, onde: №. Ind. Número de Indivíduos; $\mathrm{N}^{\circ}$ Amo - Número de unidades amostrais em que a espécie foi amostrada; Dens.re - Densidade relativa da espécie; Freq. Rel - Frequência relativa da espécie; Freq Ab - Frequência absoluta da espécie; Dens Ab - Densidade abusoluta da espécie; Alt Minaltura mínima amostrada na espécie; Alt Max - Altura máxima amostrada na espécie e Alt Med - Altura média apresentada pela espécie. 


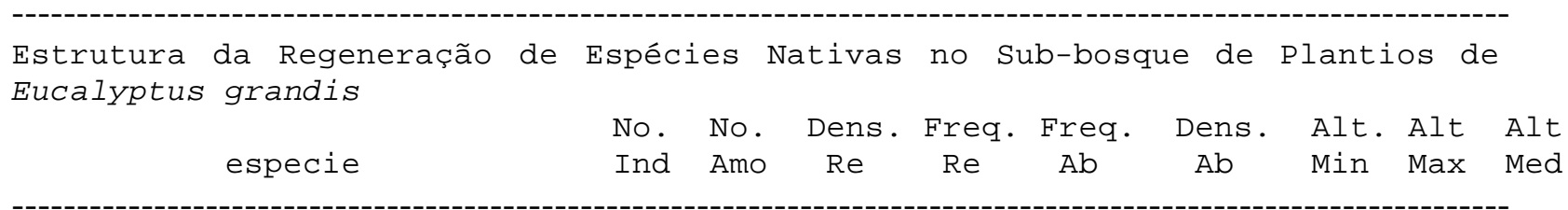

\begin{tabular}{|c|c|c|c|c|c|c|c|c|c|}
\hline Ocotea velutina.............. & 1 & 1 & 0.11 & 0.61 & 20.00 & 5.0 & 4.5 & 4.5 & 4.5 \\
\hline Maytenus evonymoidis........... & 1 & 1 & 0.11 & 0.61 & 20.00 & 5.0 & 3.4 & 3.4 & 3.4 \\
\hline Vernonia $\operatorname{sp} 4 \ldots \ldots \ldots \ldots \ldots$ & 1 & 1 & 0.11 & 0.61 & 20.00 & 5.0 & 2.0 & 2.0 & 2.0 \\
\hline Rhamnus shaerosperma.......... & 1 & 1 & 0.11 & 0.61 & 20.00 & 5.0 & 2.7 & 2.7 & 2.7 \\
\hline Piper gaudichaudianum.......... & 1 & 1 & 0.11 & 0.61 & 20.00 & 5.0 & 2.0 & 2.0 & 2.0 \\
\hline Ocotea velloziana............ & 1 & 1 & 0.11 & 0.61 & 20.00 & 5.0 & 4.0 & 4.0 & 4.0 \\
\hline Myrcia bella................ & 1 & 1 & 0.11 & 0.61 & 20.00 & 5.0 & 2.5 & 2.5 & 2.5 \\
\hline Eugenia pyriformis........... & 1 & 1 & 0.11 & 0.61 & 20.00 & 5.0 & 1.9 & 1.9 & 1.9 \\
\hline Copaifera langsdorfii......... & 1 & 1 & 0.11 & 0.61 & 20.00 & 5.0 & 2.6 & 2.6 & 2.6 \\
\hline
\end{tabular}

Quadro 6.2 - Parâmetros fitossociológicos encontrados para as espécies amostradas no subbosque de E. grandis (talhão 48), 45 meses após a exploração da primeira rotação do povoamento de eucalipto, área amostral 0,2 ha, Tratamento 1 - Testemunha, onde: $\mathrm{N}^{\circ}$. Ind. Número de Indivíduos; $\mathrm{N}^{\circ}$ Amo - Número de unidades amostrais em que a espécie foi amostrada; Dens.re - Densidade relativa da espécie; Freq. Rel - Frequência relativa da espécie; Freq Ab - Frequência absoluta da espécie; Dens Ab - Densidade abusoluta da espécie; Alt Minaltura mínima amostrada na espécie; Alt Max - Altura máxima amostrada na espécie e Alt Med - Altura média apresentada pela espécie. 


\begin{tabular}{|c|c|c|c|c|c|c|c|c|c|}
\hline $\begin{array}{c}\text { Estrutura da Regeneração de } \\
\text { Eucalyptus grandis } \\
\text { especie }\end{array}$ & $\begin{array}{l}\text { No. } \\
\text { Ind }\end{array}$ & $\begin{array}{l}\text { No. } \\
\text { Amo }\end{array}$ & $\begin{array}{c}\text { Dens. } \\
\text { Re }\end{array}$ & $\begin{array}{l}\text { Freq. } \\
\qquad \mathrm{Ab}\end{array}$ & $\begin{array}{l}\text { Freq. } \\
\text { Re }\end{array}$ & $\begin{array}{l}\text { Dens. } \\
\text { Ab }\end{array}$ & $\begin{array}{l}\text { Alt. } \\
\text { Min. }\end{array}$ & $\begin{array}{l}\text { Alt. } \\
\text { Max. }\end{array}$ & $\begin{array}{l}\text { Alt. } \\
\text { Med. }\end{array}$ \\
\hline Cupania vernalis............. & 167 & 5 & 15.46 & 100.0 & 2.87 & 835.0 & 1.5 & 3.1 & 2.0 \\
\hline Campomanesia guaviroba........ & 149 & 5 & 13.80 & 100.0 & 2.87 & 745.0 & 1.5 & 3.4 & 2.1 \\
\hline Acacia velutina.............. & 127 & 4 & 11.76 & 80.00 & 2.30 & 635.0 & 1.5 & 6.5 & 2.5 \\
\hline $\begin{array}{l}\text { Matayba } \\
\text { elaeagnoides........... }\end{array}$ & 117 & 5 & 10.83 & 100.0 & 2.87 & 585.0 & 1.5 & 4.0 & 2.2 \\
\hline Tabernaemontana hystrix....... & 78 & 4 & 7.22 & 80.00 & 2.30 & 390.0 & 1.5 & 4.2 & 2.4 \\
\hline Casearia sylvestris.......... & 67 & 5 & 6.20 & 100.0 & 2.87 & 335.0 & 1.5 & 4.2 & 2.3 \\
\hline Parapiptadenia rigida......... & 47 & 4 & 4.35 & 80.00 & 2.30 & 235.0 & 1.9 & 8.0 & 5.1 \\
\hline Sebastiania brasiliensis...... & 39 & 5 & 3.61 & 100.0 & 2.87 & 195.0 & 1.5 & 5.0 & 2.8 \\
\hline Myrciaria floribunda.......... & 23 & 5 & 2.13 & 100.0 & 2.87 & 115.0 & 1.5 & 2.2 & 1.7 \\
\hline Myrcia multiflora............ & 16 & 5 & 1.48 & 100.0 & 2.87 & 80.0 & 1.5 & 2.6 & 1.9 \\
\hline Campomanesia guazumifolia..... & 24 & 2 & 2.22 & 40.00 & 1.15 & 120.0 & 1.5 & 3.1 & 1.9 \\
\hline Eugenia hiemalis............ & 15 & 3 & 1.39 & 60.00 & 1.72 & 75.0 & 1.5 & 2.5 & 2.0 \\
\hline Solanum variabile........... & 11 & 4 & 1.02 & 80.00 & 2.30 & 55.0 & 1.5 & 3.5 & 2.3 \\
\hline Rapanea ferruginea........... & 10 & 4 & 0.93 & 80.00 & 2.30 & 50.0 & 1.6 & 4.5 & 2.7 \\
\hline Solanum pseudoquina.......... & 9 & 4 & 0.83 & 80.00 & 2.30 & 45.0 & 1.8 & 2.8 & 2.2 \\
\hline Strychnos brasiliensis........ & 12 & 3 & 1.11 & 60.00 & 1.72 & 60.0 & 1.5 & 2.4 & 1.8 \\
\hline Zanthoxylum rhoifolium....... & 8 & 4 & 0.74 & 80.00 & 2.30 & 40.0 & 1.5 & 5.0 & 2.5 \\
\hline Ocotea puberula............. & 8 & 4 & 0.74 & 80.00 & 2.30 & 40.0 & 1.6 & 7.0 & 2.8 \\
\hline Ocotea pulchella............ & 4 & 4 & 0.37 & 80.00 & 2.30 & 20.0 & 2.4 & 4.0 & 3.2 \\
\hline Cytharexylum myrianthum....... & 4 & 4 & 0.37 & 80.00 & 2.30 & 20.0 & 1.7 & 3.0 & 2.4 \\
\hline 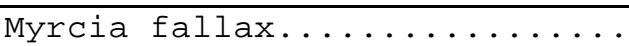 & 4 & 4 & 0.37 & 80.00 & 2.30 & 20.0 & 1.7 & 3.0 & 2.2 \\
\hline Miconia ligustroides.......... & 4 & 4 & 0.37 & 80.00 & 2.30 & 20.0 & 1.6 & 3.0 & 2.5 \\
\hline Gochnatia polymorpha.......... & 5 & 3 & 0.46 & 60.00 & 1.72 & 25.0 & 1.6 & 2.0 & 1.9 \\
\hline Bauhinia germinata.......... & 5 & 3 & 0.46 & 60.00 & 1.72 & 25.0 & 1.6 & 4.2 & 2.3 \\
\hline 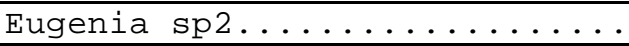 & 5 & 3 & 0.46 & 60.00 & 1.72 & 25.0 & 1.7 & 4.1 & 2.5 \\
\hline Vitex montevidensis.......... & 8 & 2 & 0.74 & 40.00 & 1.15 & 40.0 & 1.7 & 2.5 & 2.1 \\
\hline Allophyllus edulis........... & 4 & 3 & 0.37 & 60.00 & 1.72 & 20.0 & 2.0 & 4.0 & 2.8 \\
\hline Psychotria carthaginensis..... & 4 & 3 & 0.37 & 60.00 & 1.72 & 20.0 & 1.5 & 1.6 & 1.5 \\
\hline Calyptranthes concinna........ & 4 & 3 & 0.37 & 60.00 & 1.72 & 20.0 & 1.6 & 2.2 & 1.9 \\
\hline Schinus terebinthifolius...... & 4 & 3 & 0.37 & 60.00 & 1.72 & 20.0 & 1.5 & 3.0 & 2.3 \\
\hline ium $\mathrm{d}$ & 4 & 3 & 0.37 & 60.00 & 1.72 & 20.0 & 1.5 & 2.7 & 2.0 \\
\hline
\end{tabular}

Quadro 6.3 - Parâmetros fitossociológicos encontrados para as espécies amostradas no subbosque de E. grandis (talhão 48), 54 meses após a exploração da primeira rotação do povoamento de eucalipto, área amostral 0,2 ha, Tratamento 1 - Testemunha, onde: $\mathrm{N}^{\circ}$. Ind. Número de Indivíduos; $\mathrm{N}^{\circ}$ Amo - Número de unidades amostrais em que a espécie foi amostrada; Dens.re - Densidade relativa da espécie; Freq. Rel - Frequência relativa da espécie; Freq Ab - Frequência absoluta da espécie; Dens Ab - Densidade abusoluta da espécie; Alt Minaltura mínima amostrada na espécie; Alt Max - Altura máxima amostrada na espécie e Alt Med - Altura média apresentada pela espécie. 


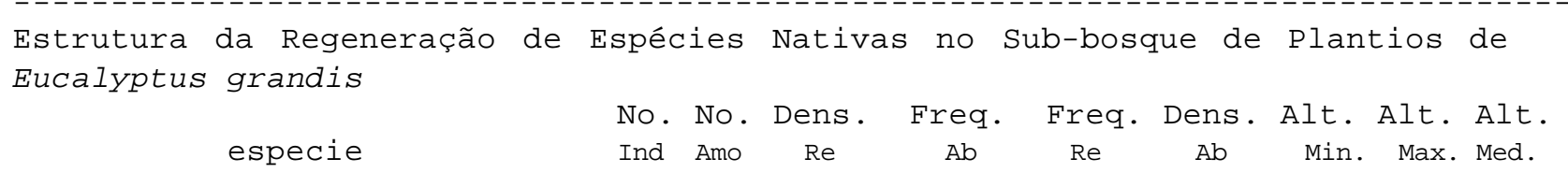

\begin{tabular}{|c|c|c|c|c|c|c|c|c|c|}
\hline Tabebuia chrysotricha......... & 3 & 3 & 0.28 & 60.00 & 1.72 & 15.0 & 1.7 & 1.8 & 1.7 \\
\hline Chomelia pohliana............ & 3 & 3 & 0.28 & 60.00 & 1.72 & 15.0 & 2.2 & 2.5 & 2.3 \\
\hline Blepharocalyx salicifolius.... & 6 & 2 & 0.56 & 40.00 & 1.15 & 30.0 & 1.6 & 2.1 & 1.9 \\
\hline Syagrus romanzoffiana......... & 6 & 2 & 0.56 & 40.00 & 1.15 & 30.0 & 2.8 & 4.7 & 3.5 \\
\hline Platypodium elegans........... & 5 & 2 & 0.46 & 40.00 & 1.15 & 25.0 & 4.0 & 5.0 & 4.5 \\
\hline Solanum bullatum............. & 4 & 2 & 0.37 & 40.00 & 1.15 & 20.0 & 1.7 & 7.0 & 3.4 \\
\hline Myrtaceae sp2........ & 4 & 2 & 0.37 & 40.00 & 1.15 & 20.0 & 1.5 & 2.2 & 1.8 \\
\hline Senna splendida............ & 4 & 2 & 0.37 & 40.00 & 1.15 & 20.0 & 2.5 & 3.0 & 2.6 \\
\hline Myrcia laruotteana............ & 3 & 2 & 0.28 & 40.00 & 1.15 & 15.0 & 1.6 & 2.0 & 1.8 \\
\hline Aegiphila sellowiana.......... & 3 & 2 & 0.28 & 40.00 & 1.15 & 15.0 & 3.0 & 5.0 & 3.8 \\
\hline Styrax acuminatus........... & 3 & 2 & 0.28 & 40.00 & 1.15 & 15.0 & 1.6 & 3.2 & 2.3 \\
\hline Tapirira guianensis........... & 6 & 1 & 0.56 & 20.00 & 0.57 & 30.0 & 1.5 & 3.5 & 2.2 \\
\hline Citrus limon................ & 2 & 2 & 0.19 & 40.00 & 1.15 & 10.0 & 2.0 & 2.5 & 2.3 \\
\hline Erythroxylum ambiguum......... & 2 & 2 & 0.19 & 40.00 & 1.15 & 10.0 & 1.6 & 1.8 & 1.7 \\
\hline Piper gaudichaudianum......... & 2 & 2 & 0.19 & 40.00 & 1.15 & 10.0 & 1.7 & 2.1 & 1.9 \\
\hline Endlicheria paniculata........ & 2 & 2 & 0.19 & 40.00 & 1.15 & 10.0 & 4.5 & 5.3 & 4.9 \\
\hline Coutarea hexandra............. & 5 & 1 & 0.46 & 20.00 & 0.57 & 25.0 & 1.5 & 1.7 & 1.6 \\
\hline Sebastiania klotzchiana....... & 4 & 1 & 0.37 & 20.00 & 0.57 & 20.0 & 1.6 & 3.3 & 2.4 \\
\hline 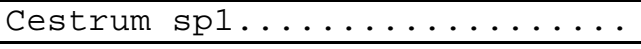 & 3 & 1 & 0.28 & 20.00 & 0.57 & 15.0 & 2.4 & 6.0 & 3.9 \\
\hline 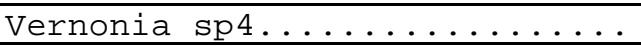 & 2 & 1 & 0.19 & 20.00 & 0.57 & 10.0 & 1.5 & 2.5 & 2.0 \\
\hline Senna bicapsulares............ & 2 & 1 & 0.19 & 20.00 & 0.57 & 10.0 & 2.0 & 2.0 & 2.0 \\
\hline Machaerium opacum............ & 2 & 1 & 0.19 & 20.00 & 0.57 & 10.0 & 1.5 & 1.8 & 1.6 \\
\hline Miconia langsdorfii.......... & 1 & 1 & 0.09 & 20.00 & 0.57 & 5.0 & 2.0 & 2.0 & 2.0 \\
\hline Alchornea triplinervia........ & 1 & 1 & 0.09 & 20.00 & 0.57 & 5.0 & 4.5 & 4.5 & 4.5 \\
\hline Helietta apiculata........... & 1 & 1 & 0.09 & 20.00 & 0.57 & 5.0 & 3.5 & 3.5 & 3.5 \\
\hline Persea pyrifolia............. & 1 & 1 & 0.09 & 20.00 & 0.57 & 5.0 & 1.7 & 1.7 & 1.7 \\
\hline Acalypha amblyodonta.......... & 1 & 1 & 0.09 & 20.00 & 0.57 & 5.0 & 1.6 & 1.6 & 1.6 \\
\hline Ixora venulosa............... & 1 & 1 & 0.09 & 20.00 & 0.57 & 5.0 & 1.8 & 1.8 & 1.8 \\
\hline 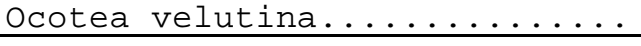 & 1 & 1 & 0.09 & 20.00 & 0.57 & 5.0 & 5.0 & 5.0 & 5.0 \\
\hline Ocotea velloziana............ & 1 & 1 & 0.09 & 20.00 & 0.57 & 5.0 & 4.0 & 4.0 & 4.0 \\
\hline Rhamnus shaerosperma.......... & 1 & 1 & 0.09 & 20.00 & 0.57 & 5.0 & 2.9 & 2.9 & 2.9 \\
\hline Maytenus evonymoidis......... & 1 & 1 & 0.09 & 20.00 & 0.57 & 5.0 & 2.6 & 2.6 & 2.6 \\
\hline
\end{tabular}

Quadro 6.3 - Parâmetros fitossociológicos encontrados para as espécies amostradas no sub-bosque de E. grandis (talhão 48), 54 meses após a exploração da primeira rotação do povoamento de eucalipto, área amostral 0,2 ha, Tratamento 1 - Testemunha, onde: $\mathrm{N}^{\circ}$. Ind. - Número de Indivíduos; $\mathrm{N}^{\circ}$ Amo Número de unidades amostrais em que a espécie foi amostrada; Dens.re Densidade relativa da espécie; Freq. Rel - Frequência relativa da espécie; Freq Ab - Frequência absoluta da espécie; Dens Ab - Densidade abusoluta da espécie; Alt Min- altura mínima amostrada na espécie; Alt Max - Altura máxima amostrada na espécie e Alt Med - Altura média apresentada pela espécie 


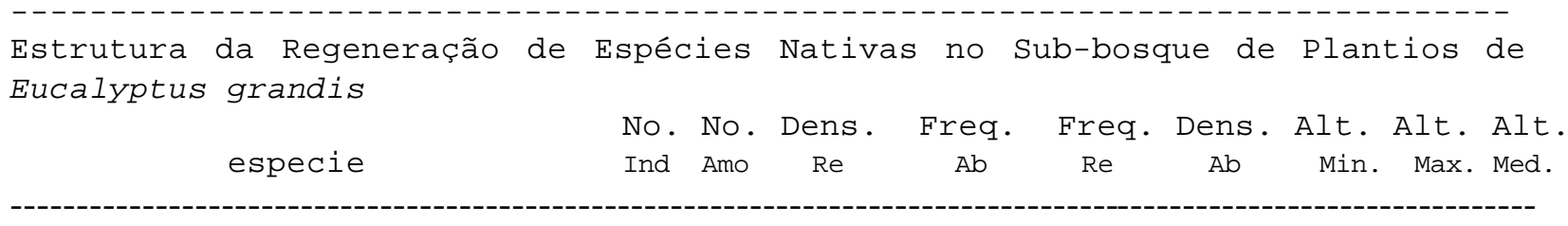

\begin{tabular}{|c|c|c|c|c|c|c|c|c|c|}
\hline Myrcia bella............... & 1 & 1 & 0.09 & 20.00 & 0.57 & 5.0 & 2.3 & 2.3 & 2.3 \\
\hline Eugenia pyriformis........... & 1 & 1 & 0.09 & 20.00 & 0.57 & 5.0 & 1.8 & 1.8 & 1.8 \\
\hline Casearia decandra............ & 1 & 1 & 0.09 & 20.00 & 0.57 & 5.0 & 1.7 & 1.7 & 1.7 \\
\hline Copaifera langsdorfii......... & 1 & 1 & 0.09 & 20.00 & 0.57 & 5.0 & 4.0 & 4.0 & 4.0 \\
\hline Chlorophora tinctoria......... & 1 & 1 & 0.09 & 20.00 & 0.57 & 5.0 & 1.7 & 1.7 & 1.7 \\
\hline Trema micrantha.............. & 1 & 1 & 0.09 & 20.00 & 0.57 & 5.0 & 1.8 & 1.8 & 1.8 \\
\hline Symplocus pubescens........... & 1 & 1 & 0.09 & 20.00 & 0.57 & 5.0 & 6.0 & 6.0 & 6.0 \\
\hline Cedrela fissilis & 1 & 1 & 0.09 & 20.00 & 0.57 & 5.0 & 3.3 & 3.3 & 3.3 \\
\hline
\end{tabular}

Quadro 6.3 - Parâmetros fitossociológicos encontrados para as espécies amostradas no sub-bosque de E. grandis (talhão 48), 54 meses após a exploração da primeira rotação do povoamento de eucalipto, área amostral 0,2 ha, Tratamento 1 - Testemunha, onde: $\mathrm{N}^{\circ}$. Ind. - Número de Indivíduos; $\mathrm{N}^{\circ} \mathrm{Amo}^{-}$ Número de unidades amostrais em que a espécie foi amostrada; Dens.re Densidade relativa da espécie; Freq. Rel - Frequência relativa da espécie; Freq Ab - Frequência absoluta da espécie; Dens Ab - Densidade abusoluta da espécie; Alt Min- altura mínima amostrada na espécie; Alt Max - Altura máxima amostrada na espécie e Alt Med - Altura média apresentada pela espécie 


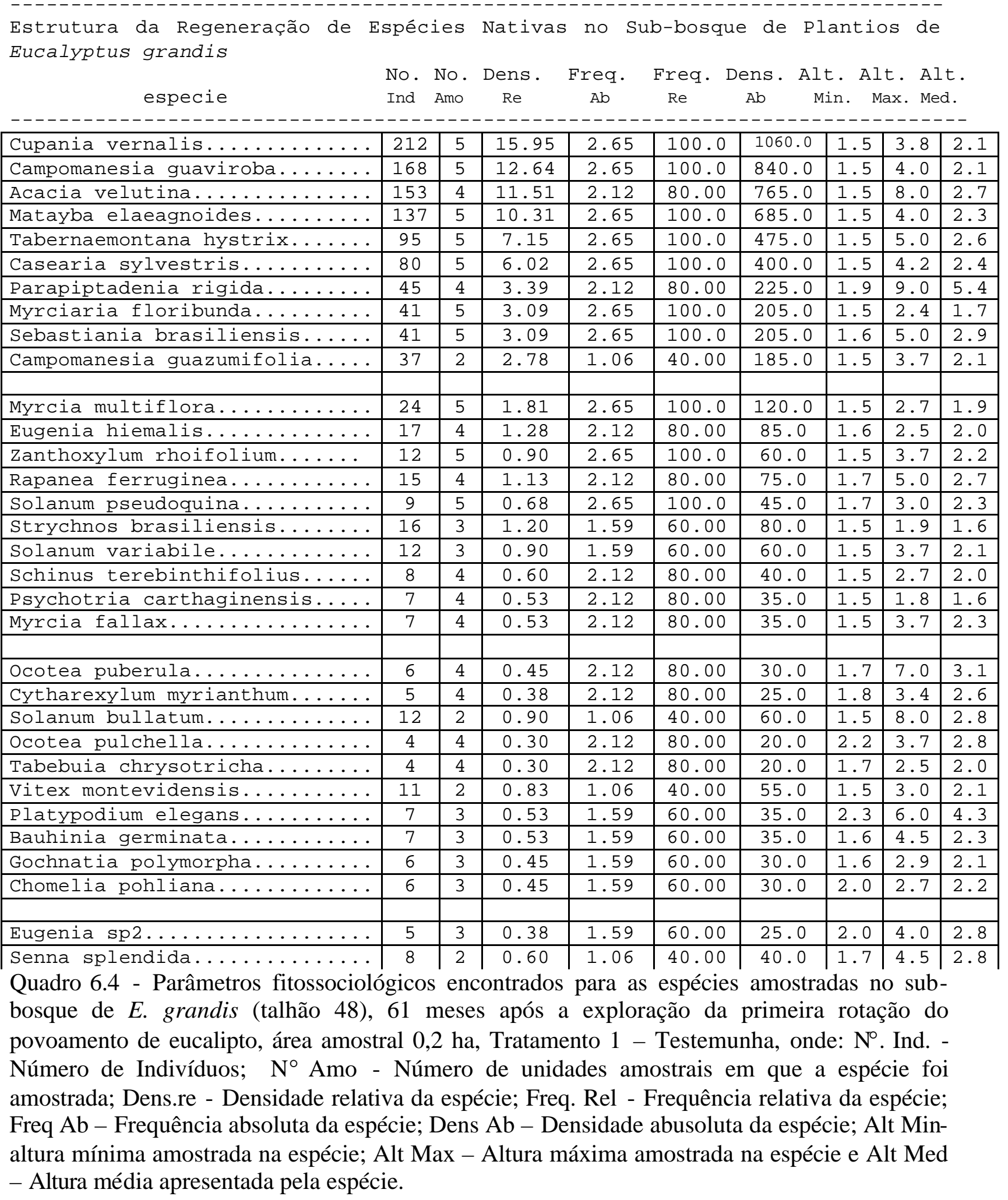




\begin{tabular}{|c|c|c|c|c|c|c|c|c|c|}
\hline $\begin{array}{l}\text { Estrutura da Regeneração de } \\
\text { Eucalyptus grandis }\end{array}$ & $\begin{array}{l}\text { No. } \\
\text { Ind }\end{array}$ & $\begin{array}{l}\text { No. } \\
\text { Amo }\end{array}$ & $\begin{array}{l}\text { Nativa } \\
\text { Dens. } \\
\text { Re }\end{array}$ & $\begin{array}{l}\text { no } \\
\text { Freq. } \\
\text { Ab }\end{array}$ & $\begin{array}{l}\text { Freq. } \mathrm{D} \\
\mathrm{Re}\end{array}$ & $\begin{array}{l}\text { Dens. } \\
\text { Ab }\end{array}$ & & & \\
\hline Calyptranthes concinna........ & 4 & 3 & 0.30 & 1.59 & 60.00 & 20.0 & 1.5 & 2.7 & 1.9 \\
\hline Styrax acuminatus........... & 4 & 3 & 0.30 & 1.59 & 60.00 & 20.0 & 1.5 & 3.4 & 2.1 \\
\hline Miconia ligustroides.......... & 4 & 3 & 0.30 & 1.59 & 60.00 & 20.0 & 1.7 & 3.5 & 2.5 \\
\hline Allophyllus edulis........... & 4 & 3 & 0.30 & 1.59 & 60.00 & 20.0 & 2.0 & 3.5 & 2.8 \\
\hline Myrtaceae sp2......... & 7 & 2 & 0.53 & 1.06 & 40.00 & 35.0 & 1.6 & 2.2 & 1.8 \\
\hline Tapirira guianensis.......... & 7 & 2 & 0.53 & 1.06 & 40.00 & 35.0 & 1.7 & 3.7 & 2.3 \\
\hline 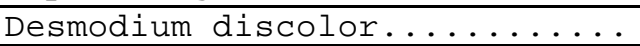 & 3 & 3 & 0.23 & 1.59 & 60.00 & 15.0 & 1.5 & 2.5 & 2.0 \\
\hline Blepharocalyx salicifolius.... & 6 & 2 & 0.45 & 1.06 & 40.00 & 30.0 & 2.0 & 2.4 & 2.1 \\
\hline 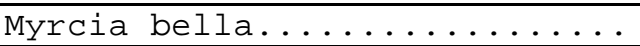 & 5 & 2 & 0.38 & 1.06 & 40.00 & 25.0 & 1.5 & 2.7 & 1.9 \\
\hline Syagrus romanzoffiana......... & 5 & 2 & 0.38 & 1.06 & 40.00 & 25.0 & 3.7 & 5.0 & 4.3 \\
\hline Coutarea hexandra............ & 8 & 1 & 0.60 & 0.53 & 20.00 & 40.0 & 1.7 & 2.0 & 1.9 \\
\hline Myrcia laruotteana........... & 3 & 2 & 0.23 & 1.06 & 40.00 & 15.0 & 1.7 & 1.9 & 1.8 \\
\hline Aegiphila sellowiana.......... & 3 & 2 & 0.23 & 1.06 & 40.00 & 15.0 & 2.7 & 5.5 & 4.1 \\
\hline Citrus limon................. & 2 & 2 & 0.15 & 1.06 & 40.00 & 10.0 & 2.0 & 2.7 & 2.3 \\
\hline Erythroxylum ambiguum......... & 2 & 2 & 0.15 & 1.06 & 40.00 & 10.0 & 1.7 & 2.1 & 1.9 \\
\hline Piper gaudichaudianum......... & 2 & 2 & 0.15 & 1.06 & 40.00 & 10.0 & 1.8 & 1.9 & 1.8 \\
\hline Endlicheria paniculata........ & 2 & 2 & 0.15 & 1.06 & 40.00 & 10.0 & 5.0 & 5.5 & 5.3 \\
\hline Sebastiania klotzchiana...... & 4 & 1 & 0.30 & 0.53 & 20.00 & 20.0 & 1.9 & 3.7 & 2.8 \\
\hline Vernonia scorpioides.......... & 3 & 1 & 0.23 & 0.53 & 20.00 & 15.0 & 1.7 & 1.9 & 1.8 \\
\hline 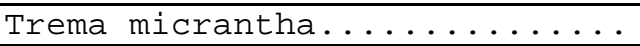 & 3 & 1 & 0.23 & 0.53 & 20.00 & 15.0 & 1.5 & 2.5 & 1.9 \\
\hline 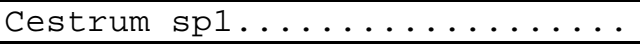 & 3 & 1 & 0.23 & 0.53 & 20.00 & 15.0 & 2.7 & 3.5 & 3.0 \\
\hline Maytenus evonymoidis.......... & 2 & 1 & 0.15 & 0.53 & 20.00 & 10.0 & 1.6 & 3.0 & 2.3 \\
\hline Senna bicapsulares........... & 2 & 1 & 0.15 & 0.53 & 20.00 & 10.0 & 2.0 & 2.0 & 2.0 \\
\hline Machaerium opacum............ & 2 & 1 & 0.15 & 0.53 & 20.00 & 10.0 & 1.9 & 2.1 & 2.0 \\
\hline Eupatorium laevigatum......... & 2 & 1 & 0.15 & 0.53 & 20.00 & 10.0 & 1.6 & 1.7 & 1.7 \\
\hline Ocotea velutina............. & 1 & 1 & 0.08 & 0.53 & 20.00 & 5.0 & 5.0 & 5.0 & 5.0 \\
\hline Ixora venulosa............... & 1 & 1 & 0.08 & 0.53 & 20.00 & 5.0 & 2.0 & 2.0 & 2.0 \\
\hline Ocotea velloziana............ & 1 & 1 & 0.08 & 0.53 & 20.00 & 5.0 & 4.2 & 4.2 & 4.2 \\
\hline Rhamnus shaerosperma......... & 1 & 1 & 0.08 & 0.53 & 20.00 & 5.0 & 3.5 & 3.5 & 3.5 \\
\hline Helietta apiculata........... & 1 & 1 & 0.08 & 0.53 & 20.00 & 5.0 & 4.3 & 4.3 & 4.3 \\
\hline Psidium cinereum............ & 1 & 1 & 0.08 & 0.53 & 20.00 & 5.0 & 1.5 & 1.5 & 1.5 \\
\hline Casearia decandra............ & 1 & 1 & 0.08 & 0.53 & 20.00 & 5.0 & 3.3 & 3.3 & 3.3 \\
\hline Eugenia sp. & 1 & 1 & 0.08 & 0.53 & 20.00 & 5.0 & 1.5 & 1.5 & 1.5 \\
\hline
\end{tabular}

Quadro 6.4 - Parâmetros fitossociológicos encontrados para as espécies amostradas no subbosque de E. grandis (talhão 48), 61 meses após a exploração da primeira rotação do povoamento de eucalipto, área amostral 0,2 ha, Tratamento 1 - Testemunha, onde: $\mathrm{N}^{\circ}$. Ind. Número de Indivíduos; $\mathrm{N}^{\circ}$ Amo - Número de unidades amostrais em que a espécie foi amostrada; Dens.re - Densidade relativa da espécie; Freq. Rel - Frequência relativa da espécie; Freq Ab - Frequência absoluta da espécie; Dens Ab - Densidade abusoluta da espécie; Alt Minaltura mínima amostrada na espécie; Alt Max - Altura máxima amostrada na espécie e Alt Med - Altura média apresentada pela espécie. 


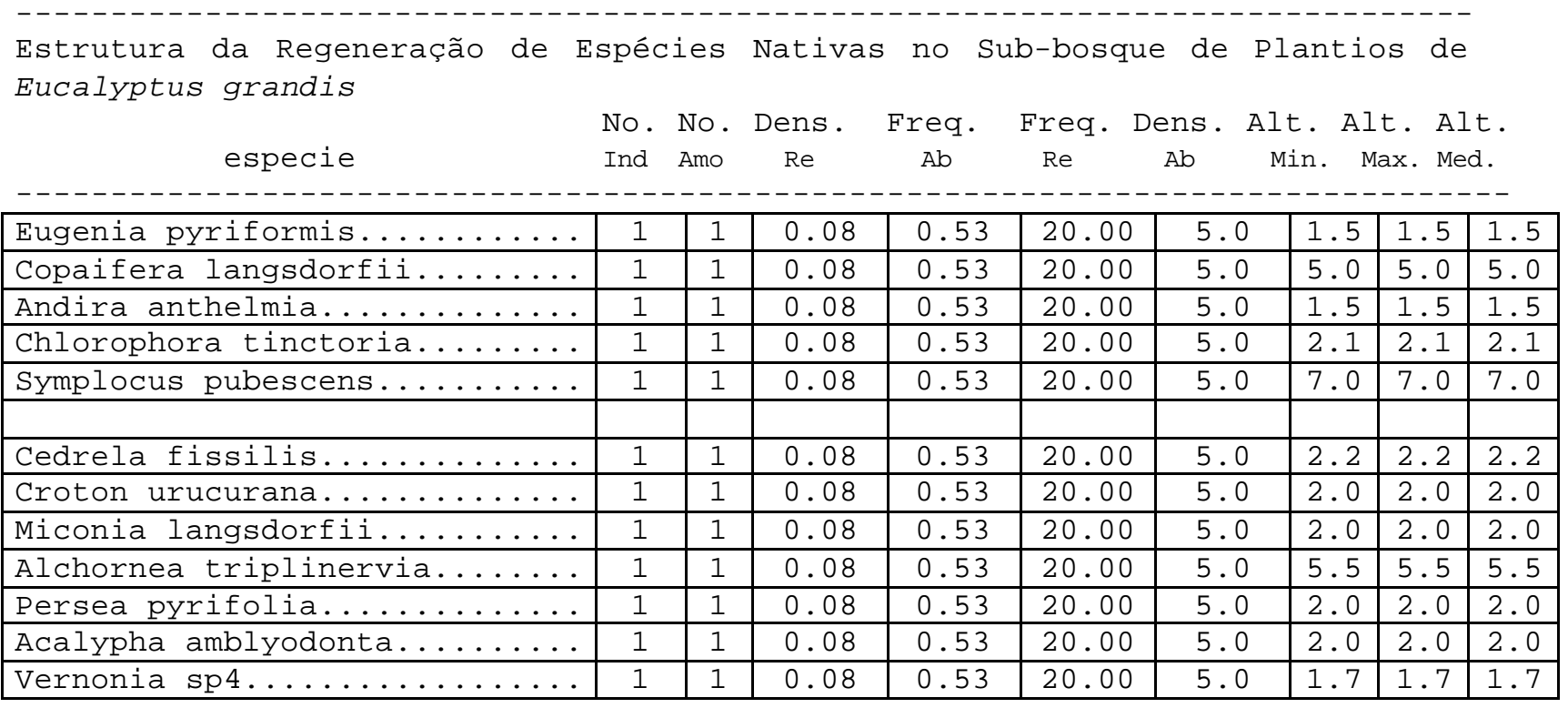

Quadro 6.4 - Parâmetros fitossociológicos encontrados para as espécies amostradas no subbosque de E. grandis (talhão 48), 61 meses após a exploração da primeira rotação do povoamento de eucalipto, área amostral 0,2 ha, Tratamento 1 - Testemunha, onde: $\mathrm{N}^{\circ}$. Ind. Número de Indivíduos; $\mathrm{N}^{\circ}$ Amo - Número de unidades amostrais em que a espécie foi amostrada; Dens.re - Densidade relativa da espécie; Freq. Rel - Frequência relativa da espécie; Freq Ab - Frequência absoluta da espécie; Dens Ab - Densidade abusoluta da espécie; Alt Minaltura mínima amostrada na espécie; Alt Max - Altura máxima amostrada na espécie e Alt Med - Altura média apresentada pela espécie. 
Conjunto de Quadros 7 - Parâmetros Fitossociológicos das espécies e famílias amostradas no tratamento 2 - desbaste de $50 \%$ do povoamento de E. grandis nos diversos levantamentos do Sub-bosque do Talhão 48.

Estrutura da Regeneração de Espécies Nativas no Sub-bosque de Plantios de Eucalyptus grandis

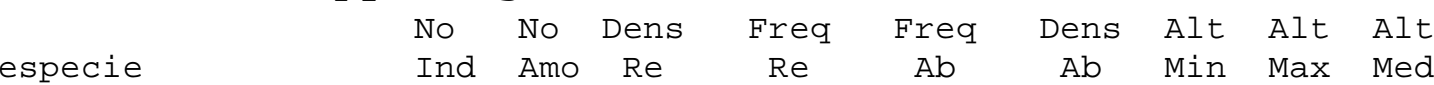

\begin{tabular}{|c|c|c|c|c|c|c|c|c|c|}
\hline 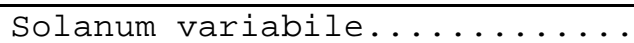 & 147 & 6 & 24.50 & 3.68 & 100.0 & 612.5 & 1.5 & 4.5 & 2.0 \\
\hline $\begin{array}{l}\text { Matayba } \\
\text { elaeagnoides........... }\end{array}$ & 88 & 6 & 14.67 & 3.68 & 100.0 & 366.7 & 1.5 & 3.0 & 1.9 \\
\hline Casearia sylvestris.... & 46 & 6 & 7.67 & 3.68 & 100.0 & 191.7 & 1.5 & 2.6 & 2.0 \\
\hline 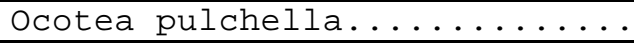 & 27 & 6 & 4.50 & 3.68 & 100.0 & 112.5 & 1.5 & 5.0 & 2.5 \\
\hline Baccharis dracunculifolia..... & 20 & 5 & 3.33 & 3.07 & 83.33 & 83.3 & 1.7 & 3.5 & 2.4 \\
\hline Gochnatia polymorpha........... & 17 & $\xi$ & 2.83 & 3.68 & 100.0 & 70.8 & 1.5 & 3.1 & 2.2 \\
\hline Acacia velutina.... & 21 & 3 & 3.50 & 1.84 & 50.00 & 87.5 & 1.6 & 4.5 & 2.2 \\
\hline Zanthoxylum rhoifolium....... & 14 & 5 & 2.33 & 3.07 & 83.33 & 58.3 & 1.5 & 4.0 & 2.2 \\
\hline Schinus terebinthifolius...... & 15 & 4 & 2.50 & 2.45 & 66.67 & 62.5 & 1.6 & 4.1 & 2.5 \\
\hline Cedrela fissilis.............. & 12 & 4 & 2.00 & 2.45 & 66.67 & 50.0 & 1.5 & 6.0 & 2.7 \\
\hline Iyr & 10 & & & & 83.33 & 1.7 & 1.6 & 2.0 & 1.8 \\
\hline Cytharexylum myrianthum....... & 11 & & 1.83 & 1.84 & 50.00 & 45.8 & 1.5 & 4.5 & 2.5 \\
\hline 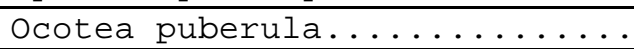 & 9 & & 1.50 & 2.45 & 66.67 & 37.5 & 1.6 & 3.0 & 2.2 \\
\hline Rhamnus shaerosper & 10 & & 1.67 & 1.84 & 50.00 & 41.7 & 2.0 & 3.5 & 2.9 \\
\hline Rapanea umbellata. & 9 & & 1.50 & 1.84 & 50.00 & 37.5 & 1.5 & 3.5 & 2.5 \\
\hline Tapirira guianensis.... & 5 & & 0.83 & 3.07 & 83.33 & 20.8 & 1.5 & 3.0 & 2.2 \\
\hline Syagrus romanzoffiana... & 8 & & 1.33 & 1.84 & 50.00 & 33.3 & 1.7 & 3.5 & 2.3 \\
\hline Styrax acuminatus.. & 8 & & 1.33 & 1.84 & 50.00 & 33.3 & 1.6 & 4.0 & 2.6 \\
\hline Parapiptadenia rigida. & 6 & & 1.00 & 2.45 & 66.67 & 25.0 & 1.7 & 5.0 & 3.2 \\
\hline Miconia ligustroides...... & 6 & 4 & 1.00 & 2.45 & 66.67 & 25.0 & 1.6 & 1.8 & 1.7 \\
\hline & & & & & & & & & \\
\hline Rapanea ferruginea. & 7 & & 1.17 & 1.84 & 50.00 & 29.2 & 1.5 & 2.6 & 2.1 \\
\hline 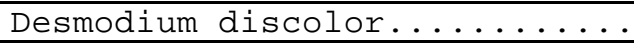 & 7 & 3 & 1.17 & 1.84 & 50.00 & 29.2 & 1.6 & 3.0 & 2.3 \\
\hline Platypodium elegans........... & 6 & 3 & 1.00 & 1.84 & 50.00 & 25.0 & 2.2 & 5.0 & 3.6 \\
\hline 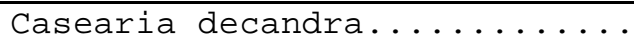 & 7 & 2 & 1.17 & 1.23 & 33.33 & 29.2 & 1.6 & 4.0 & 2.4 \\
\hline 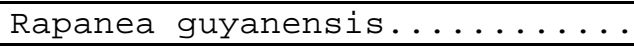 & 4 & 3 & 0.67 & 1.84 & 50.00 & 16.7 & 1.5 & 2.0 & 1.7 \\
\hline Campomanesia guavirob & 5 & 2 & 0.83 & 1.23 & 33.33 & 20.8 & 1.6 & 2.2 & 1.9 \\
\hline
\end{tabular}

Quadro 7.1 - Parâmetros fitossociológicos encontrados para as espécies amostradas no subbosque de $E$. grandis (talhão 48), tratamento 2 - desbaste de $50 \%$ do povoamento de $E$. grandis, 30 meses após a exploração da primeira rotação do povoamento, onde: $\mathrm{N}^{\circ}$. Ind. - Número de Indivíduos; $\mathrm{N}^{\circ}$ Amo - Número de unidades amostrais em que a espécie foi amostrada; Dens.re Densidade relativa da espécie; Freq. Rel - Frequência relativa da espécie; Freq Ab - Frequência absoluta da espécie; Dens Ab - Densidade abusoluta da espécie; Alt Min- altura mínima amostrada na espécie; Alt Max - Altura máxima amostrada na espécie e Alt Med - Altura média apresentada pela espécie. 
Estrutura da Regeneração de Espécies Nativas no Sub-bosque de Plantios de Eucalyptus grandis

$\begin{array}{lccccccc} & \text { No } & \text { No } & \text { Dens } & \text { Freq } & \text { Freq } & \text { Dens Alt Alt Alt } \\ \text { especie } & \text { Ind Amo } & \operatorname{Re} & \operatorname{Re} & \mathrm{Ab} & \mathrm{Ab} & \text { Min Max Med }\end{array}$

\begin{tabular}{|c|c|c|c|c|c|c|c|c|c|}
\hline Sebastiania brasili & 5 & 2 & 0.83 & 1.23 & 33.33 & 20.8 & 2.0 & 4.0 & 2.6 \\
\hline Eugenia hiemalis............ & 3 & 3 & 0.50 & 1.84 & 50.00 & 12.5 & 1.6 & 2.0 & 1.8 \\
\hline Calyptranthes concinna......... & 3 & 3 & 0.50 & 1.84 & 50.00 & 12.5 & 1.5 & 1.7 & 1.6 \\
\hline Campomanesia guazumifolia..... & 4 & 2 & 0.67 & 1.23 & 33.33 & 16.7 & 2.0 & 2.5 & 2.3 \\
\hline Acnistus cauliflorus........... & 3 & 2 & 0.50 & 1.23 & 33.33 & 12.5 & 2.0 & 4.0 & 2.8 \\
\hline Bauhinia germinata............. & 4 & 1 & 0.67 & 0.61 & 16.67 & 16.7 & 2.0 & 2.5 & 2.2 \\
\hline Allophyllus edulis............. & 2 & 2 & 0.33 & 1.23 & 33.33 & 8.3 & 1.8 & 2.5 & 2.2 \\
\hline 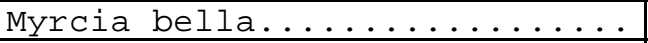 & 2 & 2 & 0.33 & 1.23 & 33.33 & 8.3 & 1.6 & 1.7 & 1.7 \\
\hline Eugenia $\operatorname{sp} 2 \ldots \ldots \ldots \ldots \ldots$ & 2 & 2 & 0.33 & 1.23 & 33.33 & 8.3 & 1.6 & 2.8 & 2.2 \\
\hline Vernonia polyanthes........... & 2 & 2 & 0.33 & 1.23 & 33.33 & 8.3 & 1.7 & 1.7 & 1.7 \\
\hline Tabernaemontana hystrix....... & 2 & 2 & 0.33 & 1.23 & 33.33 & 8.3 & 1.9 & 2.4 & 2.2 \\
\hline Ficus glabra................. & 2 & 2 & 0.33 & 1.23 & 33.33 & 8.3 & 2.4 & 3.0 & 2.7 \\
\hline Aegiphila sellowiana.......... & 2 & 2 & 0.33 & 1.23 & 33.33 & 8.3 & 2.7 & 4.0 & 3.3 \\
\hline Solanum pseudoquina........... & 2 & 2 & 0.33 & 1.23 & 33.33 & 8.3 & 2.5 & 5.5 & 4.0 \\
\hline Sida rhombifolia. & 2 & 1 & 0.33 & 0.61 & 16.67 & 8.3 & 1.6 & 2.5 & 2.0 \\
\hline Psychotria carthaginensis..... & 2 & 1 & 0.33 & 0.61 & 16.67 & 8.3 & 1.6 & 1.8 & 1.7 \\
\hline Esenbeckia febrifuga........... & 2 & 1 & 0.33 & 0.61 & 16.67 & 8.3 & 2.0 & 2.1 & 2.0 \\
\hline Tabebuia chrysotricha.......... & 2 & 1 & 0.33 & 0.61 & 16.67 & 8.3 & 1.5 & 1.7 & 1.6 \\
\hline Picramnia sellowii............. & 2 & 1 & 0.33 & 0.61 & 16.67 & 8.3 & 2.0 & 2.0 & 2.0 \\
\hline Machaerium acutifolium........ & 2 & 1 & 0.33 & 0.61 & 16.67 & 8.3 & 1.7 & 2.4 & 2.1 \\
\hline Leandra lacunosa............... & 2 & 1 & 0.33 & 0.61 & 16.67 & 8.3 & 1.7 & 1.8 & 1.8 \\
\hline Strychnos brasiliensis........ & 1 & 1 & 0.17 & 0.61 & 16.67 & 4.2 & 1.6 & 1.6 & 1.6 \\
\hline 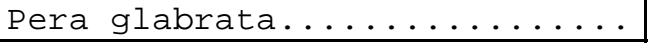 & 1 & 1 & 0.17 & 0.61 & 16.67 & 4.2 & 2.0 & 2.0 & 2.0 \\
\hline 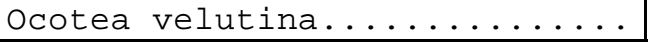 & 1 & 1 & 0.17 & 0.61 & 16.67 & 4.2 & 3.5 & 3.5 & 3.5 \\
\hline 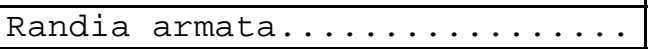 & 1 & 1 & 0.17 & 0.61 & 16.67 & 4.2 & 2.7 & 2.7 & 2.7 \\
\hline 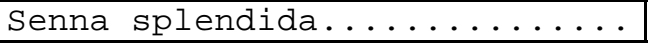 & 1 & 1 & 0.17 & 0.61 & 16.67 & 4.2 & 1.5 & 1.5 & 1.5 \\
\hline 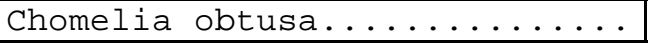 & 1 & 1 & 0.17 & 0.61 & 16.67 & 4.2 & 2.0 & 2.0 & 2.0 \\
\hline 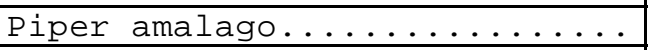 & 1 & 1 & 0.17 & 0.61 & 16.67 & 4.2 & 1.5 & 1.5 & 1.5 \\
\hline Piper aduncum & 1 & 1 & 0.17 & 0.61 & 16.67 & 4.2 & 2.1 & 2.1 & 2.1 \\
\hline
\end{tabular}

Quadro 7.1 - Parâmetros fitossociológicos encontrados para as espécies amostradas no subbosque de E. grandis (talhão 48), tratamento 2 - desbaste de $50 \%$ do povoamento de E. grandis, 30 meses após a exploração da primeira rotação do povoamento, onde: $\mathrm{N}^{\circ}$. Ind. - Número de Indivíduos; $\mathrm{N}^{\circ}$ Amo - Número de unidades amostrais em que a espécie foi amostrada; Dens.re Densidade relativa da espécie; Freq. Rel - Frequência relativa da espécie; Freq Ab - Frequência absoluta da espécie; Dens Ab - Densidade abusoluta da espécie; Alt Min- altura mínima amostrada na espécie; Alt Max - Altura máxima amostrada na espécie e Alt Med - Altura média apresentada pela espécie. 
Estrutura da Regeneração de Espécies Nativas no Sub-bosque de Plantios de Eucalyptus grandis

$\begin{array}{llcccccc} & \text { No } & \text { No Dens } & \text { Freq } & \text { Freq } & \text { Dens Alt Alt Alt } \\ \text { especie } & \text { Ind } & \text { Amo } & \text { Re } & \text { Re } & \text { Ab } & \text { Ab } & \text { Min Max Med }\end{array}$

\begin{tabular}{|c|c|c|c|c|c|c|c|c|c|}
\hline Endlicheria panicul & 1 & 1 & 0.17 & 0.61 & 16.67 & 4.2 & 1.9 & 1.9 & 1.9 \\
\hline Myrcia guianensis............ & 1 & 1 & 0.17 & 0.61 & 16.67 & 4.2 & 2.1 & 2.1 & 2.1 \\
\hline Helietta apiculata............ & 1 & 1 & 0.17 & 0.61 & 16.67 & 4.2 & 1.6 & 1.6 & 1.6 \\
\hline Citronella paniculata......... & 1 & 1 & 0.17 & 0.61 & 16.67 & 4.2 & 1.6 & 1.6 & 1.6 \\
\hline Didymopanax $\operatorname{sp} \ldots \ldots \ldots \ldots \ldots . . . .$. & 1 & 1 & 0.17 & 0.61 & 16.67 & 4.2 & 1.5 & 1.5 & 1.5 \\
\hline Eugenia pyriformis. & 1 & 1 & 0.17 & 0.61 & 16.67 & 4.2 & 1.6 & 1.6 & 1.6 \\
\hline Pterocarpus rohrii.... & 1 & 1 & 0.17 & 0.61 & 16.67 & 4.2 & 2.5 & 2.5 & 2.5 \\
\hline Vernonia $\operatorname{sp} 3 \ldots \ldots \ldots \ldots \ldots \ldots$ & 1 & 1 & 0.17 & 0.61 & 16.67 & 4.2 & 2.0 & 2.0 & 2.0 \\
\hline Campomanesia cf pubescens..... & 1 & 1 & 0.17 & 0.61 & 16.67 & 4.2 & 1.5 & 1.5 & 1.5 \\
\hline Blepharocalyx salicifolius.... & 1 & 1 & 0.17 & 0.61 & 16.67 & 4.2 & 2.5 & 2.5 & 2.5 \\
\hline Machaerium brasiliense........ & 1 & 1 & 0.17 & 0.61 & 16.67 & 4.2 & 6.0 & 6.0 & 6.0 \\
\hline Vitex montevidensis........... & 1 & 1 & 0.17 & 0.61 & 16.67 & 4.2 & 1.8 & 1.8 & 1.8 \\
\hline 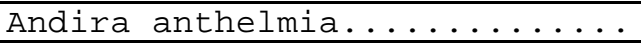 & 1 & 1 & 0.17 & 0.61 & 16.67 & 4.2 & 2.4 & 2.4 & 2.4 \\
\hline 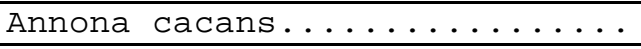 & 1 & 1 & 0.17 & 0.61 & 16.67 & 4.2 & 2.2 & 2.2 & 2.2 \\
\hline Lithraea molleoides.......... & 1 & 1 & 0.17 & 0.61 & 16.67 & 4.2 & 2.1 & 2.1 & 2.1 \\
\hline
\end{tabular}

Quadro 7.1 - Parâmetros fitossociológicos encontrados para as espécies amostradas no subbosque de $E$. grandis (talhão 48 ), tratamento 2 - desbaste de $50 \%$ do povoamento de $E$. grandis, 30 meses após a exploração da primeira rotação do povoamento, onde: $\mathrm{N}^{\circ}$. Ind. - Número de Indivíduos; $\mathrm{N}^{\circ}$ Amo - Número de unidades amostrais em que a espécie foi amostrada; Dens.re Densidade relativa da espécie; Freq. Rel - Frequência relativa da espécie; Freq Ab - Frequência absoluta da espécie; Dens Ab - Densidade abusoluta da espécie; Alt Min- altura mínima amostrada na espécie; Alt Max - Altura máxima amostrada na espécie e Alt Med - Altura média apresentada pela espécie. 
Estrutura da Regeneração de Espécies Nativas no Sub-bosque de Plantios de Eucalyptus grandis

$\begin{array}{lllccccc} & \text { No No Dens } & \text { Freq } & \text { Freq } & \text { Dens Alt Alt Alt } \\ \text { especie } & \text { Ind Amo } & \text { Re } & \text { Re } & \text { Ab } & \text { Ab } & \text { Min } & \text { Max Med }\end{array}$

\begin{tabular}{|c|c|c|c|c|c|c|c|c|c|}
\hline Matayba elaeagnoides........... & 190 & 6 & 25.37 & 2.86 & 100.0 & 791.7 & 1.5 & 5.5 & 2.2 \\
\hline Solanum variabile............ & 62 & 5 & 8.28 & 2.38 & 83.33 & 258.3 & 1.5 & 3.0 & 2.0 \\
\hline Casearia sylvestris.......... & 53 & 6 & 7.08 & 2.86 & 100.0 & 220.8 & 1.5 & 3.5 & 2.3 \\
\hline Ocotea pulchella............ & 28 & 6 & 3.74 & 2.86 & 100.0 & 116.7 & 1.7 & 5.0 & 2.7 \\
\hline Miconia ligustroides.......... & 25 & 6 & 3.34 & 2.86 & 100.0 & 104.2 & 1.5 & 2.6 & 1.7 \\
\hline Myrcia multiflora............ & 19 & 6 & 2.54 & 2.86 & 100.0 & 79.2 & 1.5 & 2.6 & 2.0 \\
\hline Campomanesia guaviroba........ & 24 & 3 & 3.20 & 1.43 & 50.00 & 100.0 & 1.5 & 2.7 & 1.9 \\
\hline Cedrela fissilis............ & 18 & 6 & 2.40 & 2.86 & 100.0 & 75.0 & 1.6 & 5.0 & 3.0 \\
\hline Zanthoxylum rhoifolium....... & 18 & 6 & 2.40 & 2.86 & 100.0 & 75.0 & 1.5 & 4.6 & 2.5 \\
\hline Schinus terebinthifolius...... & 19 & 5 & 2.54 & 2.38 & 83.33 & 79.2 & 1.5 & 3.5 & 2.5 \\
\hline Acacia velutina.............. & 20 & 4 & 2.67 & 1.90 & 66.67 & 83.3 & 1.5 & 4.5 & 2.5 \\
\hline Cytharexylum myrianthum....... & 15 & 4 & 2.00 & 1.90 & 66.67 & 62.5 & 1.5 & 4.0 & 2.2 \\
\hline Gochnatia polymorpha.......... & 11 & 6 & 1.47 & 2.86 & 100.0 & 45.8 & 1.5 & 5.0 & 2.5 \\
\hline Rhamnus shaerosperma......... & 12 & 4 & 1.60 & 1.90 & 66.67 & 50.0 & 2.3 & 5.2 & 3.6 \\
\hline Styrax acuminatus............ & 12 & 4 & 1.60 & 1.90 & 66.67 & 50.0 & 1.6 & 4.0 & 2.7 \\
\hline Rapanea ferruginea........... & 12 & 4 & 1.60 & 1.90 & 66.67 & 50.0 & 1.5 & 5.0 & 2.6 \\
\hline Ocotea puberula............. & 11 & 4 & 1.47 & 1.90 & 66.67 & 45.8 & 1.6 & 4.0 & 2.4 \\
\hline Myrcia laruotteana........... & 9 & 5 & 1.20 & 2.38 & 83.33 & 37.5 & 1.5 & 2.0 & 1.7 \\
\hline Rapanea umbellata........... & 10 & 3 & 1.34 & 1.43 & 50.00 & 41.7 & 1.6 & 4.6 & 2.9 \\
\hline Tapirira guianensis........... & 6 & 5 & 0.80 & 2.38 & 83.33 & 25.0 & 1.6 & 3.2 & 2.3 \\
\hline Desmodium discolor........... & 8 & 3 & 1.07 & 1.43 & 50.00 & 33.3 & 1.5 & 3.0 & 2.2 \\
\hline Psychotria carthaginensis..... & 6 & 4 & 0.80 & 1.90 & 66.67 & 25.0 & 1.5 & 2.0 & 1.7 \\
\hline Calyptranthes concinna........ & 6 & 4 & 0.80 & 1.90 & 66.67 & 25.0 & 1.5 & 2.1 & 1.7 \\
\hline Myrtaceae sp2......... & 6 & 4 & 0.80 & 1.90 & 66.67 & 25.0 & 1.5 & 1.7 & 1.6 \\
\hline Parapiptadenia rigida......... & 6 & 4 & 0.80 & 1.90 & 66.67 & 25.0 & 2.5 & 5.0 & 3.4 \\
\hline Tabernaemontana hystrix...... & 6 & 4 & 0.80 & 1.90 & 66.67 & 25.0 & 1.5 & 3.0 & 1.9 \\
\hline Allophyllus edulis........... & 6 & 4 & 0.80 & 1.90 & 66.67 & 25.0 & 1.5 & 2.7 & 2.1 \\
\hline Casearia decandra............ & 9 & 2 & 1.20 & 0.95 & 33.33 & 37.5 & 1.5 & 4.5 & 2.8 \\
\hline Myrciaria floribunda.......... & 5 & 4 & 0.67 & 1.90 & 66.67 & 20.8 & 1.6 & 2.0 & 1.7 \\
\hline Eugenia hiemalis............. & 5 & 4 & 0.67 & 1.90 & 66.67 & 20.8 & 1.5 & 2.5 & 1.9 \\
\hline Rapanea gu & 5 & 4 & 0.67 & 1.90 & 66.67 & 20.8 & 1.5 & 2.5 & 2.0 \\
\hline
\end{tabular}

Quadro 7.2 - Parâmetros fitossociológicos encontrados para as espécies amostradas no subbosque de E. grandis (talhão 48), tratamento 2 - Desbaste de $50 \%$ do povoamento de $E$. grandis, 45 meses após a exploração da primeira rotação do povoamento, onde: $\mathrm{N}^{\circ}$. Ind. Número de Indivíduos; $\quad \mathrm{N}^{\circ}$ Amo - Número de unidades amostrais em que a espécie foi amostrada; Dens.re - Densidade relativa da espécie; Freq. Rel - Frequência relativa da espécie; Freq Ab - Frequência absoluta da espécie; Dens Ab - Densidade abusoluta da espécie; Alt Minaltura mínima amostrada na espécie; Alt Max - Altura máxima amostrada na espécie e Alt Med - Altura média apresentada pela espécie. 


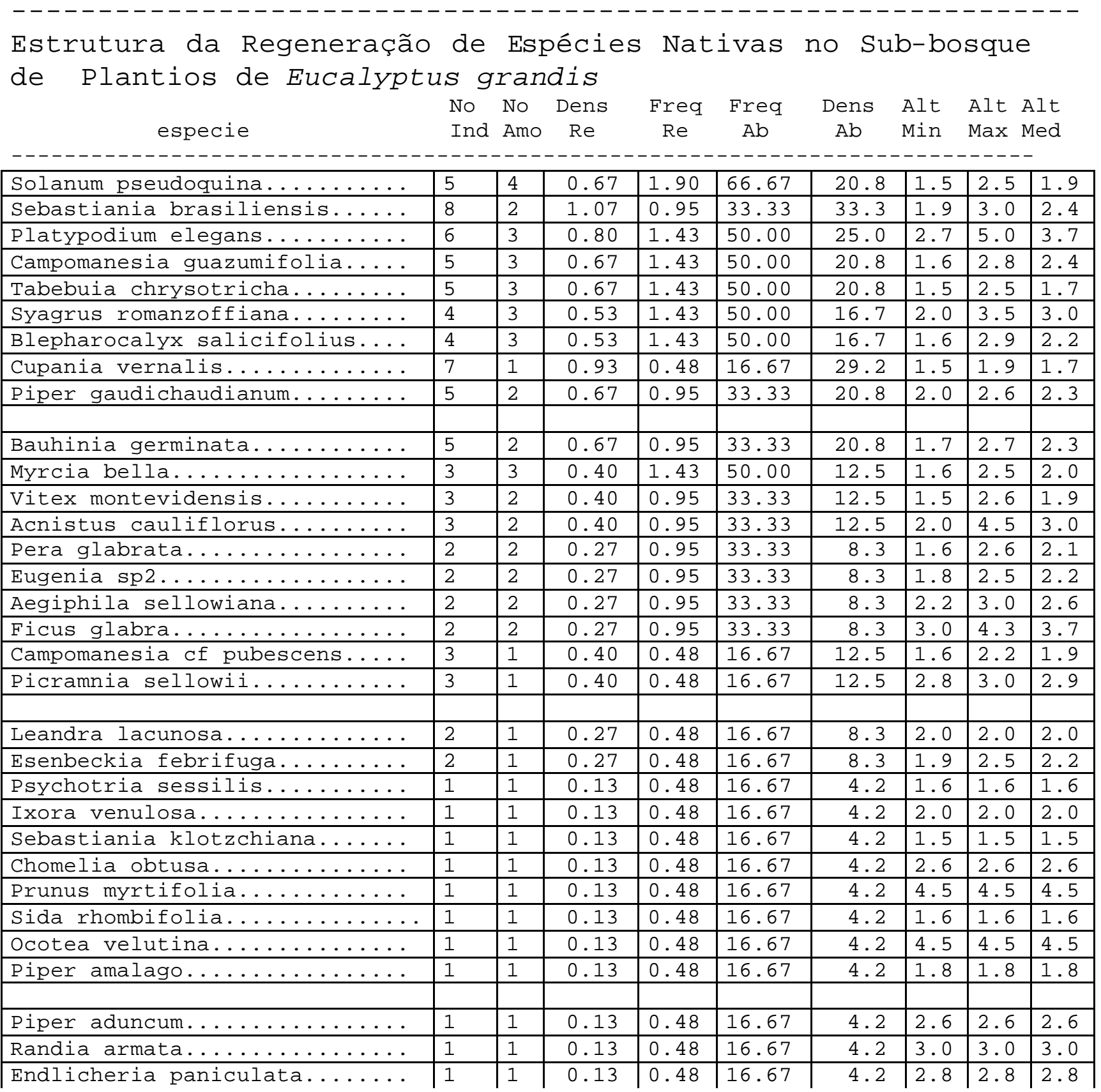

Quadro 7.2 - Parâmetros fitossociológicos encontrados para as espécies amostradas no subbosque de E. grandis (talhão 48), tratamento 2 - Desbaste de 50\% do povoamento de $E$. grandis, 45 meses após a exploração da primeira rotação do povoamento, onde: $\mathrm{N}^{\circ}$. Ind. Número de Indivíduos; $\quad \mathrm{N}^{\circ}$ Amo - Número de unidades amostrais em que a espécie foi amostrada; Dens.re - Densidade relativa da espécie; Freq. Rel - Frequência relativa da espécie; Freq Ab - Frequência absoluta da espécie; Dens Ab - Densidade abusoluta da espécie; Alt Minaltura mínima amostrada na espécie; Alt Max - Altura máxima amostrada na espécie e Alt Med - Altura média apresentada pela espécie. 


\begin{tabular}{|c|c|c|c|c|c|c|c|c|c|}
\hline \multirow{3}{*}{$\begin{array}{r}\text { Estrutura da } R \\
\text { de Plantios d } \\
\text { especie }\end{array}$} & \multicolumn{3}{|c|}{$\begin{array}{l}\text { Espécies } \\
\text { randis }\end{array}$} & \multicolumn{2}{|c|}{ Nativas } & \multicolumn{4}{|c|}{ Sub-bosque } \\
\hline & $\begin{array}{l}\text { No } \\
\text { Inc }\end{array}$ & $\begin{array}{l}\text { No } \\
\text { Amo }\end{array}$ & $\begin{array}{l}\text { Dens } \\
\text { Re }\end{array}$ & $\begin{array}{l}\text { Freq } \\
\text { Re }\end{array}$ & $\begin{array}{l}\text { Freq } \\
\mathrm{Ab}\end{array}$ & $\begin{array}{c}\text { Dens } \\
\mathrm{Ab}\end{array}$ & $\begin{array}{l}\text { Alt } \\
\text { Min }\end{array}$ & $\begin{array}{l}\text { Alt } \\
\text { Max }\end{array}$ & $\begin{array}{l}\text { Alt } \\
\text { Med }\end{array}$ \\
\hline & & & & & & & & & \\
\hline yrcia & 1 & 1 & 0 . & .48 & 6.67 & 4.2 & 2.7 & 2.7 & 2.7 \\
\hline itronella pan & 1 & 1 & & .4 & & 4.2 & .7 & 1 . & 1.7 \\
\hline enna splendida.... & 1 & 1 & & .48 & & 4 & .5 & & 1.5 \\
\hline accharis dracuncul & 7 & 1 & 0.13 & $.4 \xi$ & 6.6 & 4 & 2.5 & 2. & 2.5 \\
\hline ugenia pyriformis. & 7 & 1 & & .4 & & 4 & 1.7 & 1. & 1.7 \\
\hline terocarpus rohrii. & 1 & 1 & 0.1 & 0.4 & 16.67 & 4. & 2.6 & 2 . & 2.6 \\
\hline loysia virgata.... & 1 & 1 & .1 & 0.4 & 16.67 & 4. & 3.0 & 3. & 3.0 \\
\hline & & & & & & & & & \\
\hline achaerium bra & $\perp$ & & & & & & & & 6.0 \\
\hline Machaerium acutifolium.. & 1 & 1 & 0 . & 0.48 & 16.67 & 4.2 & 2.1 & 2.1 & 2.1 \\
\hline Vernonia $\operatorname{sp} 3 \ldots . . . \ldots$. & 1 & 1 & 0 . & 0.48 & 16.67 & 4.2 & 3.5 & 3.5 & 3.5 \\
\hline Cestrum sendtnerianum.. & 1 & 1 & 0.13 & 0.48 & 16.67 & 4.2 & 2.3 & 2.3 & 2.3 \\
\hline Chlorophora tinctoria.. & 1 & 1 & 0.13 & 0.48 & 16.67 & 4.2 & 2.0 & 2.0 & 2.0 \\
\hline ndira anthelmia... & 1 & 1 & 0 . & 0.48 & 16.67 & 4.2 & 3.0 & 3.0 & 3.0 \\
\hline ernonia polyanthes............ & 1 & 1 & 0.13 & 0.48 & 16.67 & 4.2 & 1.7 & 1.7 & 1.7 \\
\hline ithraea molleoides & 1 & 1 & 0.13 & 0.48 & 16.67 & 4.2 & 1.8 & 1.8 & 1.8 \\
\hline
\end{tabular}

Quadro 7.2 - Parâmetros fitossociológicos encontrados para as espécies amostradas no subbosque de E. grandis (talhão 48), tratamento 2 - Desbaste de $50 \%$ do povoamento de $E$. grandis, 45 meses após a exploração da primeira rotação do povoamento, onde: $\mathrm{N}^{\circ}$. Ind. Número de Indivíduos; $\quad \mathrm{N}^{\circ}$ Amo - Número de unidades amostrais em que a espécie foi amostrada; Dens.re - Densidade relativa da espécie; Freq. Rel - Frequência relativa da espécie; Freq Ab - Frequência absoluta da espécie; Dens Ab - Densidade abusoluta da espécie; Alt Minaltura mínima amostrada na espécie; Alt Max - Altura máxima amostrada na espécie e Alt Med - Altura média apresentada pela espécie. 


\begin{tabular}{|c|c|c|c|c|c|c|c|c|c|}
\hline \multicolumn{4}{|c|}{$\begin{array}{l}\text { Estrutura da Regeneração de Espécies Nativas } \\
\text { Eucalyptus grandis } \\
\text { especie } \\
\text { No. No. Dens. } \\
\text { Ind Amo Re }\end{array}$} & \multicolumn{6}{|c|}{$\begin{array}{l}\text { no Sub-bosque de Plantios de } \\
\begin{array}{c}\text { Freq. } \\
\text { Re }\end{array} \text { Ab } \quad \text { Ab } \text { Min Max Med }\end{array}$} \\
\hline \multicolumn{10}{|c|}{ 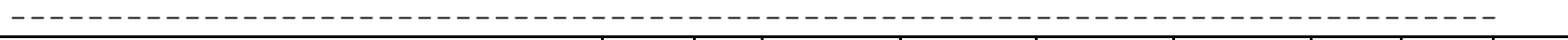 } \\
\hline $\begin{array}{l}\text { Matayba } \\
\text { elaeagnoides........... }\end{array}$ & 148 & 6 & 27.66 & 3.19 & 100.0 & 616.7 & 1.5 & 5.0 & 2.2 \\
\hline Casearia sylvestris........... & 39 & 6 & 7.29 & 3.19 & 100.0 & 162.5 & 1.5 & 4.1 & 2.4 \\
\hline Miconia ligustroides......... & 21 & 6 & 3.93 & 3.19 & 100.0 & 87.5 & 1.5 & 2.7 & 1.9 \\
\hline Myrcia multiflora............ & 21 & 5 & 3.93 & 2.66 & 83.33 & 87.5 & 1.5 & 3.2 & 2.1 \\
\hline Solanum variabile............ & 17 & 6 & 3.18 & 3.19 & 100.0 & 70.8 & 1.5 & 3.0 & 1.8 \\
\hline Ocotea pulchella............ & 18 & 5 & 3.36 & 2.66 & 83.33 & 75.0 & 2.0 & 5.1 & 2.9 \\
\hline Cytharexylum myrianthum....... & 16 & 4 & 2.99 & 2.13 & 66.67 & 66.7 & 1.5 & 3.6 & 2.3 \\
\hline Zanthoxylum rhoifolium....... & 13 & 6 & 2.43 & 3.19 & 100.0 & 54.2 & 1.5 & 4.6 & 2.6 \\
\hline 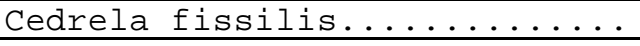 & 12 & 5 & 2.24 & 2.66 & 83.33 & 50.0 & 1.6 & 5.2 & 3.2 \\
\hline Acacia velutina.............. & 14 & 2 & 2.62 & 1.06 & 33.33 & 58.3 & 1.5 & 4.0 & 2.3 \\
\hline Campomanesia guaviroba........ & 11 & 4 & 2.06 & 2.13 & 66.67 & 45.8 & 1.5 & 3.3 & 2.1 \\
\hline Schinus terebinthifolius...... & 10 & 4 & 1.87 & 2.13 & 66.67 & 41.7 & 1.5 & 3.5 & 2.4 \\
\hline Rhamnus shaerosperma.......... & 10 & 4 & 1.87 & 2.13 & 66.67 & 41.7 & 2.0 & 5.2 & 3.4 \\
\hline Ocotea puberula.............. & 9 & 4 & 1.68 & 2.13 & 66.67 & 37.5 & 1.6 & 4.6 & 2.5 \\
\hline Rapanea ferruginea........... & 8 & 4 & 1.50 & 2.13 & 66.67 & 33.3 & 1.5 & 3.2 & 2.5 \\
\hline Parapiptadenia rigida......... & 7 & 4 & 1.31 & 2.13 & 66.67 & 29.2 & 2.2 & 5.0 & 3.7 \\
\hline Blepharocalyx salicifolius.... & 6 & 4 & 1.12 & 2.13 & 66.67 & 25.0 & 1.5 & 3.2 & 2.1 \\
\hline Gochnatia polymorpha.......... & 6 & 4 & 1.12 & 2.13 & 66.67 & 25.0 & 1.6 & 3.1 & 2.3 \\
\hline Myrcia laruotteana........... & 7 & 3 & 1.31 & 1.60 & & 29.2 & 1.5 & 2.0 & 1.7 \\
\hline Calyptranthes concinna........ & 5 & 4 & 0.93 & 2.13 & 67 & 20.8 & 1.5 & 2.0 & 1.8 \\
\hline Solanum pseudoquina.......... & 5 & 4 & 93 & 2.13 & 67 & 20.8 & 1.8 & 5.5 & 2.6 \\
\hline Rapanea umbellata........... & 6 & 3 & 1.12 & 1.60 & 50.00 & 25.0 & 1.7 & 4.0 & 2.8 \\
\hline Styrax acuminatus............ & 6 & 3 & 1.12 & 1.60 & 50.00 & 25.0 & 1.9 & 3.9 & 2.8 \\
\hline Rapanea guyanensis........... & 4 & 4 & 0.75 & 2.13 & 66.67 & 16.7 & 2.0 & 3.2 & 2.5 \\
\hline Tapirira guianensis.......... & 4 & 4 & 0.75 & 2.13 & 66.67 & 16.7 & 2.0 & 3.2 & 2.4 \\
\hline Bauhinia germinata........... & 5 & 3 & 0.93 & 1.60 & 50.00 & 20.8 & 1.7 & 3.0 & 2.2 \\
\hline 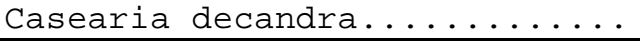 & 6 & 2 & 1.12 & 1.06 & 33.33 & 25.0 & 1.8 & 5.0 & 2.8 \\
\hline Myrciaria floribunda.......... & 4 & 3 & 0.75 & 1.60 & 50.00 & 16.7 & 1.6 & 2.0 & 1.8 \\
\hline Tabebuia chrysotricha.......... & 4 & 3 & 0.75 & 1.60 & 50.00 & 16.7 & 1.5 & 1.7 & 1.6 \\
\hline Sebastiania brasiliensis..... & 5 & 2 & 0.93 & 1.06 & 33.33 & 20.8 & 1.5 & 3.1 & 2.1 \\
\hline senbeckia & 5 & 2 & 0.93 & 1.06 & 33.33 & 20.8 & 2.0 & 3.0 & 2.3 \\
\hline
\end{tabular}

Quadro 7.3 -Parâmetros fitossociológicos encontrados para as espécies amostradas no subbosque de E. grandis (talhão 48), tratamento 2 - desbaste de $50 \%$ do povoamento de $E$. grandis, 54 meses após a exploração da primeira rotação do povoamento, onde: № . Ind. - Número de Indivíduos; $\mathrm{N}^{\circ}$ Amo - Número de unidades amostrais em que a espécie foi amostrada; Dens.re Densidade relativa da espécie; Freq. Rel - Frequência relativa da espécie; Freq Ab - Frequência absoluta da espécie; Dens Ab - Densidade abusoluta da espécie; Alt Min- altura mínima amostrada na espécie; Alt Max - Altura máxima amostrada na espécie e Alt Med - Altura média apresentada pela espécie. 


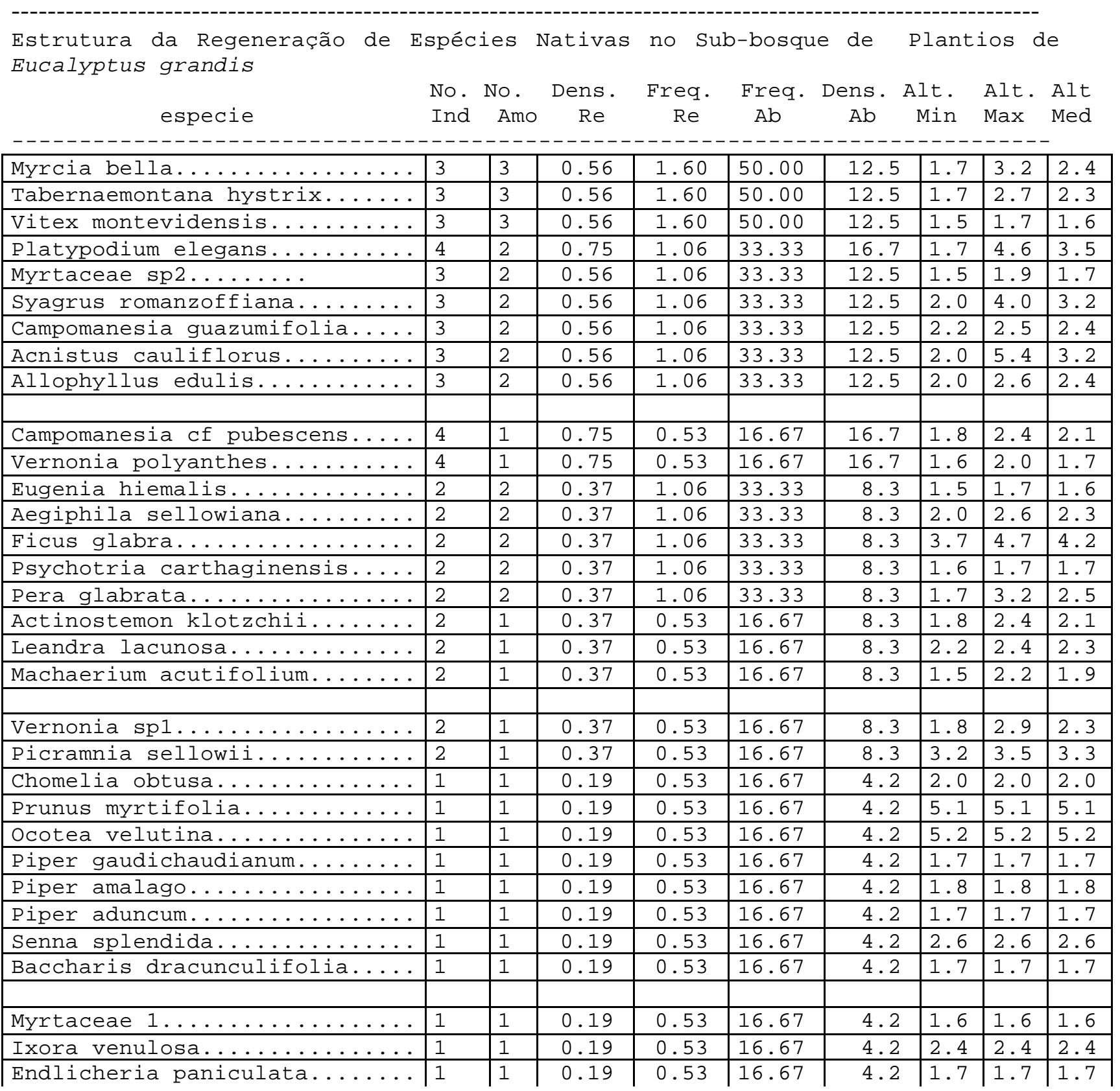

Quadro 7.3 -Parâmetros fitossociológicos encontrados para as espécies amostradas no subbosque de E. grandis (talhão 48), tratamento 2 - desbaste de $50 \%$ do povoamento de $E$. grandis, 54 meses após a exploração da primeira rotação do povoamento, onde: $\mathrm{N}^{\circ}$. Ind. - Número de Indivíduos; $\mathrm{N}^{\circ}$ Amo - Número de unidades amostrais em que a espécie foi amostrada; Dens.re Densidade relativa da espécie; Freq. Rel - Frequência relativa da espécie; Freq Ab - Frequência absoluta da espécie; Dens Ab - Densidade abusoluta da espécie; Alt Min- altura mínima amostrada na espécie; Alt Max - Altura máxima amostrada na espécie e Alt Med - Altura média apresentada pela espécie. 


\begin{tabular}{|c|c|c|c|c|c|c|c|c|c|}
\hline \multicolumn{10}{|c|}{$\begin{array}{l}\text { Estrutura da Regeneração de Espécies Nativas } \\
\text { Eucalyptus grandis }\end{array}$} \\
\hline especie & $\begin{array}{l}\text { No. } \\
\text { Ind }\end{array}$ & $\begin{array}{l}\text { No. } \\
\text { Amo }\end{array}$ & $\begin{array}{c}\text { Dens. } \\
\text { Re }\end{array}$ & $\begin{array}{l}\text { Freq. } \\
\text { Re }\end{array}$ & $\begin{array}{l}\text { Freq. } \\
\text { Ab }\end{array}$ & $\begin{array}{l}\text { Dens } \\
\text { Ab }\end{array}$ & $\begin{array}{l}\text { Alt. } \\
\text { Min }\end{array}$ & $\begin{array}{l}\text { Alt } \\
\operatorname{Max}\end{array}$ & $\begin{array}{l}\text { Alt } \\
\text { Med }\end{array}$ \\
\hline \multicolumn{10}{|c|}{------------------------------------------------------------------------------- } \\
\hline Myrcia guianensis............. & 1 & 1 & 0.19 & 0.53 & 16.67 & 4.2 & 3.0 & 3.0 & 3.0 \\
\hline 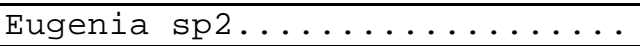 & 1 & 1 & 0.19 & 0.53 & 16.67 & 4.2 & 1.8 & 1.8 & 1.8 \\
\hline Eugenia pyriformis........... & 1 & 1 & 0.19 & 0.53 & 16.67 & 4.2 & 1.8 & 1.8 & 1.8 \\
\hline Pterocarpus rohrii........... & 1 & 1 & 0.19 & 0.53 & 16.67 & 4.2 & 3.0 & 3.0 & 3.0 \\
\hline Eugenia blastantha........... & 1 & 1 & 0.19 & 0.53 & 16.67 & 4.2 & 1.7 & 1.7 & 1.7 \\
\hline Machaerium brasiliense........ & 1 & 1 & 0.19 & 0.53 & 16.67 & 4.2 & 5.4 & 5.4 & 5.4 \\
\hline 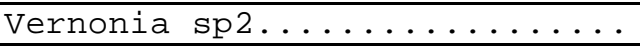 & 1 & 1 & 0.19 & 0.53 & 16.67 & 4.2 & 2.0 & 2.0 & 2.0 \\
\hline Desmodium discolor........... & 1 & 1 & 0.19 & 0.53 & 16.67 & 4.2 & 2.0 & 2.0 & 2.0 \\
\hline Andira anthelmia............ & 1 & 1 & 0.19 & 0.53 & 16.67 & 4.2 & 3.0 & 3.0 & 3.0 \\
\hline Solanum granuloso-leprosum.... & 1 & 1 & 0.19 & 0.53 & 16.67 & 4.2 & 1.5 & 1.5 & 1.5 \\
\hline Cestrum sendtnerianum....... & 1 & 1 & 0.19 & 0.53 & 16.67 & 4.2 & 1.6 & 1.6 & 1.6 \\
\hline Sebastiania klotzchiana....... & 1 & 1 & 0.19 & 0.53 & 16.67 & 4.2 & 2.0 & 2.0 & 2.0 \\
\hline Guarea guidonia............. & 1 & 1 & 0.19 & 0.53 & 16.67 & 4.2 & 1.7 & 1.7 & 1.7 \\
\hline 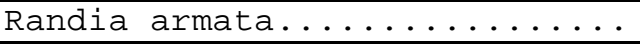 & 1 & 1 & 0.19 & 0.53 & 16.67 & 4.2 & 2.5 & 2.5 & 2.5 \\
\hline 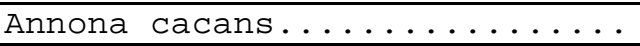 & 1 & 1 & 0.19 & 0.53 & 16.67 & 4.2 & 1.9 & 1.9 & 1.9 \\
\hline Lithraea molleoides........... & 1 & 1 & 0.19 & 0.53 & 16.67 & 4.2 & 1.5 & 1.5 & 1.5 \\
\hline
\end{tabular}

Quadro 7.3 -Parâmetros fitossociológicos encontrados para as espécies amostradas no subbosque de $E$. grandis (talhão 48 ), tratamento 2 - desbaste de $50 \%$ do povoamento de $E$. grandis, 54 meses após a exploração da primeira rotação do povoamento, onde: $\mathrm{N}^{\circ}$. Ind. - Número de Indivíduos; $\mathrm{N}^{\circ}$ Amo - Número de unidades amostrais em que a espécie foi amostrada; Dens.re Densidade relativa da espécie; Freq. Rel - Frequência relativa da espécie; Freq Ab - Frequência absoluta da espécie; Dens Ab - Densidade abusoluta da espécie; Alt Min- altura mínima amostrada na espécie; Alt Max - Altura máxima amostrada na espécie e Alt Med - Altura média apresentada pela espécie. 


\begin{tabular}{|c|c|c|c|c|c|c|c|c|c|}
\hline esp & $\begin{array}{l}\text { No. } \\
\text { Ind }\end{array}$ & $\begin{array}{l}\text { No. } \\
\text { Amo }\end{array}$ & $\begin{array}{c}\text { Dens. } \\
\text { Re }\end{array}$ & $\begin{array}{c}\text { Freq } \\
\operatorname{Re}\end{array}$ & $\begin{array}{c}\text { Freq. } \\
\text { Ab }\end{array}$ & $\begin{array}{c}\text { Dens. } \\
\text { Ab }\end{array}$ & $\begin{array}{l}\text { Alt. } \\
\text { Min }\end{array}$ & $\begin{array}{l}\text { Alt } \\
\operatorname{Max}\end{array}$ & $\begin{array}{l}\text { Alt } \\
\text { Med }\end{array}$ \\
\hline ayba elaea & 174 & 6 & 21.97 & 2.52 & 100.0 & 725.0 & 1.5 & 7.0 & 2.4 \\
\hline asearia sylvestris.. & 54 & 6 & 6.82 & 2.52 & 100.0 & 225.0 & 1.5 & 4.1 & 2.3 \\
\hline olanum variabile............. & 44 & 6 & 5.56 & 2.52 & 100.0 & 183.3 & 1.5 & 2.5 & 1.8 \\
\hline iconia ligustroides.......... & 36 & 6 & 4.55 & 2.52 & 100.0 & 150.0 & 1.5 & 3.0 & 2.2 \\
\hline yrcia multiflora. & 26 & 6 & 3.28 & 2.52 & 100.0 & 108.3 & 1.5 & 3.6 & 2.2 \\
\hline chinus terebinthifolius...... & 26 & 6 & 3.28 & 2.52 & 100.0 & 108.3 & 1.5 & 3.6 & 2.0 \\
\hline upatorium laevigatum......... & 26 & 6 & 3.28 & 2.52 & 100.0 & 108.3 & 1.5 & 3.5 & 2.1 \\
\hline Zanthoxylum rhoifolium....... & 20 & 6 & 2.53 & 2.52 & 100.0 & 83.3 & 1.6 & 5.0 & 2.7 \\
\hline Ocotea pulchella.............. & 18 & 6 & 2.27 & 2.52 & 100.0 & 75.0 & 1.5 & 5.0 & 2.7 \\
\hline 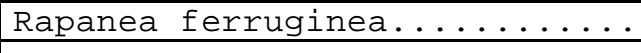 & 18 & 6 & 2.27 & 2.52 & 100.0 & 75.0 & 1.5 & 4.0 & 2.2 \\
\hline tharexylum myrial & 19 & 4 & .40 & 1.68 & 66.67 & 79.2 & 1.5 & 6.0 & 2.5 \\
\hline edrela fissilis.............. & 15 & 5 & 1.89 & 2.10 & 83.33 & 62.5 & 1.5 & 6.0 & 3.4 \\
\hline ochnatia polymorpha.......... & 12 & 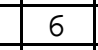 & 1.52 & 2.52 & 100.0 & 50.0 & 1.5 & 4.0 & 2.2 \\
\hline yrcia laruotteana............. & 13 & 5 & 1.64 & 2.10 & 83.33 & 54.2 & 1.5 & 2.1 & 1.7 \\
\hline cacia velutina.............. & 15 & 3 & 1.89 & 1.26 & 50.00 & 62.5 & 1.5 & 4.0 & 2.5 \\
\hline hamnus shaerosperma.......... & 13 & 4 & 1.64 & 1.68 & 66.67 & 54.2 & 1.5 & 6.0 & 3.4 \\
\hline Campomanesia guaviroba......... & 12 & 4 & .52 & 1.68 & 66.67 & 50.0 & 1.5 & 3.8 & 2.2 \\
\hline Vernonia polyanthes............ & 10 & 5 & 1.26 & 2.10 & 83.33 & 41.7 & 1.5 & 5.5 & 2.2 \\
\hline Styrax acuminatus $\ldots \ldots \ldots \ldots$ & 13 & 3 & 1.64 & 1.26 & 50.00 & 54.2 & 1.5 & 4.0 & 2.5 \\
\hline Tapirira guianensis.... & 9 & 5 & 1.14 & 2.10 & 83.33 & 37.5 & 1.5 & 3.7 & 2.2 \\
\hline Desmodium discolor & 12 & - & 1.52 & 1.26 & 50 & 50.0 & 1.6 & 2.8 & 2.1 \\
\hline Blepharocalyx salicifolius.... & 7 & 5 & 0.88 & 2.10 & 83.33 & 29.2 & 1.5 & 3.0 & 2.1 \\
\hline Rapanea umbellata............. & 10 & 3 & 1.26 & 1.26 & 50.00 & 41.7 & 1.5 & 4.2 & 2.7 \\
\hline Psychotria carthaginensis..... & 8 & 4 & 1.01 & 1.68 & 66.67 & 33.3 & 1.5 & 1.9 & 1.7 \\
\hline 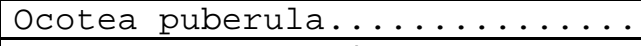 & 8 & 4 & 1.01 & 1.68 & 66.67 & 33.3 & 1.6 & 4.0 & 2.5 \\
\hline Solanum pseudoquina........... & 8 & 4 & 1.01 & 1.68 & 66.67 & 33.3 & 1.7 & 6.0 & 2.5 \\
\hline Piper gaudichaudianum......... & 9 & 3 & 1.14 & 1.26 & 50.00 & 37.5 & 1.5 & 2.5 & 1.8 \\
\hline Myrtaceae sp2......... & 7 & 4 & 0.88 & 1.68 & 66.67 & 29.2 & 1.5 & 2.5 & 1.8 \\
\hline Calyptranthes concinna........ & 6 & 4 & 0.76 & 1.68 & 66.67 & 25.0 & 1.9 & 2.4 & 2.1 \\
\hline Parapiptadenia rigida......... & 6 & 4 & 0.76 & 1.68 & 66.67 & 25.0 & 2.0 & 6.0 & 4.3 \\
\hline yrciaria floribunc & 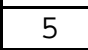 & 7 & 63 & 1.68 & 66.67 & 20.8 & 1.6 & 2.0 & 1.9 \\
\hline ampomanesia guazumifoli & 5 & 3 & 0.76 & 1.26 & 50.00 & 25.0 & 1.6 & 2.7 & 2.2 \\
\hline
\end{tabular}

Quadro 7.4 - Parâmetros fitossociológicos encontrados para as espécies amostradas no subbosque de E. grandis (talhão 48), tratamento 2 - desbaste de $50 \%$ do povoamento de $E$. grandis, 61 meses após a exploração da primeira rotação do povoamento, onde: № . Ind. - Número de Indivíduos; $\mathrm{N}^{\circ}$ Amo - Número de unidades amostrais em que a espécie foi amostrada; Dens.re Densidade relativa da espécie; Freq. Rel - Frequência relativa da espécie; Freq Ab - Frequência absoluta da espécie; Dens Ab - Densidade abusoluta da espécie; Alt Min- altura mínima amostrada na espécie; Alt Max - Altura máxima amostrada na espécie e Alt Med - Altura média apresentada pela espécie. 


\begin{tabular}{|c|c|c|c|c|c|c|c|c|c|}
\hline especie & $\begin{array}{l}\text { No. } \\
\text { Ind }\end{array}$ & $\begin{array}{l}\text { No. } \\
\text { Amo }\end{array}$ & $\begin{array}{c}\text { Dens. } \\
\text { Re }\end{array}$ & $\begin{array}{c}\text { Freq } \\
\quad \operatorname{Re}\end{array}$ & $\begin{array}{c}\text { Freq. } \\
\text { Ab }\end{array}$ & $\begin{array}{c}\text { Dens. } \\
\text { Ab }\end{array}$ & $\begin{array}{l}\text { Alt. } \\
\text { Min }\end{array}$ & $\begin{array}{l}\text { Alt } \\
\operatorname{Max}\end{array}$ & $\begin{array}{l}\text { Alt } \\
\text { Med }\end{array}$ \\
\hline latypodium elegans......... & 6 & 3 & 0.76 & 1.26 & 50.00 & 25.0 & 2.5 & 5.5 & 4.1 \\
\hline itex montevidensis........... & 6 & 3 & 0.76 & 1.26 & 50.00 & 25.0 & 1.5 & 2.1 & 1.8 \\
\hline apanea guyanensis........... & 4 & 4 & 0.51 & 1.68 & 66.67 & 16.7 & 2.1 & 4.0 & 2.9 \\
\hline llophyllus edulis........... & 5 & 3 & 0.63 & 1.26 & 50.00 & 20.8 & 1.6 & 2.8 & 2.3 \\
\hline 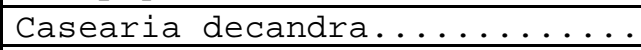 & 6 & 2 & 0.76 & 0.84 & 33.33 & 25.0 & 2.1 & 5.5 & 3.5 \\
\hline ugenia hiemalis............ & 4 & 3 & 0.51 & 1.26 & 50.00 & 16.7 & 1.5 & 2.7 & 2.0 \\
\hline estrum sendtnerianum....... & 4 & 3 & 0.51 & 1.26 & 50.00 & 16.7 & 1.5 & 2.1 & 1.8 \\
\hline Tabernaemontana hystrix....... & 4 & 3 & 0.51 & 1.26 & 50.00 & 16.7 & 1.8 & 4.0 & 2.7 \\
\hline & & & & & & & & & \\
\hline senbeckia febrifug & 7 & 1 & 0.88 & 0.42 & 16.67 & 29.2 & 1.7 & 3.1 & 2.3 \\
\hline auhinia germinata........... & 5 & 2 & 0.63 & 0.84 & 33.33 & 20.8 & 1.6 & 3.0 & 2.3 \\
\hline Sebastiania brasiliensis...... & 5 & 2 & 0.63 & 0.84 & 33.33 & 20.8 & 1.5 & 4.0 & 2.6 \\
\hline Myrcia bella................. & 3 & 3 & 0.38 & 1.26 & 50.00 & 12.5 & 1.9 & 4.0 & 2.8 \\
\hline Tabebuia chrysotricha... & 3 & 3 & 0.38 & 1.26 & 50.00 & 12.5 & 1.6 & 1.7 & 1.7 \\
\hline Senna splendida............... & 4 & 2 & .51 & 0.84 & 33.33 & 16.7 & 1.6 & 2.4 & 1.9 \\
\hline accharis dracunculifolia..... & 4 & 2 & 0.51 & 0.84 & 33.33 & 16.7 & 1.6 & 2.8 & 2.0 \\
\hline Sicramnia sellowii............ & 3 & 2 & 0.38 & 0.84 & 33.33 & 12.5 & 2.0 & 4.0 & 3.3 \\
\hline Syagrus romanzoffiana.......... & 3 & 2 & 38 & 0.84 & 33 & 12.5 & 1.8 & 5.0 & 3.6 \\
\hline runus myrtifolia....... & 3 & 2 & 0.38 & 0.84 & 33.33 & 12.5 & 1.5 & 5.0 & 2.7 \\
\hline Acnistus cauliflor & 3 & 2 & 0.38 & 0.84 & 33.33 & 12.5 & 2.1 & 6.0 & 3.5 \\
\hline 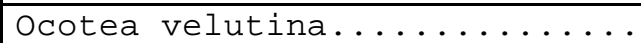 & 2 & 2 & 0.25 & 0.84 & 33.33 & 8.3 & 1.5 & 7.0 & 4.3 \\
\hline Myrtaceae $1 \ldots \ldots \ldots \ldots \ldots \ldots$ & 2 & 2 & 0.25 & 0.84 & 33.33 & 8.3 & 1.7 & 1.8 & 1.8 \\
\hline Pera glabrata................ & 2 & 2 & 0.25 & 0.84 & 33.33 & 8.3 & 2.7 & 5.0 & 3.8 \\
\hline Endlicheria paniculata........ & 2 & 2 & 0.25 & 0.84 & 33.33 & 8.3 & 1.5 & 2.0 & 1.8 \\
\hline Ficus glabra................. & 2 & 2 & 0.25 & 0.84 & 33.33 & 8.3 & 5.0 & 6.0 & 5.5 \\
\hline Andira anthelmia............. & 2 & 2 & 0.25 & 0.84 & 33.33 & 8.3 & 1.6 & 3.7 & 2.7 \\
\hline Solanum granuloso-leprosum.... & 2 & 2 & 0.25 & 0.84 & 33.33 & 8.3 & 1.7 & 2.0 & 1.9 \\
\hline Campomanesia cf pubescens..... & 3 & 1 & 0.38 & 0.42 & 16.67 & 12.5 & 2.5 & 3.5 & 3.0 \\
\hline Leandra lacunosa.............. & 2 & 1 & 0.25 & 0.42 & 16.67 & 8.3 & 2.4 & 2.5 & 2.5 \\
\hline iper aduncum. & 1 & 1 & .13 & 0.42 & 67 & 4.2 & 2.7 & 2.7 & 2.7 \\
\hline Myrtaceae $4 \ldots \ldots \ldots \ldots \ldots \ldots$ & 1 & \pm & 0.13 & 0.42 & 16.67 & 4.2 & 1.6 & 1.6 & 1.6 \\
\hline Myrcia guianensis............ & 1 & \pm & 0.13 & 0.42 & 16.67 & 4.2 & 2.7 & 2.7 & 2.7 \\
\hline Erythroxylum ambiguum. & 1 & 1 & 0.13 & 0.42 & 16.67 & 4.2 & 1.5 & 1.5 & 1.5 \\
\hline
\end{tabular}

Quadro 7.4 - Parâmetros fitossociológicos encontrados para as espécies amostradas no subbosque de E. grandis (talhão 48), tratamento 2 - desbaste de $50 \%$ do povoamento de $E$. grandis, 61 meses após a exploração da primeira rotação do povoamento, onde: № . Ind. - Número de Indivíduos; $\mathrm{N}^{\circ}$ Amo - Número de unidades amostrais em que a espécie foi amostrada; Dens.re Densidade relativa da espécie; Freq. Rel - Frequência relativa da espécie; Freq Ab - Frequência absoluta da espécie; Dens Ab - Densidade abusoluta da espécie; Alt Min- altura mínima amostrada na espécie; Alt Max - Altura máxima amostrada na espécie e Alt Med - Altura média apresentada pela espécie. 


\begin{tabular}{|c|c|c|c|c|c|c|c|c|c|}
\hline est & $\begin{array}{l}\text { No. } \\
\text { Ind }\end{array}$ & $\begin{array}{l}\text { No. } \\
\text { Amo }\end{array}$ & $\begin{array}{c}\text { Dens. } \\
\text { Re }\end{array}$ & $\begin{array}{c}\text { Freq. } \\
\text { Re }\end{array}$ & $\begin{array}{c}\text { Freq. } \\
\text { Ab }\end{array}$ & $\begin{array}{c}\text { Dens. } \\
\text { Ab }\end{array}$ & $\begin{array}{l}\text { Alt. } \\
\text { Min }\end{array}$ & $\begin{array}{l}\text { Alt } \\
\text { Max }\end{array}$ & $\begin{array}{l}\text { Alt } \\
\text { Med }\end{array}$ \\
\hline agenia sp2 & 1 & 1 & 0.13 & 0.42 & 6.67 & 4.2 & 3.0 & 3.0 & 3.0 \\
\hline ugenia pyriformis..... & 1 & 1 & 0.13 & 0.42 & 6.67 & 4.2 & 2.0 & 2.0 & 2.0 \\
\hline Cecropia pachystachya......... & 1 & 1 & 0.13 & 0.42 & 6.67 & 4.2 & 1.9 & 1.9 & 1.9 \\
\hline Eugenia blastantha............ & 1 & 1 & 0.13 & 0.42 & 6.67 & 4.2 & 1.8 & 1.8 & 1.8 \\
\hline terocarpus rohrii...... & 1 & 1 & 0.13 & 0.42 & 6.67 & 4.2 & 3.0 & 3.0 & 3.0 \\
\hline achaerium brasilier & 1 & 1 & .13 & 0.42 & 16.67 & 4.2 & 6.0 & 6.0 & 6.0 \\
\hline achaerium acutifolium. & & & 13 & & & & & & 5 \\
\hline Lantana cf brasiliensis... & 1 & 1 & 0.13 & 0.42 & 16.67 & 4.2 & 0 & .0 & 0 \\
\hline Indigofera suffruticosa....... & 1 & 1 & .13 & .42 & 16.67 & 4.2 & 1.5 & 1.5 & 1.5 \\
\hline Aegiphila sellowiana.......... & 1 & 1 & 0.13 & 0.42 & 16.67 & 4.2 & 3.0 & 3.0 & 3.0 \\
\hline Guarea guidonia................ & 1 & 1 & 0.13 & 0.42 & 16.67 & 4.2 & 2.2 & 2.2 & 2.2 \\
\hline Ossaea confertiflora........... & 1 & 1 & 0.13 & 0.42 & 16.67 & 4.2 & 1.6 & 1.6 & 1.6 \\
\hline Acosmium subelegans............ & 1 & 1 & 0.13 & 0.42 & 16.67 & 4.2 & 1.7 & 1.7 & 1.7 \\
\hline Randia & 1 & 1 & 0.13 & 0.42 & 16.67 & 4.2 & 2.0 & 2.0 & 2.0 \\
\hline Miconia langsdorfii............ & 1 & 1 & 0.13 & 0.42 & 16.67 & 4.2 & 1.5 & 1.5 & 1.5 \\
\hline Ixora venulosa.... & 1 & 1 & 0.13 & 0.42 & 16.67 & 4.2 & 2.8 & 2.8 & 2.8 \\
\hline Chomelia obtus & 1 & 1 & 0.13 & 0.42 & 16.67 & 4.2 & 2.5 & 2.5 & 2.5 \\
\hline Sebastiania klotzchiana....... & 1 & 1 & 0.13 & 0.42 & 16.67 & 4.2 & 2.0 & 2.0 & 2.0 \\
\hline 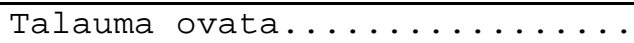 & 1 & 1 & 0.13 & 0.42 & 16.67 & 4.2 & 1.7 & 1.7 & 1.7 \\
\hline 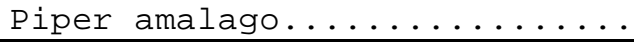 & 1 & 1 & 0.13 & 0.42 & 16.67 & 4.2 & 2.1 & 2.1 & 2.1 \\
\hline Strychnos brasiliensis........ & 1 & 1 & 0.13 & 0.42 & 16.67 & 4.2 & 1.7 & 1.7 & 1.7 \\
\hline Lithraea molleoides.......... & 1 & 1 & 0.13 & 0.42 & 16.67 & 4.2 & 1.8 & 1.8 & 1.8 \\
\hline
\end{tabular}

Quadro 7.4 - Parâmetros fitossociológicos encontrados para as espécies amostradas no subbosque de $E$. grandis (talhão 48 ), tratamento 2 - desbaste de $50 \%$ do povoamento de $E$. grandis, 61 meses após a exploração da primeira rotação do povoamento, onde: № . Ind. - Número de Indivíduos; $\mathrm{N}^{\circ}$ Amo - Número de unidades amostrais em que a espécie foi amostrada; Dens.re Densidade relativa da espécie; Freq. Rel - Frequência relativa da espécie; Freq Ab - Frequência absoluta da espécie; Dens Ab - Densidade abusoluta da espécie; Alt Min- altura mínima amostrada na espécie; Alt Max - Altura máxima amostrada na espécie e Alt Med - Altura média apresentada pela espécie. 


\section{Conjunto de Quadros 8: Parâmetros Fitossociológicos das espécies e famílias amostradas no tratamento 3 - corte raso do povoamento de E. grandis nos diversos levantamentos do Sub-bosque do Talhão 48.}

Estrutura da Regeneração de Espécies Nativas no Sub-bosque de Plantios de Eucalyptus grandis

$\begin{array}{lcccccc} & \text { No. No. Dens. } & \text { Freq. } & \text { Freq. Dens. Alt. Alt. Alt } \\ \text { especie } & \text { Ind Amo } & \text { Re } & \text { Re } & \text { Ab } & \text { Ab } & \text { Min Max Med }\end{array}$

\begin{tabular}{|c|c|c|c|c|c|c|c|c|c|}
\hline Esenbeckia febrifuga.......... & 79 & 3 & 13.41 & 1.69 & 50.00 & 329.2 & 1.5 & 3.5 & 2.3 \\
\hline Solanum variabile........... & 57 & 6 & 9.68 & 3.37 & 100.0 & 237.5 & 1.5 & 3.5 & 1.9 \\
\hline Rapanea umbellata............. & 55 & 6 & 9.34 & 3.37 & 100.0 & 229.2 & 1.5 & 5.0 & 2.3 \\
\hline $\begin{array}{l}\text { Matayba } \\
\text { elaeagnoides........... }\end{array}$ & 47 & 6 & 7.98 & 3.37 & 100.0 & 195.8 & 1.5 & 3.5 & 1.8 \\
\hline Casearia sylvestris........... & 44 & 6 & 7.47 & 3.37 & 100.0 & 183.3 & 1.5 & 3.0 & 2.2 \\
\hline Gochnatia polymorpha.......... & 24 & 6 & 4.07 & 3.37 & 100.0 & 100.0 & 1.5 & 3.0 & 2.0 \\
\hline Ocotea puberula............. & 23 & 5 & 3.90 & 2.81 & 83.33 & 95.8 & 1.5 & 4.5 & 2.3 \\
\hline Cytharexylum myrianthum....... & 15 & 6 & 2.55 & 3.37 & 100.0 & 62.5 & 1.5 & 3.2 & 2.2 \\
\hline Baccharis dracunculifolia..... & 16 & 5 & 2.72 & 2.81 & 83.33 & 66.7 & 1.5 & 3.0 & 2.3 \\
\hline Schinus terebinthifolius...... & 13 & 5 & 2.21 & 2.81 & 83.33 & 54.2 & 1.6 & 7.0 & 2.6 \\
\hline Campomanesia guaviroba........ & 16 & 3 & 2.72 & 1.69 & 50.00 & 66.7 & 1.5 & 2.5 & 1.9 \\
\hline Ocotea pulchella............. & 10 & 4 & 1.70 & 2.25 & 66.67 & 41.7 & 1.5 & 3.0 & 2.0 \\
\hline Rapanea ferruginea........... & 8 & 5 & 1.36 & 2.81 & 83.33 & 33.3 & 1.8 & 5.6 & 2.8 \\
\hline Zanthoxylum rhoifolium....... & 8 & 4 & 1.36 & 2.25 & 66.67 & 33.3 & 1.5 & 3.0 & 2.2 \\
\hline Prunus myrtifolia............ & 8 & 4 & 1.36 & 2.25 & 66.67 & 33.3 & 1.8 & 6.0 & 3.3 \\
\hline Miconia ligustroides........... & 8 & 4 & 1.36 & 2.25 & 66.67 & 33.3 & 1.5 & 3.2 & 1.9 \\
\hline Allophyllus edulis........... & 6 & 5 & 1.02 & 2.81 & 83.33 & 25.0 & 1.5 & 2.0 & 1.6 \\
\hline Desmodium discolor........... & 6 & 5 & 1.02 & 2.81 & 83.33 & 25.0 & 1.8 & 2.5 & 2.0 \\
\hline Myrcia laruotteana........... & 9 & 3 & 1.53 & 1.69 & 50.00 & 37.5 & 1.5 & 2.8 & 1.9 \\
\hline Cedrela fissilis............ & 8 & 3 & 1.36 & 1.69 & 50.00 & 33.3 & 1.5 & 3.1 & 2.4 \\
\hline Syagrus romanzoffiana......... & 6 & 4 & 1.02 & 2.25 & 66.67 & 25.0 & 2.0 & 3.7 & 2.7 \\
\hline Rhamnus shaerosperma......... & 7 & 3 & 1.19 & 1.69 & 50.00 & 29.2 & 1.5 & 3.0 & 2.1 \\
\hline Piper gaudichaudianum......... & 7 & 3 & 1.19 & 1.69 & 50.00 & 29.2 & 1.7 & 2.7 & 2.1 \\
\hline Styrax acuminatus............ & 5 & 4 & 0.85 & 2.25 & 66.67 & 20.8 & 2.0 & 4.0 & 2.5 \\
\hline Cestrum sendtnerianum....... & 5 & 3 & 0.85 & 1.69 & 50.00 & 20.8 & 2.0 & 4.0 & 2.5 \\
\hline
\end{tabular}

Quadro 8.1 - Parâmetros fitossociológicos encontrados para as espécies amostradas no subbosque de E. grandis (talhão 48), tratamento 3 - corte raso do eucalipto, 30 meses após a exploração da primeira rotação do povoamento, onde: $\mathrm{N}^{\mathrm{P}}$. Ind. - Número de Indivíduos; $\mathrm{N}^{\mathrm{P}}$ Amo - Número de unidades amostrais em que a espécie foi amostrada; Dens.re - Densidade relativa da espécie; Freq. Rel - Frequência relativa da espécie; Freq Ab - Frequência absoluta da espécie; Dens Ab - Densidade abusoluta da espécie; Alt Min- altura mínima amostrada na espécie; Alt Max - Altura máxima amostrada na espécie e Alt Med - Altura média apresentada pela espécie. 


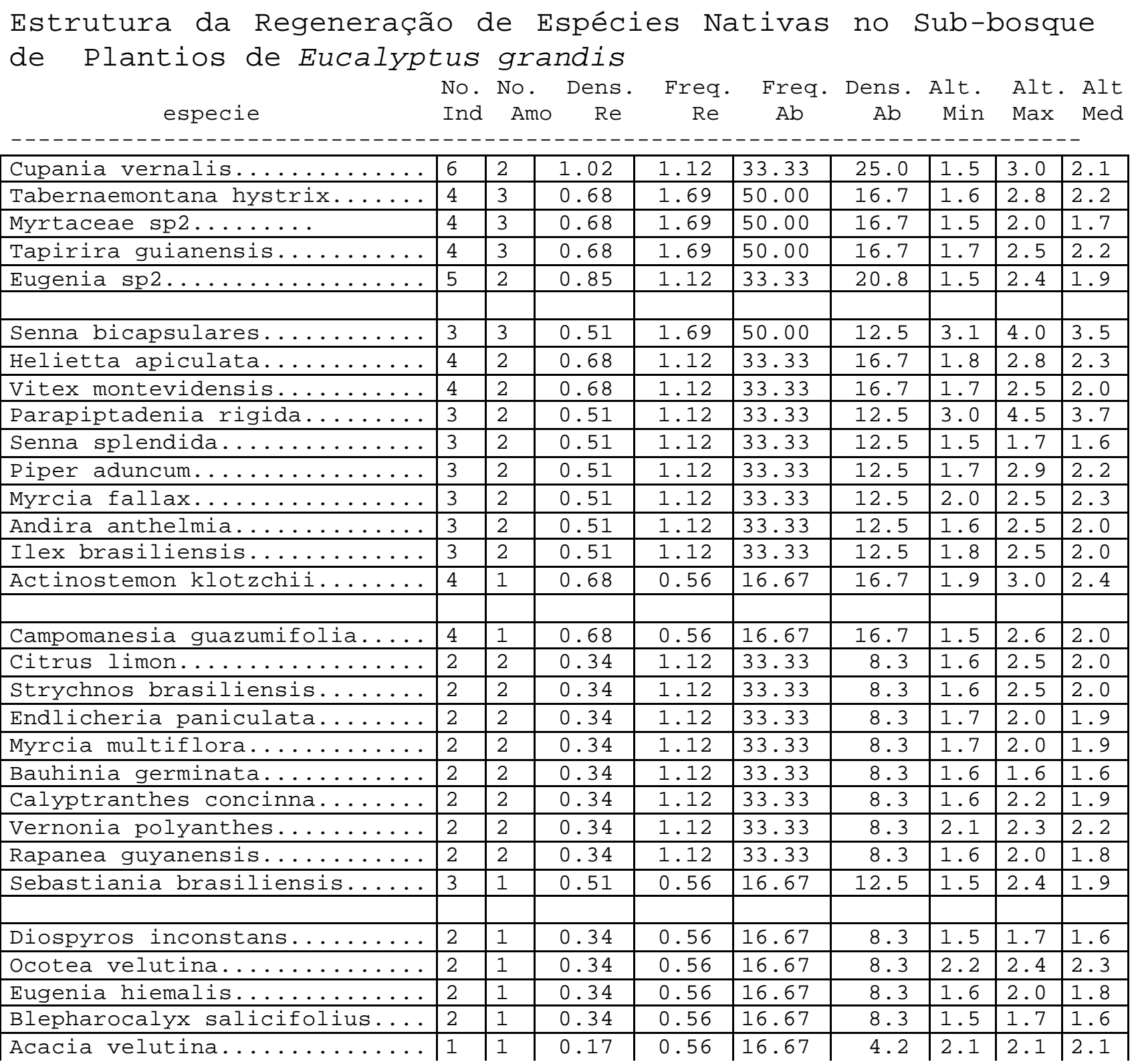

Quadro 8.1 - Parâmetros fitossociológicos encontrados para as espécies amostradas no subbosque de E. grandis (talhão 48), tratamento 3 - corte raso do eucalipto, 30 meses após a exploração da primeira rotação do povoamento, onde: $\mathrm{N}^{\circ}$. Ind. - Número de Indivíduos; $\mathrm{N}^{\circ} \mathrm{Amo}$ - Número de unidades amostrais em que a espécie foi amostrada; Dens.re - Densidade relativa da espécie; Freq. Rel - Frequência relativa da espécie; Freq Ab - Frequência absoluta da espécie; Dens Ab - Densidade abusoluta da espécie; Alt Min- altura mínima amostrada na espécie; Alt Max - Altura máxima amostrada na espécie e Alt Med - Altura média apresentada pela espécie. 


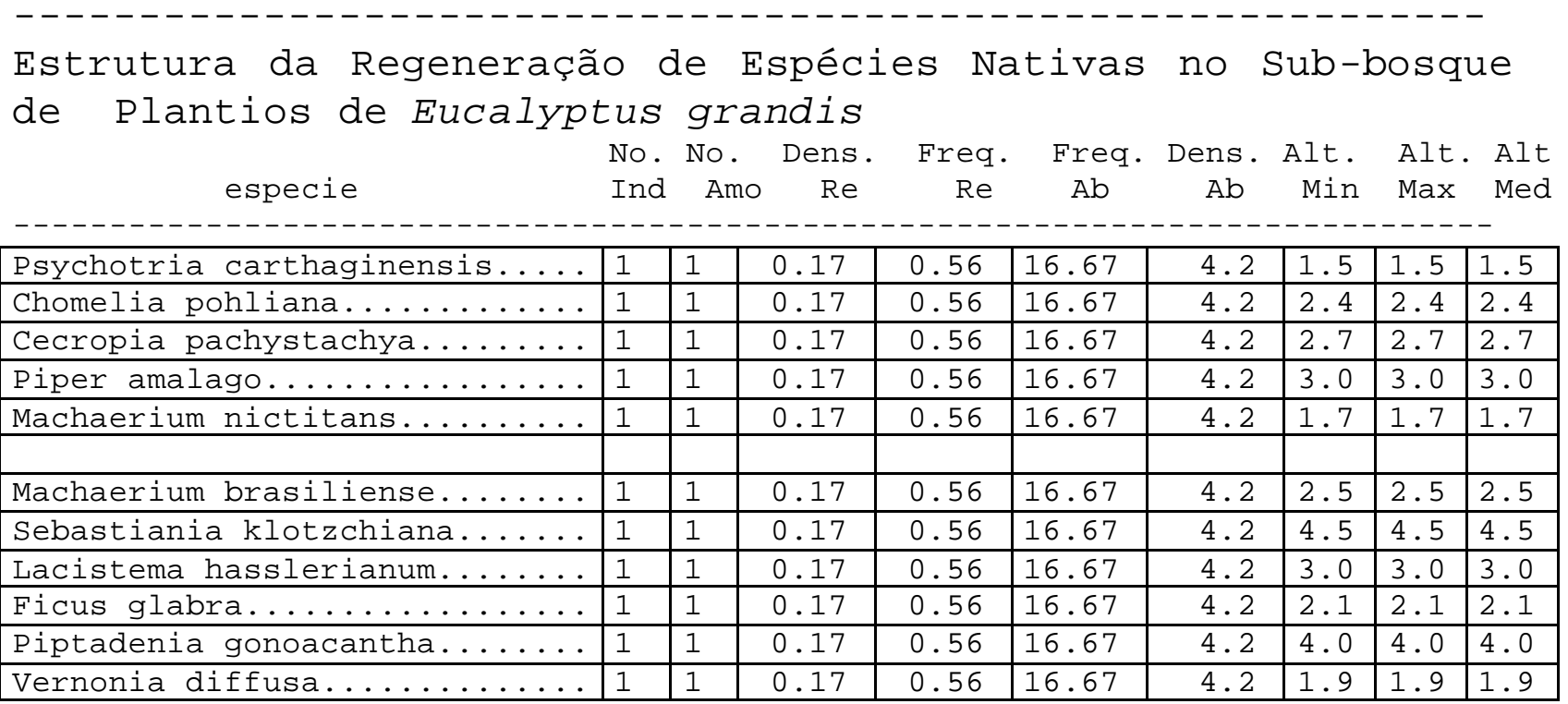

Quadro 8.1 - Parâmetros fitossociológicos encontrados para as espécies amostradas no subbosque de E. grandis (talhão 48), tratamento 3 - corte raso do eucalipto, 30 meses após a exploração da primeira rotação do povoamento, onde: $\mathrm{N}^{\mathrm{P}}$. Ind. - Número de Indivíduos; $\mathrm{N}^{\mathrm{P}}$ Amo - Número de unidades amostrais em que a espécie foi amostrada; Dens.re - Densidade relativa da espécie; Freq. Rel - Frequência relativa da espécie; Freq Ab - Frequência absoluta da espécie; Dens Ab - Densidade abusoluta da espécie; Alt Min- altura mínima amostrada na espécie; Alt Max - Altura máxima amostrada na espécie e Alt Med - Altura média apresentada pela espécie 


\begin{tabular}{|c|c|c|c|c|c|c|c|c|c|}
\hline \multicolumn{2}{|l|}{$\begin{array}{l}\text { Estrutura da Regeneração de } \\
\text { Plantios de Eucalyptus grandis }\end{array}$} & \multicolumn{2}{|c|}{ Espécies } & \multicolumn{2}{|c|}{ Nativas } & \multicolumn{3}{|c|}{ Sub-bosque } & de \\
\hline & $\begin{array}{l}\text { No. } \\
\text { Ind }\end{array}$ & $\begin{array}{l}\text { No. } \\
\text { Amo }\end{array}$ & $\begin{array}{l}\text { Dens. } \\
\quad \operatorname{Re}\end{array}$ & $\begin{array}{l}\text { Freq. } \\
\quad \operatorname{Re}\end{array}$ & $\begin{array}{l}\text { Freq. } \\
\text { Ab }\end{array}$ & $\begin{array}{l}\mathrm{ens} \text {. } \\
\mathrm{Ab}\end{array}$ & $\begin{array}{l}\text { Alt. } \\
\text { Min }\end{array}$ & $\begin{array}{l}\text { Alt. } \\
\text { Max }\end{array}$ & $\begin{array}{l}\text { Alt } \\
\text { Med }\end{array}$ \\
\hline $\begin{array}{l}\text { Matayba } \\
\text { elaeagnoides.. }\end{array}$ & 131 & 6 & 14. & 2.67 & 10 & 545 & 1.5 & 3.7 & 2.0 \\
\hline Esenbeckia febrifuga... & 117 & 4 & 13.09 & 1.78 & 66.67 & 487.5 & 1.5 & 4.0 & 2.3 \\
\hline Rapanea umbellata.............. & 73 & 6 & 8.17 & 2.67 & 100.0 & 304.2 & 1.5 & 5.1 & 2.8 \\
\hline Casearia sylvestris........... & 57 & 6 & 6.38 & 2.67 & 100.0 & 237.5 & 1.5 & 4.2 & 2.4 \\
\hline Myrcia laruotteana............ & 35 & 6 & 3.91 & 2.67 & 100.0 & 145.8 & 1.5 & 2.5 & 1.8 \\
\hline Gochnatia polymorpha........... & 26 & 6 & 2.91 & 2.67 & 100.0 & 108.3 & 1.5 & 3.7 & 2.2 \\
\hline Rapanea ferruginea............ & 24 & 6 & 2.68 & 2.67 & 100.0 & 100.0 & 1.6 & 5.0 & 2.7 \\
\hline 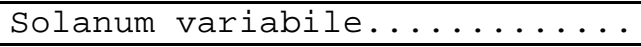 & 24 & 6 & 2.68 & 2.67 & 100.0 & 100.0 & 1.5 & 2.8 & 1.9 \\
\hline Campomanesia guaviroba......... & 28 & 3 & 3.13 & .33 & 50.00 & 116.7 & 1.5 & 3.3 & 2.2 \\
\hline Miconia ligustroides.......... & 22 & 6 & 2.46 & 2.67 & 100.0 & 91.7 & 1.5 & 4.7 & 2.0 \\
\hline xylum $n$ & 21 & 6 & .35 & 67 & 100.0 & 7.5 & 1.5 & 3.0 & 2.1 \\
\hline Ocotea puberula... & 22 & 5 & .46 & 2.22 & 83.33 & .7 & 1.6 & 5.6 & 2.4 \\
\hline Allophyllus edulis & 20 & 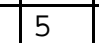 & .24 & 2.22 & 83.33 & .3 & 1.5 & 2.9 & 2.0 \\
\hline Zanthoxylum rhoifolium........ & 17 & 6 & .90 & 2.6 & 100.0 & 70.8 & 1.5 & 3.2 & 2.3 \\
\hline Psychotria carthaginensis..... & 14 & 5 & 1.57 & 2.2 & 83.33 & 58.3 & 1.5 & 2.2 & 1.7 \\
\hline Prunus myrtifolia... & 12 & 6 & 1.34 & .6 & 100.0 & 50.0 & 2.0 & 6.2 & 3.5 \\
\hline Cedrela fissilis... & 13 & 4 & 1.45 & . & 66.67 & 54.2 & 1.5 & 4.0 & 2.5 \\
\hline 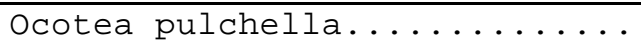 & 11 & 5 & 1.23 & 2.22 & 83.33 & 45.8 & 1.5 & 3.0 & 2.1 \\
\hline Campomanesia guazumifolia..... & 18 & 1 & 2.01 & 0.44 & 16.67 & 75.0 & 1.5 & 3.0 & 1.9 \\
\hline Piper gaudichaudianum......... & 12 & 4 & 1.34 & 1.78 & 66.67 & 50.0 & 1.5 & 2.6 & 1.9 \\
\hline & & & & & & & & & \\
\hline $\mathrm{x}$ acumin & 7 & 5 & .78 & 2 & 83.33 & 9.2 & 1.7 & 3.0 & 2.2 \\
\hline Calyptranthes concinna........ & 8 & 4 & 0.89 & 1.78 & 66.67 & 3.3 & 1.5 & 2.7 & 1.8 \\
\hline Rapanea guyanensis........... & 8 & 4 & 0.89 & 1.78 & 66.67 & 33.3 & 1.5 & 2.9 & 1.9 \\
\hline Cupania vernalis............. & 11 & 2 & 1.23 & 0.89 & 33.33 & 45.8 & 1.5 & 4.3 & 2.4 \\
\hline Syagrus romanzoffiana.......... & 7 & 4 & 0.78 & 1.78 & 66.67 & 9.2 & 1.7 & 3.7 & 2.7 \\
\hline Tabernaemontana hystrix....... & 7 & 4 & 0.78 & 1.78 & 66.67 & 9.2 & 1.6 & 3.3 & 2.1 \\
\hline Schinus terebinthifolius...... & 8 & 7 & 0.89 & 1.33 & 50.00 & 3.3 & 1.7 & 2.5 & 2.1 \\
\hline Myrtaceae sp2......... & 6 & 4 & 0.67 & 1.78 & 66.67 & 5.0 & 1.5 & 2.5 & 1.9 \\
\hline Cestrum sendtnerianum....... & 6 & 4 & 0.67 & 1.78 & 66.67 & 5.0 & 1.5 & 3.6 & 2.2 \\
\hline Rhamnus shaerosperma.......... & 7 & 3 & 0.78 & 1.33 & 50.00 & 29.2 & 2.1 & 4.1 & 3.0 \\
\hline Bauhinia ger & 5 & 4 & 56 & & 66.67 & 0.8 & 1.7 & 3.0 & 2.3 \\
\hline esmodium d & 5 & 4 & 0.56 & 1.78 & 66.67 & 20.8 & 1.6 & 2.5 & 2.0 \\
\hline
\end{tabular}

Quadro 8.2 - Parâmetros fitossociológicos encontrados para as espécies amostradas no subbosque de E. grandis (talhão 48), tratamento 3 - corte raso do eucalipto, 45 meses após a exploração da primeira rotação do povoamento, onde: $\mathrm{N}^{\mathrm{P}}$. Ind. - Número de Indivíduos; $\mathrm{N}^{\mathrm{P}}$ Amo - Número de unidades amostrais em que a espécie foi amostrada; Dens.re - Densidade relativa da espécie; Freq. Rel - Frequência relativa da espécie; Freq Ab - Frequência absoluta da espécie; Dens Ab - Densidade abusoluta da espécie; Alt Min- altura mínima amostrada na espécie; Alt Max - Altura máxima amostrada na espécie e Alt Med - Altura média apresentada pela espécie. 


\begin{tabular}{|c|c|c|c|c|c|c|c|c|c|}
\hline \multirow{2}{*}{\multicolumn{2}{|c|}{$\begin{array}{r}\text { Estrutura da Regeneração de } \\
\text { Plantios de Eucalyptus grandis } \\
\text { especie } \\
\text { No. } \\
\text { Ind }\end{array}$}} & \multicolumn{2}{|c|}{ Espécies } & \multicolumn{2}{|c|}{ Nativas } & \multicolumn{3}{|c|}{ Sub-bosque } & de \\
\hline & & $\begin{array}{l}\text { No. } \\
\text { Amo }\end{array}$ & $\begin{array}{c}\text { Dens. } \\
\text { Re }\end{array}$ & $\begin{array}{c}\text { Freq. } \\
\text { Re }\end{array}$ & $\begin{array}{c}\text { Freq } \\
\text { Ab }\end{array}$ & $\begin{array}{c}\text { Dens. } \\
\text { Ab }\end{array}$ & $\begin{array}{l}\text { Alt. } \\
\text { Min }\end{array}$ & $\begin{array}{l}\text { Alt. } \\
\operatorname{Max}\end{array}$ & $\begin{array}{l}\text { Alt } \\
\text { Med }\end{array}$ \\
\hline -ー-ー------ & & & & & & & & & \\
\hline Andira anthelmia.............. & 4 & 4 & 0.45 & 1.78 & 66.67 & 16.7 & 1.5 & 2.5 & 1.8 \\
\hline 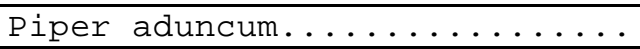 & 4 & 3 & 0.45 & 1.33 & 50.00 & 16.7 & 1.9 & 3.5 & 2.6 \\
\hline Myrcia multiflora............ & 4 & 3 & 0.45 & 1.33 & 50.00 & 16.7 & 1.5 & 2.7 & 2.1 \\
\hline Eugenia hiemalis............. & 4 & 3 & 0.45 & 1.33 & 50.00 & 16.7 & 1.5 & 2.0 & 1.8 \\
\hline Miconia langsdorfii.......... & 7 & 1 & 0.78 & 0.44 & 16.67 & 29.2 & 1.5 & 2.5 & 1.8 \\
\hline 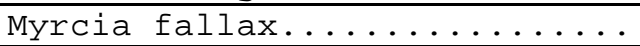 & 5 & 2 & 0.56 & 0.89 & 33.33 & 20.8 & 1.8 & 3.5 & 2.7 \\
\hline 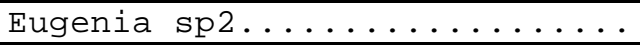 & 5 & 2 & 0.56 & 0.89 & 33.33 & 20.8 & 2.0 & 3.0 & 2.4 \\
\hline Senna splendida............ & 3 & 3 & 0.34 & 1.33 & 50.00 & 12.5 & 1.5 & 2.2 & 1.9 \\
\hline Senna bicapsulares............ & 3 & 3 & 0.34 & 1.33 & 50.00 & 12.5 & 3.5 & 4.5 & 3.9 \\
\hline Baccharis dracunculifolia..... & 3 & 3 & 0.34 & 1.33 & 50.00 & 12.5 & 2.0 & 2.5 & 2.3 \\
\hline Aegiphila sellowiana.......... & 3 & 3 & 0.34 & 1.33 & 50.00 & 12.5 & 2.1 & 2.8 & 2.5 \\
\hline Tapirira guianensis.......... & 3 & 3 & 0.34 & 1.33 & 50.00 & 12.5 & 2.1 & 4.0 & 3.0 \\
\hline Diospyros inconstans.......... & 4 & 2 & 0.45 & 0.89 & 33.33 & 16.7 & 1.6 & 2.3 & 1.9 \\
\hline Helietta apiculata........... & 4 & 2 & 0.45 & 0.89 & 33.33 & 16.7 & 1.8 & 2.8 & 2.3 \\
\hline Chomelia pohliana............ & 5 & 1 & 0.56 & 0.44 & 16.67 & 20.8 & 1.7 & 2.5 & 2.2 \\
\hline Vitex montevidensis.......... & 3 & 2 & 0.34 & 0.89 & 33.33 & 12.5 & 2.0 & 3.0 & 2.4 \\
\hline Parapiptadenia rigida......... & 3 & 2 & 0.34 & 0.89 & 33.33 & 12.5 & 4.1 & 5.5 & 4.9 \\
\hline Ilex brasiliensis............ & 3 & 2 & 0.34 & 0.89 & 33.33 & 12.5 & 2.3 & 4.1 & 3.3 \\
\hline Actinostemon klotzchii....... & 4 & 1 & 0.45 & 0.44 & 16.67 & 16.7 & 2.1 & 4.0 & 2.9 \\
\hline Citrus limon............... & 2 & 2 & 0.22 & 0.89 & 33.33 & 8.3 & 2.1 & 3.0 & 2.5 \\
\hline 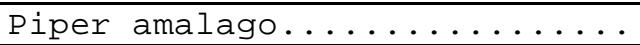 & 2 & 2 & 0.22 & 0.89 & 33.33 & 8.3 & 2.0 & 3.0 & 2.5 \\
\hline Tabebuia chrysotricha......... & 2 & 2 & 0.22 & 0.89 & 33.33 & 8.3 & 1.5 & 1.7 & 1.6 \\
\hline Vernonia polyanthes........... & 2 & 2 & 0.22 & 0.89 & 33.33 & 8.3 & 2.5 & 3.0 & 2.8 \\
\hline Strychnos brasiliensis........ & 2 & 2 & 0.22 & 0.89 & 33.33 & 8.3 & 2.5 & 2.7 & 2.6 \\
\hline Cecropia pachystachya......... & 2 & 2 & 0.22 & 0.89 & 33.33 & 8.3 & 2.2 & 3.1 & 2.7 \\
\hline Ocotea velutina............. & 3 & 1 & 0.34 & 0.44 & 16.67 & 12.5 & 2.0 & 3.7 & 3.1 \\
\hline Blepharocalyx salicifolius.... & 2 & 1 & 0.22 & 0.44 & 16.67 & 8.3 & 1.7 & 1.9 & 1.8 \\
\hline Sebastiania brasiliensis...... & 2 & 1 & 0.22 & 0.44 & 16.67 & 8.3 & 2.4 & 3.2 & 2.8 \\
\hline Vernonia diffusa............ & 2 & 1 & 0.22 & 0.44 & 16.67 & 8.3 & 5.5 & 7.0 & 6.3 \\
\hline Chomelia obtusa............ & 1 & 1 & 0.11 & 0.44 & 16.67 & 4.2 & 2.0 & 2.0 & 2.0 \\
\hline Amaioua guianensis........... & 1 & 1 & 0.11 & 0.44 & 16.67 & 4.2 & 1.7 & 1.7 & 1.7 \\
\hline Endlicheria paniculata........ & 1 & 1 & 0.11 & 0.44 & 16.67 & 4.2 & 3.0 & 3.0 & 3.0 \\
\hline
\end{tabular}

Quadro 8.2 - Parâmetros fitossociológicos encontrados para as espécies amostradas no subbosque de E. grandis (talhão 48), tratamento 3 - corte raso do eucalipto, 45 meses após a exploração da primeira rotação do povoamento, onde: $\mathrm{N}^{\mathrm{P}}$. Ind. - Número de Indivíduos; $\mathrm{N}^{\mathrm{p}}$ Amo - Número de unidades amostrais em que a espécie foi amostrada; Dens.re - Densidade relativa da espécie; Freq. Rel - Frequência relativa da espécie; Freq Ab - Frequência absoluta da espécie; Dens Ab - Densidade abusoluta da espécie; Alt Min- altura mínima amostrada na espécie; Alt Max - Altura máxima amostrada na espécie e Alt Med - Altura média apresentada pela espécie. 


\begin{tabular}{|c|c|c|c|c|c|c|c|c|c|}
\hline \multirow{3}{*}{\multicolumn{2}{|c|}{$\begin{array}{r}\text { Estrutura da Regeneração de } \\
\text { Plantios de Eucalyptus grandis } \\
\text { especie } \\
\text { No. } \\
\text { Ind }\end{array}$}} & \multicolumn{2}{|c|}{ Espécies } & \multicolumn{2}{|c|}{ Nativas } & \multicolumn{3}{|c|}{ Sub-bosque } & de \\
\hline & & $\begin{array}{l}\text { No. } \\
\text { Amo }\end{array}$ & $\begin{array}{c}\text { Dens. } \\
\text { Re }\end{array}$ & $\begin{array}{c}\text { Freq. } \\
\text { Re }\end{array}$ & $\begin{array}{c}\text { Freq } \\
\text { Ab }\end{array}$ & $\begin{array}{c}\text { Dens. } \\
\text { Ab }\end{array}$ & $\begin{array}{l}\text { Alt. } \\
\text { Min }\end{array}$ & $\begin{array}{l}\text { Alt. } \\
\operatorname{Max}\end{array}$ & $\begin{array}{l}\text { Alt } \\
\text { Med }\end{array}$ \\
\hline & & & & & & & & & \\
\hline Eupatorium inulaefolium....... & 1 & 1 & 0.11 & 0.44 & 16.67 & 4.2 & 1.6 & 1.6 & 1.6 \\
\hline Myrciaria floribunda.......... & 1 & 1 & 0.11 & 0.44 & 16.67 & 4.2 & 1.5 & 1.5 & 1.5 \\
\hline Machaerium opacum............ & 1 & 1 & 0.11 & 0.44 & 16.67 & 4.2 & 2.0 & 2.0 & 2.0 \\
\hline Machaerium nictitans......... & 1 & 1 & 0.11 & 0.44 & 16.67 & 4.2 & 2.8 & 2.8 & 2.8 \\
\hline Machaerium brasiliense........ & 1 & 1 & 0.11 & 0.44 & 16.67 & 4.2 & 2.9 & 2.9 & 2.9 \\
\hline Chorisia speciosa............ & 1 & 1 & 0.11 & 0.44 & 16.67 & 4.2 & 1.5 & 1.5 & 1.5 \\
\hline Sebastiania klotzchiana....... & 1 & 1 & 0.11 & 0.44 & 16.67 & 4.2 & 5.6 & 5.6 & 5.6 \\
\hline 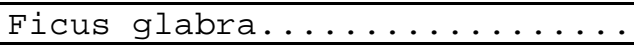 & 1 & 1 & 0.11 & 0.44 & 16.67 & 4.2 & 2.6 & 2.6 & 2.6 \\
\hline Piptadenia gonoacantha......... & 1 & 1 & 0.11 & 0.44 & 16.67 & 4.2 & 5.1 & 5.1 & 5.1 \\
\hline 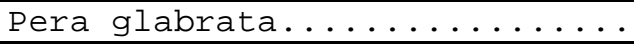 & 1 & 1 & 0.11 & 0.44 & 16.67 & 4.2 & 2.2 & 2.2 & 2.2 \\
\hline Aloysia virgata............. & 1 & 1 & 0.11 & 0.44 & 16.67 & 4.2 & 2.5 & 2.5 & 2.5 \\
\hline Acacia velutina.............. & 1 & 1 & 0.11 & 0.44 & 16.67 & 4.2 & 2.5 & 2.5 & 2.5 \\
\hline Lacistema hasslerianum........ & 1 & 1 & 0.11 & 0.44 & 16.67 & 4.2 & 4.7 & 4.7 & 4.7 \\
\hline Solanum mauritianum.......... & 1 & 1 & 0.11 & 0.44 & 16.67 & 4.2 & 1.8 & 1.8 & 1.8 \\
\hline
\end{tabular}

Quadro 8.2 - Parâmetros fitossociológicos encontrados para as espécies amostradas no subbosque de E. grandis (talhão 48), tratamento 3 - corte raso do eucalipto, 45 meses após a exploração da primeira rotação do povoamento, onde: $\mathrm{N}^{\mathrm{p}}$. Ind. - Número de Indivíduos; $\mathrm{N}^{\mathrm{p}}$ Amo - Número de unidades amostrais em que a espécie foi amostrada; Dens.re - Densidade relativa da espécie; Freq. Rel - Frequência relativa da espécie; Freq Ab - Frequência absoluta da espécie; Dens Ab - Densidade abusoluta da espécie; Alt Min- altura mínima amostrada na espécie; Alt Max - Altura máxima amostrada na espécie e Alt Med - Altura média apresentada pela espécie. 
Estrutura da Regeneração de Espécies Nativas no Sub-bosque de Plantios de Eucalyptus grandis

especie No. No. Dens. Freq. Freq. Dens. Alt. Alt. Alt

\begin{tabular}{|c|c|c|c|c|c|c|c|c|c|}
\hline Matayba elaeagnoides.......... & 72 & 6 & 16.82 & 4.05 & 100.0 & 300.0 & 1.5 & 3.0 & 1.9 \\
\hline Esenbeckia febrifuga.......... & 46 & 4 & 10.75 & 2.70 & 66.67 & 191.7 & 1.5 & 3.5 & 2.4 \\
\hline Rapanea umbellata............ & 34 & 5 & 7.94 & 3.38 & 83.33 & 141.7 & 1.5 & 5.2 & 2.8 \\
\hline Casearia sylvestris........... & 29 & 6 & 6.78 & 4.05 & 100.0 & 120.8 & 1.5 & 4.0 & 2.4 \\
\hline Campomanesia guaviroba......... & 22 & 3 & 5.14 & 2.03 & 50.00 & 91.7 & 1.5 & 3.0 & 2.2 \\
\hline Myrcia laruotteana............ & 19 & 5 & 4.44 & 3.38 & 83.33 & 79.2 & 1.5 & 3.0 & 1.9 \\
\hline Cytharexylum myrianthum....... & 13 & 5 & 3.04 & 3.38 & 83.33 & 54.2 & 1.5 & 3.3 & 2.1 \\
\hline Zanthoxylum rhoifolium....... & 10 & 5 & 2.34 & 3.38 & 83.33 & 41.7 & 1.5 & 3.5 & 2.3 \\
\hline Miconia ligustroides......... & 9 & 5 & 2.10 & 3.38 & 83.33 & 37.5 & 1.5 & 2.5 & 2.0 \\
\hline Vernonia polyanthes........... & 10 & 3 & 2.34 & 2.03 & 50.00 & 41.7 & 1.5 & 2.5 & 1.9 \\
\hline Cedrela fissilis............. & 8 & 4 & 1.87 & 2.70 & 66.67 & 33.3 & 1.7 & 3.5 & 2.7 \\
\hline Cupania vernalis............. & 10 & 2 & 2.34 & 1.35 & 33.33 & 41.7 & 1.5 & 4.0 & 2.5 \\
\hline Ocotea puberula.............. & 7 & 4 & 1.64 & 2.70 & 66.67 & 29.2 & 1.6 & 3.2 & 2.3 \\
\hline Syagrus romanzoffiana......... & 9 & 2 & 2.10 & 1.35 & 33.33 & 37.5 & 2.0 & 3.5 & 2.6 \\
\hline Prunus myrtifolia............ & 6 & 4 & 1.40 & 2.70 & 66.67 & 25.0 & 1.5 & 7.2 & 2.9 \\
\hline Campomanesia guazumifolia..... & 10 & 1 & 2.34 & 0.68 & 16.67 & 41.7 & 1.6 & 3.0 & 2.1 \\
\hline Rapanea ferruginea........... & 5 & 4 & 1.17 & 2.70 & 66.67 & 20.8 & 1.9 & 5.2 & 3.2 \\
\hline Aegiphila sellowiana......... & 4 & 4 & 0.93 & 2.70 & 66.67 & 16.7 & 1.5 & 1.7 & 1.6 \\
\hline Solanum variabile............ & 5 & 3 & 1.17 & 2.03 & 50.00 & 20.8 & 1.5 & 2.1 & 1.9 \\
\hline Myrtaceae sp2......... & 4 & 3 & 0.93 & 2.03 & 50.00 & 16.7 & 1.5 & 3.0 & 2.1 \\
\hline Piper gaudichaudianum......... & 4 & 3 & 0.93 & 2.03 & 50.00 & 16.7 & 1.9 & 2.2 & 2.0 \\
\hline Allophyllus edulis........... & 4 & 3 & 0.93 & 2.03 & 50.00 & 16.7 & 2.0 & 3.0 & 2.4 \\
\hline styrax acuminatus........... & 4 & 3 & 0.93 & 2.03 & 50.00 & 16.7 & 1.7 & 2.0 & 1.8 \\
\hline Gochnatia polymorpha.......... & 5 & 2 & 1.17 & 1.35 & 33.33 & 20.8 & 1.6 & 3.1 & 2.1 \\
\hline 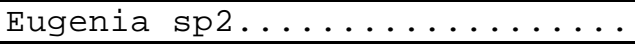 & 5 & 2 & 1.17 & 1.35 & 33.33 & 20.8 & 1.5 & 3.0 & 2.0 \\
\hline Schinus terebinthifolius...... & 3 & 3 & 0.70 & 2.03 & 50.00 & 12.5 & 1.7 & 1.7 & 1.7 \\
\hline Ocotea pulchella............ & 4 & 2 & 0.93 & 1.35 & 33.33 & 16.7 & 1.5 & 2.5 & 2.0 \\
\hline Vitex montevidensis........... & 4 & 2 & 0.93 & 1.35 & 33.33 & 16.7 & 1.7 & 2.5 & 2.0 \\
\hline Piper aduncum.............. & 3 & 2 & 0.70 & 1.35 & 33.33 & 12.5 & 1.5 & 2.6 & 2.0 \\
\hline Psychotria carthaginensis..... & 3 & 2 & 0.70 & 1.35 & 33.33 & 12.5 & 1.7 & 2.4 & 1.9 \\
\hline Diospyros inconstans.......... & 3 & 2 & 0.70 & 1.35 & 33.33 & 12.5 & 1.6 & 2.0 & 1.8 \\
\hline Actinostemon klotzchii........ & 4 & 1 & 0.93 & 0.68 & 16.67 & 16.7 & 2.4 & 3.5 & 2.9 \\
\hline Chomelia pohliana & 4 & 1 & 0.93 & 0.68 & 16.67 & 16.7 & 1.7 & 2.5 & 2.0 \\
\hline
\end{tabular}

Quadro 8.3 - Parâmetros fitossociológicos encontrados para as espécies amostradas no subbosque de E. grandis (talhão 48), ratamento 3 - corte raso do eucalipto, 54 meses após a exploração da primeira rotação do povoamento, onde: $\mathrm{N}^{\mathrm{P}}$. Ind. - Número de Indivíduos; $\mathrm{N}^{\mathrm{P}}$ Amo - Número de unidades amostrais em que a espécie foi amostrada; Dens.re - Densidade relativa da espécie; Freq. Rel - Frequência relativa da espécie; Freq Ab - Frequência absoluta da espécie; Dens Ab - Densidade abusoluta da espécie; Alt Min- altura mínima amostrada na espécie; Alt Max - Altura máxima amostrada na espécie e Alt Med - Altura média apresentada pela espécie. 


\begin{abstract}
Estrutura da Regeneração de Espécies Nativas no Sub-bosque de Plantios de Eucalyptus grandis

$\begin{array}{llccccc} & \text { No. No. Dens. } & \text { Freq. } & \text { Freq. Dens. Alt. Alt. Alt } \\ \text { especie } & \text { Ind Amo } & \text { Re } & \text { Re } & \text { Ab } & \text { Ab } & \text { Min } \\ \text { Max Med }\end{array}$
\end{abstract}

\begin{tabular}{|c|c|c|c|c|c|c|c|c|c|}
\hline Tabernaemontana hystrix....... & 2 & 2 & 0.47 & 1.35 & 33.33 & 8.3 & 2.5 & 3.3 & 2.9 \\
\hline Senna bicapsulares............ & 2 & 2 & 0.47 & 1.35 & 33.33 & 8.3 & 2.0 & 3.5 & 2.8 \\
\hline Bauhinia germinata........... & 2 & 2 & 0.47 & 1.35 & 33.33 & 8.3 & 2.1 & 2.2 & 2.2 \\
\hline Solanum bullatum............ & 2 & 2 & 0.47 & 1.35 & 33.33 & 8.3 & 1.5 & 1.7 & 1.6 \\
\hline Tapirira guianensis........... & 2 & 2 & 0.47 & 1.35 & 33.33 & 8.3 & 2.4 & 4.5 & 3.5 \\
\hline Helietta apiculata........... & 2 & 1 & 0.47 & 0.68 & 16.67 & 8.3 & 2.6 & 3.3 & 2.9 \\
\hline Eugenia hiemalis............ & 2 & 1 & 0.47 & 0.68 & 16.67 & 8.3 & 1.5 & 4.0 & 2.8 \\
\hline Calyptranthes concinna........ & 2 & 1 & 0.47 & 0.68 & 16.67 & 8.3 & 1.5 & 1.8 & 1.6 \\
\hline Rapanea guyanensis........... & 2 & 1 & 0.47 & 0.68 & 16.67 & 8.3 & 2.0 & 2.3 & 2.2 \\
\hline 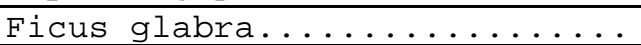 & 1 & 1 & 0.23 & 0.68 & 16.67 & 4.2 & 2.7 & 2.7 & 2.7 \\
\hline Piptadenia gonoacantha........ & 1 & 1 & 0.23 & 0.68 & 16.67 & 4.2 & 2.1 & 2.1 & 2.1 \\
\hline Parapiptadenia rigida........ & 1 & 1 & 0.23 & 0.68 & 16.67 & 4.2 & 3.7 & 3.7 & 3.7 \\
\hline Acacia velutina............. & 1 & 1 & 0.23 & 0.68 & 16.67 & 4.2 & 2.1 & 2.1 & 2.1 \\
\hline Vernonia diffusa............ & 1 & 1 & 0.23 & 0.68 & 16.67 & 4.2 & 5.2 & 5.2 & 5.2 \\
\hline Citrus limon............... & 1 & 1 & 0.23 & 0.68 & 16.67 & 4.2 & 2.5 & 2.5 & 2.5 \\
\hline Amaioua guianensis........... & 1 & 1 & 0.23 & 0.68 & 16.67 & 4.2 & 1.5 & 1.5 & 1.5 \\
\hline Cecropia pachystachya......... & 1 & 1 & 0.23 & 0.68 & 16.67 & 4.2 & 2.2 & 2.2 & 2.2 \\
\hline Rhamnus shaerosperma......... & 1 & 1 & 0.23 & 0.68 & 16.67 & 4.2 & 3.0 & 3.0 & 3.0 \\
\hline Miconia langsdorfii.......... & 1 & 1 & 0.23 & 0.68 & 16.67 & 4.2 & 1.8 & 1.8 & 1.8 \\
\hline Ocotea velutina.............. & 1 & 1 & 0.23 & 0.68 & 16.67 & 4.2 & 2.5 & 2.5 & 2.5 \\
\hline Myrtaceae $3 \ldots \ldots \ldots . \ldots . \ldots$ & 1 & 1 & 0.23 & 0.68 & 16.67 & 4.2 & 1.7 & 1.7 & 1.7 \\
\hline Myrciaria floribunda.......... & 1 & 1 & 0.23 & 0.68 & 16.67 & 4.2 & 1.6 & 1.6 & 1.6 \\
\hline Myrcia multiflora............ & 1 & 1 & 0.23 & 0.68 & 16.67 & 4.2 & 2.7 & 2.7 & 2.7 \\
\hline 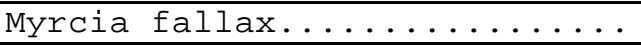 & 1 & 1 & 0.23 & 0.68 & 16.67 & 4.2 & 1.8 & 1.8 & 1.8 \\
\hline Endlicheria paniculata........ & 1 & 1 & 0.23 & 0.68 & 16.67 & 4.2 & 2.8 & 2.8 & 2.8 \\
\hline Myrcia bella................. & 1 & 1 & 0.23 & 0.68 & 16.67 & 4.2 & 1.7 & 1.7 & 1.7 \\
\hline Chorisia speciosa............ & 1 & 1 & 0.23 & 0.68 & 16.67 & 4.2 & 1.5 & 1.5 & 1.5 \\
\hline
\end{tabular}

Quadro 8.3 - Parâmetros fitossociológicos encontrados para as espécies amostradas mo subbosque de E. grandis (talhão 48), tratamento 3 - corte raso do eucalipto, 54 meses após a exploração da primeira rotação do povoamento, onde: $\mathrm{N}$. Ind. - Número de Indivíduos; $\mathrm{N}^{\mathrm{P}}$ Amo - Número de unidades amostrais em que a espécie foi amostrada; Dens.re - Densidade relativa da espécie; Freq. Rel - Frequência relativa da espécie; Freq Ab - Frequência absoluta da espécie; Dens Ab - Densidade abusoluta da espécie; Alt Min- altura mínima amostrada na espécie; Alt Max - Altura máxima amostrada na espécie e Alt Med - Altura média apresentada pela espécie. 


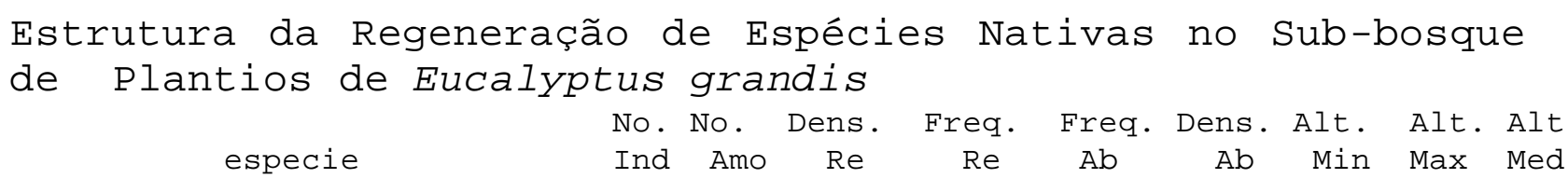

\begin{tabular}{|c|c|c|c|c|c|c|c|c|c|}
\hline Eupatorium laevigatum......... & 1 & 1 & 0.23 & 0.68 & 16.67 & 4.2 & 2.1 & 2.1 & 2.1 \\
\hline Solanum granuloso-leprosum.... & 1 & 1 & 0.23 & 0.68 & 16.67 & 4.2 & 2.0 & 2.0 & 2.0 \\
\hline Machaerium opacum............ & 1 & 1 & 0.23 & 0.68 & 16.67 & 4.2 & 1.6 & 1.6 & 1.6 \\
\hline Andira anthelmia............ & 1 & 1 & 0.23 & 0.68 & 16.67 & 4.2 & 2.0 & 2.0 & 2.0 \\
\hline 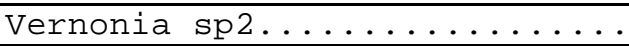 & 1 & 1 & 0.23 & 0.68 & 16.67 & 4.2 & 1.6 & 1.6 & 1.6 \\
\hline Blepharocalyx salicifolius.... & 1 & 1 & 0.23 & 0.68 & 16.67 & 4.2 & 2.5 & 2.5 & 2.5 \\
\hline 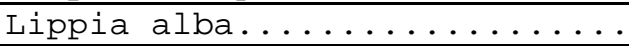 & 1 & 1 & 0.23 & 0.68 & 16.67 & 4.2 & 2.0 & 2.0 & 2.0 \\
\hline Sebastiania klotzchiana....... & 1 & 1 & 0.23 & 0.68 & 16.67 & 4.2 & 2.0 & 2.0 & 2.0 \\
\hline Solanum pseudoquina.......... & 1 & 1 & 0.23 & 0.68 & 16.67 & 4.2 & 2.0 & 2.0 & 2.0 \\
\hline 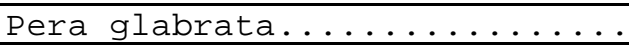 & 1 & 1 & 0.23 & 0.68 & 16.67 & 4.2 & 1.7 & 1.7 & 1.7 \\
\hline
\end{tabular}

Quadro 8.3 - Parâmetros fitossociológicos encontrados para as espécies amostradas no subbosque de E. grandis (talhão 48), tratamento 3 - corte raso do eucalipto, 54 meses após a exploração da primeira rotação do povoamento, onde: $\mathrm{N}^{\mathrm{P}}$. Ind. - Número de Indivíduos; $\mathrm{N}^{\mathrm{P}}$ Amo - Número de unidades amostrais em que a espécie foi amostrada; Dens.re - Densidade relativa da espécie; Freq. Rel - Frequência relativa da espécie; Freq Ab - Frequência absoluta da espécie; Dens Ab - Densidade abusoluta da espécie; Alt Min- altura mínima amostrada na espécie; Alt Max - Altura máxima amostrada na espécie e Alt Med - Altura média apresentada pela espécie. 


\begin{tabular}{|c|c|c|c|c|c|c|c|c|c|}
\hline \multicolumn{4}{|c|}{$\begin{array}{r}\text { Estrutura da Regeneração de Espécies Nativas } \\
\text { especie } \\
\text { No. No. Dens. } \\
\text { Ind Amo Re }\end{array}$} & & & $\begin{array}{r}\text { Den: } \\
\text { Ab }\end{array}$ & & \multicolumn{2}{|c|}{$\begin{array}{l}\text { Alt. } \\
\operatorname{Max}\end{array}$} \\
\hline . & 91 & 6 & & & & & & & \\
\hline 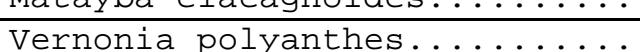 & $\perp$ & & .31 & & & & & & \\
\hline Solanum variabile. & 67 & U & 7.74 & 2.83 & 100.0 & 279.2 & \begin{tabular}{|l|l}
1.5 \\
1.5
\end{tabular} & 4.5 & $\frac{.5}{.9}$ \\
\hline Esenbeckia febrifuga........... & 58 & 4 & 6.70 & 1.89 & 66.67 & 241.7 & 1.5 & 4.6 & 2.6 \\
\hline Casearia sylvestris.......... & 50 & 6 & 5.77 & 2.83 & 100.0 & 208.3 & 1.5 & 3.5 & 2.2 \\
\hline Rapanea umbellata............ & 40 & 5 & 4.62 & 2.36 & 83.33 & 166.7 & 1.5 & 5.2 & 2.8 \\
\hline Eupatorium laevigatum......... & 40 & 4 & 4.62 & 1.89 & 66.67 & 166.7 & 1.5 & 2.9 & 2.2 \\
\hline Gochnatia polymorpha.......... & 29 & 6 & 3.35 & 2.83 & 100.0 & 120.8 & 1.5 & 4.0 & 2.0 \\
\hline Eupatorium inulaefolium....... & 31 & 5 & 3.58 & 2.36 & 83.33 & 129.2 & 1.5 & 3.6 & 2.1 \\
\hline Cytharexylum myrianthum....... & 26 & 6 & 3.00 & 2.83 & 100.0 & 108.3 & 1.5 & 4.1 & 2.4 \\
\hline Zanthoxylum rhoifolium....... & 25 & 6 & 2.89 & 2.83 & 100.0 & 104.2 & 1.5 & 6.1 & 2.4 \\
\hline Myrcia laruotteana............. & 20 & 6 & 2.31 & 2.83 & 100.0 & 83.3 & 1.5 & 2.5 & 1.8 \\
\hline Campomanesia guaviroba........ & 23 & 4 & 2.66 & 1.89 & 66.67 & 95.8 & 1.6 & 3.4 & 2.2 \\
\hline Rapanea ferruginea........... & 17 & 6 & 1.96 & 2.83 & 100.0 & 70.8 & 1.5 & 7.0 & 2.4 \\
\hline Tapirira guianensis........... & 11 & 6 & 1.27 & 2.83 & 100.0 & 45.8 & 1.5 & 4.5 & 2.1 \\
\hline Miconia ligustroides.......... & 13 & 5 & 1.50 & 2.36 & 83.33 & 54.2 & 1.5 & 3.1 & 2.1 \\
\hline Solanum granuloso-leprosum.... & 12 & 5 & 1.39 & 2.36 & 83.33 & 50.0 & 1.5 & 3.5 & 2.1 \\
\hline Tabernaemontana hystrix....... & 11 & 5 & 1.27 & 2.36 & 83.33 & 45.8 & 1.5 & 3.7 & 2.1 \\
\hline styrax acuminatus........... & 11 & 5 & 1.27 & 2.36 & 83.33 & 45.8 & 1.5 & 3.0 & 2.0 \\
\hline Desmodium discolor............ & 11 & 4 & 1.27 & 1.89 & 66.67 & 45.8 & 1.6 & 3.3 & 2.3 \\
\hline Ocotea puberula............. & 11 & 4 & 1.27 & 1.89 & 66.67 & 45.8 & 1.5 & 3.2 & 2.2 \\
\hline Campomanesia guazumifolia..... & 17 & 1 & 1.96 & 0.47 & 16.67 & 70.8 & 1.5 & 2.9 & 2.0 \\
\hline Piper gaudichaudianum......... & 10 & 4 & 1.15 & 1.89 & 66.67 & 41.7 & 1.5 & 2.5 & 2.0 \\
\hline Cedrela fissilis............. & 10 & 4 & 1.15 & 1.89 & 66.67 & 41.7 & 1.6 & 5.0 & 3.0 \\
\hline Syagrus romanzoffiana......... & 11 & 3 & 1.27 & 1.42 & 50.00 & 45.8 & 1.7 & 5.0 & 3.3 \\
\hline Cupania vernalis............ & 13 & 2 & 1.50 & 0.94 & 33.33 & 54.2 & 1.7 & 5.0 & 2.8 \\
\hline Aegiphila sellowiana.......... & 5 & 5 & 0.58 & 2.36 & 83.33 & 20.8 & 2.0 & 3.0 & 2.5 \\
\hline Schinus terebinthifolius...... & 7 & 4 & 0.81 & 1.89 & 66.67 & 29.2 & 1.6 & 2.6 & 1.9 \\
\hline Prunus myrtifolia............ & 6 & 4 & 0.69 & 1.89 & 66.67 & 25.0 & 1.6 & 8.0 & 3.2 \\
\hline Allophyllus edulis........... & 5 & 4 & 0.58 & 1.89 & 66.67 & 20.8 & 1.6 & 2.5 & 2.1 \\
\hline Cestrum sendtnerianum....... & 6 & 3 & 0.69 & 1.42 & 50.00 & 25.0 & 1.6 & 2.2 & 1.9 \\
\hline 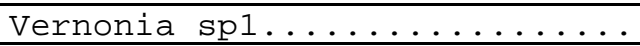 & 8 & 2 & 0.92 & 0.94 & 33.33 & 33.3 & 1.6 & 3.5 & 2.2 \\
\hline Psychotria carthaginensis..... & 5 & 3 & 0.58 & 1.42 & 50.00 & 20.8 & 1.5 & 1.9 & 1.6 \\
\hline Myrtaceae sp2.... & 5 & 3 & 0.58 & 1.42 & 50.00 & 20.8 & 1.8 & 3.1 & 2.3 \\
\hline
\end{tabular}

Quadro 8.4 - Parâmetros fitossociológicos encontrados para as espécies amostradas no subbosque de E. grandis (talhão 48), tratamento 3 - corte raso do eucalipto, 61 meses após a exploração da primeira rotação do povoamento, onde: $\mathrm{N}^{\circ}$. Ind. - Número de Indivíduos; $\mathrm{N}^{\circ}$ Amo - Número de unidades amostrais em que a espécie foi amostrada; Dens.re - Densidade relativa da espécie; Freq. Rel - Frequência relativa da espécie; Freq Ab - Frequência absoluta da espécie; Dens Ab - Densidade abusoluta da espécie; Alt Min- altura mínima amostrada na espécie; Alt Max - Altura máxima amostrada na espécie e Alt Med - Altura média apresentada pela espécie. 


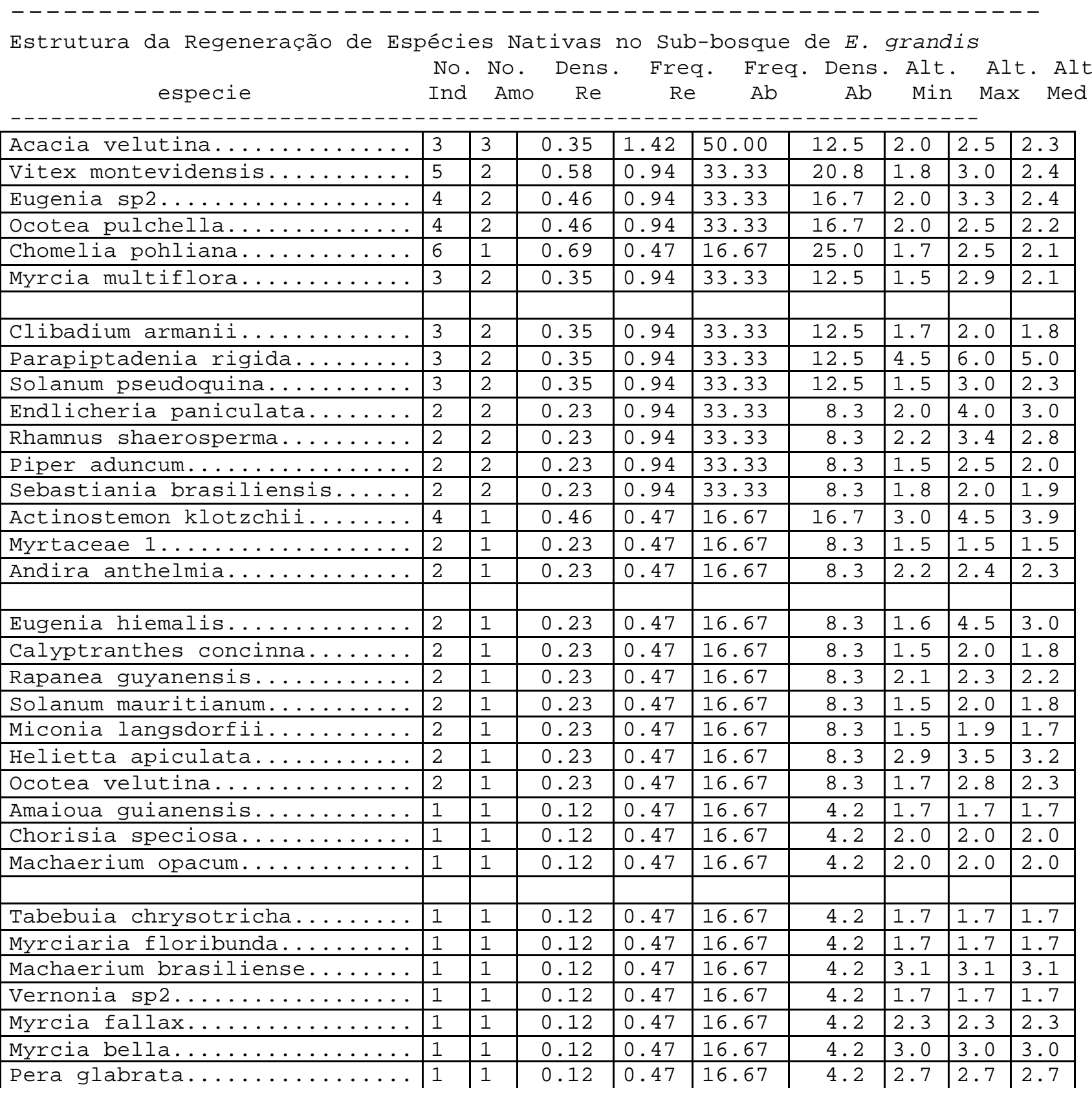

Quadro 8.4 - Parâmetros fitossociológicos encontrados para as espécies amostradas no subbosque de E. grandis (talhão 48), tratamento 3 - corte raso do eucalipto, 61 meses após a exploração da primeira rotação do povoamento, onde: $\mathrm{N}^{\circ}$. Ind. - Número de Indivíduos; $\mathrm{N}^{\circ}$ Amo - Número de unidades amostrais em que a espécie foi amostrada; Dens.re - Densidade relativa da espécie; Freq. Rel - Frequência relativa da espécie; Freq Ab - Frequência absoluta da espécie; Dens Ab - Densidade abusoluta da espécie; Alt Min- altura mínima amostrada na espécie; Alt Max - Altura máxima amostrada na espécie e Alt Med - Altura média apresentada pela espécie. 


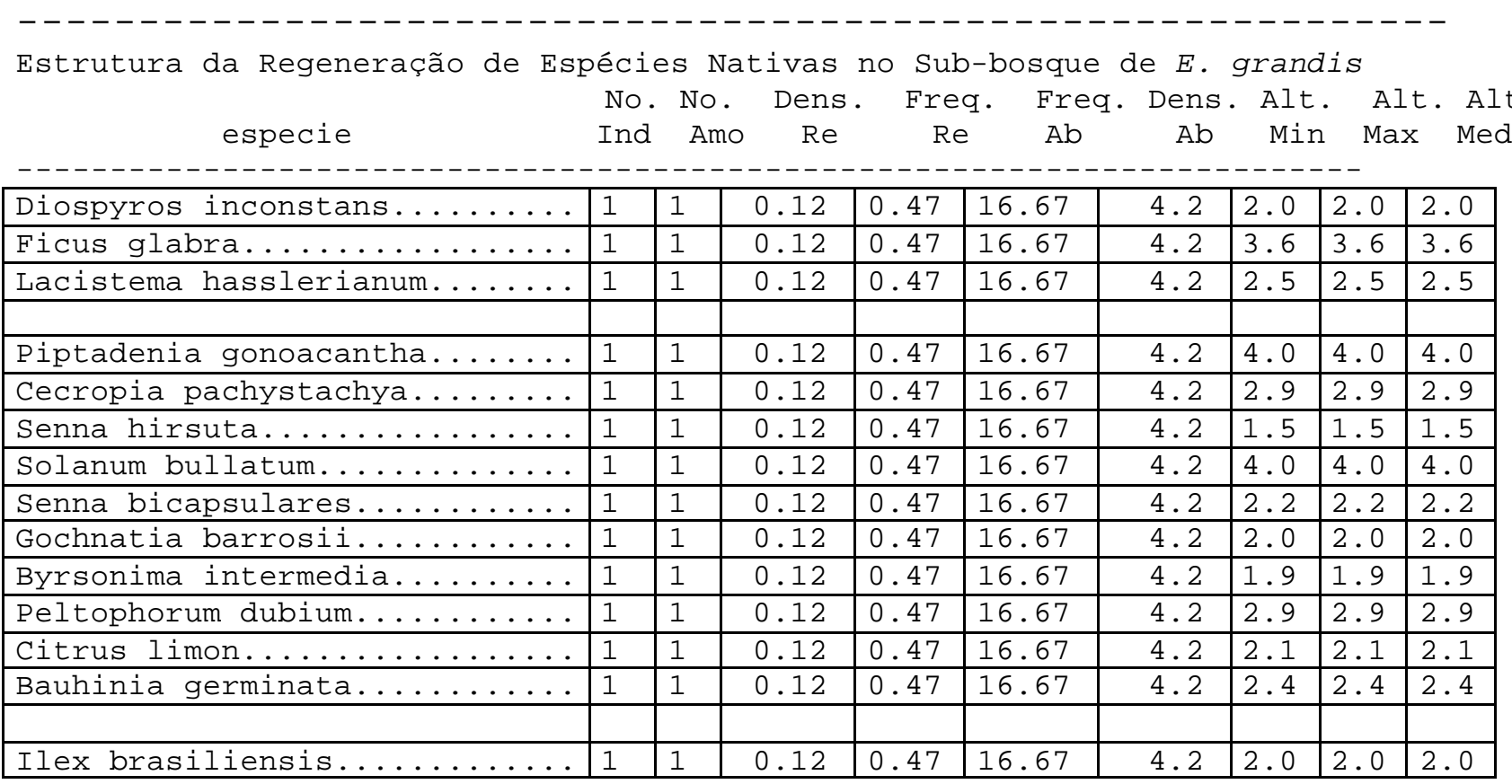

Quadro 8.4 - Parâmetros fitossociológicos encontrados para as espécies amostradas no subbosque de E. grandis (talhão 48), tratamento 3 - corte raso do eucalipto, 61 meses após a exploração da primeira rotação do povoamento, onde: $\mathrm{N}^{\circ}$. Ind. - Número de Indivíduos; $\mathrm{N}^{\circ}$ Amo - Número de unidades amostrais em que a espécie foi amostrada; Dens.re - Densidade relativa da espécie; Freq. Rel - Frequência relativa da espécie; Freq Ab - Frequência absoluta da espécie; Dens Ab - Densidade abusoluta da espécie; Alt Min- altura mínima amostrada na espécie; Alt Max - Altura máxima amostrada na espécie e Alt Med - Altura média apresentada pela espécie. 